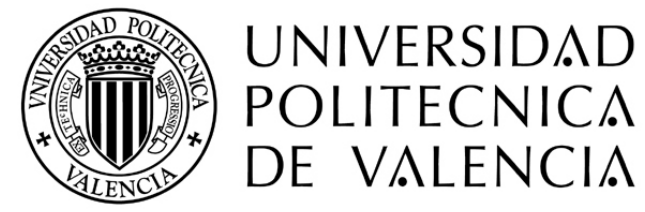

DEPARTAMENTO DE TECNOLOGÍA DE ALIMENTOS

INSTITUTO UNIVERSITARIO DE INGENIERÍA DE ALIMENTOS PARA EL DESARROLLO

\title{
DESARROLLO DE UN PRODUCTO GELIFICADO CON POMELO (var. Star Ruby) EMPLEANDO TRATAMIENTOS OSMÓTICOS
}

TESIS DOCTORAL

Presentada por:

M $^{\mathbf{a}}$ José Moraga Ballesteros

Dirigida:

Dra. Gemma Moraga Ballesteros

Dra. Nuria Martínez Navarrete

Valencia, 2008 



\section{DEPARTAMENTO DE TECNOLOGÍA DE ALIMENTOS}

UNIVERSIDAD POLITECNICA DE VALENCIA
INSTITUTO UNIVERSITARIO DE INGENIERÍA DE ALIMENTOS PARA EL DESARROLLO

Da. NURIA MARTÍNEZ NAVARRETE, CATEDRÁTICA DE UNIVERSIDAD $Y$ $D^{a}$. GEMMA MORAGA BALLESTEROS, PROFESORA TITULAR DE ESCUELA UNIVERSITARIA, AMBAS DEL DEPARTAMENTO DE TECNOLOGÍA DE ALIMENTOS DE LA UNIVERSIDAD POLITÉCNICA DE VALENCIA

CONSIDERAN: Que la memoria titulada DESARROLLO DE UN PRODUCTO GELIFICADO CON POMELO (var. Star Ruby) EMPLEANDO TRATAMIENTOS OSMÓTICOS que presenta $\mathbf{D}^{\mathbf{a}}$. Ma JOSÉ MORAGA BALLESTEROS para aspirar al grado de Doctor por la Universidad Politécnica de Valencia, y que ha sido realizada bajo su dirección en el Departamento de Tecnología de Alimentos de la Universidad Politécnica de Valencia, reúne las condiciones adecuadas para constituir su tesis doctoral, por lo que AUTORIZAN al interesado para su presentación.

Valencia, julio de 2008

Fdo.: Nuria Martínez Navarrete Directora de Tesis
Fdo.: Gemma Moraga Ballesteros Directora de Tesis 
Este trabajo ha sido posible gracias a la financiación concedida por el Ministerio de Educación y Ciencia y el Fondo Europeo de Desarrollo Regional a través de los proyectos AGL2002-01793 y AGL 2005-05994, además de la beca otorgada por el Ministerio de Educación, Cultura y Deporte. 
Al finalizar esta etapa de mi vida quiero expresar un profundo agradecimiento a quienes con su ayuda, apoyo y comprensión me ayudaron en el camino. 

"Me pregunto si las estrellas se iluminan con el fin de que algún día, cada uno pueda encontrar la suya"

El Principito.

Antoine de Saint-Exupéry. 



\section{RESUMEN}

Para ampliar la oferta en el mercado de alimentos que promuevan el consumo de fruta, en este trabajo se plantea la formulación de un producto gelificado por tratamientos osmóticos. El estudio contempla la viabilidad de la reutilización de la disolución osmótica (SO) en ciclos sucesivos de deshidratación y su incorporación final para la elaboración del gel. Con ello se pretende diseñar un proceso económicamente más rentable y respetuoso con el medio ambiente, además de obtener un producto del máximo valor nutritivo y funcional.

El estudio cinético realizado del proceso osmótico seleccionado ha permitido fijar en $180 \mathrm{~min}$ el tiempo necesario para la obtención de pomelo con aproximadamente $20^{\circ}$ Brix. Para la reutilización de la SO durante 5 ciclos consecutivos de deshidratación osmótica (DO), lo que no afecta a las características de la fruta deshidratada obtenida, se recomienda un tratamiento térmico suave $\left(72^{\circ} \mathrm{C} / 15 \mathrm{~s}\right)$ antes de cada uno de ellos. La formulación del gel con carragenato a partir de la SO reutilizada requiere su previa dilución para asegurar el equilibrio termodinámico entre éste y la fruta deshidratada. El pomelo deshidratado y el producto formulado se han estudiado desde el punto de vista de su composición en agua y sólidos solubles, acidez, ácido ascórbico (AA), tasa respiratoria (TR), color, propiedades mecánicas y crecimiento de microorganismos, considerando la evolución de todos estos aspectos con el almacenamiento en refrigeración. La presencia del gel previene de la pérdida de AA y retrasa el crecimiento de microorganismos, de manera que el producto es seguro durante al menos 12 días. El resto de propiedades no se ven afectadas ni por la matriz gelificada ni por el almacenamiento. El estudio sensorial pone de manifiesto la aceptabilidad del producto formulado.

La incorporación de lactato cálcico a la SO durante la DO conlleva una disminución de la cinética de DO de la fruta y también de la TR, lo que supone un aumento de la vida útil tanto de la fruta deshidratada como del producto gelificado. El calcio mejora el color y por tanto de la apariencia de la fruta, pero afecta negativamente a la textura, aroma y sabor. Por otra parte, contribuye a la opacidad y dureza del gel. Desde este punto de vista, la adición de calcio no sería recomendable para la formulación del producto gelificado diseñado. 



\section{RESUM}

Per a ampliar l'oferta en el mercat d'aliments que promoguen el consum de fruita, en aquest treball es planteja la formulació d'un producte gelificat per tractaments osmòtics. L'estudi preveu la viabilitat de la reutilització de la dissolució osmòtica (SO) en cicles successius de deshidratació i la seua incorporació final per a l'elaboració del gel. Amb això es pretén dissenyar un procés econòmicament més rendible i respectuós amb el medi ambient, a més d'obtenir un producte del màxim valor nutritiu i funcional.

L'estudi cinètic realitzat del procés osmòtic seleccionat ha permès fixar en 180 min el temps necessari per a l'obtenció de pomelo amb aproximadament $20^{\circ}$ Brix. Per a la reutilització de la SO durant 5 cicles consecutius de deshidratació osmòtica (DO), la qual cosa no afecta les característiques de la fruita deshidratada obtinguda, es recomana un tractament tèrmic suau $\left(72^{\circ} \mathrm{C} / 15 \mathrm{~s}\right)$ abans de cada un d'aquests. La formulació del gel amb carragenat a partir de la SO reutilitzada requereix una dilució prèvia per a assegurar l'equilibri termodinàmic entre aquest i la fruita deshidratada. El pomelo deshidratat i el producte formulat s'han estudiat des del punt de vista de la seua composició en aigua $i$ sòlids solubles, acidesa, àcid ascòrbic (AA), taxa respiratòria (TR), color, propietats mecàniques $\mathrm{i}$ creixement de microorganismes, considerant l'evolució de tots aquests aspectes amb l'emmagatzemament en refrigeració. La presència del gel prevé la pèrdua d'AA i retarda el creixement de microorganismes, de manera que el producte és segur durant almenys 12 dies. La resta de propietats no es veuen afectades ni per la matriu gelificada ni per l'emmagatzemament. L'estudi sensorial posa de manifest l'acceptabilitat del producte formulat.

La incorporació de lactat càlcic a la SO durant la DO comporta una disminució de la cinètica de DO de la fruita i també de la TR, i això suposa un augment de la vida útil tant de la fruita deshidratada com del producte gelificat. El calci millora el color i per tant l'aparença de la fruita, però afecta negativament a la textura, aroma i sabor. D'altra banda, contribueix a l'opacitat i duresa del gel. Des d'aquest punt de vista, l'addició de calci no seria recomanable per a la formulació del producte gelificat dissenyat. 



\begin{abstract}
The formulation of a grapefruit-gel product by using osmotic treatments has been considered, trying to extend the fruit-food market supply in order to promote fruit consumption. The study considers the viability of the osmotic solution (OS) re-use in successive dehydration cycles and its final incorporation to the gel development. In this way, the aim was to design a process more economic and environmentally friendly, and to obtain a product with the maximum nutritive and functional value.

The kinetic study performed of the osmotic selected process allowed us to fix in $180 \mathrm{~min}$ the time needed to obtain grapefruit with approximately $20^{\circ} \mathrm{Brix}$. For the re-use of the OS during 5 consecutive cycles of osmotic dehydration (OD), which does not affect to the characteristics of the dehydrated fruit, a previous soft thermal treatment $\left(72^{\circ} \mathrm{C} / 15 \mathrm{~s}\right)$ before each one of them is recommended. The gel formulation with carrageenan and the re-used OS requires its previous dilution to assure the thermodynamic equilibrium between this one and the dehydrated fruit. The dehydrated grapefruit and the formulated product have been studied from the point of view of their composition in water and soluble solids, acidity, ascorbic acid (AA), respiration rate (RR), colour, mechanical properties and microorganisms growth, considering the evolution of all these aspects during chilling storage. The presence of the gel preserves grapefruit AA loss and delays microorganisms growth, so that the product is safe for at least 12 days. The rest of properties are not affected by the jellied matrix or the storage. The sensory study reveals the acceptability of the formulated product. The incorporation of calcium lactate to the OS during the OD implies a decrease of the fruit dehydration kinetic and also of the RR, which supposes an increase of the shelf-life of the dehydrated fruit and the fruit-gel product. The calcium improves the colour and therefore of the appearance of the fruit, but it affects negatively to the texture, aroma and flavour. On the other hand, it contributes to the opacity and hardness of the gel. From this point of view, the addition of calcium would not be recommendable for the formulation of the designed grapefruit-gel product.
\end{abstract}





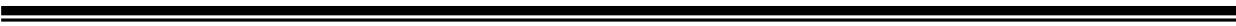

ÍNDICE

ב. 



\section{ÍNDICE DE CONTENIDOS}

\section{JUSTIFICACIÓN E INTERÉS DEL TRABAJO}

I. INTRODUCCIÓN

I.1. ASPECTOS GENERALES DEL POMELO 8

I.1.1. Origen y nombre científico 8

I.1.2. Producción y comercialización 8

I.1.3. Descripción histológica 10

$\begin{array}{ll}\text { I.1.4. Variedades } & 12\end{array}$

I.1.5. Propiedades nutritivas del pomelo 13

$\begin{array}{ll}\text { I.1.6. Fisiología Celular } & 17\end{array}$

I.1.6.1. Respiración 19

I.1.6.2. Fermentación 25

I.1.6.3. Tasa respiratoria y coeficiente respiratorio 27

I.2. PROCESOS DE DESHIDRATACIÓN OSMÓTICA E IMPREGNACIÓN A VACÍO 29

I.2.1. Cinética de la deshidratación osmótica 32

I.2.2. Problemática de la disolución osmótica 36

I.3. EL CALCIO 37

I.3.1. Importancia del calcio en la salud humana 37

I.3.2. Distribución y transporte del calcio a nivel celular en tejidos vegetales $\quad 40$

I.3.3. Efecto del calcio en frutas mìnimamente procesadas 43

I.4. PRODUCTOS GELIFICADOS 45

I.4.1. Carragenatos 48

I.4.1.1. Estructura y tipos 48

I.4.1.2. Mecanismos de gelificación 51

I.4.1.3. Funcionalidad de los carragenatos 51 
I.4.1.4. Aplicaciones de los carragenatos 53

I.5. ANÁLISIS SENSORIAL 55

I.5.1. Definición e importancia del análisis sensorial 55

I.5.2. Los jueces 56

I.5.3. Tipo de pruebas sensoriales 58

II. OBJETIVOS Y PLAN DE TRABAJO 65

II.1. OBJETIVOS 65

II.1.1. Objetivo principal $\quad 65$

II.1.2. Objetivos específicos 66

II.2. PLAN DE TRABAJO 67

III. DESARROLLO DE UN PRODUCTO GELIFICADO CON POMELO POR TRATAMIENTOS OSMÓTICOS 73

III.1. MATERIALES Y MÉTODOS 73

III.1.1. Materia Prima 73

III.1.1.1. Fruta 73

III.1.1.2. Disolución osmótica 74

III.1.1.3. Agente gelificante $\quad 74$

III.1.2. Procedimiento experimental 75

III.1.2.1. Preparación de las muestras de pomelo fresco $\quad 75$

III.1.2.2. Tratamientos osmóticos 76

III.1.2.2.1. Estudio cinético 78

III.1.2.2.2. Obtención de pomelo deshidratado para la 80

formulación del producto gelificado

III.1.2.3. Preparación de los geles con pomelo 81

III.1.2.3.1. Estudio previo 81

III.1.2.3.2. Formulación seleccionada 84

III.1.2.4. Almacenamiento en refrigeración 84

III.1.3. Análisis realizados $\quad 85$

III.1.3.1. Determinación de la actividad del agua 85 
III.1.3.2. Determinación de los sólidos solubles 85

III.1.3.3. Determinación de la humedad 86

III.1.3.4. Determinación del pH 87

III.1.3.5. Determinación de la acidez valorable 87

III.1.3.6. Determinación del ácido ascórbico 88

III.1.3.7. Medidas de la concentración de cationes 89

III.1.3.8. Variación de masa 91

III.1.3.9. Determinación de las propiedades mecánicas $\quad 91$

III.1.3.10. Determinación del color 92

III.1.3.11. Medidas de tasa de respiración 93

III.1.3.12. Análisis microbiológico 95

III.2. RESULTADOS Y DISCUSIÓN 97

III.2.1. Estudio cinético de la deshidratación osmótica del $\begin{array}{ll}\text { pomelo } & 97\end{array}$

III.2.1.1. Caracterización de las propiedades fisicoquímicas del pomelo durante la deshidratación osmótica

III.2.1.2. Estimación de la difusividad efectiva del agua 99

III.2.1.3. Cinética de pérdida de agua y ganancia de solutos 101

III.2.2. Obtención de pomelo deshidratado para la formulación del producto gelificado

III.2.2.1. Efecto de la reutilización de la disolución osmótica en el recuento de microorganismos del pomelo 106 deshidratado osmóticamente almacenado en refrigeración III.2.2.2. Efecto de la reutilización de la disolución osmótica y del almacenamiento en refrigeración en las propiedades del pomelo deshidratado.

III.2.2.2.1. Efecto sobre la humedad, sólidos solubles y actividad del agua

III.2.2.2.2. Efecto sobre la acidez, pH y ácido ascórbico 
III.2.2.2.3. Efecto sobre el contenido en cationes $\quad 120$

III.2.2.2.4. Efecto sobre la tasa respiratoria 122

III.2.3. Optimización de la formulación de un producto gelificado empleando tratamientos osmóticos. Efecto del 125 almacenamiento en refrigeración.

III.2.3.1. Estudio previo 125

III.2.3.2. Estudio de almacenamiento del producto gelificado optimizado

III.2.3.2.1. Evolución del contenido en ácido ascórbico (AA)

III.2.3.2.2. Color y propiedades mecánicas 134

III.2.3.3. Estudio microbiológico

IV. ESTUDIO DEL EFECTO DE LA ADICIÓN DE LACTATO CÁLCICO A LA DISOLUCIÓN OSMÓTICA PARA LA 143 OBTENCIÓN DE PRODUCTOS GELIFICADOS CON POMELO

IV.1. MATERIALES Y MÉTODOS 143

IV.1.1. Materia Prima 143

IV.1.1.1. Fruta 143

IV.1.1.2. Disoluciones 144

IV.1.1.3. Agente gelificante 144

IV.1.2. Procedimiento experimental 145

IV.1.2.1. Preparación de las muestras de pomelo fresco $\quad 145$

IV.1.2.2. Estudio cinético 145

IV.1.2.3. Tratamientos de impregnación a vacío y de 145

deshidratación osmótica con pulso de vacío

IV.1.2.4. Preparación de los geles con pomelo 147

IV.1.2.5. Almacenamiento en refrigeración $\quad 147$

IV.1.3. Análisis realizados 148

IV.1.3.1. Determinación de las propiedades mecánicas $\quad 148$ 
IV.2.1. Estudio cinético de la deshidratación osmótica del pomelo. Influencia del catión calcio

IV.2.1.1. Caracterización de las propiedades fisicoquímicas del pomelo durante la deshidratación osmótica

IV.2.1.2. Estimación de la difusividad efectiva del agua

IV.2.1.3. Cinética de pérdida de agua y ganancia de solutos

IV.2.2. Obtención de pomelo deshidratado para la formulación del producto gelificado. Influencia del catión calcio, del pulso de vacío y del almacenamiento en refrigeración

IV.2.2.1. Efecto de los tratamientos de impregnación a vacío y de deshidratación osmótica con pulso de vacío en la fruta deshidratada. Influencia del catión calcio y del almacenamiento en refrigeración

IV.2.2.1.1. Efecto sobre la humedad y los sólidos solubles

IV.2.2.1.2. Efecto sobre el pH y la acidez valorable

IV.2.2.1.3. Efecto sobre el contenido en cationes

IV.2.2.1.4. Efecto sobre la tasa respiratoria

IV.2.2.1.5. Efecto sobre las propiedades mecánicas

IV.2.2.1.6. Análisis microbiológico de las muestras de pomelo deshidratado. Efecto del catión calcio

IV.2.2.1.7. Análisis sensorial de las muestras de pomelo deshidratado. Efecto del catión calcio y del almacenamiento en refrigeración

IV.2.2.2. Estudio del efecto del almacenamiento en refrigeración del producto gelificado formulado con lactato cálcico 
IV.2.2.2.1. Evolución de los cationes en los geles y en la fruta deshidratada

IV.2.2.2.2. Estudio microbiológico de las muestras

IV.2.2.2.3. Análisis sensorial de geles con fruta deshidratada con y sin calcio. Estudio del 196 almacenamiento

V. CONCLUSIONES

VI. BIBLIOGRAFÍA 


\section{ÍNDICE DE TABLAS}

Tabla I.1. Valor nutricional del pomelo por $100 \mathrm{~g}$ de sustancia comestible.

Tabla I.2. Cantidad diaria recomendada de calcio (mg/día).

Tabla I.3. Contenido en calcio de algunos alimentos.

Tabla III.1. Fracción másica de agua y sólidos solubles y actividad del agua del pomelo deshidratado osmóticamente en función del tiempo de deshidratación.

Tabla III.2. Valores de la variación relativa de masa total $\left(\Delta \mathrm{M}_{\mathrm{T}}\right)$, ganancia de solutos $\left(\Delta M_{S}\right)$ y pérdida de agua $\left(\Delta M_{W}\right)$, referidos por unidad de masa inicial de producto en función del tiempo de deshidratación osmótica.

Tabla III.3. Parámetros fisicoquímicos analizados en el pomelo fresco (PF) y pomelo deshidratado, con disolución osmótica sin reutilizar (PD1) y reutilizada durante 3 (PD3) y 5 (PD5) ciclos sucesivos de deshidratación, durante su almacenamiento $\left(10^{\circ} \mathrm{C}\right)$. Tabla III.4. Contenido en ácido cítrico (AC), expresado como mg $\mathrm{AC} / 100 \mathrm{~g}$ muestra y como $\mathrm{mg} \mathrm{AC} / 100 \mathrm{~g}$ del correspondiente pomelo fresco (PF) de partida, analizado en el pomelo fresco (PF) y pomelo deshidratado con disolución osmótica sin reutilizar (PD1) y reutilizada durante 3 (PD3) y 5 (PD5) ciclos sucesivos de deshidratación. Evolución durante su almacenamiento $\left(10^{\circ} \mathrm{C}\right)$.

Tabla III.5. Valores de $\mathrm{pH}$ analizado en el pomelo fresco (PF) y pomelo deshidratado, con disolución osmótica sin reutilizar (PD1) y reutilizada durante 3 (PD3) y 5 (PD5) ciclos sucesivos de deshidratación. Evolución durante su almacenamiento $\left(10^{\circ} \mathrm{C}\right)$. 
Tabla III.6. Contenido en ácido ascórbico (AA), expresado como mg $A A / 100 g$ muestra y como mg AA/100g $P F$ de partida, analizado en el pomelo fresco (PF) y pomelo deshidratado, con disolución osmótica sin reutilizar (PD1) y reutilizada durante 3 (PD3) y 5 (PD5) ciclos sucesivos de deshidratación, durante su almacenamiento $\left(10^{\circ} \mathrm{C}\right)$.

Tabla III.7. Contenido en cationes de pomelo fresco (PF) y deshidratado después de 1 (PD1), 3 (PD3) y 5 (PD5) ciclos de deshidratación y porcentaje de pérdida de cada mineral.

Tabla III.8. Contenido en cationes de la disolución osmótica ( $\mathrm{mg} / 100 \mathrm{~g} \mathrm{SO}$ ) después de 1 , 3 y 5 ciclos de deshidratación.

Tabla III.9. Fracción másica de agua y solutos de la fruta y del gel para el sistema PFG55 a cada tiempo de almacenamiento a $10^{\circ} \mathrm{C}$.

Tabla III.10. Fracción másica de agua y solutos de la fruta y del gel para el sistema PDOG50 a cada tiempo de almacenamiento a $10^{\circ} \mathrm{C}$.

Tabla III.11. Fracción másica de agua y solutos de la fruta y del gel para el sistema PFG30 a cada tiempo de almacenamiento a $10^{\circ} \mathrm{C}$.

Tabla III.12. Fracción másica de agua y solutos de la fruta y del gel para el sistema PDOG30 a cada tiempo de almacenamiento a $10^{\circ} \mathrm{C}$.

Tabla III.13. Valores de tono $\left(\mathrm{h}^{*}\right)$, croma $\left(\mathrm{C}^{*}\right)$ y diferencia de color calculada en función del tiempo de almacenamiento $(\Delta \mathrm{E})$ para las muestras de pomelo fresco (PF), pomelo deshidratado (PD) y pomelo deshidratado incluido en la matriz gelificada (PDG). 
Tabla VI.1. Fracción másica de agua y sólidos solubles y 155 actividad del agua del pomelo deshidratado osmóticamente, con $2 \%$ de lactato cálcico añadido, en función del tiempo de deshidratación.

Tabla IV.2. Valores de la variación de masa total $\left(\Delta \mathrm{M}_{T}\right)$, 158 ganancia de solutos $\left(\Delta \mathrm{M}_{S}\right)$ y pérdida de agua $\left(\Delta \mathrm{M}_{\mathrm{W}}\right)$, referidos por unidad de masa inicial de producto en función del tiempo de deshidratación osmótica.

Tabla IV.3. Composición de las muestras sin almacenar.

Tabla IV.4. Composición de las muestras tras 7 días de 162 almacenamiento en refrigeración.

Tabla IV.5. Contenido en calcio de las muestras estudiadas. Ganancias o pérdidas de $\mathrm{Ca}^{2+}$ como consecuencia del tratamiento y del almacenamiento.

Tabla IV.6. Frecuencia de las respuestas de los catadores en la comparación pareada múltiple de las muestras tratadas con calcio $\left(\mathrm{PD}_{2 \%}\right)$ y sin calcio $\left(\mathrm{PD}_{0 \%}\right)$, así como con y $\sin 5$ días de almacenamiento $(5 d)$ en refrigeración.

Tabla IV.7. Suma de rangos en la comparación pareada múltiple de las muestras tratadas con calcio $\left(\mathrm{PD}_{2 \%}\right)$ y sin calcio $\left(\mathrm{PD}_{0 \%}\right)$, así como con y $\sin 5$ días de almacenamiento (5d) en refrigeración.

Tabla IV.8. Valores $T$ de Friedman para los distintos atributos 186 analizados.

Tabla IV.9. Diferencia entre suma de rangos en el análisis sensorial de pomelo deshidratado con calcio $\left(\mathrm{PD}_{2 \%}\right)$ y sin calcio $\left(\mathrm{PD}_{0 \%}\right)$, así como con y $\sin 5$ días de almacenamiento $(5 \mathrm{~d})$ en refrigeración. 
Tabla IV.10. Porcentaje de variabilidad explicado por los factores 189 del análisis de correspondencias.

Tabla IV.11. Contribuciones de los factores a la inercia de las 189 muestras.

Tabla IV.12. Contribuciones de los factores a la inercia de los 190 atributos.

Tabla IV.13. Respuestas de los catadores en el análisis 196 sensorial de geles con pomelo deshidratado con calcio $\left(\mathrm{PDG}_{2 \%}\right)$ y $\sin$ calcio $\left(\mathrm{PDG}_{0 \%}\right.$ ), así como con y $\sin 7$ días de almacenamiento $(7 \mathrm{~d})$ en refrigeración.

Tabla IV.14. Suma de rangos en el análisis sensorial de geles con pomelo deshidratado con calcio $\left(\mathrm{PDG}_{2}\right.$ ) y $\sin$ calcio (PDG ${ }_{0 \%}$ ), así como con y sin 7 días de almacenamiento (7d) en refrigeración.

Tabla IV.15. Test de Friedman en el análisis sensorial de geles con pomelo deshidratado.

Tabla IV.16. Diferencia entre suma de rangos en el análisis sensorial de geles con pomelo deshidratado con calcio $\mathrm{PDG}_{2 \%}$ y sin calcio $\mathrm{PDG}_{0 \%}$, así como con y sin 7 días de almacenamiento (7d) en refrigeración.

Tabla IV.17. Factores del análisis sensorial de geles con pomelo 200 deshidratado.

Tabla IV.18. Contribuciones de los factores a la inercia de las 201 muestras.

Tabla IV.19. Contribuciones de los factores a la inercia de los 201 atributos. 


\section{ÍNDICE DE FIGURAS}

Figura I.1. a) Sección transversal de las vesículas y sus 12 filamentos en un fruto de 3 meses de edad de mandarina. b) Sección transversal de un fruto de pomelo.

Figura I.2. Variedades del pomelo.

Figura I.3. Esquema simplificado de la glucólisis.

Figura I.4. Esquema del Ciclo de Krebs.

Figura I.5. Transferencia de electrones y fosforilación oxidativa en la cadena respiratoria mitocondrial.

Figura I.6. Fermentación ácido-láctica.

Figura I.7. Fermentación etanólica.

Figura I.8. Tipos de transporte en el tejido vegetal.

Figura 1.9. Movimiento del $\mathrm{Ca}^{2+}$ en una célula vegetal.

Figura I.10. Estructura de los residuos de disacáridos repetidos

de los tres carragenatos principales utilizados en la industria agroalimentaria.

Figura III.1. Preparación de las muestras frescas.

Figura III.2. a) Equipo con cámara de vacío; b) Baño termostático con agitación.

Figura III.3. a) Cromatógrafo líquido de intercambio iónico; b) Carro de automatización de muestras.

Figura III.4. a) Prensa universal de textura. b) Célula Otawa.

Figura III.5. a) Analizador de gases CheckMate 9900 PBI 94 Dansensor; b) Ejemplo de toma de muestras.

Figura III.6. Esquema de la preparación de las diluciones, 96 teniendo en cuenta que se realizaban 2 repeticiones para cada dilución. 
Figura III.7. Representación de $1-Y_{w}^{t}$ frente a la raíz cuadrada 101 del tiempo.

Figura III.8. Relación entre la pérdida de peso de las muestras a cada tiempo de deshidratación y la pérdida de agua más la ganancia de solutos.

Figura III.9. Valores de la pérdida de masa total, ganancia de solutos y pérdida de agua, referidos por unidad de masa inicial de producto, en función del tiempo de deshidratación osmótica.

Figura III.10. Recuento de viables totales y mohos y levaduras, 107 en pomelo fresco, pomelo deshidratado osmóticamente con SO sin reutilizar y reutilizada durante 3 y 5 ciclos de deshidratación, sin tratamiento térmico de la disolución osmótica antes de cada ciclo.

Figura III.11. Recuento de viables totales y mohos y levaduras, en pomelo fresco, pomelo deshidratado osmóticamente con SO sin reutilizar y reutilizada durante 3 y 5 ciclos de deshidratación, previo tratamiento térmico suave de la SO antes de cada ciclo.

Figura III.12. Valores medios de ${ }^{\circ}$ Brix de la SO en función del 113 número de ciclos de deshidratación.

Figura III.13. Contenido en AA de la $\mathrm{SO}$ en función del número 119 de ciclos de deshidratación.

Figura III.14. Tasa respiratoria, expresada como $\mathrm{mL} \quad \mathrm{CO}_{2} 123$ producido/kg h, del pomelo fresco y pomelo deshidratado osmóticamente con SO sin reutilizar y reutilizada durante 3 (PD3) y 5 ciclos de deshidratación y su evolución durante el almacenamiento de las muestras a $10^{\circ} \mathrm{C}$.

Figura III.15. Evolución de la $a_{w}$ de la fruta y del gel en los cuatro 126 sistemas estudiados. 
Figura III.16. Diseño experimental para la preparación del 131 producto gelificado optimizado.

Figura III.17. Evolución del contenido en AA de las muestras de pomelo deshidratado no incluido en gel, pomelo deshidratado incluido en gel y del gel.

Figura III.18. Diagrama cromático $\left(a^{*}, b^{*}\right)$ obtenido para las 136 muestras de pomelo fresco, pomelo deshidratado e inmerso en la matriz gelificada seleccionada.

Figura III.19. Curvas fuerza (N)-distancia (d) tipo obtenidas en pomelo fresco y deshidratado sin almacenar, así como pomelo incluido en el la matriz gelificada durante 10 días de almacenamiento.

Figura III.20. Valores de la fuerza máxima obtenidos a partir del ensayo de compresión-extrusión de las muestras de pomelo fresco, pomelo deshidratado e inmerso en la matriz gelificada.

Figura III.21. Recuento de viables totales y mohos y levaduras, en pomelo fresco, pomelo deshidratado y en el producto gelificado seleccionado.

Figura IV.1. Punzón empleado en el ensayo de punción- 149 compresión y zona de la muestra analizada.

Figura IV.2. Preparación de las muestras para los análisis 151 sensoriales.

Figura IV.3. Representación de $1-Y_{w}^{t}$ frente a la raíz cuadrada del tiempo.

Figura IV.4. Relación entre la pérdida de peso de las muestras a cada tiempo de deshidratación y la pérdida de agua más la ganancia de solutos. 
Figura IV.5. Variación de masa total, solutos y agua con el tiempo de procesado osmótico.

Figura IV.6. Acidez valorable (mg ácido cítrico/100 g muestra) y 162 $\mathrm{pH}$ de las muestras de pomelo fresco, pomelo impregnado a vacío con disolución isotónica y pomelo deshidratado, antes y después de 7 días de almacenamiento en refrigeración.

Figura IV.7. Contenido en $\mathrm{Na}^{+}, \mathrm{K}^{+}$y $\mathrm{Mg}^{2+}$ de las muestras estudiadas antes y después de 7 días de almacenamiento en refrigeración, en función del calcio añadido.

Figura IV.8. Tasas respiratorias expresadas como consumo de $\mathrm{O}_{2}$ y generación $\mathrm{CO}_{2}$, y cociente respiratorio de las muestras estudiadas.

Figura IV.9. Curva típica fuerza $(F)$-deformación relativa $(\varepsilon) 176$ obtenida en el pomelo fresco y parámetros mecánicos evaluados. Figura IV.10. Parámetros mecánicos obtenidos a partir de las 177 curvas de punción de pomelo fresco, pomelo impregnado a vacío con disolución isotónica y pomelo deshidratado, antes y después de 7 días de almacenamiento en refrigeración.

Figura IV.11. Recuento durante el período de almacenamiento 180 en refrigeración a $10^{\circ} \mathrm{C}$ de: (a) viables totales y (b) mohos y levaduras, en pomelo fresco (PF) y deshidratado con $\left(\mathrm{PD}_{2} \%\right.$ y $\sin$ $2 \%$ lactato cálcico $\left(\mathrm{PD}_{0 \%}\right)$.

Figura IV.12. Test de Friedman (suma de rangos, obtenido de la comparación pareada múltiple) de las muestras tratadas con calcio y sin calcio, así como sin y con 5 días de almacenamiento en refrigeración.

Figura IV.13. Representación de las coordenadas de ambos factores en el plano factorial. 
Figura IV.14. Evolución del $\mathrm{Ca}^{2+}$ en la fruta deshidratada y el gel del producto $\mathrm{PDG}_{2 \%}$ durante su almacenamiento en refrigeración.

Figura IV.15. Evolución del $\mathrm{K}^{+}$en la fruta deshidratada y el gel 194 del producto $\mathrm{PDG}_{2 \%}$ durante su almacenamiento en refrigeración.

Figura IV.16. Recuento durante el período de almacenamiento 195 en refrigeración a $10^{\circ} \mathrm{C}$ de: (a) viables totales y (b) mohos y levaduras, para las muestras de pomelo fresco (PF) y las muestras de geles de pomelo deshidratado con calcio $\left(\mathrm{PDG}_{2} \%\right.$ y sin calcio añadido $\left(\mathrm{PDG}_{0 \%}\right)$.

Figura IV.17. Test de Friedman (suma de rangos, obtenido de la 198 comparación pareada múltiple) de los geles con calcio y sin calcio, así como con y $\sin 7$ días de almacenamiento en refrigeración.

Figura IV.18. Representación de las coordenadas de ambos 202 factores en el plano factorial. 



\section{NOMENCLATURA}

$a^{*}$ : Coordenada de color CIEL*a*b* (rojo-verde).

AA: Ácido ascórbico.

AC: Ácido cítrico.

$\mathrm{A}_{\mathrm{T}}$ : Área total

$a_{w}$ : Actividad del agua.

$b^{*}$ : Coordenada de color CIEL*a*b* (amarillo-azul).

$C^{*}$ : Croma o saturación.

CR: Cociente respiratorio.

$\mathrm{d}$ : distancia $(\mathrm{mm})$.

$D_{\mathrm{e}}$ : Difusividad efectiva del agua $\left(\mathrm{m}^{2} / \mathrm{s}\right)$.

DHA: Ácido L-dehidroascórbico.

DO: Deshidratación osmótica.

DOPV: Deshidratación osmótica con pulso de vacío.

E: Pendiente del tramo inicial de la curva de punción.

$\mathrm{e}_{0}$ : Espesor inicial de la muestra.

F: Fuerza (N).

$\mathrm{F}_{\mathrm{F}}$ : Fuerza de fractura $(\mathrm{N})$.

$\mathrm{F}_{\text {máx: }}$ Fuerza máxima $(\mathrm{N})$.

G30: Gel de $30^{\circ}$ Brix.

G50: Gel de $50^{\circ}$ Brix.

G55: Gel de 55Brix.

$\mathrm{h}^{*}$ : Ángulo de tono.

HDM: Mecanismo de transporte hidrodinámico.

IM: Índice de madurez.

IV: Impregnación a vacío.

$\mathrm{IV}_{0 \%}$ : Pomelo impregnado a vacío con disolución isotónica al $0 \%$ de lactato cálcico.

$\mathrm{IV}_{1 \%}$ : Pomelo impregnado a vacío con disolución isotónica al $1 \%$ de lactato cálcico. 
$\mathrm{IV}_{2 \%}$ : Pomelo impregnado a vacío con disolución isotónica al $0 \%$ de lactato cálcico.

$\mathrm{K}_{\mathrm{s}}$ : Coeficiente binario de la ecuación generalizada de Norrish para la sacarosa.

$L^{*}$ : Coordenada de color CIEL*a* ${ }^{*}$ (Luminosidad).

I: Semiespesor de la muestra.

M: Masa de las muestras.

$M_{\text {ácido }}$ : Peso molecular del ácido cítrico.

$\mathrm{N}_{\mathrm{NaOH}}$ : Normalidad del $\mathrm{NaOH}$.

PD: Pomelo deshidratado

$\mathrm{PD}_{0 \%}$ : Pomelo deshidratado osmóticamente con disolución hipertónica al $0 \%$ de lactato cálcico.

$\mathrm{PD}_{1 \%}$ : Pomelo deshidratado osmóticamente con disolución hipertónica al 1\% de lactato cálcico.

$\mathrm{PD}_{2 \%}$ : Pomelo deshidratado osmóticamente con disolución hipertónica al 2\% de lactato cálcico.

$\mathrm{PD}_{0 \%}$ (5d): Pomelo deshidratado osmóticamente con disolución hipertónica al $0 \%$ de lactato cálcico almacenado durante 5 días a $10^{\circ} \mathrm{C}$.

$\mathrm{PD}_{2 \%}$ (5d): Pomelo deshidratado osmóticamente con disolución hipertónica al $2 \%$ de lactato cálcico almacenado durante 5 días a $10^{\circ} \mathrm{C}$.

PD1: Pomelo deshidratado osmóticamente con SO sin reutilizar.

PD3: Pomelo deshidratado con SO reutilizada durante 3 ciclos sucesivos de deshidratación.

PD5: Pomelo deshidratado con SO reutilizada durante 5 ciclos sucesivos de deshidratación.

PDG: Pomelo deshidratado incluido en matriz gelificada.

$\mathrm{PDG}_{0 \%}$ : Pomelo deshidratado incluido en la matriz gelificada al $0 \%$ de lactato cálcico.

$\mathrm{PDG}_{2 \%}$ : Pomelo deshidratado incluido en la matriz gelificada al $2 \%$ de lactato cálcico.

$\mathrm{PDG}_{0 \%}$ (7d): Pomelo deshidratado incluido en la matriz gelificada al $0 \%$ de lactato cálcico almacenado durante 7 días a $10^{\circ} \mathrm{C}$. 
$\mathrm{PDG}_{2 \%}(7 \mathrm{~d})$ : Pomelo deshidratado incluido en la matriz gelificada al $2 \%$ de lactato cálcico almacenado durante 7 días a $10^{\circ} \mathrm{C}$.

PDOG30: Pomelo deshidratado e incluido en un gel de $30^{\circ}$ Brix.

PDOG50: Pomelo deshidratado osmóticamente e incluido en un gel de $50^{\circ}$ Brix).

PF: Pomelo fresco.

PFG30: Pomelo fresco en gel de $30^{\circ}$ Brix.

PFG55: Pomelo fresco en gel de $55^{\circ}$ Brix.

SO: Solución osmótica.

SO1: Solución osmótica sin reutilizar.

SO3: Solución osmótica reutilizada durante 3 ciclos consecutivos de deshidratación.

SO5: Solución osmótica reutilizada durante 5 ciclos consecutivos de deshidratación.

T: Temperatura.

t: Tiempo.

TR: Tasa respiratoria $\left(\mathrm{mLkg}^{-1} \mathrm{~h}^{-1}\right)$.

Ufc/g: Unidades formadoras de colonias por gramo de muestra.

V: Volumen.

$\mathrm{V}_{\mathrm{e}}$ : Volumen del espacio de cabeza.

$\mathrm{V}_{\mathrm{NaOH}}$ : Volumen de $\mathrm{NaOH}$ consumido en la valoración ( $\mathrm{L}$ ).

$X_{s}$ : Fracción molar de la sacarosa.

$\mathrm{x}_{\mathrm{s}}$ : Fracción másica de sólidos solubles en la muestra.

$\mathrm{x}_{\mathrm{s} 0}$ : Fracción másica de sólidos solubles a tiempo 0 .

$x_{s t}$ : Fracción másica de sólidos solubles a tiempo $t$.

$x_{\mathrm{w}}$ : Fracción másica de agua en la muestra.

$X_{w}$ : Fracción molar del agua.

$\mathrm{x}_{\mathrm{w} 0}$ : Fracción másica de agua a tiempo 0

$\mathrm{x}_{\mathrm{wt}}$ : Fracción másica de agua a tiempo $\mathrm{t}$.

$Y_{w}^{t}$ : Fuerza impulsora para la transferencia de agua a cada tiempo.

$\mathrm{y}_{\mathrm{t}}$ : Concentración de gas $\left(\% \mathrm{O}_{2}\right.$ ó $\left.\% \mathrm{CO}_{2}\right)$ a tiempo $\mathrm{t}$.

$\mathrm{y}_{\mathrm{t}}^{0}$ : Concentración de gas $\left(\% \mathrm{O}_{2}\right.$ ó $\left.\% \mathrm{CO}_{2}\right)$ inicial. 
$z_{\mathrm{s}}$ : Fracción másica de sólidos solubles en la fase líquida.

$\mathrm{Z}_{\mathrm{W}}^{0}$ : Fracción másica de agua en la fase líquida a tiempo cero $\left(\mathrm{g}_{\mathrm{w}} / \mathrm{g}_{\mathrm{FL}}\right)$.

$\mathrm{Z}_{\mathrm{w}}^{\mathrm{t}}$ : Fracción másica de agua en la fase líquida a tiempo $\mathrm{t}\left(\mathrm{g}_{\mathrm{w}} / \mathrm{g}_{\mathrm{FL}}\right)$.

$Z_{\mathrm{w}}^{\mathrm{e}}$ : Fracción másica de agua en la fase líquida cuando la muestra está en equilibrio con la disolución osmótica $\left(\mathrm{g}_{\mathrm{w}} / \mathrm{g}_{\mathrm{FL}}\right)$.

Símbolos griegos:

$\Delta \mathrm{E}^{*}$ : Diferencia de color.

$\Delta \mathrm{M}$ : Variación relativa de masa.

$\Delta \mathrm{M}_{\mathrm{s}}$ : Variación relativa del contenido en sólidos.

$\Delta \mathrm{M}_{\mathrm{w}}$ : Variación relativa del contenido en agua.

$\Delta \mathrm{M}_{\mathrm{T}}$ : Variación relativa de masa total.

$\varepsilon$ : Deformación relativa.

$\varepsilon_{F}$ : Deformación relativa en el punto de fractura. 
JUSTIFICACIÓN E INTERÉS DEL TRABAJO 



\section{JUSTIFICACIÓN E INTERÉS DEL TRABAJO}

Las frutas constituyen un grupo de alimentos indispensable para nuestra salud y bienestar, especialmente por su aporte de fibra, vitaminas, minerales y otras sustancias de acción antioxidante (vitamina C, Vitamina E, beta-caroteno, licopeno, luteína, flavonoides, antocianinas, etc.). El pomelo, en concreto, contiene flavanonas glicósidas, como la hesperidina, narirutina y naringina, además de otros compuestos funcionales con interesantes propiedades para la salud (Gil-lzquierdo et al., 2001; Del Caro et al., 2004; Peiró et al., 2006). La naringina es precisamente el flavonoide mayoritario del pomelo, el cual es, a su vez, responsable del sabor amargo de esta fruta que limita su consumo.

A pesar del interés de su consumo, los hábitos más recientes de alimentación producto de los nuevos estilos de vida (falta de tiempo para cocinar, haciendo uso de comida rápida, alimentos de larga vida útil), han ido desplazando el consumo de fruta fresca a favor de productos procesados como zumos, concentrados y batidos, muchos de los cuales poseen contenidos de fruta mínimos, suplidos mediante el agregado, en muchos casos, de gran cantidad de aditivos. Sin embargo, la tendencia actual de los consumidores está cada vez más determinada por el consumo de alimentos cuyas características sensoriales sean muy similares a las del producto fresco y con pocos aditivos. En este sentido se prefiere lo que se conoce como productos mínimamente procesados, entre los que se encuentran una gran variedad de frutas y vegetales.

Los productos mínimamente procesados, aunque son más estables que los frescos, tienen una vida útil bastante limitada, puesto que, además de permitir el crecimiento de microorganismos, mantienen 
actividad fisiológica, que conlleva en muchos casos pérdida de firmeza y cambios de color durante el almacenamiento. Esto es debido a la liberación de enzimas endógenos, que provocan una disgregación de las estructuras celulares llegando así a la putrefacción, aumentado la tasa de respiración y el crecimiento microbiano, con la consiguiente reducción de la vida útil del producto (Wiley, 1997). Todos estos daños se ven acelerados por los daños mecánicos causados a las células en las operaciones de corte que sufren las frutas durante el procesado mínimo, que facilitan el contacto de los enzimas con el sustrato (King y Bolin, 1989) y alteran el metabolismo de ácidos orgánicos (Tovar et al., 2001a). Sin embargo, se ha comprobado que un tratamiento moderado de deshidratación osmótica junto con un almacenamiento a bajas temperaturas puede utilizarse para controlar la tasa respiratoria de frutas como mango (Tovar et al., 2001b; Torres et al., 2004), fresa (Castelló et al., 2004) y manzana (Igual et al., 2004), así como extender la vida útil de papaya (Escriche et al., 1999), pomelo (Ivorra et al., 2003; Moraga et al.,2008), etc., manteniendo características similares a las del producto fresco.

El tratamiento de deshidratación osmótica de frutas se realiza generalmente con disoluciones azucaradas, lo que, en el caso concreto del pomelo, resulta beneficioso desde el punto de vista de que el aumento del dulzor enmascara en cierta medida el carácter amargo propio, lo que aumenta su aceptabilidad.

Por otra parte, la aplicación de un pulso de vacío durante la operación de deshidratación osmótica permite sustituir el gas ocluido en los poros del tejido por fase líquida externa, debido a la acción de mecanismos hidrodinámicos promovidos por los cambios de presión (Fito y Pastor, 1994). De esta forma se acelera el proceso y se pueden incorporar compuestos como vitaminas, antioxidantes y minerales. En 
este sentido, se ha demostrado que el calcio aplicado en forma de lactato cálcico en fruta cortada como manzana y fresa reduce la tasa respiratoria de las mismas (Castelló et al., 2004) y permite que la vida útil del producto sea más elevada (Agar et al., 1999). También ha sido empleado para incrementar la firmeza de tejido parenquimático en manzana, fresa, mango y melón (Ponting et al., 1971; Ponting et al., 1972; Morris et al., 1985; Rosen y Kader, 1989; Castelló et al., 2004; Torres et al., 2006; Gorny et al., 1998; Luna-Guzmán et al., 1999).

La aplicación de la deshidratación osmótica tiene ventajas frente a otros métodos de eliminación de agua. Como el proceso puede realizarse a temperaturas bajas o moderadas, no hay cambios de fase implicados, lo que permite conservar mejor algunas propiedades de los productos como su color, textura, aroma o sabor. No obstante, durante los tratamientos de deshidratación osmótica, se han detectado pérdidas de calcio y otros minerales, ácidos orgánicos, etc. que pasan de la fruta a la disolución osmótica (Peiró et al., 2006).

Por otra parte, un factor importante en esta técnica de deshidratación es un incremento en el coste cuando se considera la disolución osmótica como un subproducto que se desecha (Torreggiani y Bertolo, 2001). Otros estudios han puesto de manifiesto la posibilidad de reutilizar la disolución osmótica (SO) en más de un ciclo de deshidratación. Pero además, teniendo en cuenta que ésta contiene micronutrientes y otros compuestos funcionales procedentes de la fruta, su utilización final para la formulación de nuevos productos, puede suponer un aprovechamiento integral de los componentes utilizados en la operación de deshidratación osmótica de frutas (Moreno, 1999; Shi et al., 1996; García- Martínez et al., 2002a,b).

El desarrollo de alimentos a base de la fruta deshidratada y la SO utilizada para su deshidratación permitiría ampliar la oferta de productos 
de fruta en el mercado promoviendo su consumo y una nutrición más sana en el contexto de condicionantes impuestos por los nuevos hábitos de consumo. La utilización de la SO en la formulación contribuiría a potenciar el aroma y sabor de la fruta, además de recuperar los micronutrientes perdidos por la misma durante su procesado. En base a esto, el trabajo desarrollado en esta Tesis Doctoral supone una contribución al desarrollo de un producto gelificado con pomelo formulado por tratamientos osmóticos. El estudio contempla la viabilidad de la reutilización de la SO en ciclos sucesivos de deshidratación y su incorporación final para la elaboración del gel. Además se ha estudiado el efecto de la incorporación de calcio a la disolución osmótica durante el procesado de la fruta. El pomelo deshidratado y el producto formulado se han estudiado desde el punto de vista de su composición en agua y sólidos solubles, acidez, ácido ascórbico, tasa respiratoria, color, propiedades mecánicas y crecimiento de microorganismos, considerando la evolución de todos estos aspectos con el almacenamiento en refrigeración. Se ha estudiado también la aceptación sensorial del pomelo deshidratado y del producto gelificado antes y después de su almacenamiento en refrigeración. 
I. INTRODUCCIÓN 



\section{INTRODUCCIÓN}

Como ya se ha comentado, este trabajo se ha centrado en algunos aspectos relacionados con el desarrollo de un producto gelificado formulado por tratamientos osmóticos y el posible beneficio de la adición de calcio durante el procesado. En esta introducción se recogen cuestiones generales de especial interés para el seguimiento del trabajo realizado, relacionadas con la fisiología del pomelo, el proceso de la deshidratación osmótica, el papel del calcio a nivel celular y el proceso de gelificación. Además, por el especial peso dado a la evaluación sensorial, se incluye un apartado relacionado con este tipo de análisis. 


\section{I.1. ASPECTOS GENERALES DEL POMELO}

\section{I.1.1. Origen y nombre científico}

El origen del pomelo es algo incierto aunque numerosas investigaciones señalan que se trata de un cruce natural de naranjo dulce (Citrus sinensis) y pummelo (Citrus grandis), que se produjo en Barbados (Indias Occidentales), hacia principios del siglo XVIII. Esta fruta era popularmente conocida como "el fruto prohibido" y fue un conde francés quien lo trasladó desde las Bahamas hasta Florida, donde alcanzó su máximo desarrollo.

El pomelo es una especie que se cultiva actualmente en las regiones de clima tropical y subtropical siendo uno de los cítricos más sensibles al frío.

Los cítricos pertenecen a la clase Angiospermae, a la subclase Dicotiledónea, a la orden Rutae, a la familia Rutaceae y al género Citrus y cuenta con más de 145 especies, entre las que se destacan: naranja (Citrus sinensis), mandarina (Citrus reticulata), limón (Citrus limon), lima (Citrus aurantifolia) y pomelo (Citrus paradisi).

\section{I.1.2. Producción y comercialización}

La producción mundial de frutas está liderada por los cítricos, con valores superiores a los 95 millones de toneladas de los cuales corresponden a las principales especies los siguientes porcentajes: naranjas $(61.9 \%)$, mandarinas $(16.8 \%)$, limas-limones $(11.0 \%)$, pomelos (4.9\%) y otros cítricos (5.4\%) (FAO, 2002).

Como para la producción de pomelo son más adecuados los climas tropicales, su producción se encuentra esparcida en los países que 
están a lo largo de la línea del Ecuador, es decir, América Latina, África y Asia. El productor más grande, sin embargo, es los Estados Unidos, que es el mayor exportador de pomelo fresco, produciendo casi un $40 \%$ del total de las exportaciones mundiales. Sudáfrica e Israel son los siguientes exportadores de importancia. Turquía es un nuevo exportador de pomelos frescos (FAO, 2003).

España es el principal productor de cítricos en Europa, quinto en el ranking del mundo en toneladas, seguido de Brasil, China, EE.UU. y México. Valencia es la región más importante de cítricos en España. Los otros principales productores de cítricos en Europa son Italia, Grecia y Portugal (FAO, 2002).

Entre las principales variedades de cítricos, sólo el pomelo tiene un nivel de utilización comparable a la naranja. En el período 1997-99, el promedio de utilización como producto fresco fue de 3.5 millones de toneladas y el destinado a la elaboración de productos derivados fue de 1.9 millones de toneladas; los productos destinados a la elaboración representaron el $36 \%$ de la utilización total. En Cuba, la utilización con fines de elaboración aumentó espectacularmente: en 1999 se destinó a la elaboración el $90 \%$ del producto cultivado (FAO, 2003).

La proyección de la producción mundial de pomelos para el año 2010 indica una cifra de 6.23 millones de toneladas, lo que representa un aumento del $14 \%$ con respecto al promedio de 1997-99. Casi todo el incremento se producirá en países en desarrollo. Se prevé que la producción de los Estados Unidos e Israel permanezca sin variaciones, y que se registren aumentos moderados en Cuba, México, Argentina y Sudáfrica. El alto nivel de nuevas plantaciones observado recientemente en Turquía generará una mayor producción y competirá con los Estados Unidos e Israel en el mercado europeo (FAO, 2003). 
El aumento de la competencia de otras frutas frescas dará lugar a pequeñas reducciones del consumo de pomelos frescos por habitante. Se prevé asimismo una reducción del consumo por habitante de pomelos elaborados. Los pomelos elaborados compiten directamente con las naranjas elaboradas. A medida que los consumidores de los países desarrollados sigan prefiriendo el zumo de naranja al zumo de pomelo, los productores de pomelos necesitarán encontrar nuevos mercados y/o nuevos productos (FAO, 2003).

\section{I.1.3. Descripción histológica}

El fruto del pomelo es una baya, que botánicamente se conoce con el nombre de hesperidio, de tamaño grande y forma redonda y algo aplastada. El conjunto de capas que forman el fruto recibe el nombre de pericarpio que a su vez está dividido en tres partes (Agustí, 2003):

Exocarpo o flavedo: son importantes los pigmentos y los aceites esenciales que presenta. Los aceites esenciales también se localizan en células especiales de la corteza. Los pigmentos dan su color amarillo o anaranjado a los frutos. Antes de madurar predomina el color verde del pigmento clorofila. A medida que la fruta va madurando aparecen los carotenoides que estaban enmascarados por la clorofila. Pueden utilizarse sustancias que destruyen la clorofila para acelerar la aparición de los carotenoides (desverdización). Los principales carotenoides son: caroteno, xantofila y criptoxantina. El contenido global de carotenos es muy pequeño en los pomelos y oscila de 1 a 5 miligramos por kilo de corteza fresca. Además de carotenoides, el pomelo, especialmente el rosado, es rico en licopeno, que además de contribuir al color, junto con otros terpenos, da el aroma característico de cada fruta. 
Mesocarpo o albedo: está formado por células parenquimáticas débilmente empaquetadas y con grandes espacios intercelulares, lo que le da al tejido ese aspecto esponjoso que lo caracteriza. Es de color blanco y está compuesto por: agua, azúcares, celulosa, lignina, sustancias pécticas, glucósidos (principalmente naringina), ácidos orgánicos y otras sustancias. Las sustancias pécticas tienen la propiedad de embeber grandes cantidades de agua y formar un gel, de aquí la importancia del albedo para la elaboración de mermeladas. Entre los ácidos orgánicos destacan el ácido cítrico (90\% del total) y después, sorprendentemente, el málico (abundante en las manzanas).

Endocarpo (blanco, rosa o rojo) o pulpa: formado por una epidermis y varias capas de células, formando un parénquima compacto. Presenta tricomas con jugo. Es la parte comestible y supone el $80 \%$ del peso de la fruta. Está constituido por segmentos, gajos o lóculos, que se distribuyen alrededor de un eje central, corazón o médula, de estructura blanca y composición análoga al albedo. Los segmentos están envueltos por una pared muy fina, membrana carpelar, que está compuesta por un tejido de origen epidérmico. En las vesículas, celdillas, encontramos el zumo en el fruto maduro. Estas se encuentran compactadas alojadas dentro de los segmentos y unidas a su pared mediante sutiles papilas.

La figura I.1 representa una sección transversal de un fruto de pomelo donde se distinguen las partes descritas anteriormente y la sección transversal de las vesículas. Las vesículas son estructuras en forma de saco que se inician a partir del endocarpo y que progresan hacia el interior del gajo hasta llenarlo por completo. Se fusionan entre sí y con otros orgánulos celulares, formando grandes vacuolas que 
contienen ácidos orgánicos y azúcares, sustancias que junto con el agua, constituyen el zumo (Agustí, 2003).

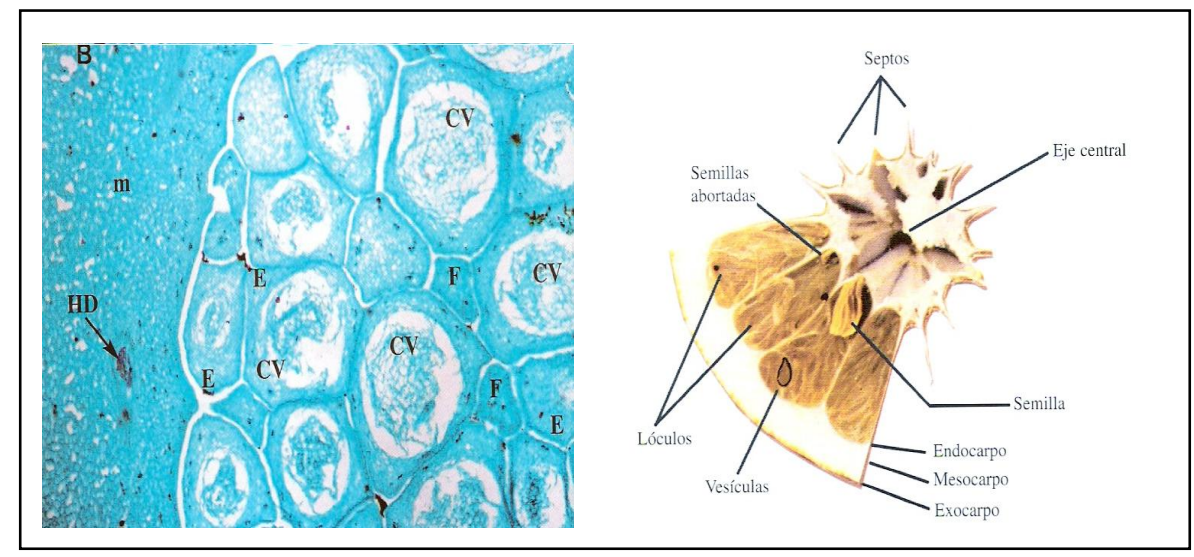

(a)

(b)

Figura I.1. a) Sección transversal de las vesículas y sus filamentos en un fruto de 3 meses de edad de mandarina. E: epidermis; CV: células vacuoladas interiores en expansión; F: filamento; m: mesocarpo; HD: haces dorsales; b) Sección transversal de un fruto de pomelo (Agustí, 2003).

\section{I.1.4. Variedades}

Las variedades de pomelo (Figura I.2), pueden clasificarse en dos grupos dependiendo de la tonalidad de su pulpa. En el primer grupo se incluyen las variedades blancas o comunes que tienen la pulpa de color amarillo; entre ellas podemos distinguir las variedades Duncan y Marsh (Marsh seedles), siendo esta última la más importante. El segundo grupo engloba las variedades pigmentadas, con la pulpa de un tono rosa y rojizo debido al pigmento licopeno, entre las que destacamos las 
variedades Burgundy, Ruby (Ruby red, Redblush, Henninger), Star Ruby, Thompson o Pink Marsh. Por esta característica estas variedades están adquiriendo mayor popularidad entre los consumidores (www.infoagro.com).

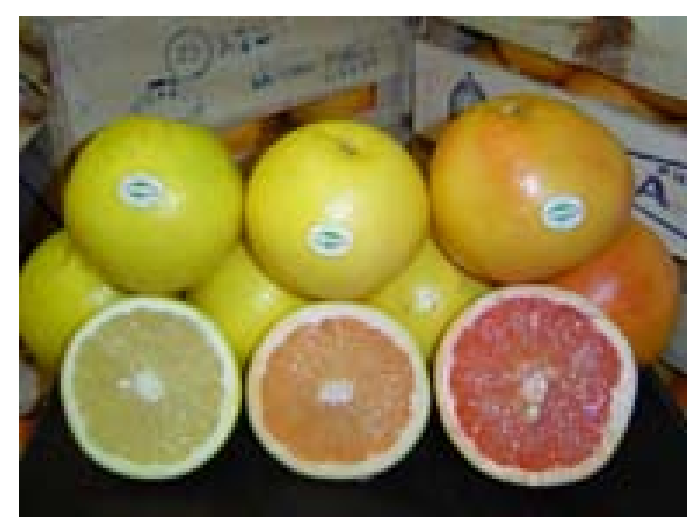

Figura I.2. Variedades del pomelo.

La variedad seleccionada en este trabajo es la Star Ruby por ser la comercialmente disponible que presenta una coloración tanto interior como exterior más oscura y por ello más atractiva. Además, tanto el alto contenido en ${ }^{\circ}$ Brix como el alto contenido de zumo, incrementan la apetencia y el sabor agradable de esta variedad. Por otra parte, produce un escaso número de semillas y alcanza un buen tamaño (www.ivia.es).

\section{I.1.5. Propiedades nutritivas del pomelo}

En la tabla I.1 se muestra la composición y el valor nutricional del pomelo. Como puede observarse, el agua es el principal componente de este cítrico, de ahí su escaso valor calórico, a expensas básicamente de los hidratos de carbono y con escasos lípidos y proteínas. En lo que se refiere a su contenido mineral, el pomelo es rico en potasio, además de 
aportar cierta cantidad de calcio, fósforo y magnesio y un bajo contenido en sodio. El potasio es un mineral necesario para la transmisión y generación del impulso nervioso y para la actividad muscular normal e interviene en el equilibrio de agua dentro y fuera de la célula.

Hoy en día se conoce que además de los nutrientes, el pomelo, como el resto de frutas, contiene componentes no nutricionales que contribuyen a sus efectos beneficiosos sobre la salud del ser humano. Son sustancias como la pectina y diversos fitoquímicos, entre los que se encuentran flavonoides y carotenoides, los responsables de estos efectos (Del Caro et al., 2004; Peiró et al., 2006).

Tabla I.1. Valor nutricional del pomelo por $100 \mathrm{~g}$ de sustancia comestible (www.infoagro.com).

\begin{tabular}{cccc}
\hline \multicolumn{4}{c}{ Valor nutricional del pomelo en $\mathbf{1 0 0}$ g de sustancia } \\
\multicolumn{4}{c}{ comestible } \\
\hline Agua (g) & 88,4 & Ác. málico (mg) & 80 \\
Proteínas (g) & 0,6 & Ác. cítrico (mg) & 1460 \\
Lípidos (g) & 0,1 & Sodio (mg) & 2 \\
Carbohidratos (g) & 9,8 & Potasio (mg) & 198 \\
Calorías (kcal) & 39 & Calcio (mg) & 17 \\
Vitamina A (U.I.) & 80 & Magnesio (mg) & 10 \\
Vitamina B1 (mg) & 0,04 & Manganeso (mg) & 0,01 \\
Vitamina B2 (mg) & 0,02 & Hierro (mg) & 0,3 \\
Vitamina B6 (mg) & 0,02 & Cobre (mg) & 0,02 \\
Ác. nicotínico (mg) & 0,2 & Fósforo (mg) & 16 \\
Ác. pantoténico (mg) & 0,25 & Azufre (mg) & 5 \\
Vitamina C (mg) & 40 & Cloro (mg) & 3 \\
\hline
\end{tabular}

El pomelo destaca por su extraordinaria riqueza en vitamina C (40 $\mathrm{mg} / 100 \mathrm{~g}$ ) y ácido fólico. La vitamina $\mathrm{C}$ interviene en la formación de colágeno, huesos y dientes, glóbulos rojos y favorece la absorción del 
hierro de los alimentos y la resistencia a las infecciones. Es efectiva en la prevención y tratamiento de la arteriosclerosis y sus complicaciones (Gey et al., 1993; Wills, 1985). El ácido fólico interviene en la producción de glóbulos rojos y blancos, en la síntesis material genético y la formación anticuerpos del sistema inmunológico. Éste está asociado a la prevención de diferentes enfermedades del tubo neural en fetos, cáncer de mama y colorectal, enfermedad de Alzheimer, ataques al corazón, entre otros (Soto, 2005).

La provitamina $A$ o beta caroteno se transforma en vitamina $A$ en nuestro organismo conforme éste lo necesita. Dicha vitamina es esencial para la visión, el buen estado de la piel, el cabello, las mucosas, los huesos y para el buen funcionamiento del sistema inmunológico. Ambas vitaminas, cumplen además una función antioxidante.

En cuanto a los ácidos destacan el ácido málico, oxálico, tartárico y cítrico, siendo éste último el mayoritario, el cual potencia la acción de la vitamina $\mathrm{C}$; además son los responsables de su sabor y de diversas propiedades que se le atribuyen al pomelo. El elevado contenido en agua, potasio y ácido cítrico (alcaliniza la orina), convierten al pomelo en una fruta con efecto diurético, beneficioso en caso de hiperuricemia o gota y litiasis renal (favorece la eliminación de ácido úrico y sus sales), hipertensión arterial u otras enfermedades asociadas a retención de líquidos y para quienes toman diuréticos que eliminan potasio. Sin embargo, las personas que padecen insuficiencia renal y que requieren de dietas especiales controladas en potasio, deberán moderar el consumo. El contenido en ácido cítrico hace del pomelo una fruta con propiedades antisépticas sobre las vías digestivas y urinarias. Esta sustancia, junto con otros ácidos orgánicos, le proporcionan el característico sabor ácido al pomelo, por lo que su consumo puede 
provocar molestias a quienes sufren hernia de hiato, acidez de estómago, gastritis y úlcera gástrica o gastroduodenal.

La pectina es un tipo de fibra vegetal, en su mayor parte soluble, que se encuentra en la piel blanca de los cítricos. Concretamente en el pomelo se encuentra en la fibra que forma su pulpa y en la capa blanquecina que se encuentra debajo de la corteza y entre los gajos (Agustí, 2003). Estudios científicos han demostrado que la pectina impide la multiplicación de las células cancerosas, siendo muy eficaz en casos de melanomas cutáneos y cáncer de próstata. A la vez muestra efectos anticolesterol y protege la pared de las arterias, gracias a su acción antioxidante e inhibidora de la formación de trombos o placas arterioscleróticas (Baker, 1994; Mikhailova, 2005).

Algunos flavonoides del pomelo como la naringina son capaces de fluidificar la sangre, tienen propiedades antioxidantes y anticancerígenas (Middleton y Kandaswami, 1994). La naringina es el flavonoide más importante del pomelo y el principal responsable de su sabor amargo (Hagen et al., 1966). Los carotenoides, presentes fundamentalmente en los pomelos de pulpa roja, potencian la acción antioxidante de la vitamina $\mathrm{C}$ y los flavonoides. Otros terpenoides como el limoneno, responsable también en parte pero en menor medida de su sabor amargo, junto a la naringina, presentan una probada acción anticancerígeno (Olson, 1988). La sustancia amarga del pomelo, abre el apetito y favorece la producción de bilis, de ahí que se considere al pomelo como alimento digestivo y beneficioso para el hígado. 


\section{I.1.6. Fisiología celular}

Las frutas sufren tras su recolección numerosos cambios físicoquímicos determinantes de su calidad cuando son adquiridas por el consumidor (Wills et al., 1984).

La maduración organoléptica de frutas y hortalizas, es decir, la transformación de un tejido fisiológicamente maduro pero no comestible en otro visual, olfatorio y gustativamente atractivo, requiere de la síntesis de nuevas proteínas, ARNm, pigmentos y compuestos aromáticos. Estos procesos anabólicos demandan energía y aporte de esqueletos carbonados, que son suministrados por la respiración (Seymour et al., 1993).

El estudio de los patrones respiratorios (intensidad respiratoria, IR) en condiciones ambientales de numerosas especies ha puesto de manifiesto la existencia en frutos de dos perfiles claramente diferenciados, climatéricos y no climatéricos (Biale, 1964). La clasificación dentro de un grupo u otro, depende de la presencia o no, en la fruta, de un máximo en la respiración (McMurchi et al., 1972) y la producción de etileno durante la maduración.

Las frutas climatéricas son aquellas especies en las que el aumento respiratorio está asociado con cambios físicos, químicos, fisiológicos y metabólicos, presentes en la fase de transición existente entre la plena madurez y la senescencia (descomposición y muerte celular), al contrario que para las frutas no climatéricas.

Las frutas no climatéricas tienen tasas respiratorias altas en las etapas tempranas de desarrollo que disminuyen regularmente con la maduración (López-Gálvez et al., 1997). Estas frutas maduran de forma lenta y no tienen cambios bruscos en su aspecto y composición. Su contenido en almidón es mayor que en las climatéricas. La recolección 
se hace después de la maduración porque si se hace cuando están verdes, posteriormente no maduran, solo se ponen blandas. Dentro de este grupo se encuentran los cítricos.

El etileno es un compuesto químico (gas incoloro) que produce la fruta antes de madurar y es fundamental para que madure. La crisis respiratoria en los frutos climatéricos está asociada a una emisión de etileno (crisis etilénica) que proviene de una síntesis autocatalítica de ese gas. En las frutas climatéricas su presencia determina el momento de la maduración, por lo cual, el control de su producción será clave para su conservación. Una aplicación de etileno de corta duración es suficiente para provocar de forma irreversible la crisis respiratoria de los frutos climatéricos. En las frutas no climatéricas, a excepción de las cerezas (Li et al., 1994), la presencia de etileno provoca un aumento en la tasa de respiración en respuesta al etileno exógeno (Biale, 1964) ya que no son capaces de sintetizar este gas de forma autocatalítica; (Côme y Corbineau, 2001). Por ejemplo, en los cítricos, los antagonistas del etileno previenen los cambios de color en el flavedo (Goldschmidt et al., 1993). La evidencia de la participación del etileno en la desverdización en cítricos está reforzada por los datos que muestran que la degradación de clorofilas (Purvis y Barmore, 1981) y la biosíntesis de carotenoides están estimulados por el etileno (Stewart y Wheaton, 1972).

El punto fundamental de la conservación de las frutas será el control de su respiración, evitando la maduración de las climatéricas y procurando que en las no climatéricas sea lo más lenta posible. 


\section{I.1.6.1. Respiración}

Los productos agrícolas, al momento de ser cosechados, están vivos y realizan procesos fisiológicos propios de organismos vivientes. Desde el punto de vista de post-cosecha el más importante de todos éstos es el de la respiración. Las frutas y hortalizas respiran tomando oxígeno $\left(\mathrm{O}_{2}\right)$ y desprendiendo dióxido de carbono $\left(\mathrm{CO}_{2}\right)$ y calor. También transpiran, es decir, pierden agua (Wills et al., 1984).

La respiración es el proceso metabólico que proporciona la energía para los procesos bioquímicos. Este proceso puede tener lugar en presencia de oxígeno (respiración aeróbica) o en su ausencia (respiración anaeróbica, a veces denominada fermentación) (Wills et al., 1984). La respiración aeróbica consiste en la oxidación de las reservas orgánicas a otras moléculas más simples, formando $\mathrm{CO}_{2}$ y agua, con liberación de energía. Los sustratos orgánicos que pueden intervenir en este proceso son carbohidratos, lípidos y ácidos orgánicos. Además, abarca tres rutas metabólicas principales: la glucólisis, el ciclo de los ácidos tricarboxílicos y el transporte de electrones (Fernie et al., 2004).

Glucólisis: Tiene lugar en el citoplasma celular, en condiciones totalmente anaerobias (Figura I.3). En esta fase se produce la hidrólisis de la glucosa que, a través de una serie de reacciones enzimáticas catalizadas cada una de ellas por un enzima (en total actúan 11 enzimas que se encuentran en el citosol y no en la mitocondria), genera 2 moléculas de piruvato (molécula de 3 carbonos). La glucólisis se puede dividir en 2 fases, en la primera de ellas se requiere energía en forma de ATP para fosforilar la glucosa en glucosa 6-fosfato. La glucosa 6-fosfato se isomeriza a fructosa 6difosfato que a su vez se fosforila a fructosa 1, 6-difosfato gracias a otra molécula de ATP. Luego esta molécula se divide en dos 
moléculas de tres carbonos: la gliceraldehido-3-fosfato (G3P) y la dihidroxiacetona-fosfato (que más tarde se transforma en G3P). En la segunda fase, las dos moléculas de G3P se convierten finalmente a 2 moléculas de ácido pirúvico o piruvato y se obtiene energía en forma de ATP. En un primer lugar cada gliceraldehido se oxida y parte de la energía liberada es guardada temporalmente como $\mathrm{NADH}$ reducido, la otra parte es utilizada para añadir un fosfato inorgánico a la molécula G3P y formar 1-3 difosfoglicérico. Después, los grupos fosfato de esta molécula son cedidos uno a uno al ADP para formar ATP.

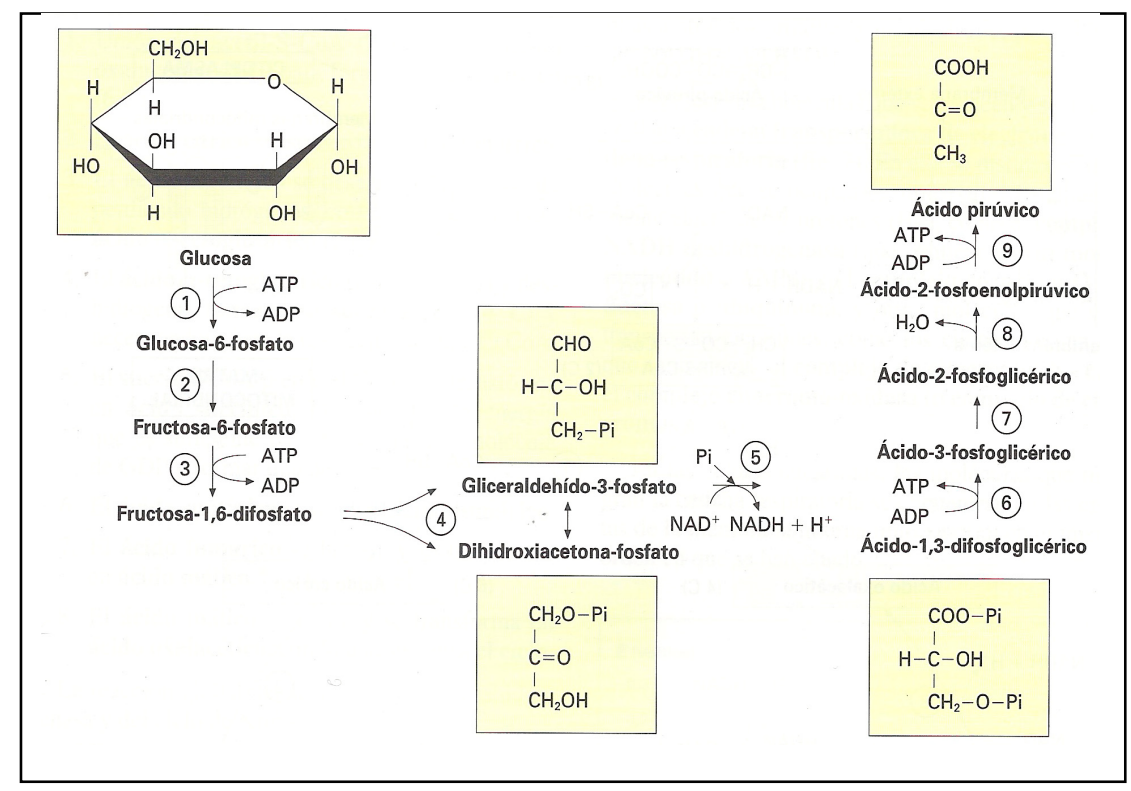

Figura I.3. Esquema simplificado de la glucólisis (Jimeno et al., 1997).

El balance global de este proceso es el siguiente:

Glucosa $+2 \mathrm{NAD}^{+}+2 \mathrm{ADP}+2 \mathrm{Pi} \rightarrow 2$ piruvato $+2 \mathrm{NADH}+2 \mathrm{H}^{+}+2 \mathrm{ATP}$ 
Cuando el proceso de glucólisis finaliza, el NADH debe ser oxidado para poder ser utilizado en forma de $\mathrm{NAD}^{+}$, proceso que se puede llevar a cabo de dos formas: en condiciones anaeróbicas y en condiciones aeróbicas (Berkaloff et al., 1986).

El lazo de unión entre la glucólisis y el ciclo de Krebs es la oxidación del piruvato. El ácido pirúvico producido en la glucólisis, para poder ser oxidado por respiración debe entrar en el interior de las mitocondrias atravesando la doble membrana de éstas. Para ello, mediante una reacción irreversible, se une a una coenzima $A$ y sufre una descarboxilación y una oxidación en el que intervienen varias enzimas y coenzimas (el denominado sistema piruvatodeshidrogenasa), formándose: $\mathrm{CO}_{2}, \mathrm{NADH}$ y acetil coenzima $\mathrm{A}$ (acetil-CoA).

Ciclo de Krebs o de los ácidos tricarboxílicos: se realiza en la matriz mitocondrial de la célula donde se oxida el acetil-CoA o ácido acético activado (Taiz y Zeiger, 1991) (Figura I.4). En la matriz, este ciclo empieza por la formación del ácido cítrico, mediante la condensación del acetil-CoA con el ácido oxalacético. Seguidamente, el ácido cítrico es isomerizado a ácido isocítrico, que es entonces oxidado y descarboxilado en ácido $\alpha$-cetoglutámico con reducción del $\mathrm{NAD}^{+}$. Una descarboxilación oxidativa en presencia de la coenzima A origina el succinil-CoA. El succinil-CoA pierde el coenzima A y se transforma en ácido succínico, liberándose una energía que es suficiente para fosforilar una molécula de GDP y formar una de GTP (equivalente a una de ATP) (Berkaloff et al., 1986). La oxidación del ácido succínico conduce al ácido fumárico, que rápidamente es hidratado para formar ácido málico, el cual se oxida dando lugar de nuevo a ácido oxalacético, que vuelve a reiniciar el ciclo. 
Por cada molécula de acetil-CoA que ingresa en el ciclo se obtienen 2 moléculas de $\mathrm{CO}_{2}, 1$ molécula de $\mathrm{FADH}_{2}, 3$ moléculas de $\mathrm{NADH}, 1$ molécula de GTP (equivalente a 1 de ATP) y queda libre una coenzima-A que puede ser reutilizada.

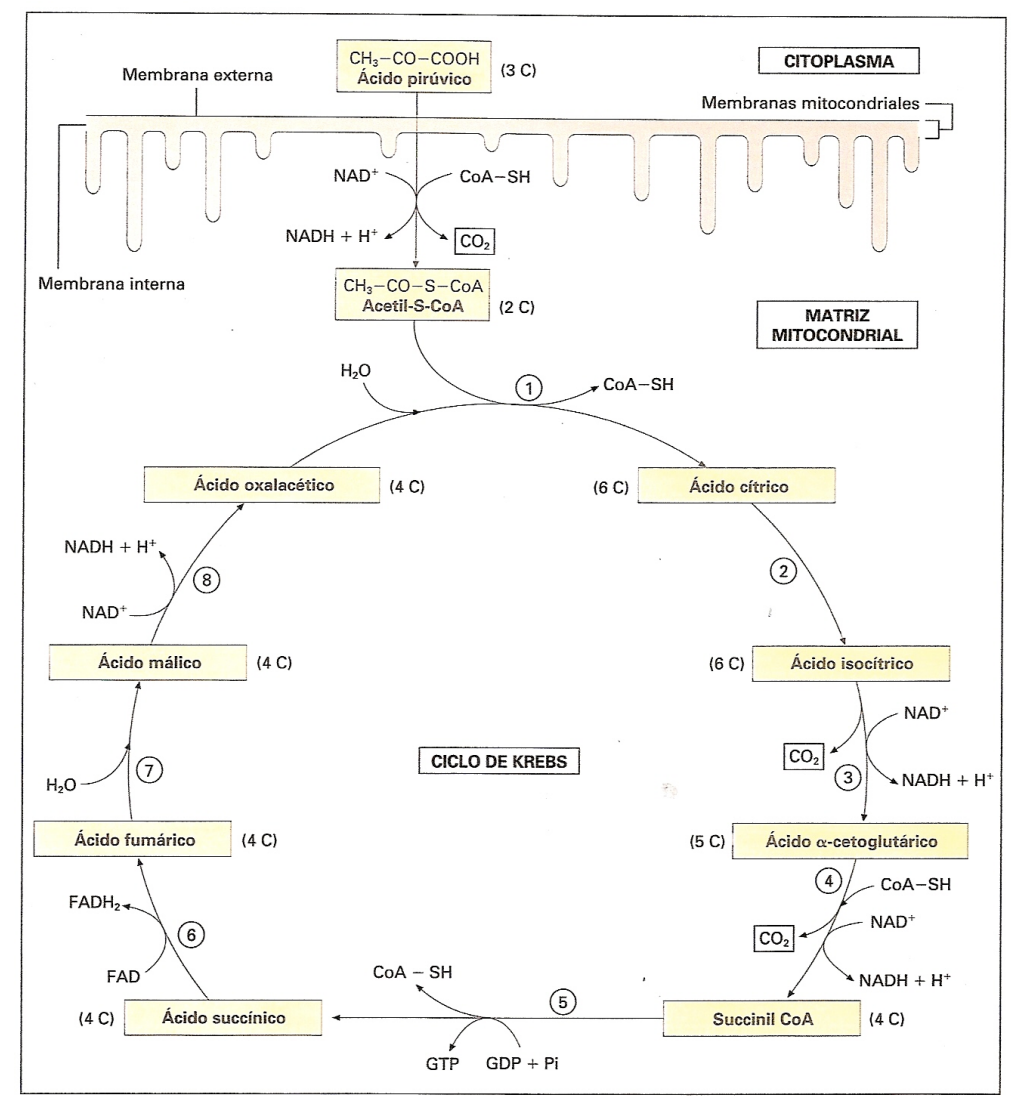

Figura I.4. Esquema del Ciclo de Krebs (Jimeno et al., 1997).

La reacción global del sistema piruvato-deshidrogenasa y del ciclo de Krebs es el siguiente:

Piruvato $+2 \mathrm{H}_{2} \mathrm{O}+4 \mathrm{NAD}^{+}+\mathrm{FAD}+\mathrm{GDP}+\mathrm{Pi} \rightarrow 3 \mathrm{CO}_{2}+4 \mathrm{NADH}+$ $4 \mathrm{H}^{+}+\mathrm{FADH}_{2}+\mathrm{GTP}$ 
Como en el ciclo de Krebs penetra un compuesto de dos $C$ (el acetil-CoA) y se producen dos descarboxilaciones, la molécula queda totalmente degradada. Además, como en la glucólisis se pueden formar dos moléculas de ácido pirúvico, para la degradación total de una molécula de glucosa son necesarias dos vueltas del ciclo de Krebs.

Cadena respiratoria (Figura I.5.): En este punto la célula ha ganado solo 4 ATP, 2 en la glucólisis y 2 en el ciclo de Krebs, sin embargo ha capturado electrones energéticos en $10 \mathrm{NADH}$ y $2 \mathrm{FADH}_{2}$. Estos transportadores depositan sus electrones en el sistema de transporte de electrones. Esta fase tiene lugar en la membrana interna de la mitocondria y consiste en una serie de centros redox unidos a la membrana que catalizan la transferencia de electrones desde el $\mathrm{NADH}$ y el $\mathrm{FADH}_{2}$ hasta el oxígeno formando agua y traslocándose protones a través de la membrana interna (AzcónBieto y Talón, 2000). Todo este proceso se lleva a cabo por tres complejos proteicos con moléculas transportadoras que son comunes a todas las mitocondrias (animales y vegetales) y se denominan complejo I, II y III. La secuencia que se sigue sería la siguiente:

- Paso de los electrones a través del primer complejo (NADH-Q reductasa) hasta la ubiquinona $(Q)$, los iones $\mathrm{H}^{+}$traspasan la membrana hacia el espacio intermembrana.

- El $2^{\circ}$ complejo (citocromo C reductasa) transfiere electrones desde la NADH-Q reductasa al citocromo $c$, generando un nuevo bombeo de protones al exterior.

- El $3^{\text {er }}$ complejo es un citocromo $c$ oxidasa, que pasa los electrones del citocromo $c$ al oxígeno, así el oxígeno reducido (1/2 $\mathrm{O}_{2}{ }^{-}$) toma dos iones $\mathrm{H}^{+}$y forma $\mathrm{H}_{2} \mathrm{O}$. 
Además la cadena respiratoria incorpora 2 enzimas adicionales: $\mathrm{NADH}$ deshidrogenasa y una oxidasa alternativa, que no translocan protones y por ello no están ligadas a la síntesis de ATP (AzcónBieto y Talón, 2000).

En una serie de reacciones, una molécula de $\mathrm{NADH}$ produce 3 moléculas de ATP mientras que una molécula de $\mathrm{FADH}_{2}$ produce 2 moléculas de ATP. Sin embargo, el número exacto de moléculas de ATP producidas durante el transporte de electrones no depende sólo de la energía contenida en $\mathrm{NADH}$ y $\mathrm{FADH}_{2}$ sino también del ambiente químico dentro de la célula y la mitocondria (Kader y Saltveit, 2002).

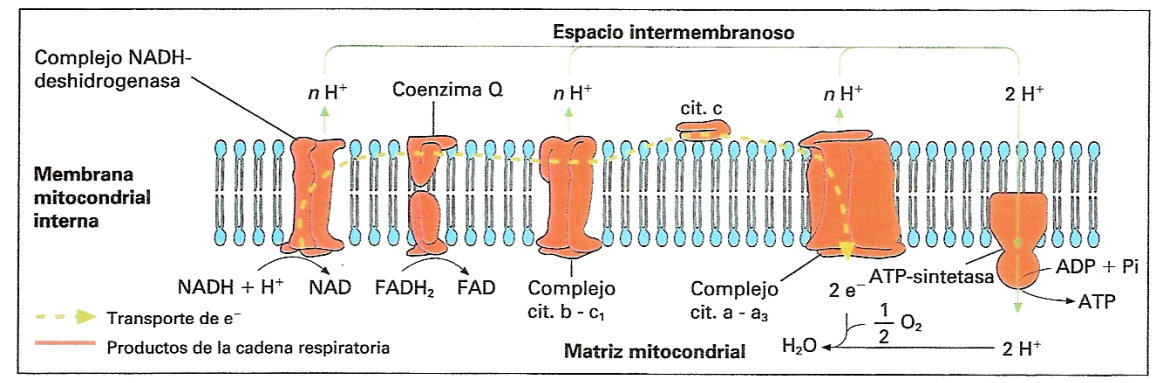

Figura I.5. Transferencia de electrones y fosforilación oxidativa en la cadena respiratoria mitocondrial (Jimeno et al., 1997).

Los electrones son transferidos a lo largo de las proteínas de la cadena y el protón al espacio intermembrana, donde genera un gradiente. Los protones vuelven a entrar pasando por el complejo ATP sintetasa, generando ATP. Las ATPasas funcionan con el potencial químico de los $\mathrm{H}^{+}$a ambos lados de al membrana, produciéndose más ATP cuanto mayor sea la concentración de los mismos en el citoplasma (Elston et al., 1998). 
Desde el punto de vista químico, la respiración es expresada comúnmente en términos de la oxidación de la glucosa. La eficiencia de la respiración llega casi al $40 \%$ de la energía presente inicialmente en la molécula de glucosa y es conservada en forma de ATP. El resto se libera como calor.

La reacción global de la oxidación completa de la glucosa con todo el NADH y el $\mathrm{FADH}_{2}$ convertidos en ATP por la respiración es el siguiente:

Glucosa $+6 \mathrm{O}_{2}+38 \mathrm{ADP}+38 \mathrm{Pi} \rightarrow 6 \mathrm{CO}_{2}+6 \mathrm{H}_{2} \mathrm{O}+38 \mathrm{ATP}+$ calor

Dos de los NADH se forman en el citoplasma durante la glucólisis y para ser transportados a la matriz mitocondrial y ser posteriormente oxidados por la cadena transportadora de electrones, tienen que pasar por medio de transporte activo al interior de la mitocondria. Esto consume una molécula de ATP por cada NADH. Por lo tanto el balance final resulta en 36 ATP por glucosa:

Glucosa $+6 \mathrm{O}_{2} \rightarrow 6 \mathrm{CO}_{2}+6 \mathrm{H}_{2} \mathrm{O}+36$ ATP

\section{I.1.6.2. Fermentación}

En presencia de $\mathrm{O}_{2}$, el piruvato procedente de la glucólisis será incorporado a las mitocondrias donde continuará su proceso de oxidación completa hasta dióxido de carbono y agua mediante el ciclo de Krebs. Sin embargo puede ocurrir que en algunas condiciones de almacenamiento, el oxígeno pueda quedar considerablemente reducido y resultar insuficiente para un metabolismo completamente aeróbico (Tadege et al., 1999). En este caso los tejidos pueden iniciar una ruta 
alternativa en que la glucosa se convierte en piruvato y éste se transforma a su vez en ácido láctico, acético o acetaldehído y seguidamente en etanol en el proceso denominado fermentación. El término fermentación, en su acepción estricta, se refiere a la obtención de energía en ausencia de oxígeno y generalmente lleva agregado el nombre del producto final de la reacción. La fermentación más importante es la de los hidratos de carbono. De acuerdo a los productos formados hay 6 tipos: láctica, etanólica, butírica, propiónica, ácido-mixta y homoacética.

Este proceso produce mucha menos energía por mol de glucosa que las rutas aeróbicas pero al menos permite poner a disposición del tejido cierta cantidad de energía en condiciones adversas. También produce metabolitos que son dañinos para el tejido vegetal como el etanol, el lactato o el acetato.

Los 2 caminos más comunes son: la fermentación ácido-láctica y la fermentación etanólica aunque existen más, como la acética, más común en hortalizas. En la fermentación ácido-láctica hay una conversión del piruvato, catalizado por lactato deshidrogenasa (LHD) con oxidación de NADH (Figura I.6).

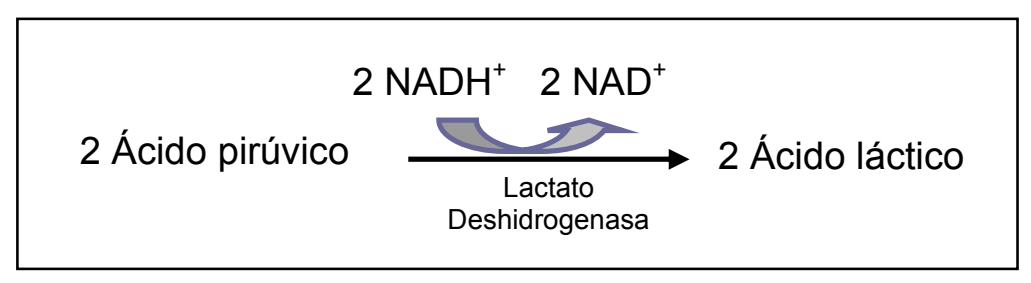

Figura I.6. Fermentación ácido-láctica.

La fermentación etanólica tiene 2 pasos en los cuales el piruvato es descarboxilado a acetaldehído por piruvato descarboxilasa (PDC), 
seguidamente el acetaldehído se convierte a etanol por medio de alcohol deshidrogenasa regenerando $\mathrm{NAD}^{+}$(Tadege et al., 1999) (Figura I.7). El etanol es el producto final mayoritario en condiciones de baja concentración de $\mathrm{O}_{2}$ (Ke y Kader, 1992).

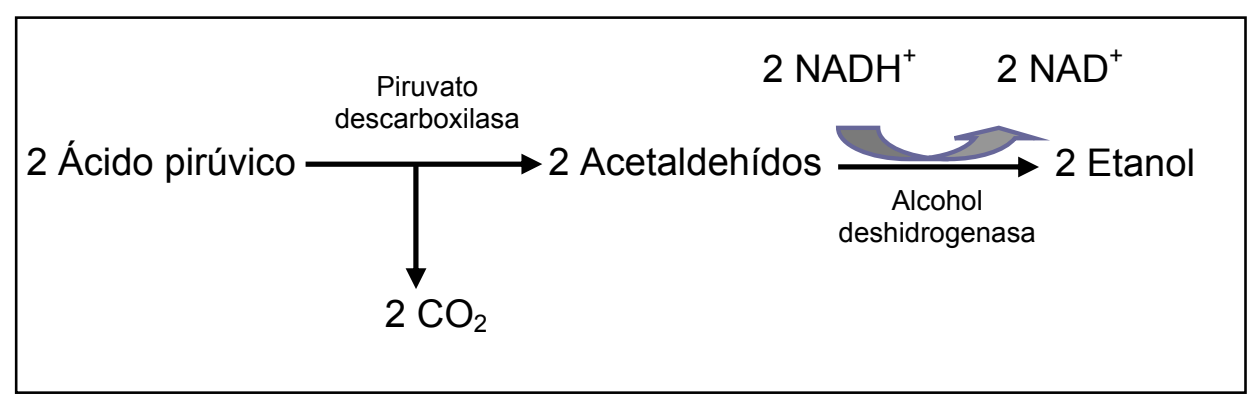

Figura I.7. Fermentación etanólica.

La acumulación del ácido láctico en el citoplasma, al ser ácido puede afectar al pH y causar daños. El etanol al contrario que el ácido láctico, difunde en el medio extracelular y por tanto no causa tantos daños (Tadege et al., 1999).

\section{I.1.6.3. Tasa respiratoria y coeficiente respiratorio}

Tanto la emisión de $\mathrm{CO}_{2}$ como el consumo de $\mathrm{O}_{2}$ pueden ser utilizados para medir la tasa de respiración (TR) de las plantas (AzcónBieto y Talón, 2000). La tasa respiratoria se define como la cantidad de anhídrido carbónico emitido y de oxígeno consumido por kg de fruta y por hora (Fonseca et al., 2002).

Los cítricos están considerados como frutos con una tasa respiratoria débil, de entre 5 y $10 \mathrm{mg} \mathrm{CO} / \mathrm{kg} \mathrm{h}$ para una temperatura de $5^{\circ} \mathrm{C}$ (Kader, 1985). Pero además, esta tasa respiratoria no es 
constante para los distintos tejidos que componen el fruto, existiendo un gradiente de crecimiento de la misma desde el interior hacia el exterior del mismo (Hussein, 1944). Numerosos factores externos determinan la TR. La propia recolección así como la manipulación, estimulan la TR de los frutos cítricos (Parker et al., 1984). También la temperatura juega un importante papel en la TR (Vakis et al., 1970).

Para determinar la naturaleza del sustrato utilizado en la respiración se utiliza normalmente el coeficiente respiratorio (CR) (Ecuación I.1): relación entre el volumen de $\mathrm{CO}_{2}$ producido y $\mathrm{O}_{2}$ consumido por el fruto en un mismo tiempo. Se asume que si el sustrato metabólico son carbohidratos, el CR es igual a la unidad. La oxidación total de $1 \mathrm{~mol}$ de hexosa consume 6 moles de $\mathrm{O}_{2}$ y produce 6 moles de $\mathrm{CO}_{2}$. Si el sustrato es un lípido, el $\mathrm{CR}$ es siempre menor que la unidad y si el sustrato es un ácido, el CR es mayor que la unidad. Por lo tanto, el valor normal del CR en la bibliografía muestra un intervalo desde 0,7 hasta 1,3 dependiendo del sustrato metabólico (Kader, 1987; Kader et al., 1989). Renault et al., (1994) justificaron un valor de CR de 1,0 para fresas, reflejando las ricas reservas glucosídicas. Beaudry et al. (1992) explicaron el valor de CR de 1,3 observado para arándanos por su alto contenido en ácido cítrico.

$$
\mathrm{CR}=\frac{\left[\mathrm{TR} \mathrm{CO}_{2}\right]}{\left[\mathrm{TR} \mathrm{O}_{2}\right]} \quad \text { (moles ó volumen) }
$$

Así, para un producto con un CR igual a la unidad, una modificación hacia valores superiores a la unidad puede estar indicando que se está produciendo una fermentación (Fonseca et al., 2002). Las modificaciones en el cociente respiratorio a lo largo del desarrollo y el 
almacenamiento pueden indicar el cambio del tipo de sustrato que está siendo metabolizado.

\section{I.2. PROCESOS DE DESHIDRATACIÓN OSMÓTICA E IMPREGNACIÓN A VACÍO}

La deshidratación osmótica es una técnica ampliamente utilizada para la obtención de alimentos parcialmente deshidratados y como etapa previa al secado convencional y/o congelación de frutas y hortalizas (Chiralt et al., 2001; Moraga, 2002; Moraga et al., 2006). El consumidor espera de los productos de fruta pelados y cortados que se sirven en el mercado que se encuentren en óptimas condiciones de frescura y que su apariencia en cuanto a textura, color y sabor sea lo más similar posible al producto fresco. En este sentido, la deshidratación osmótica se presenta como una técnica que disminuye los cambios no deseados que se pueden producir con otro tipo de secado. Entre las principales ventajas se encuentra el uso de bajas temperaturas, por lo que la eliminación del agua se realiza sin cambio de estado minimizándose el daño en el color, sabor y textura del producto (Moreno, et al., 2000; Moraga et al., 2000). Además, esta técnica potencia la biosíntesis de componentes clave del aroma de frutas como la fresa (Zabetakis y Holden, 1997; Escriche et al., 2000a; Talens et al., 2002), la piña (Pino et al., 1999) y el kiwi (Bereiter, 2001). Esto, junto con la reducción de la acidez y el aumento en la concentración de solutos (azúcares), puede contribuir a mejorar el sabor de frutas ácidas y/o amargas como el pomelo. Por otro lado, la formación de una capa compacta de células deshidratadas en la superficie, podrían actuar como barrera protectora del resto del tejido 
conservando las características del producto fresco (Tovar et al., 2001b).

La deshidratación osmótica (DO) consiste en sumergir al producto sólido, en piezas o entero, en una disolución hipertónica, de menor $\mathrm{a}_{\mathrm{w}}$, la cual suele ser una disolución azucarada en el caso de la deshidratación de frutas. Esto provoca al menos dos flujos principales simultáneos en contracorriente: un importante flujo de agua del alimento hacia la disolución y una transferencia de solutos desde la disolución hacia el alimento, los cuales son debidos a los gradientes de concentración de agua y solutos, a un lado y otro de las membranas que forman el tejido parenquimático del producto (Torreggiani, 1993). El flujo de componentes de una fase a otra ocurre de forma espontánea hasta alcanzar la igualdad de potenciales químicos de los diferentes componentes en el sistema. De esta forma se consigue el principal objetivo de cualquier técnica de deshidratación, extender la vida útil del producto mediante una disminución del contenido de humedad, reduciendo así la actividad del agua y como consecuencia el crecimiento microbiano y la actividad enzimática, factores que provocan el deterioro de los alimentos (Fellows, 1988).

Se ha comprobado que la velocidad a la que sale el agua del alimento hacia la disolución concentrada es mayor que la de entrada de los sólidos solubles hacia el interior del alimento (Karel, 1973; Lenart y Lewicki, 1990; Vial et al., 1991). Sin embargo, se considera que después de un cierto tiempo de tratamiento osmótico, que depende mayoritariamente de las condiciones del proceso, la permeabilidad selectiva de la membrana es destruída y el soluto puede entonces penetrar por difusión (Levi et al., 1983; Heng et al., 1990). Por otra parte, existe un tercer flujo, de salida de sustancias hidrosolubles propias de la fruta (azúcares, ácidos orgánicos, minerales, vitaminas, 
etc.) a la disolución osmótica (García-Martínez et al., 2002a; Peiró et al., 2006). Este flujo, aunque cuantitativamente menor, puede llegar a generar pérdidas de algunos de estos componentes entre un 10 y un $59 \%$ de su contenido en las frutas frescas. Desde ese punto de vista, el enriquecimiento de la disolución osmótica en estos compuestos de alto valor nutricional, hace que sea interesante su aprovechamiento para la formulación de otros productos derivados, como productos gelificados a base de fruta, objeto de este estudio. De esta forma, se contribuye, además, a la gestión medioambiental del proceso.

Por otra parte, la cinética del proceso de deshidratación se puede mejorar mediante la aplicación de un pulso de vacío que permite sustituir el gas ocluido en los poros del tejido por disolución osmótica, aumentando así la superficie de contacto de la fruta con la fase líquida y haciéndose mayor la transferencia de masa, tanto del agua que sale del producto hacia la disolución, como de los sólidos solubles que salen de la disolución hacia el producto (Escriche et al., 2000b; Fito y Chiralt, 2000; Barat et al., 2001b).

Fito y Pastor (1994) explicaron el mecanismo de la impregnación a vacío a través del denominado Mecanismo Hidrodinámico (HDM). Según estos autores, lo que le ocurre al producto sumergido en el líquido a presiones subatmosféricas es que el gas ocluido en los poros sufre una expansión para equilibrarse con la presión impuesta en el sistema, lo que implica por una parte, un nivel de desgasificación de la estructura porosa del alimento función de la presión aplicada y, por otra, una penetración del líquido por capilaridad una vez alcanzado el equilibrio de presiones en el sistema. En segundo lugar, la instauración de la presión atmosférica provoca un nuevo gradiente de presiones que va a actuar como fuerza impulsora y que hará que los espacios intercelulares se llenen parcialmente de líquido. Este fenómeno puede 
ser aprovechado para incorporar componentes de interés en el interior del producto.

Algunos resultados obtenidos de aplicación de la deshidratación osmótica con una etapa previa de impregnación a vacío (Fito y Pastor, 1994) ponen de manifiesto que los cambios de presión inducidos en el sistema provocan importantes cambios estructurales en el alimento que se impregna. Los resultados indican que el HDM está acoplado a fenómenos de deformación relajación (DRP) en la matriz sólida, con propiedades viscoelásticas, del alimento poroso. La actuación del HDM y DRP está muy afectada por la microestructura del alimento y sus propiedades mecánicas, lo que simultáneamente puede dar origen a importantes cambios en las propiedades físicas del producto.

La cantidad de líquido que impregne la estructura dependerá de las características intrínsecas del producto (porosidad, tamaño de los poros, características viscoelásticas del material, etc.), de las propiedades de la disolución de impregnación (Martínez-Monzó et al., 1998b) y del nivel de desgasificación que será función de la presión de trabajo (Fito et al., 1996).

\section{I.2.1. Cinética de la deshidratación osmótica}

Los factores más importantes que se tienen en cuenta al analizar la cinética de la DO y que influyen a la hora de su modelización son: las características de la materia prima (estructura, composición y tamaño de piezas del producto), la concentración y naturaleza del agente osmótico, la temperatura y la presión de trabajo.

La modelización de esta operación está limitada por la dificultad de considerar la influencia particular de la estructura de cada tejido y los 
mecanismos activos y pasivos de transporte en la velocidad de transporte de agua y solutos.

En la estructura celular, durante la deshidratación osmótica, se producen unos cambios (alteración de las paredes celulares, desgarramiento de la lámina media, lisis de membranas (plasmalema y tonoplasto), pérdida de volumen del tejido, etc.) que provocan una gran alteración en la compartimentación celular, de modo que estas modificaciones de la matriz extracelular y la membrana plasmática afectarán en gran medida a las propiedades de transporte durante el tratamiento (Nieto et al., 2004). Varios trabajos (Alzamora et al., 1997; Martínez-Monzó et al., 1998a; Barat et al., 1998, 1999; Fito et al., 2000; Barat et al., 2001a; Barrera et al., 2004) han contribuido a esclarecer el papel de la estructura, y sus cambios a lo largo del proceso, en las velocidades de transporte y cinética del mismo. No obstante, la complejidad y diversidad de los tejidos (en estructura y fisiología) hace que haya todavía muchos aspectos oscuros.

Podemos distinguir tres tipos de mecanismos de transporte de masa en el interior del tejido vegetal sometido a tratamiento osmótico (Figura I.8):

- Transporte apoplástico: ocurre en el exterior de la membrana celular y puede visualizarse como una difusión de moléculas en la pared celular y los espacios intercelulares.

- $\quad$ Transporte simplástico: se realiza en el interior del plasmalema y se caracteriza por el movimiento de moléculas de una célula a otra a través de los plasmodesmos.

- Transporte transmembrana: es un intercambio que tiene lugar a través del mecanismo osmótico, entre el protoplasma y el espacio libre que comprende el espacio intercelular y la pared celular. 


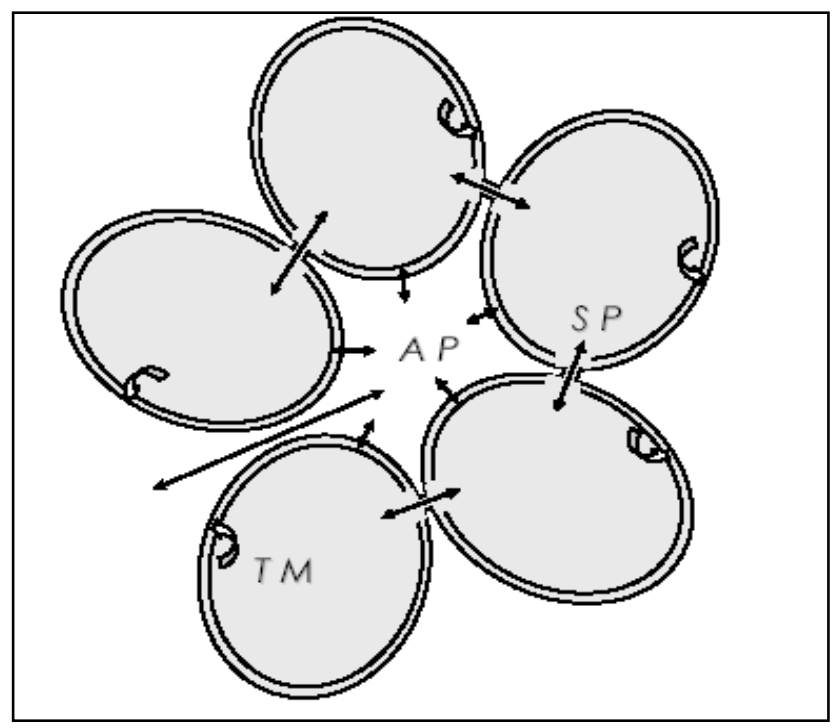

Figura I.8. Tipos de transporte en el tejido vegetal: Apoplástico (AP), simplástico (SP) y transmembrana (TM). (Adaptado de Albors, 2002).

Los enfoques utilizados hasta ahora para caracterizar los fenómenos de transporte simultáneos que se verifican en el proceso de deshidratación osmótica se han basado, en primer lugar, en la microestructura del alimento, enfoque mediante el cual la transferencia de agua se aproxima a un mecanismo de transporte transmembrana y que se realiza en base a principios termodinámicos. Un segundo enfoque ha sido sustentado en la segunda ley de Fick, que incorpora los términos de coeficientes de difusividad tanto para la pérdida de agua como para la ganancia de sólidos. Por último, algunos trabajos han constituido un tercer enfoque basado en las manifestaciones macroscópicas de los fenómenos de transporte, lo que ha sido de utilidad en la modelización empírica del proceso osmótico (Panagiotou 
et al., 1998; Fito et al., 2001) y que permite prefijar tiempos de proceso en función del nivel de concentración deseado para el producto.

En el proceso de DO el mecanismo de transporte predominante es el transporte transmembrana, sin embargo existen también otros mecanismos difusionales y capilares que ocurren de forma solapada en los espacios intercelulares o poros del tejido y que dependen de las condiciones de presión de trabajo (Fito et al., 1994; Chiralt y Fito, 2003).

En condiciones con cambios de presión o de baja presión se potencian los mecanismos hidrodinámicos y la capilaridad, mientras que a presión atmosférica se solapan básicamente fenómenos de ósmosis y difusión. Además, si se aplica un pulso de vacío al principio del tratamiento, restituyendo después la presión atmosférica, la entrada de fase líquida externa en los espacios intercelulares puede jugar un papel importante en la transferencia de materia global.

La cinética de deshidratación osmótica ha sido analizada con frecuencia en términos de velocidades de pérdida de agua, ganancia de sólidos y pérdida de peso del alimento (Ponting et al., 1966; Garrote y Bertone, 1989). Se ha propuesto un modelo (Fito y Chiralt, 1997; Barat et al., 1997) que contempla, por un lado, la cinética de los cambios de composición de la fracción líquida de la fruta, que determinan la calidad del producto y su estabilidad y por otro lado, la cinética de pérdida de peso asociada con la pérdida de agua y ganancia de solutos, que determina la rentabilidad del proceso.

Normalmente las velocidades de flujo de agua son altas durante las primeras 2 horas y la mayor cantidad de sólidos ganados ocurre dentro de los primeros 30 minutos de tratamiento. A partir de ese punto los flujos se hacen muy lentos (Conway et al., 1983; Guennengues, 1986; Giangiacomo et al., 1987) por lo que la DO no es aconsejable para obtener unas reducciones del contenido en agua superiores al $50 \%$. 


\section{I.2.2. Problemática de la disolución osmótica}

El principal problema de la aplicación industrial de la DO (para la obtención de frutas confitadas, escarchadas o productos con humedad intermedia con una mayor vida útil en el mercado), radica en la disolución osmótica sobrante del proceso. Parte de la viabilidad económica del proceso depende de la gestión de esta SO, ya que se trata de un subproducto que, desde el punto de vista medioambiental y debido a su elevada demanda bioquímica de oxigeno $\left(\mathrm{DBO}_{5}\right)$, requiere un tratamiento previo a su eliminación similar al de las aguas residuales, utilizando para ello resinas de intercambio iónico, procesos de ósmosis inversa, micro y ultra-filtración, etc. (Dalla Rosa y Giroux, 2001) incrementando así el coste de los productos obtenidos.

Existe la posibilidad de reutilizar la $\mathrm{SO}$ en más ciclos de $\mathrm{DO}$ con o sin una etapa previa de reconcentración, teniendo en cuenta, en ambos casos, la posible contaminación microbiológica de la misma. Lo primero supondría un coste adicional del proceso, mientras que lo segundo puede estar limitado fundamentalmente por los cambios experimentados durante la etapa, ya que la progresiva dilución de la SO después de cada ciclo de DO podría implicar la disminución de la velocidad de transferencia de materia en el producto a deshidratar y el consecuente alargamiento del proceso. No obstante, estudios previos (García-Martínez et al., 2002a; Peiró et al., 2006) han puesto de manifiesto que, en determinadas condiciones de proceso, esto no supone un inconveniente aún cuando la misma SO se reutiliza durante incluso más de 10 ciclos consecutivos de DO.

Por otro lado, durante la DO, la fruta, además de perder agua, libera algunos de sus componentes naturales, como pigmentos, aromas, ácidos, minerales y vitaminas a la disolución (Valdez-Fragoso et al., 
1998; Dalla Rosa y Giroux, 2001; García-Martínez et al., 2002a; Córdoba et al., 2002). La reutilización de la SO supondría una acumulación cada vez mayor de estos compuestos y, desde este punto de vista, su aprovechamiento como ingrediente en la formulación de nuevos productos es una alternativa de interés para la gestión final de la misma. En este sentido, hay autores que proponen su uso para la elaboración de mermelada sin tratamientos térmicos (Shi et al., 1996; García-Martínez et al., 2002b), productos semi-confitados (GonzálesMariño et al., 2001), como líquido de gobierno en productos enlatados o como componente de bebidas carbonatadas junto a zumos de frutas y dióxido de carbono, etc. (Dalla Rosa y Giroux, 2001).

Esta tesis está centrada en el estudio de las posibilidades de reutilización de la SO en varios ciclos consecutivos de DO de pomelo y su posterior utilización para la elaboración de un producto gelificado junto con el pomelo deshidratado.

\section{I.3. EL CALCIO}

\section{I.3.1. Importancia del calcio en la salud humana}

El calcio ejerce una gran cantidad de funciones en nuestro organismo, siendo por tanto un micronutriente esencial para la salud humana. Su contenido en el organismo humano es de algo más de $1 \mathrm{~kg}$. Éste se encuentra en los huesos (un 99\%), los dientes, en la sangre y en los tejidos. Entre sus funciones podemos citar su actividad como segundo mensajero, su papel en la estabilización de diversas proteínas o su función en la coagulación. Como consecuencia de una ingesta baja en calcio prolongada se produce una desmineralización ósea (descalcificación) que vuelve frágil al hueso (osteoporosis), provocando 
un problema de salud de importancia creciente. Las causas de la osteoporosis son múltiples: hormonales (déficit de estrógenos), falta de ejercicio físico, la edad avanzada y el aporte insuficiente de calcio durante varios años (Cervera et al., 2005).

El porcentaje de calcio absorbido es del 10 al $40 \%$ del calcio ingerido y el restante se elimina por las heces. Asimismo, aunque se haga una dieta sin calcio, el intestino sigue eliminando cierta cantidad de calcio diaria. La lactosa, las proteínas y la vitamina $D_{3}$, facilitan su absorción. Los oxalatos, presentes en las acelgas, las espinacas y otras verduras y los fitatos que se encuentran en el salvado de trigo y en el tegumento de otros cereales dificultan su absorción debido a que forman sales insolubles con el calcio. Los fosfatos mantienen un equilibrio con las sales de calcio, por lo que se recomienda que el aporte de los dos elementos mantengan una proporción Ca:P igual a 1.

Debido a la gran variabilidad de las sustancias que favorecen y dificultan la absorción de calcio, no es fácil precisar las necesidades mínimas de este mineral. En la tabla 1.2 se muestran las cantidades diarias recomendadas (CDR) para los principales subgrupos de la población.

En cuanto al contenido en calcio de algunos alimentos (Tabla I.3) podemos destacar que la leche es la fuente principal de calcio, al igual que el queso, los yogures y otras leches fermentadas; la mantequilla no aporta casi calcio. Hay que tener en cuenta que en la leche descremada hay la misma cantidad de calcio que en la leche entera.

Las legumbres y los frutos secos grasos son también una fuente importante de calcio aunque el nivel de absorción sea menor. Las carnes, pescados, frutas y verduras contienen cantidades discretas. 
Tabla I.2. Cantidad diaria recomendada de calcio (mg/día).

\begin{tabular}{cccc}
\hline Edad & $\begin{array}{c}\text { FAO-OMS } \\
(\mathbf{1 9 7 5 )}\end{array}$ & $\begin{array}{c}\text { EE.UU } \\
\mathbf{( 1 9 8 9 )}\end{array}$ & $\begin{array}{c}\text { Europa } \\
\mathbf{( 1 9 9 4 )}\end{array}$ \\
\hline $\mathbf{0 - 1 2}$ meses & 600 & 600 & 400 \\
Niños & 600 & 800 & 550 \\
Adolescentes & 700 & 1200 & $800-1000$ \\
Adultos & 500 & 800 & +800 \\
Embarazadas & 700 & 1200 & 700 \\
Lactantes & $1000-1200$ & 1200 & 1200 \\
\hline
\end{tabular}

Tabla I.3. Contenido en calcio de algunos alimentos (Cervera et al., 2005).

\begin{tabular}{cc}
\hline 100 g de & Ca (mg) \\
\hline Leche entera & 125 \\
Yogur & 148 \\
Leche descremada & 120 \\
Queso (promedio) & 400 \\
Carne (promedio) & 12 \\
Pescado (promedio) & 30 \\
Huevo & 55 \\
Legumbres secas (promedio) & $70-150$ \\
Pan blanco & 100 \\
Frutas (promedio) & $15-25$ \\
Verduras (promedio) & $60-150$ \\
Arroz, pastas de sopa & 15 \\
\hline
\end{tabular}




\subsubsection{Distribución y transporte del calcio a nivel celular en tejidos vegetales}

El calcio es necesario para muchos procesos celulares y se distribuye tanto en el interior como en el exterior de la célula. La mayor parte del $\mathrm{Ca}^{2+}$ se localiza extracelularmente en la pared celular, en los pectatos de la lámina media, en las membranas y en algunos orgánulos celulares. Este catión mantiene la estabilidad de la célula, de las membranas y de las proteínas de membrana por su capacidad de actuar como "puente" de residuos químicos entre diversas estructuras. Además juega un papel fundamental en la homeostasis celular y el desarrollo de tejidos (Piñeros y Tester, 1997).

La distribución del calcio dentro de la célula es muy importante, por ello existen gradientes electroquímicos de calcio a través de la membrana plasmática, el tonoplasto, el retículo endoplasmático, la mitocondria y el cloroplasto, ya que son gradientes que influyen en la transducción de la señal y en la regulación de procesos metabólicos en el citoplasma y orgánulos (Bush, 1995). Las composiciones iónicas de las soluciones de cualquier lado de la membrana y del tonoplasto son muy diferentes. El calcio en el citosol se mantiene a una concentración de aproximadamente 30 a $200 \mathrm{nM}$, muy inferior a la encontrada en los orgánulos y el medio extracelular (Piñeros y Tester, 1997).

Dentro de la célula vegetal, la vacuola es el orgánulo de mayor volumen y, como tal, también es el orgánulo que mayor flujo de calcio implica. Existen en la vacuola cinco canales de entrada y salida de calcio, unos con gasto de energía y otros sin gasto. También encontramos dos canales en el retículo endoplasmático, uno en el cloroplasto y tres en la membrana plasmática, por lo que todos estos orgánulos se ven envueltos en la distribución de calcio hacia el citosol 
(Piñeros y Tester, 1997; Evans, et al., 1991). Dichos canales se muestran en la figura I.9.

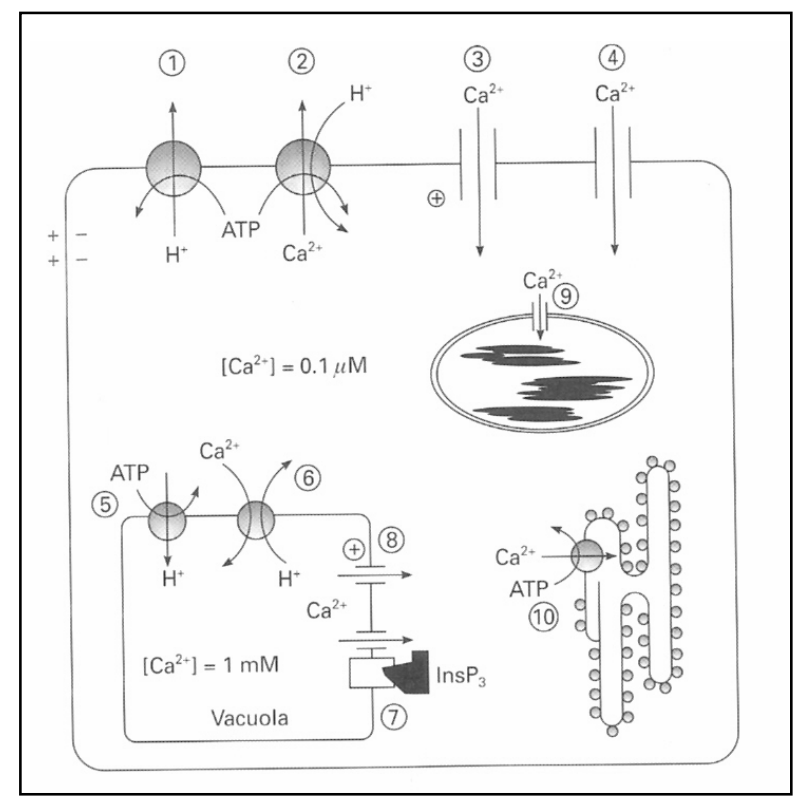

Figura I.9. Movimiento del $\mathrm{Ca}^{2+}$ en una célula vegetal. 1) $\mathrm{H}^{+}-\mathrm{ATP}_{\text {asa. }}$ 2) $\mathrm{Ca}^{2+}-\mathrm{ATP}_{\text {asa }}$ del plasmalema. 3) y 4) Distintos tipos de canales de $\mathrm{Ca}^{2+}$. 5) $\mathrm{H}^{+}-\mathrm{ATP}_{\text {asa }}$ de la vacuola. 6) Antiporte $\mathrm{Ca}^{2+}-\mathrm{H}^{+}$del tonoplasto. 7) y 8) Canales de $\mathrm{Ca}^{2+}$ del tonoplasto; el signo + y el InsP3 significan que los canales se activan por voltaje y por inositol 1-4-5 trifosfato. 9) Canal de $\mathrm{Ca}^{2+}$ en el cloroplasto. 10) $\mathrm{Ca}^{2+}$-ATPasa del retículoendoplasmático (Azcón-Bieto y Talón, 2000).

Como acabamos de comentar, el transporte de calcio a nivel celular puede ser con gasto de energía (transporte activo) mediante proteínas y sin gasto de energía mediante difusión (transporte pasivo).

A continuación se detallan cada uno de estos mecanismos de transporte. 
Transporte con gasto de energía: Se lleva a cabo a través de unas bombas ATP $_{\text {asas }}$ que utilizan la hidrólisis del ATP para obtener la energía necesaria para el transporte de iones. Estas bombas pueden ser $\mathrm{H}^{+}$ATP $_{\text {asas, }}$, cuya función es controlar el movimiento de solutos a través de la membrana celular. La bomba $\mathrm{H}^{+}-\mathrm{ATP}_{\text {asa }}$ que está situada en la membrana plasmática acopla directamente la hidrólisis del ATP con el transporte de $\mathrm{H}^{+}$dentro del apoplasto (Figura 1.9.). El gradiente electroquímico de protones es utilizado como fuerza de conducción para el transporte secundario de iones y nutrientes dentro y fuera de la célula (De Nisi et al., 1999). También existen las $\mathrm{Ca}^{2+}$-ATP asas que tienen una gran afinidad por el calcio (Bush, 1995). Existen $\mathrm{Ca}^{2+}-\mathrm{ATP}_{\text {asas }}$ en la membrana plasmática y en el tonoplasto (Figura I.9.). La bomba $\mathrm{Ca}^{2+}$ $\mathrm{ATP}_{\text {asa }}$ de la membrana plasmática es la que cataliza la entrada de calcio contra gradiente electroquímico y a su vez permite el flujo al interior de la célula de protones, proporcionando energía extra para el trasporte activo de calcio (Bush, 1995; Evans et al., 1991). Es por tanto la responsable de la regulación de la concentración de calcio citosólico (Evans et al., 1991). Este bombeo de protones a través de la membrana y del tonoplasto se utiliza para acidificar la vacuola o la matriz extracelular (Chrispeels et al., 1999).

Transporte sin gasto de energía: El calcio puede atravesar la membrana plasmática y la de los diferentes orgánulos sin necesidad de gastar la energía de los ATP. Este se considera un transporte pasivo y se lleva a cabo por proteínas de membrana. Este tipo de transporte puede ser del tipo antiporter o puede ser también de transporte regulado por canales de voltaje. En la membrana plasmática encontramos un canal de voltaje por el cual entra el $\mathrm{Ca}^{2+}$ al interior, así como un canal regulado por estimulación mecánica (Evans et al., 1991; Piñeros y Tester, 1997). La entrada de calcio a la vacuola tiene lugar por medio de 
un antiporter $\mathrm{H}^{+}-\mathrm{Ca}^{2+}$ de manera que la salida de $\mathrm{H}^{+}$se ve acompañada por la entrada de iones $\mathrm{Ca}^{2+}$. Además en la vacuola también existe un canal de voltaje que se activa cuando el potencial es más negativo. En el retículo endoplasmático existe un trasporte de $\mathrm{Ca}^{2+}$ sin gasto de energía por medio de un canal de voltaje (Piñeros y Tester, 1997) (Figura I.9.).

\section{I.3.3. Efecto del calcio en frutas mínimamente procesadas}

El calcio es esencial para el mantenimiento de la estructura y el funcionamiento de las paredes y membranas celulares (Izumi y Watada, 1994). Aumenta la firmeza de los tejidos vegetales ya que interacciona con el ácido péctico de las paredes celulares para formar pectato cálcico (Rolle y Chism, 1987). Éste aumenta la rigidez de los sistemas de membrana de la lámina media y la pared celular (Poovaiah, 1986), aumentando también la resistencia al ataque de la poligalacturonasa (enzima que degrada los pectatos) sobre los pectatos de la lámina media y la pared celular e inhibiendo así la degradación de los mismos (Buescher y Hobson, 1982). Asimismo, los iones de calcio también pueden contribuir a la firmeza del tejido mediante un incremento en la integridad de la membrana, consiguiéndose el mantenimiento o aumento de la presión de turgencia en la célula (Mignani et al., 1995).

En este sentido, se ha estudiado el efecto del $\mathrm{Ca}^{2+}$, en forma de cloruro cálcico, sobre la firmeza de varias frutas, como por ejemplo manzanas enteras (Sams et al., 1993), fresas enteras y en láminas (Rosen y Kader, 1989; García et al., 1996) y en tomates cortados en cubos (Floros et al., 1992). Sin embargo, el cloruro cálcico imparte amargor o sabores extraños (Olsen et al., 1966; Huxsoll y Bolin, 1989; Monsalve-González et al., 1993). Una alternativa a esta sal es el lactato 
cálcico, utilizado como agente potenciador de firmeza en fresas (Morris et al., 1985; Main et al., 1986) y en uvas (Baker, 1993) sin encontrar grandes diferencias de sabor con los productos no tratados. Otros autores como Luna-Guzmán y Barret (2000) estudiaron el efecto tanto del cloruro cálcico como del lactato cálcico en la calidad del melón Cantaloupe cortado, comprobando que el efecto del calcio aplicado en forma de lactato es más efectivo y que a mayor concentración de calcio añadido, mayor firmeza se obtiene, además de reducir la tasa respiratoria en los tratamientos post-cosecha, lo que posiblemente contribuya a un aumento de la vida útil. El lactato cálcico produjo un efecto de secado en las superficies de melón mínimamente procesado, lo que limitó el crecimiento bacteriano, probablemente debido a la reducción en la disponibilidad de agua superficial. La adición de calcio reduce la tasa respiratoria y suprime la producción de etileno de determinados productos, retardando la senescencia, debido a que concentraciones superiores a $1 \mu \mathrm{M}$ de calcio citosólico pueden inhibir la acción de muchas enzimas (Azcón-Bieto y Talón, 2000).

Según la bibliografía consultada, en las frutas mínimamente procesadas las sales de calcio forman parte de los agentes mejoradores y conservantes de las características sensoriales y nutricionales. Por este motivo las sales de calcio se consideran una alternativa para los tratamientos post-cosecha y para la formulación de nuevos productos. El lactato cálcico ha sido la sal utilizada en este trabajo para la obtención de los productos por sus características sensoriales, su solubilidad y su disponibilidad. 


\section{I.4. PRODUCTOS GELIFICADOS}

La clave para el óptimo desarrollo de cualquier producto gelificado reside en la adecuada selección del hidrocoloide, teniendo en cuenta las características del medio en que va ser adicionado.

El interés en los hidrocoloides está basado en su comportamiento reológico, por ejemplo, la viscosidad, la formación de gel y sus efectos estabilizantes. Estas propiedades pueden obtenerse sólo después de alcanzar la solubilización completa de las moléculas. Una vez solubilizados o dispersados en agua, se reordenan. Ese reordenamiento está relacionado con:

- El peso molecular.

- El volumen molecular.

- La presencia o no de grupos funcionales en la molécula.

- La temperatura del medio.

- Las interacciones con otros ingredientes en los medios, tales como otros hidrocoloides y cationes.

Todos estos parámetros tienen un efecto diferente en cada tipo de hidrocoloide y pueden afectar mucho a la textura del producto final.

En cuanto a las propiedades gelificantes de estas macromoléculas, necesitamos definir "gel". No hay definición alguna que sea satisfactoria, porque no existe una frontera neta entre una disolución muy espesa y una solución gelificada. El estado "gel" se puede considerar como intermedio entre el estado líquido, puesto que ciertos geles pueden tener hasta $99,9 \%$ de agua, y el estado sólido, puesto que su organización permite mantener su forma y resistir a ciertos esfuerzos. Por tanto, el gel es un sistema bifásico constituido por una red macromolecular tridimensional sólida que retiene entre sus mallas una fase líquida. Antes de la gelificación, las moléculas del polímero forman 
una verdadera solución y la formación del gel implica, por consiguiente, la asociación de cadenas entre sí o de segmentos de cadenas entre ellas.

Entre los principales tipos de hidrocoloides se pueden destacar:

- Gelatina: obtenida de subproductos animales. Solamente forma geles a temperaturas bajas, por lo tanto cuando se desea que el gel se mantenga a temperatura ambiente, o incluso más elevada, debe recurrirse a otras sustancias.

- Almidón: actúa muy bien como espesante en condiciones normales, pero tiene tendencia a perder líquido cuando el alimento se congela y se descongela.

- Pectinas: Funcionan como agentes gelificantes y espesantes en una gran variedad de productos. Las pectinas comerciales son galactouranoglicanos con varios contenidos de grupos éster metilo. Las pectinas naturales se encuentran en las paredes celulares y capas intercelulares de todas las plantas terrestres y son moléculas más complejas que se convierten en productos comerciales vía la extracción ácida (BeMiller y Whistler, 1996).

- Alginatos: se obtiene a partir de diferentes tipos de algas (Macrocrystis, Fucus, Laminaria, etc.) extrayéndolo con carbonato sódico y precipitándolo mediante tratamiento con ácido. No todos los alginatos gelifican, pero son bien conocidos por su capacidad para producir geles irreversibles en agua fría, en la presencia de iones calcio. Esta propiedad de gelificar en el agua fría diferencia a los alginatos de las gomas derivadas de las algas rojas. Muchos alginatos son usados, frecuentemente, como espesantes, estabilizantes de emulsiones, gelificantes, inhibidores de sinéresis (Dziezak, 1991). 
- Agar: se extrae con agua hirviendo de varios tipos de algas rojas, entre ellas las del género Gellidium. A concentraciones del 1-2\% forma geles firmes y rígidos, reversibles al calentarlos, pero con una característica peculiar, su gran histéresis térmica (Dziezak, 1991).

- Goma Gelana: es un polisacárido extracelular elaborado por un microorganismo, Pseudomonas elodea, cuando crece sobre materiales azucarados. Es capaz de formar geles en presencia de calcio o de ácidos con concentraciones de polisacárido bajas $(0,05 \%)$ (Dziezak, 1991). Es un hidrocoloide multifuncional con potencial para ser usado en una gran variedad de alimentos como gelificante, texturizante, estabilizante, formador de películas, y agente estructurante y de suspensión (Sworn et al., 1995).

- Gomas vegetales: obtenidos de exudados (resinas) y semillas de vegetales, o producidas por microorganismos. No suelen formar geles sólidos sino soluciones más o menos viscosas (Pasquel, 2001).

- Carragenatos: son polisacáridos naturales que se extraen de ciertas variedades de algas rojas (Gigartina, Chondrus, Furcellaria y otras). Pueden formar coloides viscosos y geles a partir de medios acuosos y/o lácteos.

El objetivo general de esta tesis ha sido la evaluación, desde diferentes puntos de vista, de un producto gelificado elaborado con pomelo deshidratado osmóticamente y la propia disolución osmótica utilizada para su deshidratación. Las características de esta SO en cuanto a su $\mathrm{pH}$, fuerza iónica y composición hace que no todos los hidrocoloides capaces de formar geles puedan ser utilizados. En concreto, según García-Martínez (2005), se observa una escasa eficacia de la pectina y/o gelatina en este medio. En cambio, se 
describe la idoneidad del $\kappa$-carragenato, por lo que éste fue el hidrocoloide seleccionado para su formación y, por ello, a continuación se comentan algunos aspectos específicos.

\section{I.4.1. Carragenatos}

Los carragenatos están aprobados como aditivo (E-407) en la industria agroalimentaria, por el Real Decreto 142/2002, Ministerio de Sanidad y Consumo, BOE $n^{\circ}$ 44, 20 de febrero de 2002, permitiéndose su uso para distintos alimentos. Se comercializa en forma de polvo blanco cremoso. A partir de una concentración del 0,025\% los carragenatos estabilizan suspensiones y a partir del $0,15 \%$ proporcionan ya texturas sólidas.

\section{I.4.1.1. Estructura y tipos}

Químicamente, son poligalactanos, polímeros lineales de moléculas alternadas de D-galactosa y 3-6 anhidro-D-Galactosa (3-6 AG) unidas por enlaces $\alpha(1-3)$ y $\beta(1-4)$ (Thomas, 1992; Oakenfull, 1998). Las moléculas de galactosa poseen grupos sulfato y/o piruvato, que le aportan el carácter hidrofílico y la solubilidad, encontrándose generalmente como sales de sodio, potasio o calcio (Stanley, 1990).

Según el grado de sulfatación y la posición de los carbonos sustituidos por los ésteres sulfatos, se distinguen diferentes tipos: kappa $(\kappa)$, iota ( 1 ) y lambda $(\lambda)$, como se observa en la figura I.10. 


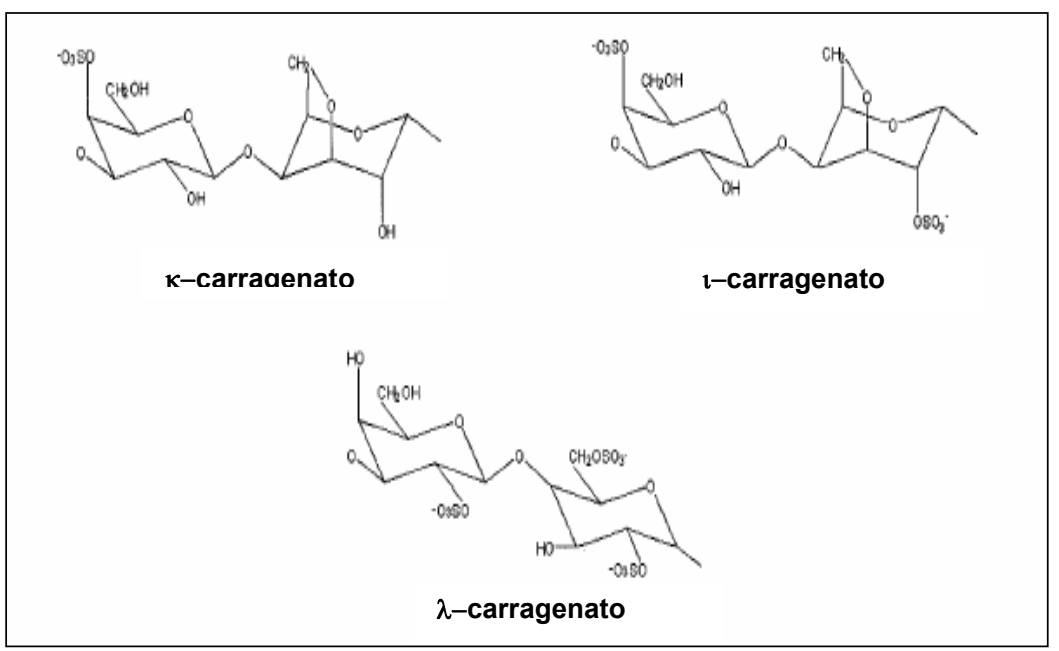

Figura I.10. Estructura de los residuos de disacáridos repetidos de los tres carragenatos principales utilizados en la industria agroalimentaria (Roberts y Quemener, 1999).

Kappa (к): Es un polisacárido aniónico lineal formado por unidades disacáridas repetidas con enlaces $\alpha(1,3)$ D-galactosa-4-sulfato y $\beta(1-4)$ 3,6-anhidro-D-galactosa (Thomas, 1992; Oakenfull, 1998), como se puede observar en la figura I.10. Es el carragenato con mayor poder de gelificación y con mayor reactividad con las proteínas lácteas. Es estable en forma gelificada. Su contenido en éster sulfato oscila entre $24-28 \%$ y entre $34-40 \%$ de 3,6 anhidro-Dgalactosa (AG). Debido al alto contenido de 3,6 AG, produce geles firmes, quebradizos, ligeramente opacos y elásticos en agua y leche con moderada sinéresis cuando se enfrían. En presencia de iones $\mathrm{K}^{+}$, sus enlaces a los grupos sulfato causan una estructura con forma de doble hélice antiparalela. En presencia de iones $\mathrm{Ca}^{2+}$ el gel se contrae y se vuelve frágil y quebradizo. Requiere de alta temperatura para su completa disolución (aproximadamente $75^{\circ} \mathrm{C}$ ) y 
forma geles termorreversibles sin necesidad de refrigeración para su gelificación. Al calentar las dispersiones acuosas de $\kappa$-carragenato por encima de $60^{\circ} \mathrm{C}$, los polisacáridos se hidratan y adoptan una conformación helicoidal. Sólo las sales de sodio de $\kappa$-carragenato son solubles en agua fría (Imeson, 1997).

lota (1): Posee un contenido entre $30-32 \%$ de éster sulfato y entre $28-32 \%$ de 3,6 AG. Forma geles muy elásticos en agua y leche con baja sinéresis. Requiere de temperatura para su completa disolución (aproximadamente $65^{\circ} \mathrm{C}$ ). Al igual que los $\kappa$-carragenato, sólo las sales de sodio de 1 -carragenato son solubles en agua fría (Imeson, 1997). Para que se produzca gelificación en agua es imprescindible la presencia de iones $\mathrm{K}^{+}$y $\mathrm{Ca}^{2+}$. No precisan de iones en la leche, formando geles a menor concentración que en agua $(0,2 \%$ en comparación a una concentración mínima de 0,5\% en agua).

Lambda ( $\lambda$ ): Es el carragenato más soluble en agua y leche (debido a su alto contenido en sulfatos) solubilizándose a temperatura ambiente. Posee un contenido de alrededor de un 35\% de éster sulfato y un $0 \%$ de 3,6 AG, lo que imposibilita la gelificación. Necesitan condiciones de alta viscosidad y bajas temperaturas. Se emplean básicamente para aplicaciones como espesante.

Con mezclas adecuadas de los distintos tipos de carragenatos se puede conseguir una amplia gama de viscosidades (tanto en frío como en caliente) y de formas de geles (desde elásticos y cohesivos a firmes y quebradizos) en una amplia gama de productos alimenticios acuosos, dulces y lácteos. Esta gran versatilidad, unida a los menores precios, están desplazando al agar de su aplicación en la industria alimentaria. 


\section{I.4.1.2. Mecanismos de gelificación}

El proceso de gelificación está altamente influenciado por muchos factores, como son:

- El tipo y concentración de sales en disolución.

- La velocidad de calentamiento y enfriamiento.

- La concentración del hidrocoloide.

- La presencia de otros biopolímeros.

Modificaciones de estos factores pueden afectar en gran medida a las temperaturas de gelificación y a las propiedades reológicas de los geles.

El mecanismo de gelificación de los $\kappa$ y -carragenatos se basa en la formación de geles termorreversibles por disposición de cadenas desordenadas en doble o triple hélice, asociadas a la estructura primaria de las macromoléculas, seguida de la agregación de las dobles hélices entre sí y la formación de una red tridimensional. La doble hélice sin embargo, no es continua, debido a irregularidades en la cadena (Rao, 1999; Whistler, 1997).

\section{I.4.1.3. Funcionalidad de los carragenatos}

En cuanto a sus propiedades nutricionales, al no poder ser digeridos por el cuerpo humano no proporcionan ningún beneficio nutricional. De ahí que su único valor en la industria de alimentos sea sus propiedades funcionales, las cuales pueden ser utilizadas para el control de humedad y textura y para estabilizar alimentos (Eliasson, 1996). Sus propiedades espesantes y gelificantes los hacen muy útiles en la industria alimentaria (Dickinson y Pawlowsky, 1997). El $80 \%$ del carragenato extraído en el mundo se emplea como espesante y agente 
estabilizante (E-407) en productos lácteos, postres de tipo gelatina, jugos de fruta, mermeladas, helados etc. Se encuentran entre los aditivos más versátiles (Glicksman, 1976), teniendo también mucha importancia en la industria de cosméticos (pasta de dientes, barras aerosoles), productos farmacéuticos (contra úlceras gástricas e infecciones víricas), etc. (Guo et al., 1998; Mangione et al., 2003).

Los carragenatos tienen sinergismo con ciertos galactomananos y glucomananos como es el caso de los $\kappa$-carragenatos con la goma de garrofín y la harina de Konjac. El uso de estos hidrocoloides potencia la fuerza de gel y reduce la sinéresis por la obtención de texturas más elásticas. Los i-carragenatos tienen un sinergismo con el almidón, produciendo un aumento en la viscosidad en sistemas acuosos (aumenta 10 veces la viscosidad del almidón).

Las disoluciones de carragenato son estables a $\mathrm{pH}$ neutro o ligeramente ácido. La exposición a pH ácidos, en combinación con altas temperaturas y tiempos prolongados produce hidrólisis ácida del carragenato (Glicksman, 1969), provocando una pérdida de viscosidad y de fuerza del gel. Por esta razón es recomendable ajustar el $\mathrm{pH}$ a valores mayores a 3,7 formando un sistema buffer mediante la adición de citrato de sodio o potasio. En sistemas de bajo $\mathrm{pH}$ se recomienda la disolución de carragenatos previamente a la adición del ácido y un enfriamiento lo más rápido posible del sistema. Una vez que el gel se ha formado éste no es afectado por un pH ácido (Imeson, 1997).

Los geles de i-carragenato, a bajas concentraciones, poseen un comportamiento tixotrópico, es decir, mediante algún esfuerzo de cizalla (agitación, bombeo), disminuyen su viscosidad de manera reversible, volviendo a su estado original una vez que el esfuerzo o deformación es retirado. 
Existe una alta reactividad de los carragenatos especialmente los de tipo Kappa con los sistemas lácteos, obteniéndose geles firmes a muy bajas concentraciones de carragenato. Este sinergismo se debe a la interacción directa entre el carragenato, molécula cargada negativamente, y la K-caseína, que posee una carga neta positiva. La reacción ocurre en un amplio intervalo de $\mathrm{pH}$ y es reforzada por puentes de calcio. En sistemas cárnicos, el carragenato ayuda a retener agua en los espacios intersticiales del gel de proteína formado, reforzando la estructura y logrando una mayor firmeza del producto final.

Los $\kappa$-carragenatos interactúan con las sales de potasio y calcio, aumentando la firmeza, la temperatura de gelificación, la temperatura de fusión, así como también la fracturabilidad del gel y la sinéresis.

Los polifosfatos y citratos de sodio o potasio facilitan la solubilidad de los carragenatos disminuyendo su viscosidad debido a que secuestran iones divalentes. Además favorecen su estabilidad en medios ácidos.

\section{I.4.1.4. Aplicaciones de los carragenatos}

Entre los distintos usos que se le puede dar a los carragenatos en la industria alimentaria destacamos los siguientes:

Productos a base de frutas:

Postres tipo gelatina: Se emplean carragenatos tipo Kappa y lota ya que son estables a temperatura ambiente $y$ no requieren refrigeración para su gelificación. Confieren textura fresca y agradable al paladar.

Preparados de frutas: En preparaciones de fruta, ya sea para uso en yogurt $u$ otras aplicaciones, se utilizan carragenatos tipo Kappa e 
lota los cuales aumentan el rendimiento y aportan una mejor consistencia y suavidad al producto final, controlan la sinéresis, permiten suspender trozos de fruta, mejoran el brillo y acentúan el color sin afectar a la liberación del sabor. El manejo de algunos factores permite mejorar la funcionalidad de los carragenatos. Es así como la presencia de sólidos favorece la gelificación y el uso en conjunto con el almidón presenta un efecto sinérgico en la viscosidad.

Jugos de fruta: Carragenatos Kappa y Lambda dan estabilidad y cuerpo a la pulpa de fruta, provocando agrado al paladar. El $\mathrm{pH}$ debe ser superior a 3,5.

Mermeladas: Se emplean carragenatos tipo Kappa y lota.

\section{Alimentos preparados y productos lácteos:}

Aderezo de ensalada: se utilizan los Lambda e lota, que permiten dar cuerpo a estos sistemas, además de controlar la viscosidad, estabilizar la emulsión al prevenir la separación de fases (aceite/agua), suspender partículas y controlar la consistencia manteniéndola uniforme después del envasado.

Suspensión y estabilización en leche: se utiliza, por ejemplo, Kappa en leches chocolateadas como agente estabilizante del cacao. Aumentan cuerpo y palatabilidad. En leches fortificadas actúan como agentes estabilizantes de las grasas y proteínas adicionales. En leches reconstituidas, evaporadas y cremas espesas se emplean para estabilizar, aumentar el cuerpo y palatabilidad.

Emulsiones lácteas: los kappa se emplean para reducir el derretimiento en helados de crema, retardar la formación de cristales de hielo y evitar la separación de suero. Tanto en productos batidos 
como en crema para batirse se emplean los carragenatos (Kappa) como estabilizantes de la emulsión y de la espuma.

Productos lácteos fermentados: los kappa se utilizan para la fabricación de imitaciones de quesos cremosos (aumenta cremosidad y persistencia de la estructura). Estabiliza y espesa el yogur y las pulpas de fruta en yogures batidos y leches fermentadas.

\section{$\checkmark$ Productos cárnicos:}

Productos reconstituidos: los carragenatos incorporados a este tipo de aplicación permiten mejorar la ligazón y la palatabilidad del producto final, mejorando la jugosidad ya que mejoran la retención de agua. Se utilizan carragenatos tipo lota y Kappa. Los lota presentan excelentes propiedades en productos que son congelados y posteriormente descongelados, como hamburguesas, nuggets de ave y surimi debido a que presentan enlaces más elásticos que evitan la exudación de líquidos durante la descongelación.

Carnes procesadas: una de las aplicaciones más importantes del carragenato en la industria cárnica es la elaboración de jamón, especialmente en los casos en que el porcentaje de inyección es mayor al $60 \%$.

\section{I.5. ANÁLISIS SENSORIAL}

\section{I.5.1. Definición e importancia del análisis sensorial}

El análisis sensorial es el análisis de alimentos u otros materiales por medio de los sentidos. Es una técnica de medición y análisis tan importante como los métodos físicos, químicos, microbiológicos, etc. y puede ser tan objetiva como éstas (Anzaldúa-Morales, 1994). Este tipo 
de análisis tiene la ventaja de que la persona que efectúa las mediciones lleva consigo sus propios instrumentos de análisis, sus sentidos, por lo que es el único que permite averiguar las verdaderas motivaciones que tiene un consumidor a la hora de elegir un alimento.

En las tecnologías modernas, los científicos son cada vez más conscientes de la necesidad de potenciar métodos analíticos basados en la percepción sensorial (León-Crespo y Galán-Soldevilla, 1991). La información sobre la naturaleza del estímulo que percibe el consumidor la aporta el análisis de los componentes químicos y las propiedades físicas de un alimento, pero no pueden ofrecer información sobre la sensación que el consumidor experimenta al ingerirlo (Costell y Durán, 1981).

Según la norma UNE 87-001-94 (AENOR, 1997) el análisis sensorial es el examen de las propiedades organolépticas de un producto realizable por los sentidos. La evaluación simultánea de muchos atributos de forma objetiva o subjetiva por el consumidor es lo que se llama calidad sensorial.

\section{I.5.2. Los jueces}

El panel de catadores es un "método de medida" y por tanto los resultados de las pruebas realizadas dependerán de los miembros de dicho panel (AENOR, 1997).

Existen cuatro grupos de jueces: el experto, el catador o entrenado, el degustador o semientrenado y el consumidor.

El juez experto es aquel en que su habilidad, experiencia y criterio son tales que en las pruebas que efectúa sólo es necesario contar con su respuesta (Anzaldúa-Morales, 1994). Permite discernir diferencias 
muy sutiles entre dos alimentos y describir las características de los productos a estudio e incluso medirlas con las escalas de intensidad.

El juez entrenado o catador es una persona que posee bastante habilidad para la detección de alguna propiedad sensorial o algún sabor o textura en particular, que ha recibido cierta enseñanza teórica y práctica acerca de la evaluación sensorial. Los jueces entrenados se emplean principalmente para pruebas sensoriales descriptivas o para pruebas discriminativas complejas.

El juez degustador o semientrenado o "de laboratorio» es aquel que ha recibido un entrenamiento teórico similar al de los jueces entrenados, que realiza pruebas sensoriales con frecuencia y posee suficiente habilidad, pero que solamente participa en pruebas discriminativas sencillas, las cuales no requieren de una definición muy precisa de términos o escalas (Larmond, 1977; 1973).

El juez consumidor no tiene que ver con las pruebas, ni trabaja con alimentos como investigador o empleado de fábricas procesadoras de alimentos, ni ha efectuado evaluaciones sensoriales periódicas. Por lo general son personas tomadas al azar, ya sea en la calle, o en una tienda, escuela, etc. Este tipo de jueces deben emplearse solamente para pruebas afectivas y nunca para discriminativas o descriptivas. Es importante escoger jueces que sean los consumidores habituales del producto a probar o, en el caso de productos completamente nuevos, que sean consumidores potenciales de dicho alimento (AnzaldúaMorales, 1994).

En función de la tarea que se vaya a confiar a los catadores, se elegirán los tipos de jueces y el entrenamiento que van a recibir. Hay que tener en cuenta que, a veces, estos métodos de selección son solo una forma de coger a los candidatos más motivados entre aquellos que 
tenemos disponibles, más que a los que responden a un criterio determinado (AENOR,1997).

\section{I.5.3. Tipo de pruebas sensoriales}

Dependiendo de la finalidad con la que se realice un análisis sensorial se utilizará un tipo de prueba u otra. Podemos hablar de tres tipos de pruebas sensoriales: afectivas, descriptivas y discriminativas (Anzaldúa-Morales, 1994).

Pruebas afectivas: En este tipo de pruebas el juez expresa su reacción ante el producto de forma subjetiva, indicando si le gusta o no, si lo rechaza o si lo prefiere a otro (Larmond, 1977). Si no se desea sólo que el consumidor exprese el grado de satisfacción, sino también la aceptación que tiene el producto entre los consumidores, en el cuestionario no sólo tendrá que haber preguntas acerca de la apreciación sensorial del producto, sino también otras destinadas a saber si el consumidor compraría o no ese producto (Anzaldúa-Morales, 1994). Es necesario contar con un mínimo de 30 jueces no entrenados y éstos deben ser consumidores habituales y compradores de ese tipo de alimento en cuestión. Las pruebas afectivas pueden clasificarse en tres tipos: pruebas de preferencia, pruebas de grado satisfacción y pruebas de aceptación.

Pruebas descriptivas: En las pruebas descriptivas se trata de definir las propiedades del alimento y medirlas de la manera más objetiva posible. Aquí importa la magnitud o intensidad de los atributos de los alimentos y no la preferencia entre una muestra u otra (Amerine et al., 1965). Proporcionan más información acerca del producto que el resto de pruebas, pero son más difíciles de realizar, porque la interpretación de los datos es más costosa y el entrenamiento de los jueces es más 
intenso (Anzaldúa-Morales, 1982). Podemos hablar de distintos tipos de pruebas descriptivas: calificación con escalas no-estructuradas, calificación con escalas de intervalo, calificación con escalas estándar, calificación proporcional (estimación de magnitud), medición de atributos sensoriales con relación al tiempo, determinación de perfiles sensoriales, relaciones psicofísicas, etc.

Pruebas discriminativas: Las pruebas discriminativas son aquellas en las que no se requiere conocer la sensación subjetiva que produce un alimento a una persona, sino que se desea establecer si hay diferencias o no entre dos o más muestras y, en algunos casos, la magnitud de esa diferencia (Larmond, 1977). Estas pruebas son utilizadas en el control de calidad para evaluar si las muestras de un lote están siendo producidas con una calidad uniforme, si son comparables a estándares, etc. (Kramer y Twigg, 1972). Asimismo, por medio de ellas se puede determinar el efecto de modificaciones en las condiciones del proceso sobre la calidad sensorial del producto, las alteraciones introducidas por la sustitución de un ingrediente por otro, etc. (Amerine et al., 1965; Larmond, 1973; Navarro, 1975). Para este tipo de pruebas pueden usarse jueces semientrenados cuando las pruebas son sencillas (comparación apareada simple, dúo-trío o triangular). Sin embargo para comparaciones más complejas (comparaciones múltiples) es preferible que los jueces sean entrenados, ya que hay que considerar diferencias en cuanto a algún atributo en particular y evaluar la magnitud de la diferencia (Anzaldúa-Morales et al., 1983). Las pruebas discriminativas más comúnmente empleadas son las siguientes: prueba triangular, prueba dúo-trío, prueba de comparaciones múltiple, prueba de ordenamiento, prueba de comparación por parejas múltiple, etc. 
Prueba de comparación por parejas múltiple: Este tipo de prueba es la que se ha utilizado en los análisis sensoriales realizados en este trabajo. En esta prueba se presentan dos muestras a cada juez y se le pide que las compare en cuanto a uno o varios atributos, indicando cuál de las dos muestras tiene mayor intensidad de dicha propiedad (Larmond, 1973). Tiene la ventaja de que es muy sencilla y el juez no requiere de muchas instrucciones (Larmond, 1977).

El número de participantes de las pruebas depende de si éstas son direccionales, que en este caso con 7 catadores basta, o si son de preferencia, para lo que se necesitan 30 catadores como mínimo (AENOR, 1997).

Para la preparación de las muestras hay que tener en cuenta (AENOR, 1997):

- Que la cantidad de muestras individuales sea suficiente para todos los catadores.

- Que los catadores no tengan información sobre las muestras que pueda influir en el resultado de los análisis.

- Que la temperatura de todas las muestras sea la misma.

- Que los recipientes donde está contenida la muestra esté identificado con un código de tres cifras.

Las muestras que constituyen un par se pueden presentar simultánea o sucesivamente para su valoración. El orden de presentación debe ser equilibrado, de modo que las combinaciones $A B$ y $B A$ aparezcan el mismo número de veces y se distribuyan al azar entre los jueces. Se puede presentar varios pares sucesivamente, siempre que los participantes no acusen fatiga sensorial. Éstos deberán probar las muestras en el orden que se les indique (AENOR, 1997). 
La manera de hacer las preguntas es muy importante porque puede dar lugar a un error sistemático en la respuesta de los catadores. Según sea el propósito de la prueba se pueden hacer las siguientes preguntas:

- Para conocer si hay diferencia en la dirección que se presupone: ¿Es la muestra $A$ más... que la $B$ ? (unilateral). Para conocer la dirección en que se manifiesta la diferencia: ¿Cuál de estas dos muestras es más...?

- Prueba de preferencias: ¿Cuál de estas dos muestras prefiere usted?

- Entrenamiento: ¿Cuál de estas dos muestras es la más...?

Para elegir la técnica a utilizar, la persona que dirige la prueba puede optar por las siguientes posibilidades:

- Juicio forzado: obligar a los jueces a que indiquen cual de las dos muestras consideran que posee el atributo elegido en mayor o menor grado, o cual prefieren, incluso cuando no adviertan diferencia alguna.

- Permitir la respuesta "no hay diferencia" o "no hay preferencia". Cualquiera que sea la técnica escogida, los formularios han de contener una única respuesta, aunque necesariamente deben dejar espacio para otras series de pares. Si fuese necesario hacer más de una pregunta, las muestras se deben presentar de nuevo e identificar con una nueva clave para cada pregunta por separado (AENOR, 1997). 

II. OBJETIVOS Y PLAN DE TRABAJO 



\section{OBJETIVOS}

\section{II.1.1. Objetivo Principal}

El objetivo principal de esta Tesis Doctoral reside en la obtención de un producto gelificado a partir de pomelo procesado por deshidratación osmótica, que sea sensorialmente aceptable y estable durante su almacenamiento en refrigeración. Como aspectos clave que forman parte de este objetivo principal se encuentran la minimización de la generación de subproductos durante el proceso y el efecto de la adición de lactato cálcico al producto. 


\section{II.1.2. Objetivos Específicos}

Para alcanzar el objetivo general se plantearon los siguientes objetivos específicos:

1. Estudiar la cinética de deshidratación del pomelo con aplicación de una etapa previa de impregnación a vacío, en unas condiciones prefijadas, evaluando el cambio en las propiedades fisicoquímicas de la fruta a lo largo del proceso, para finalmente seleccionar el tiempo óptimo de deshidratación.

2. Estudiar la posibilidad de reutilizar la disolución osmótica, sin reconcentrar, durante varios ciclos sucesivos de deshidratación de pomelo, analizando la composición de las muestras deshidratadas, las propiedades fisicoquímicas y físicas, así como su actividad fisiológica. Estudiar su evolución durante el almacenamiento en refrigeración y establecer la vida útil microbiológica de la fruta deshidratada.

3. Optimizar la formulación de un producto gelificado composicionalmente estable obtenido a partir del pomelo deshidratado y la disolución osmótica empleada para su deshidratación y establecer su vida útil microbiológica.

4. Analizar el interés de la impregnación a vacío como técnica para promover la incorporación de calcio al pomelo, estudiando su efecto en la composición, las propiedades fisicoquímicas y físicas, así como en su actividad fisiológica durante el almacenamiento en refrigeración.

5. Estudiar la influencia del catión calcio en la cinética de deshidratación del pomelo, en las mismas condiciones prefijadas con anterioridad. 
6. Evaluar el efecto de la adición de calcio sobre las propiedades fisicoquímicas, físicas y sensoriales del pomelo deshidratado. Estudiar su evolución durante el almacenamiento en refrigeración y establecer la vida útil microbiológica.

7. Analizar el efecto de la adición de calcio en el producto gelificado, estudiando el efecto en sus propiedades fisicoquímicas, características sensoriales y vida útil microbiológica del producto almacenado en refrigeración.

\section{II.2. PLAN DE TRABAJO}

Para cubrir dichos objetivos se diseñó el siguiente plan de trabajo con las actividades descritas a continuación:

1. Revisión bibliográfica de los siguientes temas: efecto de la deshidratación osmótica e impregnación a vacío en frutas, elaboración de geles, influencia del calcio en el metabolismo celular y análisis sensorial.

2. Elaboración de un producto gelificado con pomelo empleando tratamientos osmóticos y minimizando la generación de subproductos.

2.1. Estudio de la cinética de deshidratación osmótica con pulso de vacío del pomelo en las condiciones fijadas en base a estudios previos.

2.1.1. Análisis de los cambios en la masa, los sólidos solubles ( $\left.{ }^{\circ} B r i x\right)$, humedad $\left(\mathrm{x}_{\mathrm{w}}\right)$ y actividad del agua $\left(\mathrm{a}_{\mathrm{w}}\right)$ de la fruta durante el proceso de deshidratación.

2.1.2. Estimación de la difusividad efectiva del agua en el proceso de deshidratación. 
2.1.3. Análisis en términos de pérdidas de agua y ganancias de solutos durante el proceso de deshidratación.

2.1.4. Selección del tiempo óptimo de tratamiento osmótico.

2.2. Estudio de la viabilidad de reutilización de la disolución osmótica en sucesivos ciclos de deshidratación.

2.2.1. Estudio de la necesidad de aplicación de un tratamiento térmico previo a la reutilización de la disolución osmótica desde el punto de vista microbiológico.

2.2.2. Análisis de los sólidos solubles, humedad, actividad del agua, acidez valorable, $\mathrm{pH}$, ácido ascórbico, concentración de cationes y actividad respiratoria de las muestras deshidratadas con la disolución reutilizada hasta 5 ciclos.

2.2.3. Seguimiento de la evolución durante el almacenamiento a $10^{\circ} \mathrm{C}$ de los sólidos solubles, humedad, actividad del agua, acidez valorable, $\mathrm{pH}$, ácido ascórbico, concentración de cationes, actividad respiratoria, color y propiedades mecánicas de las muestras deshidratadas con la disolución reutilizada hasta 5 ciclos. Control del crecimiento de microorganismos para establecer la vida útil microbiológica de las muestras.

2.3. Optimización de la formulación de un producto gelificado empleando tratamientos osmóticos.

2.3.1. Elaboración de diferentes productos gelificados empleando fruta fresca ó deshidratada y disolución osmótica (nueva o reutilizada) de diferentes concentraciones como fase líquida para la gelificación con k-carragenato. Análisis de los sólidos solubles, humedad y 
actividad del agua de la fruta durante su almacenamiento a $10^{\circ} \mathrm{C}$.

2.3.2. En base a los resultados obtenidos en el punto anterior, selección del producto gelificado óptimo. Estudio de la evolución en el contenido en ácido ascórbico, concentración de cationes, análisis del color y de las propiedades mecánicas del pomelo incluido en el gel durante durante su almacenamiento a $10^{\circ} \mathrm{C}$. Control del crecimiento de microorganismos y caracterización del perfil sensorial y de aceptación de este nuevo producto gelificado, antes y después de 7 días a $10^{\circ} \mathrm{C}$.

3. Elaboración de un producto gelificado con pomelo empleando el tratamiento osmótico seleccionado del estudio anterior con la incorporación de lactato cálcico.

3.1. Estudio del efecto de la adición de lactato cálcico en la cinética de deshidratación osmótica con pulso de vacío del pomelo en las condiciones fijadas, siguiendo el plan de trabajo descrito en el punto 2.1 .

3.2. Análisis del efecto del pulso de vacío en el contenido de sólidos solubles, humedad, acidez valorable, $\mathrm{pH}$, concentración de cationes, actividad respiratoria y propiedades mecánicas de la fruta.

3.3. Estudio del efecto de la incorporación del calcio y del almacenamiento en refrigeración en las propiedades del pomelo deshidratado. Se realizará un análisis de los sólidos solubles, humedad, actividad del agua, acidez valorable, $\mathrm{pH}$, ácido ascórbico, concentración de cationes, actividad respiratoria, color y propiedades mecánicas de las muestras deshidratadas con calcio, antes y después de 5 días almacenadas a $10^{\circ} \mathrm{C}$. Se 
establecerá la vida útil microbiológica y se caracterizará el perfil sensorial y de aceptación del producto, antes y después de 5 días a $10^{\circ} \mathrm{C}$.

3.4. Análisis del efecto de la adición de calcio en la formulación del producto gelificado seleccionado en el punto 2.3.2 estudiando los cambios en la concentración de cationes durante su almacenamiento a $10^{\circ} \mathrm{C}$, la vida útil microbiológica y caracterizando el perfil sensorial y de aceptación de este nuevo producto gelificado, antes y después de 7 días a $10^{\circ} \mathrm{C}$. 
III. DESARROLLO DE UN PRODUCTO GELIFICADO CON POMELO POR TRATAMIENTOS OSMÓTICOS 



\section{DESARROLLO DE UN PRODUCTO GELIFICADO CON POMELO POR TRATAMIENTOS OSMÓTICOS}

\section{III.1. MATERIALES Y MÉTODOS}

\section{III.1.1. Materia prima}

\section{III.1.1.1. Fruta}

La fruta utilizada fue pomelo (Citrus paradisi) de la variedad Star Ruby, obtenido de los supermercados de la ciudad de Valencia. Las piezas de fruta fueron seleccionadas teniendo en cuenta su firmeza, tamaño, aspecto y la ausencia de daños físicos o fisiológicos en su superficie, según una apreciación visual. Posteriormente, fueron 
almacenadas en una cámara de refrigeración a $10^{\circ} \mathrm{C}$ hasta el momento de su utilización.

\section{III.1.1.2. Disolución osmótica}

Como agente osmótico se empleó una disolución de sacarosa de 55 ${ }^{\circ}$ Brix, preparada con agua destilada $(45 \% \mathrm{p} / \mathrm{p})$ y sacarosa $(55 \% \mathrm{p} / \mathrm{p})$ en forma de azúcar de grado comercial. Dicha disolución osmótica (SO) se preparó en un vaso de precipitados de plástico de $5 \mathrm{~L}$ de capacidad con esta proporción de agua y sacarosa, agitando y calentando dicha mezcla a una temperatura no superior a $30^{\circ} \mathrm{C}$.

\section{III.1.1.3. Agente gelificante}

Como agente gelificante se utilizó $\kappa$-carragenato (Industria garrofera valenciana, INGAVASA, S.A), en una concentración $0,75 \%$ (p/p). La selección y proporción del tipo de gelificante utilizado para la formulación de los productos gelificados se hizo en función de los resultados obtenidos en otros estudios (García-Martínez, 2005).

La ficha técnica del carragenato, según el suministrador era la siguiente:

> Descripción: hidrocoloide natural extraído de algas rojas de la clase Rhodophyceae. Polvo de color beige, inodoro e insípido, para aplicación en la industria alimentaria. Está estandarizado con dextrosa alimentaria para una fuerza del gel constante en agua y leche.

> Características:

○ Fuerza del gel bloom: $575 \pm 100 \mathrm{~g}$ 
○ Fuerza de ruptura: $950 \pm 150 \mathrm{~g}$

○ $p H: 7-9.5$

○ Humedad: $12 \%$ máx

○ RIA: $2 \%$ máx

- Arsénico: menos de 2 ppm

- Plomo: menos de 10 ppm

- Granulometría: $98 \%$ de la goma inferior a 250 micras

- Análisis microbiológico: ausencia de patógenos

$\checkmark$ Germenes totales: máx. 5000 ufc/g

$\checkmark$ Mohos y levaduras: máx. $100 \mathrm{ufc/g}$

$\checkmark$ E. coli: ausencia/g

$\checkmark$ Salmonella: ausencia/g

$>$ Propiedades: dispersable en frío y totalmente soluble por encima de $70^{\circ} \mathrm{C}$, gelificando cuando la disolución se enfría. En un medio ácido, la degradación de la fuerza del gel aumenta con la temperatura y con el tiempo de calentamiento. Es estable en un medio neutro o álcali medio.

\section{III.1.2. Procedimiento experimental}

\section{III.1.2.1. Preparación de las muestras de pomelo fresco}

Con el objetivo de conseguir la mayor homogeneidad posible en cuanto al grado de madurez de la fruta fresca empleada, minimizando así los efectos de la variabilidad natural del pomelo, se realizó un análisis previo del contenido en sólidos solubles de las pieza de fruta adquiridas. Se seleccionaron aquellos pomelos que presentaron un valor de ${ }^{\circ}$ Brix comprendido entre 9 y 12, dependiendo de la época del año. 
Los pomelos así seleccionados fueron previamente lavados con agua corriente y etanol al 95\%. A continuación se pelaron y cortaron con la ayuda de una lonchadora, para realizar el corte lo más limpio y homogéneo posible, cuatro rodajas centrales de $10 \mathrm{~mm}$ de espesor que a su vez fueron cortadas por la mitad, como muestra la figura III.1. Todo el material se limpió cuidadosamente con etanol para evitar contaminaciones externas a la propia fruta.

Esta preparación de las muestras frescas fue común para todas las experiencias de deshidratación llevadas a cabo en esta tesis.

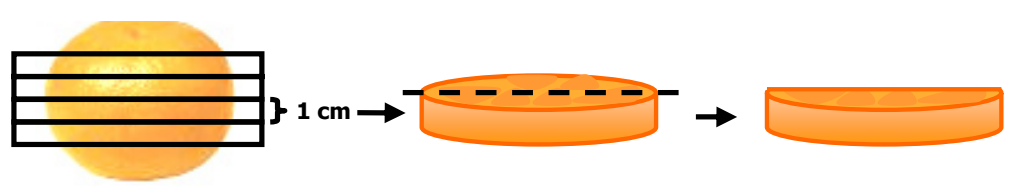

Figura III.1. Preparación de las muestras frescas.

\section{III.1.2.2. Tratamientos osmóticos}

La deshidratación osmótica con pulso de vacío (DOPV) se llevó a cabo por inmersión de las muestras de pomelo en la disolución osmótica preparada como se indica en el apartado III.1.1.2, en una proporción disolución:fruta 10:1, con la ayuda de una rejilla de plástico para evitar que la fruta flotara en la disolución y evitando así el contacto con el agitador. Seguidamente se procedió a la aplicación de un pulso de vacío (50 mbar) durante los primeros 10 minutos del tratamiento osmótico con un equipo formado por una cámara de vacío (Figura III.2a), donde las presiones subatmosféricas se consiguen mediante una bomba de anillo líquido para vacío elevado (SIHI LOHE-25007 
BN131.010) conectada al sistema, y un panel de control que permite regular la presión de trabajo.

Tras los 10 minutos a vacío se restauró la presión atmosférica, promoviéndose la impregnación de las muestras y se continuó con la deshidratación osmótica en un baño termostático (P-Selecta mod. Precisterm S-141) de acero inoxidable (Figura III.2b), donde se introdujo el vaso de precipitados asegurando la temperatura deseada $\left(30^{\circ} \mathrm{C}\right)$ durante toda la operación.

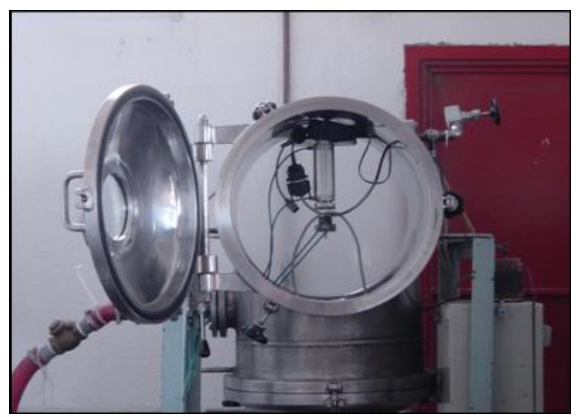

(a)

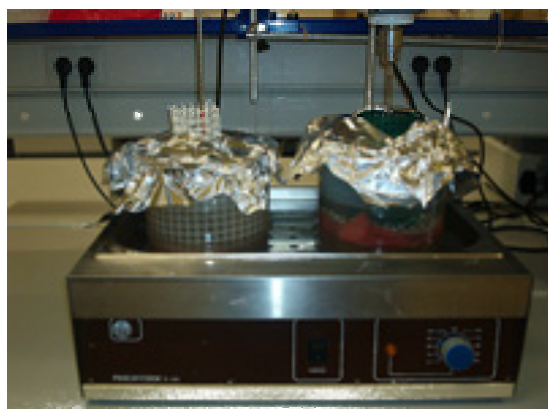

(b)

Figura III.2. a) Equipo con cámara de vacío; b) Baño termostático con agitación.

La SO permaneció en agitación continua con la ayuda de unos agitadores mecánicos (Heidolph RZR2102, velocidad de agitación, 250 rpm), para la homogeneización de la misma, evitando las diluciones locales en la interfase muestra-disolución.

Este procedimiento fue común posteriormente tanto para el estudio cinético como para el estudio de reutilización de la SO en la deshidratación osmótica de pomelo que se detallan a continuación. 


\section{III.1.2.2.1. Estudio cinético}

Para el estudio cinético de la deshidratación del pomelo, las muestras preparadas como se indica en el apartado III.1.2.1, se pesaron y se colocaron en las rejillas de plástico. En este caso, éstas fueron previamente divididas en compartimentos para poder identificar cada una de las muestras.

Posteriormente, se procedió al tratamiento osmótico como se explica en el apartado anterior, trabajando con las mismas variables del proceso. En este caso, una vez restaurada la presión atmosférica, se extrajo muestra a diferentes tiempos de deshidratación. Los tiempos elegidos para este estudio fueron: $0,15,30,45,60,90,180,300,480$ min. El tiempo 0 corresponde a la muestra tras los 10 minutos de pulso y una vez restaurada la presión atmosférica.

Una vez extraídas las muestras del vaso, se eliminó la disolución superficial usando papel absorbente. Para cada tiempo de estudio se analizaron en las muestras la masa, el contenido en humedad, los sólidos solubles y la actividad del agua tal y como se detalla en el apartado III.1.3.

Para estimar la difusividad efectiva $\left(D_{e}\right)$ se consideró que el transporte de agua se da mayoritariamente a través de las superficies planas de la muestra, asumiendo así una geometría de lámina infinita y utilizando como dimensión característica el semiespesor de la rodaja. Se utilizó el desarrollo matemático de Crank (1975) para tiempos cortos basado en la segunda Ley de Fick (Ecuación III.1). La fuerza impulsora para la transferencia de agua a cada tiempo $\left(Y_{\mathrm{w}}^{\mathrm{t}}\right)$, mostrada en la ecuación III.2, se determinó a partir de la fracción másica de agua en la fase líquida de la muestra $\left(z_{w}\right)$. 


$$
1-Y_{w}^{t}=2 \cdot\left(\frac{D_{e}}{I^{2} \cdot \Pi}\right)^{1 / 2} \cdot t^{1 / 2}
$$

donde:

I: Semiespesor $(\mathrm{m})$ de las mitades de rodaja de pomelo.

$\mathrm{t}$ : Tiempo de proceso (s).

$D_{\mathrm{e}}$ : Difusividad efectiva del agua $\left(\mathrm{m}^{2} / \mathrm{s}\right)$.

$$
Y_{w}^{t}=\frac{Z_{w}^{t}-Z_{w}^{e}}{Z_{w}^{0}-Z_{w}^{e}}
$$

donde:

$\mathrm{Z}_{\mathrm{w}}^{0}$ : Fracción másica de agua en la fase líquida $(\mathrm{FL})$ a tiempo cero, obtenida a partir de la fracción másica de solutos en la FL (Ecuación III.3) $\left(g_{\mathrm{w}} / \mathrm{g}_{\mathrm{FL}}\right)$.

$z_{w}^{t}$ : Fracción másica de agua en la FL a tiempo $t\left(g_{w} / g_{F L}\right)$.

$\mathrm{Z}_{\mathrm{w}}^{\mathrm{e}}$ : Fracción másica de agua en la $\mathrm{FL}$ cuando la muestra está en equilibrio con la disolución osmótica $\left(\mathrm{g}_{\mathrm{w}} / \mathrm{g}_{\mathrm{FL}}\right)$.

$$
z_{w}=1-z_{s}
$$

donde $\mathrm{z}_{\mathrm{s}}$ son los ${ }^{\circ}$ Brix medidos en las muestras $\left(\mathrm{g}_{\mathrm{s}} / \mathrm{g}_{\mathrm{FL}}\right)$.

Así, con el ajuste lineal de los valores de $1-Y_{w}^{t}$ frente a la raíz cuadrada del tiempo, se puede calcular la $D_{e}$ a partir de la pendiente. 
III.1.2.2.2. Obtención de pomelo deshidratado para la formulación del producto gelificado

Como paso previo para la optimización de esta etapa se realizó un estudio que permitiera identificar la viabilidad de la reutilización de la SO en función de la vida útil microbiológica de la fruta deshidratada y los cambios ocurridos en la SO y en la fruta después de cada ciclo de deshidratación. En este estudio, la SO se reutilizó durante 5 ciclos de deshidratación. Se entiende por ciclo de deshidratación cada operación de DOPV Ilevada a cabo tal y como se detalla en el apartado III.1.2.2, manteniendo las mismas variables del proceso y partiendo siempre de fruta fresca. A su vez, la SO reutilizada en cada ciclo corresponde a la del ciclo anterior sin ningún tratamiento previo de reconcentración. Este estudio se hizo hasta 5 ciclos porque en un trabajo previo realizado en las mismas condiciones, la reutilización de la SO entre 4 y 5 ciclos permite minimizar la cantidad de SO sobrante cuando se formula el producto (Peiró-Mena, 2007).

Con el fin de estudiar la necesidad de aplicación de un tratamiento térmico previo a la reutilización de la SO se realizaron dos experiencias paralelas donde en una de ellas se sometió a la SO a una pasteurización suave, manteniéndola a una temperatura de $72^{\circ} \mathrm{C}$ durante 15 segundos antes de cada ciclo de deshidratación. Posteriormente, se procedió a la deshidratación de la fruta durante 3 horas de tratamiento osmótico. Este tiempo se seleccionó en base a los resultados obtenidos en los estudios previos de cinética (apartado III.2.1 de resultados).

A partir de los resultados de la vida útil microbiológica de las muestras deshidratadas después de 1,3 y 5 ciclos de reutilización de la $\mathrm{SO}$, con y sin tratamiento térmico previo y almacenadas en refrigeración 
(apartado III.2.2.1 de resultados), se llegó a la conclusión de que era conveniente someter a la SO a una pasteurización suave previamente a su reutilización. De esta manera, para el resto del estudio, cada uno de los ciclos de deshidratación se llevó a cabo con SO tratada térmicamente según se describe en el párrafo anterior.

A las muestras de pomelo fresco y deshidratadas después de 1, 3 y 5 ciclos de reutilización de la SO se les analizó su contenido en cationes mayoritarios. Por otro lado, a todas las muestras mencionadas se les determinó, durante el almacenamiento en refrigeración, su contenido en humedad, sólidos solubles, $\mathrm{a}_{\mathrm{w}}, \mathrm{pH}$, acidez, ácido ascórbico, así como la tasa de respiración.

El almacenamiento, en todos los casos, se realizó según se describe en el apartado III.1.2.4.

En cuanto a la $\mathrm{SO}$, se analizaron los ${ }^{\circ} B r i x, a_{w}$ y el contenido en ácido ascórbico (AA), así como los cationes mayoritarios después de 1, 3 y 5 ciclos de reutilización.

\section{III.1.2.3. Preparación de los geles con pomelo}

\section{III.1.2.3.1. Estudio previo}

Se realizó un estudio para comprobar la estabilidad en cuanto al contenido en agua, sólidos solubles y actividad del agua, tanto del pomelo fresco como deshidratado almacenados en un gel formulado a partir de SO de 55, 50 (obtenida después de 5 ciclos de DO) y $30^{\circ}$ Brix. La metodología empleada para estas formulaciones se describe a continuación. 


\section{Productos PFG55 y PFG30}

Las mitades de rodajas de pomelo fresco de $1 \mathrm{~cm}$ de espesor, preparadas tal y como se detalla en el apartado III.1.2.1 de materiales y métodos, se colocaron en envases PET, pesando la cantidad de pomelo destinada para cada tarrina de producto final.

Para la gelificación se utilizó como fase líquida una SO de $55^{\circ}$ Brix y otra de $30^{\circ}$ Brix calentadas entre $60-70^{\circ} \mathrm{C}$ y $\mathrm{\kappa}$-carragenato al $0,75 \%$ en peso como agente gelificante, previamente disperso en unas gotas de etanol para evitar la formación de grumos. Una vez mezclados, se llevó a ebullición durante 1 minuto para asegurar la disolución completa del gelificante (Imeson, 1997). Las pérdidas de peso por evaporación fueron corregidas añadiendo agua destilada. Una vez enfriada y antes de su gelificación, se procedió al llenado de las tarrinas de forma que en cada una hubiera una relación fruta fresca:gel de 35:65 en peso, asegurándose de que la fruta quedara totalmente incluida en el gel. A estos productos gelificados objeto de estudio se les denominó PFG55 y PFG30 (pomelo fresco incluido en un gel de 55 y $30{ }^{\circ}$ Brix, respectivamente).

Las tarrinas se dejaron enfriar, se cerraron y se almacenaron en refrigeración, en las condiciones que aparecen en el apartado III.1.2.4 de materiales y métodos, hasta su posterior análisis.

\section{Productos PDOG50 y PDOG30}

En este caso, con la fruta deshidratada y la SO obtenidas después del $5^{\circ}$ ciclo de deshidratación $\left(\mathrm{SO}_{(5)}\right)$, se procedió a la formulación del producto gelificado. La $\mathrm{SO}_{(5)}$ se dividió en dos mitades. Una mitad se utilizó directamente para la formulación del producto. Se añadió en 
caliente el $\kappa$-carragenato $(0,75 \%$ en peso), de la misma manera que para PFG55, y se mantuvo la relación fruta:gel de 35:65 en peso. La concentración de azúcares inicial en el gel resultó ser de 50,2 $\pm 0,8$. A este producto gelificado se le denominó PDOG50 (pomelo deshidratado osmóticamente e incluido en un gel de $50^{\circ}$ Brix).

A la otra mitad de $\mathrm{SO}_{(5)}$ se le añadió agua destilada hasta igualar su $a_{w}$ con la de la fruta deshidratada, para que fuera termodinámicamente estable y así evitar una deshidratación progresiva de la fruta durante su posterior almacenamiento en el interior del gel. El cálculo de la cantidad de agua a agregar se efectuó mediante la ecuación de predicción de Norrish (Ecuación III.4), que se ha aplicado con buenos resultados en la predicción de la actividad del agua en alimentos y disoluciones binarias de diversos solutos no electrolitos (Norrish, 1966). Se consideró la existencia de un único soluto, la sacarosa.

$$
a_{w}=-X_{w} \cdot-\exp \left(-K_{s} \cdot X_{s}^{2}\right)
$$

donde:

$\mathrm{X}_{\mathrm{w}}$ : Fracción molar del agua (moles de agua/moles totales).

$\mathrm{X}_{\mathrm{S}}$ : Fracción molar de la sacarosa (moles de sacarosa /moles totales), calculada a partir de los ${ }^{\circ}$ Brix.

$\mathrm{K}_{\mathrm{s}}$ : Coeficiente binario de la ecuación generalizada de Norrish para la sacarosa $\left(K_{s}=6,47\right)$.

La concentración final en azúcares de este gel resultó ser de 29,6 \pm $0,8^{\circ}$ Brix. Posteriormente, se añadió $\kappa$-carragenato $(0,75 \%$ en peso) y se llenaron las tarrinas restantes al igual que en el caso anterior. Este producto gelificado fue denominado PDOG30 (pomelo deshidratado, e 
incluido en un gel de $30^{\circ}$ Brix). Las tarrinas se dejaron enfriar, se cerraron y se almacenaron en refrigeración, en las condiciones que aparecen en el apartado III.1.2.4 de materiales y métodos, hasta su posterior análisis.

En todas las formulaciones se analizó el contenido en humedad, sólidos solubles y $a_{w}$ de la fruta y del gel por separado, durante su almacenamiento en refrigeración.

\section{III.1.2.3.2. Formulación seleccionada}

En base a los resultados obtenidos (apartado III.2.3.1 de resultados) se seleccionó la formulación PDOG30 para su posterior estudio. De esta manera, además, al sistema PDOG30 se le analizó durante su almacenamiento en refrigeración, la evolución del contenido en ácido ascórbico (AA) tanto en la fruta como en el gel, así como su estabilidad microbiológica.

Por otro lado, a la fruta incluida en el gel, una vez separada de la matriz gelificada, se le analizaron sus propiedades físicas (color y propiedades mecánicas) así como su evolución durante el almacenamiento en refrigeración, comparándose con la fruta fresca y deshidratada con SO sin reutilizar.

El almacenamiento se realizó en las condiciones descritas en el apartado siguiente.

\section{III.1.2.4. Almacenamiento en refrigeración}

El almacenamiento en refrigeración $\left(10^{\circ} \mathrm{C}\right)$ se llevó a cabo para las muestras de pomelo fresco y deshidratado después de 1, 3 y 5 ciclos de deshidratación, así como para los productos gelificados obtenidos, 
PFG55, PFG30, PDOG50 y PDOG30. Todas las muestras se almacenaron en tarrinas (envases PET), previamente abiertas y expuestas bajo la luz ultravioleta durante $30 \mathrm{~min}$ en la campana de flujo laminar. Para el estudio de la tasa respiratoria, las muestras fueron almacenadas en las mismas condiciones pero en botes de cristal.

Los tiempos de almacenamiento variaron en función del parámetro controlado, siendo en todos los casos inferiores a 20 días.

\section{III.1.3. Análisis realizados}

La metodología seguida para la realización de los análisis mencionados en cada estudio se describe a continuación.

\section{III.1.3.1. Determinación de la actividad del agua}

Las determinaciones de $a_{w}$ se realizaron por triplicado empleando un higrómetro de punto de rocío marca Decagón modelo CX-2, con una sensibilidad de $\pm 0,003$, previamente calibrado con una disolución salina saturada de dicromato potásico en un intervalo de temperatura comprendido entre 25 y $30^{\circ} \mathrm{C}$. Las muestras se homogenizaron previamente con un equipo Ultra-Turrax modelo T25 a 9500 rpm. Se realizaron medidas hasta obtener un valor constante durante 2 lecturas consecutivas.

\section{III.1.3.2. Determinación de los sólidos solubles}

La determinación del contenido en sólidos solubles de las muestras de fruta homogeneizadas previamente por un equipo Ultra-Turrax T25 a 9500 rpm, se llevó a cabo empleando un refractómetro ABBE marca 
ATAGO modelo $3 \mathrm{~T}$, termostatado a $20^{\circ} \mathrm{C}$ con una sensibilidad de 0,01 ${ }^{\circ}$ Brix. Se midieron los ${ }^{\circ}$ Brix de la fase líquida de las muestras $\left(Z_{s}\right)$, recogida con ayuda de una pipeta Pasteur, y se calculó la fracción másica de sólidos solubles en la muestra aplicando la Ecuación III.5.

$$
x_{s}=\frac{Z_{s}^{*} x_{w}}{1-Z_{s}}
$$

donde:

$Z_{s}:{ }^{\circ}$ Brix/100.

$\mathrm{x}_{\mathrm{s}}$ : Fracción másica de sólidos solubles en la muestra $(\mathrm{g} / \mathrm{g})$.

$x_{\mathrm{w}}$ : Fracción másica de agua en la muestra $(\mathrm{g} / \mathrm{g})$.

\section{III.1.3.3. Determinación de la humedad}

Para la determinación de la humedad $\left(\mathrm{x}_{\mathrm{w}}\right)$ se siguió el método 20.013 (AOAC, 1980) para frutas ricas en azúcar. Las muestras de pomelo fueron previamente homogeneizadas con un equipo UltraTurrax T25 a 9500 rpm. Este método se basa en la determinación de la pérdida de peso de una muestra cuando se coloca en una estufa de vacío a una temperatura constante de $60^{\circ} \mathrm{C}$ permaneciendo en dicha estufa hasta alcanzar un peso constante.

La variación de peso antes y después del secado en la estufa, referida al peso inicial de la muestra, proporciona la humedad de la misma (g agua / g muestra). Ésta se determinó con una balanza digital con una sensibilidad de $\pm 0,0001 \mathrm{~g}$ (Mettler AE 100). 


\section{III.1.3.4. Determinación del pH}

Para la determinación del $\mathrm{pH}$ se utilizó el pH-metro CRISON micropH con electrodo de penetración en la muestra perfectamente homogeneizada.

\section{III.1.3.5. Determinación de la acidez valorable}

Para la determinación de la acidez valorable se usó la norma UNE34-211-81. Este método se basa en la valoración con una disolución de $\mathrm{NaOH} 0,1 \mathrm{~N}$ utilizando como indicador fenolftaleína. La valoración fue controlada mediante un $\mathrm{pH}$-metro hasta un $\mathrm{pH}$ de 8,1-8,2 ya que al ser la muestra de color anaranjado no se aprecia el viraje de la fenolftaleína. Se pesaron $9 \mathrm{~g}$ de muestra añadiendo $40 \mathrm{~mL}$ de agua destilada. Los resultados se expresaron como gramos de ácido cítrico por $100 \mathrm{~g}$ de muestra, según la ecuación III.6.

$$
\frac{g_{\text {ácido }}}{100 g_{\text {muestra }}}=\frac{V_{\mathrm{NaOH}} \cdot \mathrm{N}_{\mathrm{NaOH}} \cdot\left(\frac{M_{\text {ácido }}}{V_{\text {alencia }}}\right)}{P_{\text {muestra }}} \cdot 100
$$

donde:

$\mathrm{V}_{\mathrm{NaOH}}$ : $\mathrm{L} \mathrm{NaOH}$ consumidos en la valoración.

$\mathrm{N}_{\mathrm{NaOH}}$ : Normalidad del $\mathrm{NaOH}$.

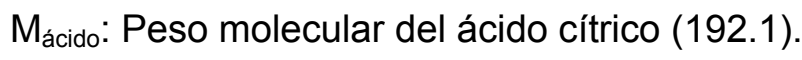

Valencia: Valencia del ácido cítrico (3).

$P_{\text {muestra: }}$ Peso de la muestra $(\mathrm{g})$. 


\section{III.1.3.6. Determinación del ácido ascórbico}

El ácido ascórbico (AA) fue determinado por el método de valoración de acuerdo a la Asociación Oficial de Químicos Analíticos (AOAC, 2000) que establece como método aprobado para la detección del $A A$, el Método Tillmans. Éste se basa en una valoración de oxidación-reducción, donde se permite la oxidación del ácido ascórbico presente en la materia evaluada mediante un tinte orgánico conocido como 2,6-dicloroindofenol (DCP).

Preparación de las disoluciones:

a. Ácido metafosfórico:

Preparación de ácido metafosfórico al $25 \%$ en agua destilada y hervida (previamente enfriada). Esta disolución se debe disolver en agitación y una vez preparada se debe mantener en refrigeración hasta el momento de su utilización. Es conveniente preparar una disolución nueva cada semana.

b. Disolución de Indofenol (tinte para valorar):

Preparación de una disolución de $80 \mathrm{mg}$ de 2,6 diclorofenolindofenol /100 mL de agua destilada y hervida a la que se ha añadido $2 \mathrm{mg}$ de bicarbonato sódico. Se guarda en nevera envolviendo el matraz con papel de aluminio.

\section{$>$ Estandarización del indicador:}

Preparación de una disolución patrón de ácido ascórbico de 250 ppm (mg/kg) a la que se le añaden $20 \mathrm{~mL}$ de ácido metafosfórico al $25 \%$ enrasando hasta $100 \mathrm{~mL}$ con agua destilada hervida. Por ser muy inestable esta disolución debe prepararse inmediatamente antes de su utilización. Para la valoración del indicador se vertió en un vaso de precipitados de $25 \mathrm{~mL}, 10 \mathrm{~mL}$ de la disolución patrón de ácido ascórbico 
(recién preparada). Se valoró rápidamente con la disolución del indicador hasta la aparición de una coloración ligeramente rosa que persista 30 segundos.

> Preparación de la muestra:

En un aforado de $50 \mathrm{~mL}$ se introducen $10 \mathrm{~g}$ de muestra, $10 \mathrm{~mL}$ de disolución acuosa de ácido metafosfórico al $25 \%$ y se enrasa con agua destilada y hervida. Se toman $10 \mathrm{~mL}$ de la disolución anterior, se introducen en un vaso de precipitados de $25 \mathrm{~mL}$ y se deja caer desde la bureta el indicador (previamente valorado) hasta la formación de un color rosa leve persistente durante 30 segundos.

> Contenido en ácido ascórbico:

El resultado fue expresado como mg AA/ $100 \mathrm{mg}$ muestra, previa determinación del volumen del zumo obtenido por gramo de pomelo, según la ecuación III.7:

$$
\frac{\mathrm{mg}_{\mathrm{AA}}}{100 \mathrm{~g}_{\text {muestra }}}=\frac{\mathrm{C} \cdot \mathrm{V} \cdot \mathrm{FD} \cdot 100}{\mathrm{P}_{\mathrm{m}}}
$$

donde:

C: $\mathrm{mg}$ de ácido ascórbico/mL tinte.

$\mathrm{V}: \mathrm{mL}$ tinte para titular muestra.

FD: Factor de dilución utilizado.

$\mathrm{P}_{\mathrm{m}}$ : Peso de la muestra.

\section{III.1.3.7. Medidas de la concentración de cationes}

La cuantificación de los cationes se llevó a cabo empleando un cromatógrafo líquido de intercambio iónico, Methrom Ion Analysis, IC 838, IC 761. El equipo (Figura III.3a) consta de 4 módulos: 
$>$ El carro de automatización de muestras.

$>$ El modulo de análisis de aniones y cationes.

$>$ El módulo de análisis de aminas.

$>$ El módulo de análisis de azúcares.

Todos los módulos están conectados a un ordenador que hace las funciones de control y de adquisición de datos.

El cambiador de muestras (Figura III.3b) es el encargado de seleccionar el vial que se va a inyectar; tiene una capacidad de 146 muestras y dispone a su vez de tres frascos lavadores que se utilizan para limpiar el inyector una vez se realiza una inyección.

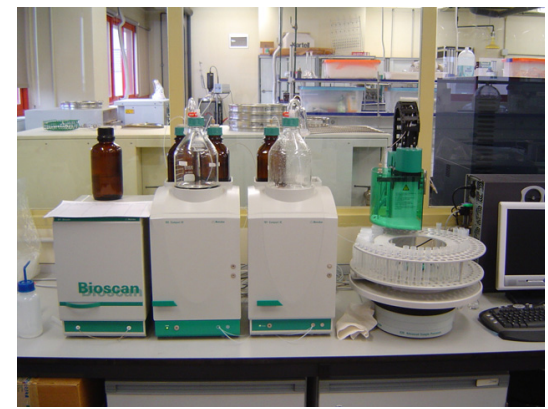

(a)

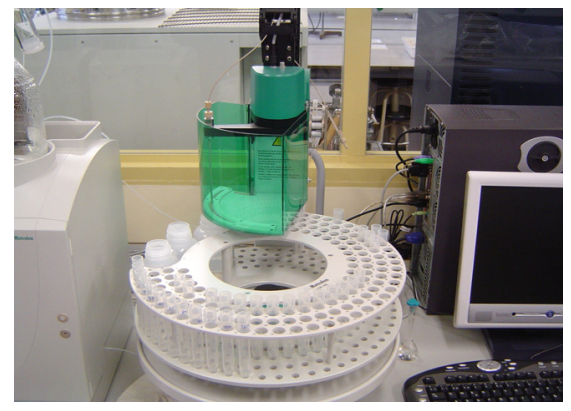

(b)

Figura III.3. a) Cromatógrafo líquido de intercambio iónico; b) Carro de automatización de muestras.

En los tubos de centrífuga se pesó una cantidad conocida $(\sim 10 \mathrm{~g}) \mathrm{de}$ muestra previamente homogeneizada. Posteriormente se centrifugó $\left(5^{\circ} \mathrm{C}, 5000 \mathrm{rpm}\right.$ durante 20 minutos). Se tomó $1 \mathrm{~mL}$ del sobrenadante (fase líquida) y se enrasó hasta $50 \mathrm{~mL}$ con agua miliQ (o agua bidestilada). De ahí se rellenaron los viales para el análisis.

El equipo proporciona los datos de los iones en $\mathrm{ppm}(\mathrm{mg} / \mathrm{kg}$ de zumo). Estos resultados se corrigieron con la dilución y se expresaron como mg de cada catión/100g de muestra. 
Se necesitan 40 minutos para la representación completa del cromatograma, que muestra picos a diferentes tiempos de retención correspondientes a los iones analizados. La integral de los picos, indica respectivamente el contenido de esos iones en las disoluciones inyectadas en ppm.

\section{III.1.3.8. Variación de masa}

Se determinó la variación de masa de las muestras antes y después de cada tiempo de deshidratación, así como durante el almacenamiento en refrigeración, en una balanza digital de precisión 0,001 g.

\section{III.1.3.9. Determinación de las propiedades mecánicas}

El equipo utilizado fue una prensa universal de ensayos mecánicos (Stable Micro Systems modelo TA-XTPlus, Inglaterra), como el que se observa en la figura III.4a. Se realizó un ensayo de compresiónextrusión, con una célula Ottawa (A/OTC) y un plato de extrusión (A/HOL, $6.5 \mathrm{~mm}$ agujero) (Figura III.4b). Se aplicó una deformación relativa del $95 \%$ a las muestras y se realizó a una velocidad de $1 \mathrm{~mm} \mathrm{~s}^{-1}$.

El ensayo de compresión-extrusión se llevó a cabo a temperatura ambiente en las muestras, previamente atemperadas, de pomelo fresco, pomelo deshidratado osmóticamente e inmerso en matriz gelificada, durante su almacenamiento en refrigeración. Se realizaron 6 repeticiones para cada tratamiento, obteniéndose las correspondientes curvas fuerza (N)-distancia $(\mathrm{mm})$. A partir de ellas se analizó la $\mathrm{F}_{\text {máx }}(\mathrm{N})$ y su evolución con el tiempo. 


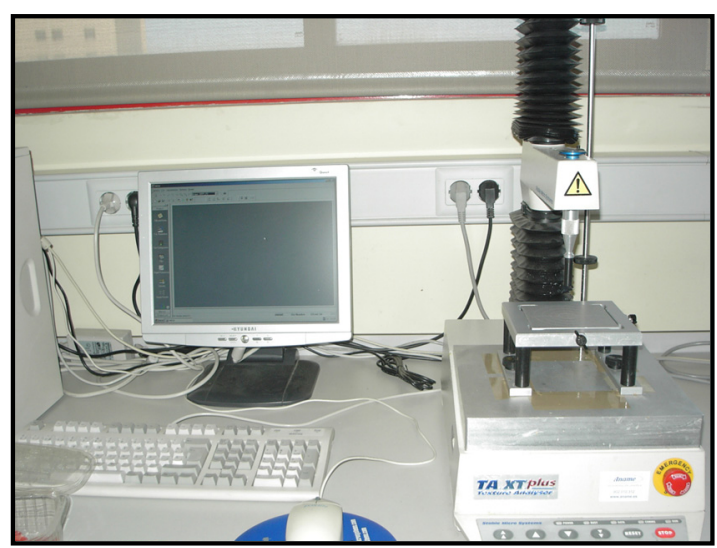

(a)

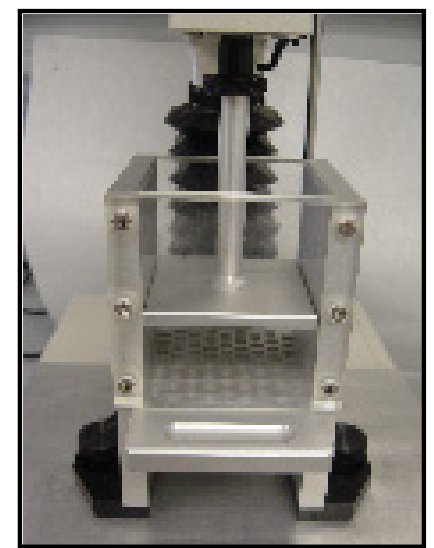

(b)

Figura III.4. a) Prensa universal de textura. b) Célula Otawa.

\section{III.1.3.10. Determinación del color}

Se midió por reflexión con un espectrocolorímetro Minolta modelo CM-3600D, Tokio, Japón, utilizando como sistema de referencia el iluminante $\mathrm{D} 65$ y el observador $10^{\circ}$. A partir del espectro de reflexión se obtuvieron las coordenadas de color CIE L*a*b*, correspondientes a la claridad o luminosidad, $L^{*}$ (0, negro; 100 , blanco) y a las coordenadas cromáticas, $a^{*} \mathrm{y} \mathrm{b}^{*}$, donde $\mathrm{a}^{*}$ representa la cantidad de rojo $(+) /$ verde $(-), y b^{*}$ la cantidad de amarillo (+) / azul (-). A partir de los valores $L^{*}, a^{*}$ $y b^{*}$, se calcularon las coordenadas psicométricas, tono $\left(h^{*}\right)$ y croma $\left(C^{*}\right)$ y al mismo tiempo se calculó la diferencia de color entre dos muestras $\left(\Delta \mathrm{E}^{*}\right)$. Para ello se aplicaron las siguientes ecuaciones:

$$
\begin{gathered}
h^{*}=\operatorname{arctg} \frac{b^{*}}{a^{*}} \\
C^{*}=\sqrt{\left(a^{* 2}+b^{* 2}\right)}
\end{gathered}
$$




$$
\Delta \mathrm{E}^{*}=\sqrt{\left(\Delta \mathrm{a}^{*}\right)^{2}+\left(\Delta \mathrm{b}^{*}\right)^{2}+\left(\Delta \mathrm{L}^{*}\right)^{2}}
$$

\section{III.1.3.11. Medidas de tasa de respiración}

Se eligió un método cerrado o estático para determinar la tasa respiratoria en mitades de rodajas de pomelo fresco y procesado. Se introdujo una cantidad conocida de muestra $(\sim 160 \mathrm{~g})$ en recipientes de cristal de 0,884 L, cerrados herméticamente. Cada recipiente estaba provisto de una tapa, en cuya superficie se colocó un septum para facilitar la toma de muestra de gas que hay en el espacio de cabeza a los distintos tiempos de estudio. Las muestras se tomaron cada 15 y 30 minutos durante las dos primeras horas y cada 60 ó 90 minutos hasta completar las 8 horas de medidas. Los recipientes fueron almacenados a $10^{\circ} \mathrm{C}$. El equipo usado para las medidas fue un analizador de gases (CheckMate 9900 PBI Dansensor, Ringsted, Dinamarca) que registra valores de $\% \mathrm{CO}_{2}$ y $\% \mathrm{O}_{2}$ mediante una aguja que tiene conectada (Figura III.5). Para el estudio de almacenamiento, los botes se airearon cada día durante los 6 días de almacenamiento para renovar la composición de gases del espacio de cabeza y evitar así condiciones de anaerobiosis.

Se eligieron como puntos experimentales aquellos que presentaron una buena relación lineal entre la concentración del gas y el tiempo, lo que indica que durante ese periodo de tiempo no ocurrieron cambios en la pauta respiratoria de las muestras y los cambios en la composición del espacio de cabeza no produjeron notables alteraciones en el metabolismo de las frutas.

Los datos procesados muestran la tasa respiratoria de las muestras (TR $\left(\mathrm{mLkg}^{-1} \mathrm{~h}^{-1}\right)$ ) en términos de $\mathrm{O}_{2}$ consumido y $\mathrm{CO}_{2}$ generado, 
calculada a partir de la pendiente obtenida del ajuste lineal de la ecuación III.11.

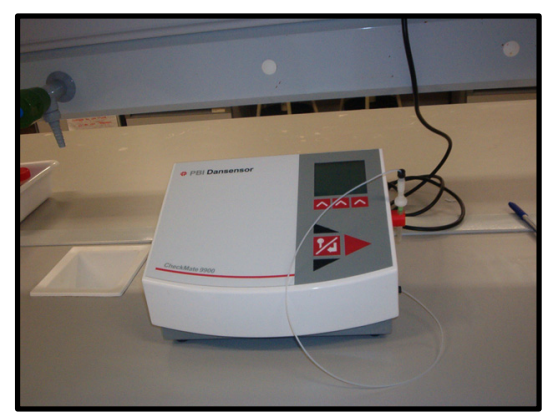

(a)

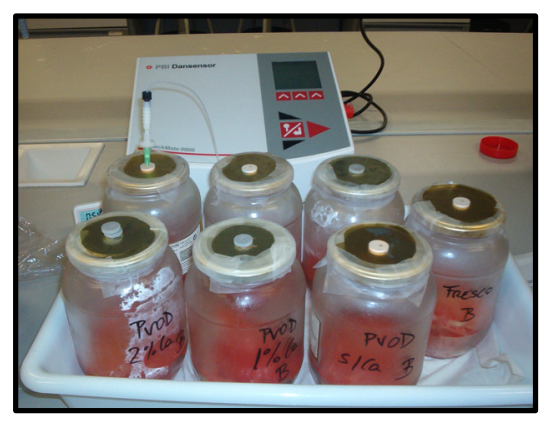

(b)

Figura III.5. a) Analizador de gases CheckMate 9900 PBI Dansensor; b) Ejemplo de toma de muestras.

$$
\mathrm{y}_{\mathrm{t}}=\mathrm{y}_{\mathrm{t} 0} \pm 100 \cdot \mathrm{TR} \cdot \frac{\mathrm{M}}{\mathrm{V}} \cdot \mathrm{t}
$$

donde

$\mathrm{y}_{\mathrm{t}}$ : Concentración de gas $\left(\mathrm{mL} \mathrm{CO} \mathrm{CO}_{2} \mathrm{~mL} \mathrm{O}_{2} / 100 \mathrm{~mL}\right)$ a tiempo $\mathrm{t}$.

$\mathrm{y}_{\mathrm{t} 0}$ : Concentración de gas $\left(\mathrm{mL} \mathrm{CO} \mathrm{CO}_{2} \mathrm{~mL} \mathrm{O} / 100 \mathrm{~mL}\right)$ inicial.

M: Masa de las muestras $(\mathrm{kg})$.

$\mathrm{V}$ : Volumen del espacio de cabeza $(\mathrm{mL})$.

$\mathrm{t}$ : Tiempo (h).

\pm : Signo + cuando se expresa la generación de $\mathrm{CO}_{2}$ y signo - cuando se expresa el consumo de $\mathrm{O}_{2}$

Las unidades de la tasa respiratoria se expresaron por $\mathrm{kg}$ de muestra fresca inicial antes de ser sometida a los distintos tratamientos, considerando que el flujo de materia durante los procesos de impregnación y deshidratación sólo afecta a los solutos y al agua. 


\section{III.1.3.12. Análisis microbiológico}

Para el análisis microbiológico de las muestras se tuvieron en cuenta los organismos viables totales y los mohos y levaduras. Para el recuento de microorganismos viables totales se efectuó una siembra por vertido en placa y por duplicado, utilizando como medio de cultivo Plate Count Agar. Se incubó en una estufa a la temperatura de $31 \pm 1^{\circ} \mathrm{C}$ realizándose la lectura pasadas 48-72h, contándose el número de colonias en las placas que mostraron entre 30 y 300 (límite establecido) y multiplicando después por el factor de dilución. El total de gérmenes se expresó como el logaritmo de unidades formadoras de colonias por gramo (log Ufc/g). Para la siembra de mohos y levaduras se usó el medio de cultivo Sabourand Cloramphenicol Agar. La siembra también fue por vertido en placa y por duplicado. La temperatura de incubación en este caso fue de $30 \pm 1^{\circ} \mathrm{C}$. La lectura se realizó entre los 3 y 5 días de incubación. El recuento se estableció a partir del número de colonias aparecidas en las placas que contuvieron entre 0-30. El número total de colonias se expresó en log Ufc/g.

Para llevar a cabo el análisis microbiológico, todo el material necesario (material de vidrio, medios de cultivo, etc.) se esterilizó en autoclave (Presoclave 75 , J.P. Selecta S.A.), a $121^{\circ} \mathrm{C}$ durante 15 minutos. Posteriormente se pesaron aproximadamente 10 gramos de la muestra a analizar en una bolsa stomacher, en condiciones de asepsia, a la que se le agregó $90 \mathrm{~mL}$ de agua de peptona y se homogeneizó todo en el Stomacher. Esto corresponde a la suspensión madre con un título de 1:10 y la primera dilución de la serie $\left(10^{-1}\right)$. Se procedió a la siembra por vertido en placa, pipeteando un volumen conocido $(1 \mathrm{~mL})$ y vertiéndolo en placas estériles rotuladas, a las que se añadió el medio estéril correspondiente, mezclando y dejando solidificar. 
Se prepararon tubos de ensayo a razón de $9 \mathrm{~mL}$ de agua de peptona para obtener así las diluciones decimales seriadas $\left(10^{-2} ; 10^{-3}\right.$; etc.), siguiendo el proceso que se refleja en la figura III.6.

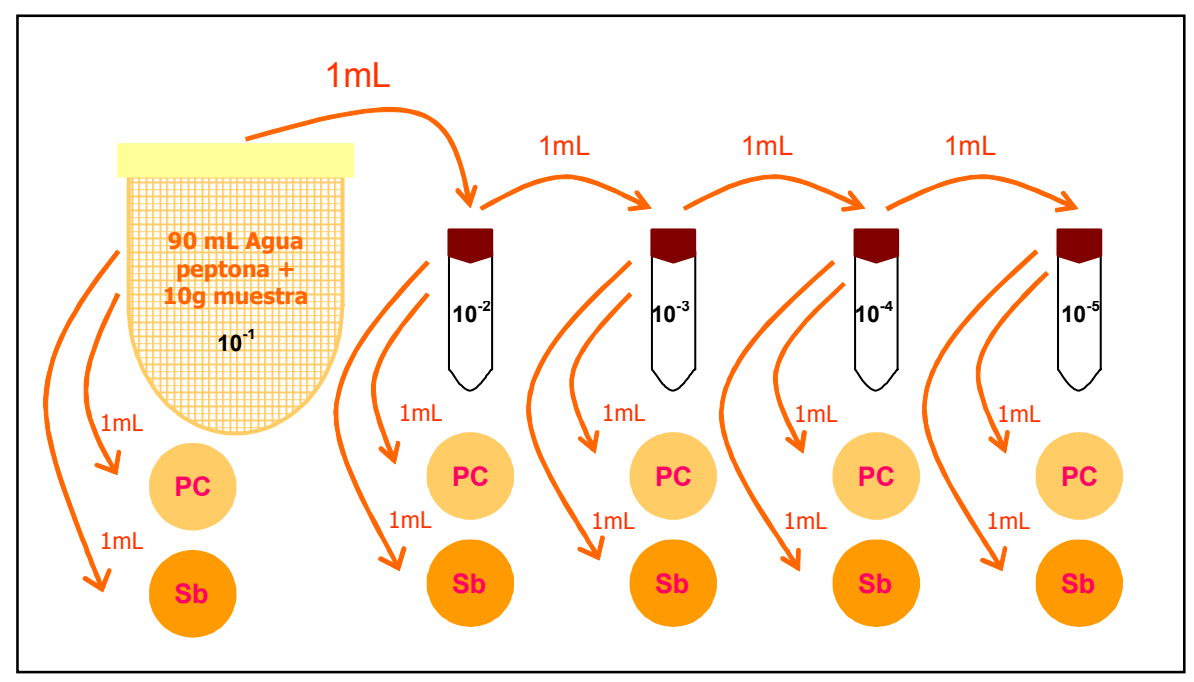

Figura III.6. Esquema de la preparación de las diluciones, teniendo en cuenta que se realizaban 2 repeticiones para cada dilución.

A uno de los tubos se transfirió $1 \mathrm{~mL}$ de la suspensión madre mezclándose 30 segundos en agitador excéntrico para obtener así la dilución 1:100. Seguidamente se procedió a la siembra de la misma forma, pipeteando un volumen conocido $(1 \mathrm{~mL})$ y vertiéndolo en las placas estériles rotuladas, a las que se añadió el medio estéril. Se desechó la pipeta usada.

De la mezcla anterior, y con nueva pipeta estéril, se incorporó $1 \mathrm{~mL}$ a otro tubo con $9 \mathrm{~mL}$ de agua peptonada. Se mezclaron 30 segundos en agitador excéntrico, obteniéndose así la dilución 1:1000. La siembra se realizó de la misma forma que las diluciones anteriores. Así sucesivamente. 


\section{DESARROLLO DE UN PRODUCTO GELIFICADO CON POMELO POR TRATAMIENTOS osMótICOS}

\section{III.2. RESULTADOS Y DISCUSIÓN}

III.2.1. Estudio cinético de la deshidratación osmótica del pomelo

Con el fin de seleccionar el tiempo óptimo de deshidratación del pomelo que posteriormente se empleará para la elaboración del producto gelificado, se estudió la cinética de deshidratación osmótica de la fruta cortada en mitades de rodajas, siguiendo el procedimiento experimental que aparece en el apartado III.1.2.2.1 de materiales y métodos. 
III.2.1.1. Caracterización de las propiedades fisicoquímicas del pomelo durante la deshidratación osmótica

El lote de pomelos frescos de partida utilizados para este estudio fue homogéneo en cuanto a los ${ }^{\circ}$ Brix, presentando un valor promedio de 8,9 $\pm 0,8$. Además, los pomelos frescos presentaron un valor de $a_{w}$ de 0,988 $\pm 0,003$ y una $x_{w}$ de $0,867 \pm 0,003$.

La tabla III.1 muestra los valores promedio de las fracciones másicas de agua y sólidos solubles, así como la actividad del agua $\left(\mathrm{a}_{\mathrm{w}}\right)$ del pomelo deshidratado osmóticamente en función del tiempo de deshidratación. En esta tabla, el tiempo cero corresponde al pomelo después de la aplicación del pulso de vacío y una vez restaurada la presión atmosférica. Debido a la entrada de la disolución osmótica en los poros del tejido durante la impregnación a vacío, se observa un cambio inicial importante en la composición de la fruta. A partir de este momento se observa una disminución más gradual en la fracción másica de agua a lo largo del tiempo así como un aumento en la fracción de sólidos solubles, como era de esperar debido a los gradientes de concentración que se producen al introducir la fruta en una disolución hipertónica.

La cinética de transferencia de agua y solutos parece ser más rápida en los primeros $180 \mathrm{~min}$ del proceso, mientras que a partir de este tiempo parece alcanzar un valor asintótico en ambos casos.

En cuanto a los valores de actividad del agua de las muestras se observa una ligera disminución con el tiempo de deshidratación, a excepción del valor obtenido a 480 min que parece un dato anómalo. Como las desviaciones experimentales de la medida de este parámetro fueron inferiores a la sensibilidad del equipo $(0,003)$, se ha considerado dicha sensibilidad como desviación. 
Tabla III.1. Fracción másica de agua y sólidos solubles y actividad del agua del pomelo deshidratado osmóticamente en función del tiempo de deshidratación.

\begin{tabular}{crllll}
\hline $\mathbf{t}(\mathbf{m i n})$ & \multicolumn{2}{c}{$\mathbf{x}_{\mathbf{w}}$} & \multicolumn{2}{c}{$\mathbf{x}_{\mathbf{s}}$} & \multicolumn{2}{c}{$\mathbf{a}_{\mathbf{w}}$} \\
\hline 0 & $0,8387 \pm 0,0017^{(\mathrm{a})}$ & $0,1468 \pm 0,0013^{(\mathrm{a})}$ & $0,983 \pm 0,003^{(\mathrm{a})}$ \\
15 & $0,820 \pm 0,003^{(\mathrm{b})}$ & $0,168 \pm 0,002^{(\mathrm{b})}$ & $0,981 \pm 0,003^{(\mathrm{a})}$ \\
30 & $0,8189 \pm 0,0013^{(\mathrm{b})}$ & $0,170 \pm 0,002^{(\mathrm{b})}$ & $0,982 \pm 0,003^{(\mathrm{a})}$ \\
45 & $0,7951 \pm 0,0017^{(\mathrm{d})}$ & $0,1920 \pm 0,0005^{(\mathrm{d})}$ & $0,982 \pm 0,003^{(\mathrm{a})}$ \\
60 & $0,809 \pm 0,002^{(\mathrm{c})}$ & $0,1753 \pm 0,0012^{(\mathrm{c})}$ & $0,977 \pm 0,003^{(\mathrm{b})}$ \\
90 & $0,8138 \pm 0,0009^{(\mathrm{c})}$ & $0,1738 \pm 0,0002^{(\mathrm{c})}$ & $0,979 \pm 0,003^{(\mathrm{b})}$ \\
180 & $0,7747 \pm 0,0008^{(\mathrm{e})}$ & $0,214 \pm 0,003^{(\mathrm{e})}$ & $0,978 \pm 0,003^{(\mathrm{b})}$ \\
300 & $0,763 \pm 0,003^{(\mathrm{f})}$ & $0,218 \pm 0,003^{(\mathrm{f})}$ & $0,978 \pm 0,003^{(\mathrm{b})}$ \\
480 & $0,7709 \pm 0,0017^{(\mathrm{e})}$ & $0,2124 \pm 0,0005^{(\mathrm{e})}$ & $0,981 \pm 0,003^{(\mathrm{a})}$
\end{tabular}

$(a)(b)(c)(d)(e)(f)$ Grupos homogéneos establecidos por el ANOVA $(\alpha<0,05)$ con el factor tiempo de deshidratación.

\section{III.2.1.2. Estimación de la difusividad efectiva del agua}

Un parámetro interesante a conocer en todo proceso de deshidratación es la difusividad efectiva del agua. En el caso de las frutas como el pomelo, éstas tienen una estructura celular vegetal en la que el agua es transportada a través de las membranas plasmáticas por diferentes mecanismos, tal y como se explica en el apartado I.2.1 de la introducción. De tal manera intervendrán transportes pasivos, entre los que se incluyen los difusionales, y transportes activos regulados en algunos casos por el catión calcio (Tyerman et al., 1999). Al mismo tiempo, en el transporte de agua a través del tejido intervendrán fenómenos de difusión a través de los espacios extracelulares (tanto de agua como de solutos), mecanismos de compresión-relajación del tejido y transporte simplástico a través de los plasmodesmos, etc. Así pues la 
difusividad efectiva $\left(D_{\mathrm{e}}\right)$ será un coeficiente global de transporte que incluirá los distintos mecanismos explicados anteriormente y la ecuación utilizada, descrita a continuación, servirá para ajustar los datos experimentales empíricamente.

Debido a la geometría de las muestras empleadas, se supone que la mayor parte del transporte se produce a través de la cara plana de la rodaja. Esto es debido a que la cara cilíndrica conserva parte del tejido epidérmico de los sacos y a que la dimensión característica de esta geometría es mucho menor que la plana. De esta manera, se utilizó el desarrollo realizado por Crank (1975) para geometrías planas infinitas.

A partir de la ecuación III.1, y siguiendo el procedimiento descrito en el apartado III.1.2.2.1 para la obtención de la $D_{e}$, se representa en la figura III.7 la concentración reducida $\left(1-Y_{\mathrm{w}}^{\mathrm{t}}\right)$ frente a la raíz cuadrada del tiempo. La pendiente de la recta obtenida por regresión lineal de los datos experimentales ajustados, permite obtener el valor de la difusividad efectiva del agua que resultó ser de $3,64 \cdot 10^{-11} \mathrm{~m}^{2} / \mathrm{s}$ $\left(R^{2}=0,856\right)$.

Este valor es del mismo orden al encontrado para otras frutas en las mismas condiciones a las llevadas a cabo en este estudio. Así, en mitades de fresa (Talens, 2002) y cilindros de mango de $1,5 \mathrm{~cm}$ de espesor y $2 \mathrm{~cm}$ de diámetro (Giraldo et al., 2003), los valores de $D_{e}$ fueron de $3,53 \cdot 10^{-11} \mathrm{~m}^{2} / \mathrm{s}$ y de $6,4 \cdot 10^{-11} \mathrm{~m}^{2} / \mathrm{s}$, respectivamente. La manzana cortada en rodajas de $1 \mathrm{~cm}$ de espesor, presenta un valor más alto de $D_{e}$, siendo de $23,0 \cdot 10^{-11} \mathrm{~m}^{2} / \mathrm{s}$ (Barrera et al., 2004). Las diferencias entre frutas serán principalmente consecuencia de las características de la estructura del tejido correspondiente. 


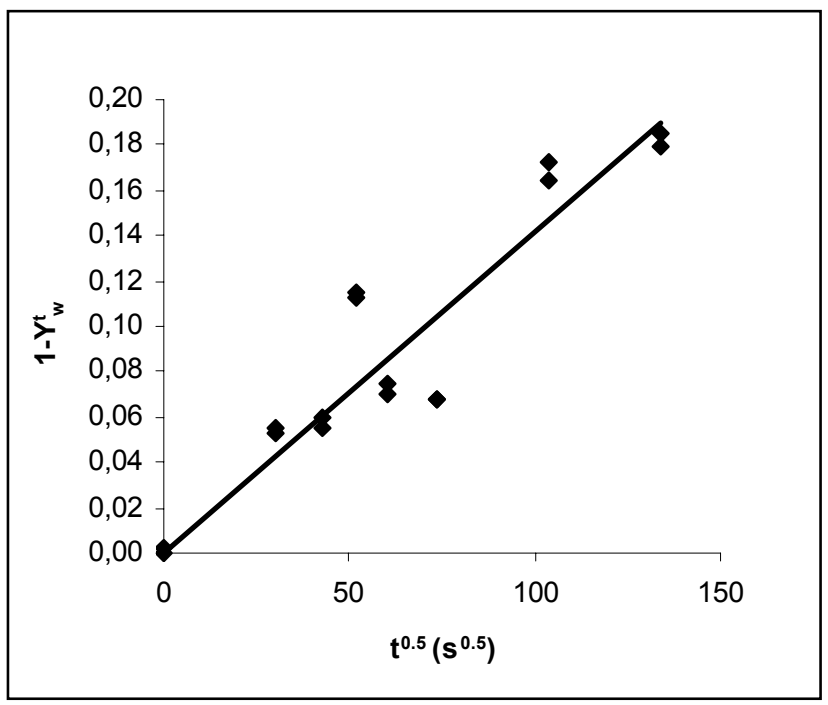

Figura III.7. Representación de $1-Y_{\mathrm{w}}^{\mathrm{t}}$ frente a la raíz cuadrada del tiempo (ver ecuación III.1).

\section{III.2.1.3. Cinética de pérdida de agua y ganancia de solutos}

Siguiendo el modelo descrito por Fito y Chiralt (1997), a partir de los datos de peso de cada una de las muestras sometidas al proceso de deshidratación osmótica, se calcularon las variaciones relativas de peso $(\Delta \mathrm{M})$ en función del tiempo de tratamiento a través de la ecuación III.12. Además, conocida la humedad y los sólidos solubles promedio de las muestras a cada tiempo y empleando las ecuaciones III.13 y III.14 se calcularon las variaciones relativas de agua $\left(\Delta \mathrm{M}_{\mathrm{w}}\right)$ y de solutos $\left(\Delta \mathrm{M}_{\mathrm{s}}\right)$ respectivamente.

$$
\Delta \mathrm{M}_{\mathrm{T}}=\frac{\mathrm{M}_{\mathrm{t}}-\mathrm{M}_{\mathrm{o}}}{\mathrm{M}_{\mathrm{o}}}
$$




$$
\begin{aligned}
& \Delta M_{w}=\frac{M_{t} x_{w t}-M_{0} x_{w 0}}{M_{0}} \\
& \Delta M_{s}=\frac{M_{t} x_{s t}-M_{0} x_{s 0}}{M_{0}}
\end{aligned}
$$

donde:

$\mathrm{M}_{\mathrm{o}}=$ Masa inicial de muestra $(\mathrm{g})$.

$\mathrm{M}_{\mathrm{t}}=$ Masa de muestra a tiempo $\mathrm{t}(\mathrm{g})$.

$\mathrm{x}_{\mathrm{so}}=$ Fracción másica de sólidos solubles de la muestra a tiempo 0 $\left(g_{s} / g_{m}\right)$.

$\mathrm{x}_{\mathrm{st}}=$ Fracción másica de sólidos solubles de la muestra a tiempo $\mathrm{t}$ $\left(g_{s} / g_{m}\right)$.

$\mathrm{X}_{\mathrm{wo}}=$ Fracción másica de agua de la muestra a tiempo $0\left(\mathrm{~g}_{\mathrm{w}} / \mathrm{g}_{\mathrm{m}}\right)$.

$x_{w t}=$ Fracción másica de agua de la muestra a tiempo $t\left(g_{w} / g_{m}\right)$.

En la tabla III.2 se muestran los valores obtenidos de la variación de masa total $\left(\Delta \mathrm{M}_{\mathrm{T}}\right)$, ganancia de solutos $\left(\Delta \mathrm{M}_{\mathrm{S}}\right)$ y pérdida de agua $\left(\Delta \mathrm{M}_{\mathrm{W}}\right)$, referidos por unidad de masa inicial de producto en función del tiempo de deshidratación osmótica.

Con el objetivo de evaluar en la medida de lo posible la magnitud de los errores experimentales, en la figura III.8 se representan las pérdidas relativas de agua más las ganancias de solutos frente a las pérdidas de masa total. Como puede observarse, los puntos experimentales se ajustan bastante bien a la diagonal, verificando el balance de materia (Ecuación III.15) en esta experiencia de deshidratación osmótica de pomelo.

$$
\Delta \mathrm{M}_{\mathrm{T}}=\Delta \mathrm{M}_{\mathrm{s}}+\Delta \mathrm{M}_{\mathrm{w}}
$$


Tabla III.2. Valores de la variación relativa de masa total $\left(\Delta \mathrm{M}_{\mathrm{T}}\right)$, ganancia de solutos $\left(\Delta \mathrm{M}_{\mathrm{S}}\right)$ y pérdida de agua $\left(\Delta \mathrm{M}_{\mathrm{W}}\right)$, referidos por unidad de masa inicial de producto en función del tiempo de deshidratación osmótica.

\begin{tabular}{|c|c|c|c|c|c|c|c|c|}
\hline \multirow{2}{*}{$\frac{t(\min )}{0}$} & \multicolumn{2}{|c|}{$\Delta \mathbf{M}_{\mathrm{T}}$} & \multicolumn{3}{|c|}{$\Delta M_{w}$} & \multicolumn{3}{|c|}{$\Delta \mathbf{M}_{\mathbf{s}}$} \\
\hline & $-0,06$ & $\pm 0,02$ & & - & & & - & \\
\hline 15 & $-0,078$ & $\pm 0,008$ & $-0,084$ & \pm & 0,003 & 0,009 & \pm & 0,001 \\
\hline 30 & $-0,08$ & $\pm 0,02$ & $-0,08$ & \pm & 0,02 & 0,011 & \pm & 0,002 \\
\hline 45 & $-0,061$ & $\pm 0,003$ & $-0,093$ & \pm & 0,001 & 0,034 & \pm & 0,001 \\
\hline 60 & $-0,035$ & $\pm 0,012$ & $-0,059$ & \pm & 0,008 & 0,023 & \pm & 0,003 \\
\hline 90 & $-0,0702$ & $\pm 0,0114$ & $-0,083$ & \pm & 0,008 & 0,016 & \pm & 0,002 \\
\hline 180 & $-0,119$ & $\pm 0,008$ & $-0,158$ & \pm & 0,005 & 0,0426 & \pm & 0,001 \\
\hline 300 & $-0,069$ & $\pm 0,009$ & $-0,13$ & \pm & 0,01 & 0,057 & \pm & 0,005 \\
\hline 480 & $-0,07$ & $\pm 0,03$ & $-0,12$ & \pm & 0,02 & 0,052 & \pm & 0,007 \\
\hline
\end{tabular}

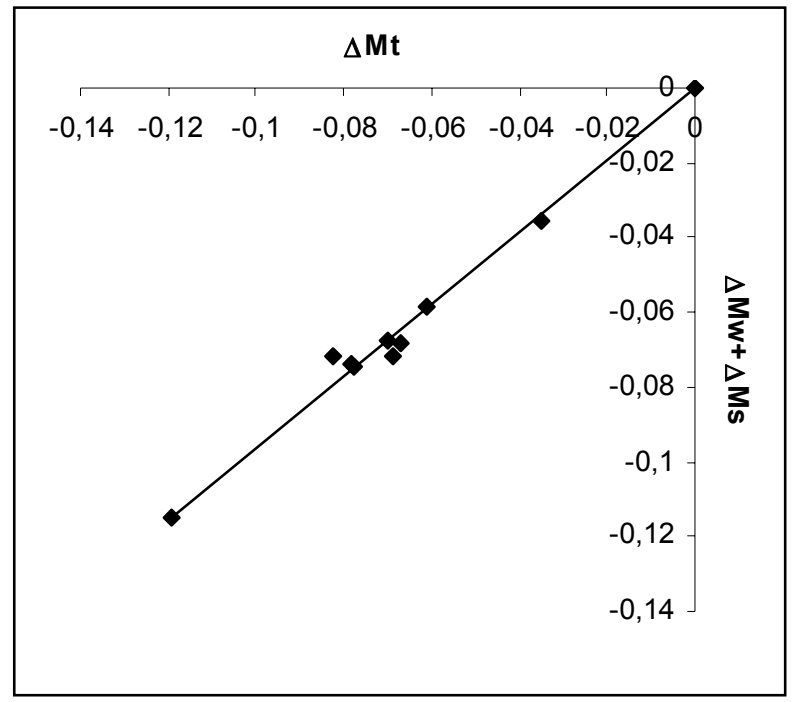

Figura III.8. Relación entre la pérdida de peso de las muestras a cada tiempo de deshidratación y la pérdida de agua más la ganancia de solutos. 
La representación gráfica de las variaciones de masa total, masa de agua y masa de solutos frente al tiempo de tratamiento (Figura III.9) permite observar un comportamiento oscilante en cada una de ellas. Dicho comportamiento, observado también por otros autores (Katime et al., 1994; Seguí et al., 2006), puede ser causa del acoplamiento de dos mecanismos contrapuestos, el mecánico, como consecuencia de los fenómenos de relajación-compresión del tejido causado por el pulso de vacío y por el encogimiento celular, y el difusional, debido al gradiente de potencial químico del agua entre la fruta y la disolución osmótica.

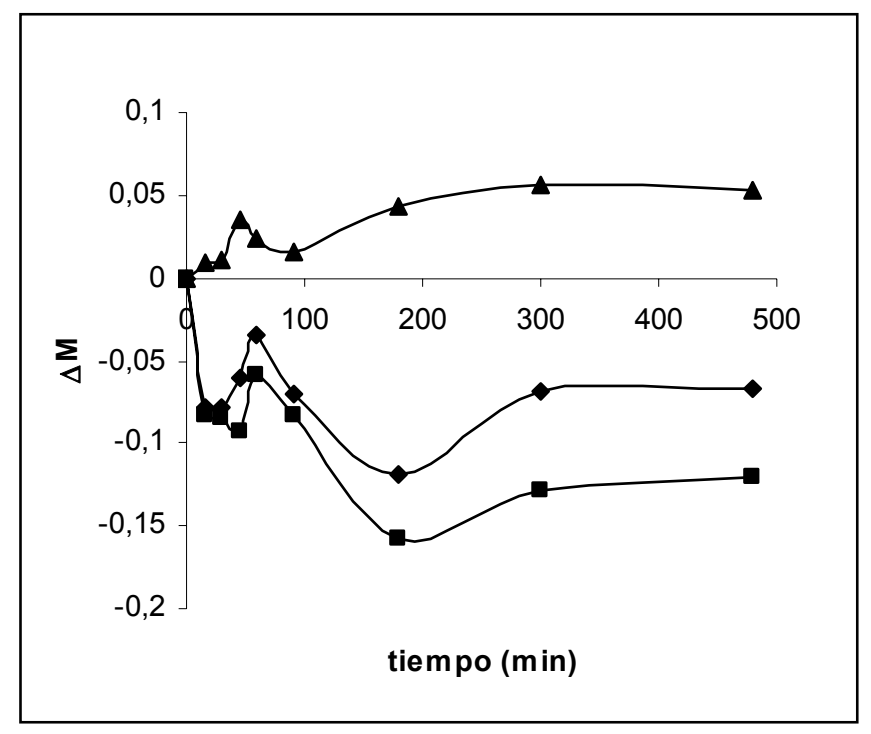

Figura III.9. Valores de la pérdida de masa total ( $\bullet$ ), ganancia de solutos ( $\mathbf{\Delta}$ ) y pérdida de agua ( $\mathbf{\square})$, referidos por unidad de masa inicial de producto, en función del tiempo de deshidratación osmótica.

El pulso de vacío genera compresión del tejido relajándose posteriormente de manera paulatina en mayor o menor grado en función 
de la elasticidad del mismo. Dicha relajación se transformará en gradientes de presión en el interior de la fruta. Si la relajación supera el límite mecánico del tejido el sistema volverá a encogerse provocando de nuevo gradientes de presión de sentido contrario. Dicho fenómeno se repetirá hasta alcanzar la situación de tensión normal del tejido, provocando mientras tanto un efecto oscilante en los flujos totales de agua y solutos. Al mismo tiempo, la plasmólisis celular puede generar el mismo efecto al comprimirse y relajarse de manera paulatina el tejido al separarse la membrana plasmática de la pared celular (Seguí et al., 2006). Por otro lado, como consecuencia del diferente potencial químico del agua en la fruta y en la disolución, la fruta continuará deshidratándose hasta alcanzar el equilibrio termodinámico del sistema.

En este sentido, en la figura III.9, se observa inicialmente un ciclo donde predominan fundamentalmente los mecanismos difusionales alcanzándose una pérdida de agua en torno al 10\%. Posteriormente, a partir de los $45 \mathrm{~min}$, hay una entrada de fase líquida (tanto de agua como solutos) al tejido, como consecuencia de los gradientes de presión generados, y entre 60 y $180 \mathrm{~min}$, comienza de nuevo otro ciclo donde predominan los mecanismos difusionales, para alcanzar el equilibrio mecánico aproximadamente a los $300 \mathrm{~min}$.

En cualquier caso, a los $180 \mathrm{~min}$ de tratamiento, los valores de variación de masa total y pérdida de agua, referidos por unidad de masa inicial de producto, alcanzan un valor máximo mientras que la ganancia de solutos se aproxima a un valor asintótico. Por este motivo, y por el hecho de que nos interesa obtener un producto mínimamente procesado, se seleccionó este tiempo como el óptimo para el procesado de la fruta y su posterior uso en la elaboración del producto gelificado.

En estas condiciones, el pomelo deshidratado presenta una humedad del $77,47 \%$, unos ${ }^{\circ}$ Brix de 21,4 y una $a_{w}$ de 0,978 . 
III.2.2. Obtención de pomelo deshidratado para la formulación del producto gelificado

A continuación se presentan los resultados obtenidos del estudio previo realizado, tal y como se indica en el apartado III.1.2.2.2 de materiales y métodos, para identificar la viabilidad de la reutilización de la SO en ciclos sucesivos de DO de fruta fresca, en función de la vida útil microbiológica de la fruta deshidratada y los cambios ocurridos en la SO y en la fruta después de cada ciclo de deshidratación y durante el almacenamiento de esta última en refrigeración.

III.2.2.1. Efecto de la reutilización de la disolución osmótica en el recuento de microorganismos del pomelo deshidratado osmóticamente almacenado en refrigeración

Tal y como se indica en el apartado III.1.2.2.2 de materiales y métodos, con el fin de estudiar la necesidad de aplicación de un tratamiento térmico previo a la reutilización de la SO se realizaron dos experiencias paralelas. En una no se aplicó ningún tratamiento a la SO mientras que en la otra se sometió a la SO a una pasteurización suave manteniéndola a una $\mathrm{T}$ de $72^{\circ} \mathrm{C}$ durante 15 segundos antes de cada ciclo de deshidratación. Los resultados obtenidos se comentan a continuación.

Debido al pH tan ácido que presenta el pomelo, el estudio se realizó sobre viables totales y mohos y levaduras, ya que la microflora se reduce principalmente a estos microorganismos sin existencia de patógenos. La mayor parte de las bacterias son incapaces de crecer a los niveles de $\mathrm{pH}$ que presentan los derivados de frutas (Cardona et al., 1992), ya que prefieren un $\mathrm{pH}$ neutro para su desarrollo. 
Contrariamente, las levaduras y mohos pueden crecer y desarrollarse en estas condiciones, de ahí que la mayor parte de las alteraciones microbianas que tienen lugar en zumos y derivados de frutas sean debidas a las levaduras, más del 90\% según Cardona et al. (1992), y buena parte del resto a mohos.

La figura III.10 muestra los recuentos obtenidos en el análisis microbiológico realizado durante el almacenamiento a $10^{\circ} \mathrm{C}$ de pomelo fresco (PF) y pomelo deshidratado osmóticamente con SO sin reutilizar (PD1), así como pomelo deshidratado con SO reutilizada durante 3 (PD3) y 5 (PD5) ciclos sucesivos de deshidratación, sin someter previamente a la SO a ningún tratamiento térmico.

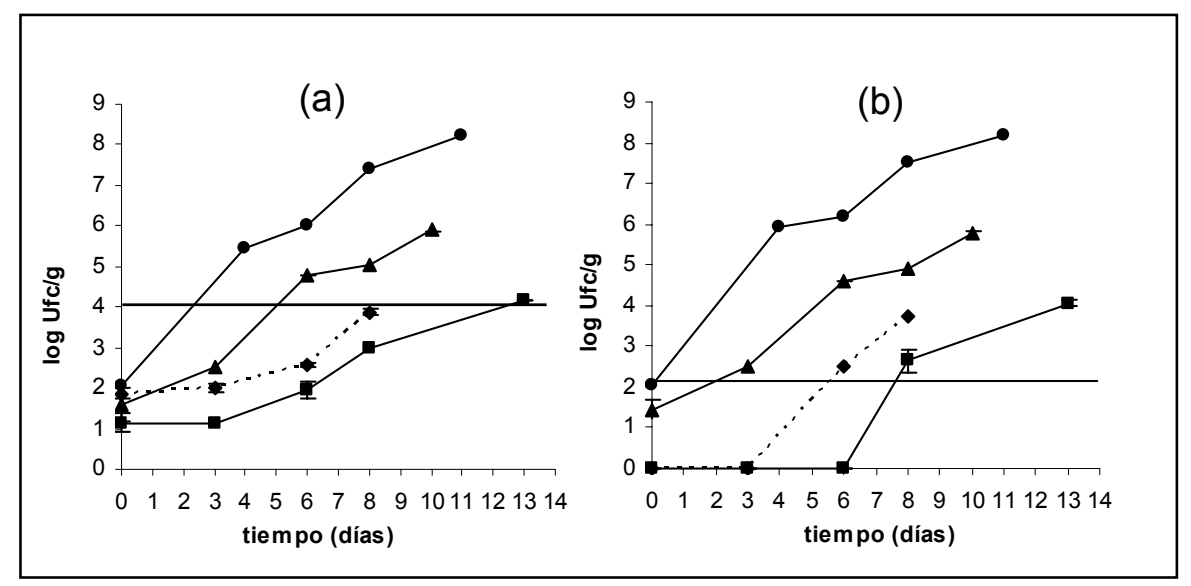

Figura III.10. Recuento de (a) viables totales y (b) mohos y levaduras, en pomelo fresco $(\diamond)$, pomelo deshidratado osmóticamente con SO sin reutilizar $(\boldsymbol{\bullet})$ y reutilizada durante $3(\boldsymbol{\Delta})$ y $5(\bullet)$ ciclos de deshidratación, sin tratamiento térmico de la disolución osmótica antes de cada ciclo.

No hay legislación en cuanto al número máximo de microorganismos permitido en este tipo de productos. Lo único que se especifica en el 
Real Decreto 1050/2003 de 1 de Agosto que mantiene la vigencia del Real Decreto 667/1983 del 2 de Marzo, es que los zumos de frutas y otros vegetales y sus derivados, no contendrán agentes patógenos o perjudiciales para el propio consumidor.

Al no establecerse ningún límite en el número de microorganismos se buscó en bibliografía uno de los valores más restrictivos encontrados para alimentos (Pascual y Calderón, 2000), remitiéndonos a los valores establecidos para cereales, que coinciden con los establecidos para la miel, en cierta manera con componentes similares a nuestro producto. En la Orden de 5 de agosto de 1983 (B.O.E. 13-8-83) por la que se aprueba la Norma de Calidad para la miel destinada al mercado interior, se especifica como Norma Microbiológica un máximo de $10^{4} \mathrm{Ufc/g}$ y $10^{2} \mathrm{Ufc} / \mathrm{g}$ para viables totales $\left(31 \pm 1^{\circ} \mathrm{C}\right)$ y mohos y levaduras, respectivamente.

Siendo el límite para mohos y levaduras el primero que se alcanzó en nuestro estudio, como era de esperar, fue éste el factor limitante considerado para asignar la vida útil microbiológica del pomelo. En este sentido, la fruta fresca y deshidratada osmóticamente después de un ciclo de deshidratación alcanzaron el límite establecido para mohos y levaduras a los 5 y 7 días de almacenamiento en refrigeración, respectivamente (Figura III.10). Sin embargo, la reutilización de la disolución osmótica supuso un incremento de la carga microbiana presente en la fruta, tanto mayor cuanto más veces se reutilizó la disolución osmótica. La vida útil microbiológica resultó ser de 2 días en las muestras deshidratadas con SO reutilizada durante 3 ciclos, alcanzándose el límite establecido inmediatamente después de deshidratar la fruta en las muestras deshidratadas con la SO reutilizada durante 5 ciclos de deshidratación. 
Como puede observarse, cuando se aplicó un tratamiento térmico suave entre ciclos (Figura III.11), la vida útil microbiológica de las muestras deshidratadas aumentó, siendo de 6, 12 y 9 días en las muestras PD1, PD3 y PD5, respectivamente.

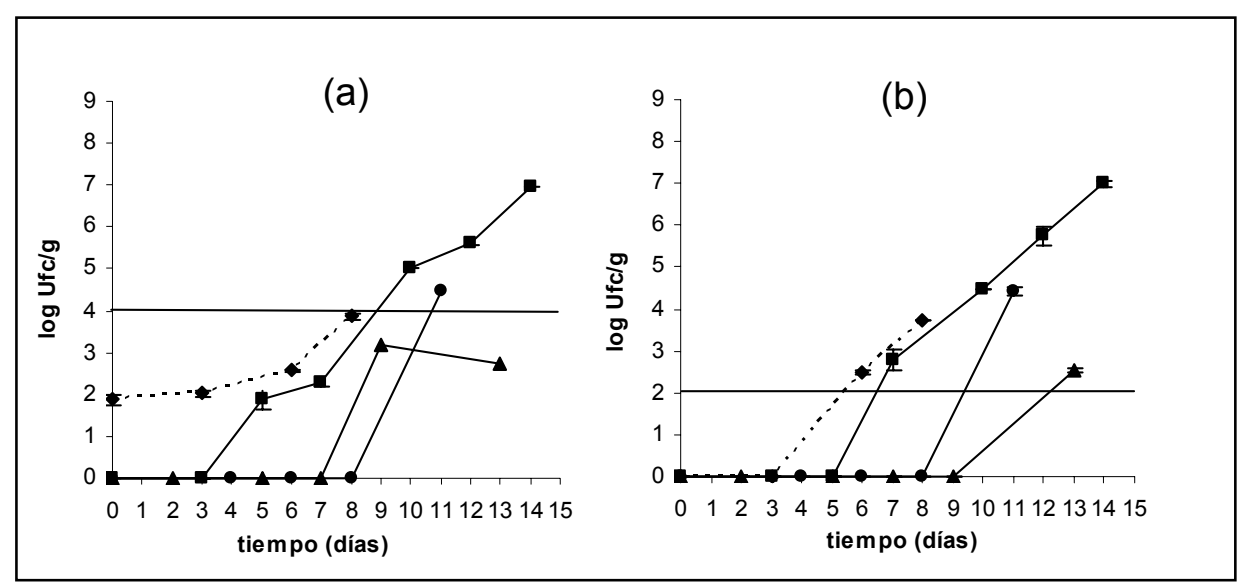

Figura III.11. Recuento de (a) viables totales y (b) mohos y levaduras, en pomelo fresco $(\diamond)$, pomelo deshidratado osmóticamente con SO sin reutilizar ( $(\mathbf{)})$ y reutilizada durante $3(\boldsymbol{\Delta})$ y $5(\bullet)$ ciclos de deshidratación, previo tratamiento térmico suave de la SO antes de cada ciclo.

La carga microbiana de las muestras PD1 (obtenidas con SO sin reutilizar), con y sin tratamiento térmico previo, fue similar, lo que indica la buena calidad microbiológica de la SO antes de su uso. Sin embargo, sí que se observa una mejora de la calidad microbiológica de la fruta por los tratamientos térmicos sucesivos aplicados a la disolución osmótica. El efecto acumulativo de los tratamientos térmicos de la SO en los diferentes ciclos de DO puede ser responsable de la mayor vida útil de las muestras PD3 y PD5. No obstante, la incorporación de fruta fresca nueva para cada ciclo de deshidratación parece contribuir con un 
incremento de la carga microbiana, de manera que la carga microbiana de las muestras PD5 es mayor que la de las PD3. Es decir, el efecto acumulativo de los tratamientos térmicos sucesivos parece verse contrarrestado por la mayor carga microbiana procedente de la fruta fresca introducida en cada ciclo.

En este sentido parece viable la reutilización de la SO siempre y cuando se le aplique un tratamiento térmico suave previo. El número de ciclos dependerá de la vida útil que se quiera dar a la fruta, aunque hay que recordar que en este caso, el límite microbiológico escogido no se corresponde con un deterioro legal ni visible en el pomelo deshidratado. De hecho, ninguna de las muestras presentó crecimiento microbiológico apreciable al final del estudio de almacenamiento.

Teniendo en cuenta estos resultados, el resto del estudio, cuyos resultados se comentan a continuación, se realizó aplicando el tratamiento térmico mencionado antes de cada ciclo de deshidratación.

\section{III.2.2.2. Efecto de la reutilización de la disolución osmótica y del almacenamiento en refrigeración en las propiedades del pomelo deshidratado}

\section{IIl.2.2.2.1. Efecto sobre la humedad, sólidos solubles y actividad del} agua

La tabla III.3 muestra los valores del contenido en agua $\left(\mathrm{x}_{\mathrm{w}}\right)$, sólidos solubles ( ${ }^{\circ}$ Brix) y actividad del agua $\left(\mathrm{a}_{\mathrm{w}}\right)$ analizados en el pomelo fresco y deshidratado con disolución osmótica sin reutilizar (PD1) y reutilizada durante 3 (PD3) y 5 (PD5) ciclos sucesivos de deshidratación, antes y después de su almacenamiento, a diferentes tiempos, en refrigeración $\left(10^{\circ} \mathrm{C}\right)$. 
Tabla III.3. Parámetros fisicoquímicos analizados en el pomelo fresco (PF) y pomelo deshidratado, con disolución osmótica sin reutilizar (PD1) y reutilizada durante 3 (PD3) y 5 (PD5) ciclos sucesivos de deshidratación, durante su almacenamiento $\left(10^{\circ} \mathrm{C}\right)$.

\begin{tabular}{|c|c|c|c|c|}
\hline Muestras & t(días) & $\begin{array}{c}X_{w} \\
\text { (g agua/100g) } \\
\end{array}$ & ${ }^{\circ}$ Brix & $a_{w}{ }^{(1)}$ \\
\hline \multirow{5}{*}{ PF } & 0 & $87,20 \pm 0,06^{(w)}$ & $12,27 \pm 0,06^{(w)}$ & 0,987 \\
\hline & 3 & $86,44 \pm 0,09^{(x)}$ & $13,53 \pm 0,06^{(x)}$ & 0,990 \\
\hline & 6 & $87,47 \pm 0,02^{(v)}$ & $12,0 \pm 0,0^{(v)}$ & 0,988 \\
\hline & 8 & $86,20 \pm 0,08^{(y)}$ & $13,77 \pm 0,06^{(y)}$ & 0,990 \\
\hline & 10 & $87,43 \pm 0,10^{(v)}$ & $12,07 \pm 0,06^{(v)}$ & 0,989 \\
\hline \multirow{5}{*}{ PD1 } & 0 & (a) $73,0 \pm 0,5^{\text {(y) }}$ & (a) $_{26,4} \pm 0,0^{(\mathrm{x})}$ & (b) $0,978^{(v)}$ \\
\hline & 3 & $76,14 \pm 0,06^{(v)}$ & $23,43 \pm 0,06^{(w)}$ & $0,981^{(w)(x)}$ \\
\hline & 6 & $76,53 \pm 0,07^{(v)}$ & $22,93 \pm 0,06^{(v)}$ & $0,980^{(v)(w)}$ \\
\hline & 8 & $73,89 \pm 0,15^{(x)}$ & $25,37 \pm 0,06^{(y)}$ & $0,979^{(v)(w)}$ \\
\hline & 10 & $75,02 \pm 0,12^{(w)}$ & $24,37 \pm 0,06^{(y)}$ & $0,983^{(x)}$ \\
\hline \multirow{5}{*}{ PD3 } & 0 & (c) $76,2 \pm 0,1^{(y)}$ & ${ }^{(\mathrm{c})} 23,17 \pm 0,06^{\text {(w) }}$ & ${ }^{(\mathrm{c})} 0,980^{(\mathrm{x})}$ \\
\hline & 3 & $75,8 \pm 0,1^{(\mathrm{x})}$ & $23,6 \pm 0,0^{(\mathrm{x})}$ & $0,972^{(v)}$ \\
\hline & 6 & $73,7 \pm 0,3^{(v)}$ & $25,47 \pm 0,06^{(z)}$ & $0,975^{(v)(w)}$ \\
\hline & 8 & $74,6 \pm 0,1^{(w)}$ & $24,6 \pm 0,0^{(y)}$ & $0,979^{(w)(x)}$ \\
\hline & 10 & $76,2 \pm 0,1^{(y)}$ & $23,07 \pm 0,06^{(v)}$ & $0,979^{(w)(x)}$ \\
\hline \multirow{5}{*}{ PD5 } & 0 & (b) $75,2 \pm 0,4^{\text {(v) }}$ & (b) $24,47 \pm 0,06^{\text {(z) }}$ & (a) $0,972^{\text {(v) }}$ \\
\hline & 4 & $75,1 \pm 0,2^{(v)}$ & $23,6 \pm 0,0^{(y)}$ & $0,978^{(w)}$ \\
\hline & 6 & $76,5 \pm 0,0^{(w)}$ & $23,0 \pm 0,0^{(\mathrm{x})}$ & $0,979^{(w)}$ \\
\hline & 8 & $77,3 \pm 0,1^{(\mathrm{x})}$ & $22,2 \pm 0,2^{(v)}$ & $0,980^{(w)}$ \\
\hline & 10 & $76,5 \pm 0,3^{(w)}$ & $22,73 \pm 0,06^{(w)}$ & $0,980^{(w)}$ \\
\hline
\end{tabular}

(1) La desviación standard fue, en todos los casos, menor que la sensibilidad del equipo $(0,003)$.

(a)(b)(c) Grupos homogéneos establecidos por el ANOVA $(\alpha<0,05)$ para los pomelos recién deshidratados con el factor ciclo de deshidratación.

$(v)(w)(x)(y)(z)$ Grupos homogéneos establecidos por el ANOVA $(\alpha<0,05)$ para cada PD con el factor tiempo de almacenamiento. 
El lote de fruta fresca empleado para el estudio presentó un valor de humedad (g agua/100g producto), ${ }^{\circ}$ Brix y $\mathrm{a}_{\mathrm{w}}$ de 87,20 \pm 0,06, 12,27 \pm 0,06 y $0,987 \pm 0,001$, respectivamente. Como consecuencia del tratamiento de deshidratación osmótica aplicado, la concentración en sólidos solubles de las muestras de pomelo aumentó, disminuyendo su $a_{w}$ y su contenido en agua, como era de esperar. Si se comparan estos resultados con los mostrados en el estudio cinético correspondientes a 180 min de tratamiento (Tabla III.1), puede observarse una buena reproducibilidad en cuanto al tratamiento osmótico, pues se alcanzan valores muy similares de humedad. El valor más diferente es el del PD1, que sin embargo resulta algo bajo si se tiene en cuenta su evolución con el almacenamiento. Por su parte, los ${ }^{\circ}$ Brix son algo superiores en todos los pomelos deshidratados, pero también el pomelo fresco de partida mostró mayor contenido en sólidos solubles. La $a_{w}$ fue del mismo orden en todos los casos.

Con el fin de evaluar el posible efecto de los cambios de composición de la SO, asociados a su reutilización, en la transferencia de agua y solutos durante el proceso de deshidratación, se realizó un ANOVA $(\alpha<0,05)$ para comparar las distintas muestras deshidratadas a tiempo 0 de almacenamiento en refrigeración. Los grupos homogéneos ( $a, b, c)$ establecidos por el ANOVA, considerando como factor el número de ciclos de reutilización de la $\mathrm{SO}$, aparecen en la tabla III.3.

Las muestras deshidratadas con la SO sin reutilizar presentaron un valor de $x_{w}$ significativamente menor $y$ un valor de ${ }^{\circ}$ Brix significativamente mayor que las muestras deshidratadas con disolución reutilizada. No obstante, como ya se ha comentado, estos valores hay que considerarlos con precaución comparados con el resto de datos mostrados en la tabla III.3. Por otra parte, las muestras PD5 presentaron un nivel de deshidratación significativamente mayor a las 
PD3, lo que no parece coherente con los cambios composicionales de la SO que presenta una concentración de solutos inicial de 55,05 \pm 0,07 ${ }^{\circ}$ Brix y se va diluyendo progresivamente hasta alcanzar un valor de $51,85 \pm 0,07^{\circ}$ Brix después de 5 ciclos de deshidratación (Figura III.12). Por todo lo anterior, parece que las diferencias observadas podrían ser atribuidas más bien a la variabilidad propia de la muestra que al efecto de la dilución de la SO.

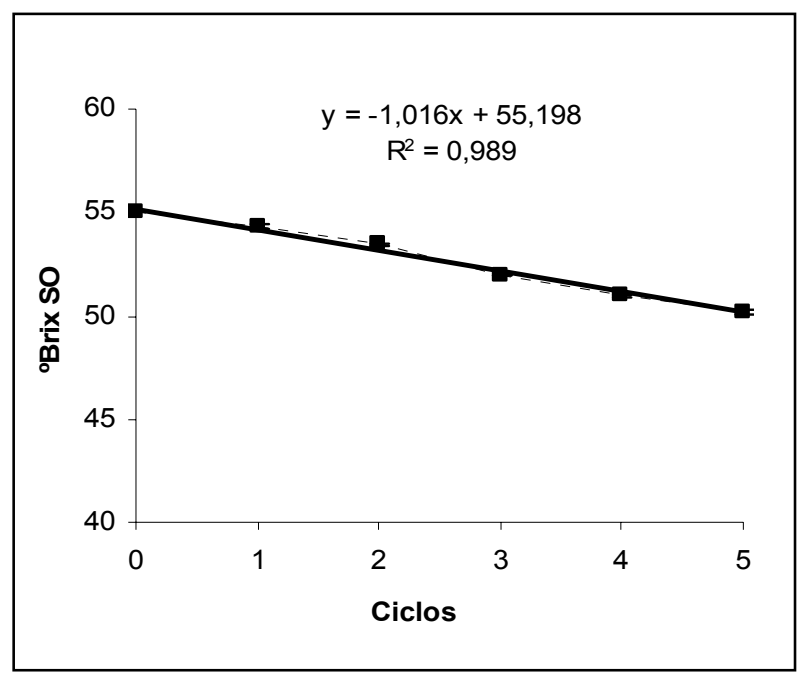

Figura III.12. Valores medios de ${ }^{\circ}$ Brix de la SO en función del número de ciclos de deshidratación.

Desde este punto de vista, parece viable la reutilización de la disolución osmótica durante 5 ciclos de deshidratación, lo que concuerda con los resultados obtenidos por otros autores al reutilizar la SO durante la deshidratación osmótica de kiwi, piña y pomelo en condiciones experimentales similares (García-Martínez et al., 2002a; Peiró et al., 2006; Peiró-Mena et al., 2007a). 
Durante el período de almacenamiento, se observaron cambios significativos en todos los parámetros fisicoquímicos analizados (Tabla III.3). Sin embargo, no se observó una clara tendencia de los mismos con el tiempo, por lo que nuevamente las diferencias parecen más asociarse a la variabilidad propia de la fruta que a un efecto del almacenamiento.

\section{IIl.2.2.2.2. Efecto sobre la acidez, pH y ácido ascórbico}

El tratamiento de deshidratación también implicó un descenso significativo $(\alpha<0,05)$ en la acidez de las muestras, expresada como contenido en ácido cítrico (AC), por ser éste el ácido mayoritario en el pomelo. En la tabla III.4 aparecen los resultados en dos bases de cálculo diferentes. Por un lado se muestran los mg de AC por cada 100 $\mathrm{g}$ de muestra (fresca o deshidratada). Por otro lado, en el caso de la fruta deshidratada, los resultados se expresaron además por cada $100 \mathrm{~g}$ de fruta fresca de partida, para hacer los valores comparables y, a su vez, poder calcular las pérdidas ocasionadas durante los tratamientos de deshidratación expresadas en mg de AC perdidos por cada $100 \mathrm{mg}$ de AC presente en el pomelo fresco de partida.

Las pérdidas en AC resultaron ser menores en las muestras deshidratadas con SO reutilizada, observándose un efecto del número de ciclos, lo que podría ser debido probablemente al enriquecimiento de la SO en ácidos naturales procedentes de la fruta en los sucesivos ciclos de deshidratación.

Durante el período de almacenamiento, se observaron cambios significativos en los parámetros de acidez y pH (Tablas III.4 y III.5, respectivamente). Así, el pomelo fresco presentó una ligera pérdida de la acidez así como un ligero aumento de $\mathrm{pH}$ durante el almacenamiento. 
Tabla III.4. Contenido en ácido cítrico (AC), expresado como mg AC/

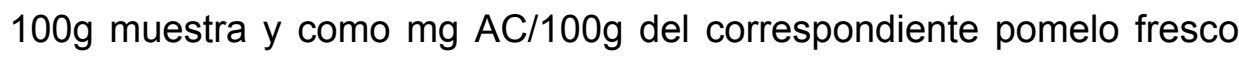
(PF) de partida, analizado en el pomelo fresco (PF) y pomelo deshidratado con disolución osmótica sin reutilizar (PD1) y reutilizada durante 3 (PD3) y 5 (PD5) ciclos sucesivos de deshidratación. Evolución durante su almacenamiento $\left(10^{\circ} \mathrm{C}\right)$.

\begin{tabular}{|c|c|c|c|c|c|}
\hline Muestras & t(días) & $\mathrm{mgAC} / 100 \mathrm{gPD}$ & $\mathrm{mgAC} / 100 \mathrm{gPF}$ & $\left.\Delta \mathrm{AC}_{\text {tratamiento }}{ }^{*}\right)$ & $\Delta \mathrm{AC}_{\text {almacen. }}{ }^{\left({ }^{*}\right)}$ \\
\hline \multirow{5}{*}{ PF } & 0 & - & $1,346 \pm 0,006^{(w)}$ & - & - \\
\hline & 3 & - & $1,13 \pm 0,02^{(\mathrm{x})}$ & - & $-15,90$ \\
\hline & 6 & - & $0,92 \pm 0,03^{(y)}$ & - & $-32,02$ \\
\hline & 8 & - & $0,874 \pm 0,016^{(z)}$ & - & $-35,05$ \\
\hline & 10 & - & $0,94 \pm 0,03^{(y)}$ & - & $-29,95$ \\
\hline \multirow{5}{*}{ PD1 } & 0 & (a) $1,01 \pm 0,02$ & ${ }^{(a)} 0,89 \pm 0,02^{(y)}$ & $-33,95$ & - \\
\hline & 3 & $1,12 \pm 0,15$ & $0,99 \pm 0,13^{(x)(y)}$ & - & - \\
\hline & 6 & $1,365 \pm 0,015$ & $1,203 \pm 0,013^{(\mathrm{w})}$ & - & - \\
\hline & 8 & $1,209 \pm 0,015$ & $1,065 \pm 0,014^{(x)}$ & - & - \\
\hline & 10 & $0,802 \pm 0,014$ & $0,707 \pm 0,012^{(z)}$ & - & - \\
\hline \multirow{5}{*}{ PD3 } & 0 & (b) $1,100 \pm 0,001$ & ${ }^{(b)} 0,985 \pm 0,007^{(w)}$ & $-26,84$ & - \\
\hline & 3 & $1,10 \pm 0,01$ & $0,9817 \pm 0,0099^{(w)}$ & - & $-0,32$ \\
\hline & 6 & $1,001 \pm 0,009$ & $0,897 \pm 0,008^{(y)}$ & - & $-8,95$ \\
\hline & 8 & $1,06 \pm 0,01$ & $0,946 \pm 0,013^{(x)}$ & - & $-3,94$ \\
\hline & 10 & $1,08 \pm 0,02$ & $0,97 \pm 0,02^{(w)}$ & - & $-1,73$ \\
\hline \multirow{5}{*}{ PD5 } & 0 & (c) $1,14 \pm 0,04$ & (c) $1,03 \pm 0,04^{(w)}$ & $-23,46$ & - \\
\hline & 3 & $0,905 \pm 0,007$ & $0,816 \pm 0,007^{(z)}$ & - & $-20,77$ \\
\hline & 6 & $1,037 \pm 0,008$ & $0,935 \pm 0,007^{(y)}$ & - & $-9,20$ \\
\hline & 8 & $1,080 \pm 0,005$ & $0,974 \pm 0,005^{(\mathrm{x})}$ & - & $-5,42$ \\
\hline & 10 & $1,04 \pm 0,03$ & $0,94 \pm 0,02^{(x)(y)}$ & - & $-8,60$ \\
\hline
\end{tabular}

$\left.{ }^{*}\right)$ Porcentaje de pérdidas de AC por efecto del tratamiento o almacenamiento con respecto al tiempo cero, expresado en $\mathrm{mg} \mathrm{AC}$ perdidos/100mg AC inicial.

(a)(b)(c) Grupos homogéneos establecidos por el ANOVA $(\alpha<0,05)$ con el factor ciclo de deshidratación.

$(w)(x)(y)(z)$ Grupos homogéneos establecidos por el ANOVA $(\alpha<0,05)$ con el factor tiempo de almacenamiento.

Las pérdidas de AC ocasionadas durante el almacenamiento fueron, en general, inferiores en las muestras deshidratadas, aunque si se 
considera en conjunto el efecto del tratamiento y del almacenamiento, son pérdidas del mismo orden que las del pomelo fresco al final del período de almacenamiento considerado. Los datos de almacenamiento de las muestras PD1 no se consideraron pues se vieron afectados por un error experimental.

Tabla III.5. Valores de pH analizado en el pomelo fresco (PF) y pomelo deshidratado, con disolución osmótica sin reutilizar (PD1) y reutilizada durante 3 (PD3) y 5 (PD5) ciclos sucesivos de deshidratación. Evolución durante su almacenamiento $\left(10^{\circ} \mathrm{C}\right)$.

\begin{tabular}{ccccc}
\hline t(días) & PF & PD1 & PD3 & PD5 \\
\hline 0 & $3,223 \pm 0,015^{(\mathrm{v})}$ & ${ }^{(\mathrm{a})} 3,137 \pm 0,006^{(\mathrm{v})}$ & ${ }^{(\mathrm{c})} 2,77 \pm 0,06^{(\mathrm{v})}$ & ${ }^{(\mathrm{b})} 2,83 \pm 0,06^{(\mathrm{v})}$ \\
3 & $3,247 \pm 0,006^{(\mathrm{w})}$ & $3,17 \pm 0,04^{(\mathrm{w})}$ & $3,27 \pm 0,06^{(\mathrm{x})}$ & $3,33 \pm 0,06^{(\mathrm{x})}$ \\
6 & $3,337 \pm 0,010^{(\mathrm{x})}$ & $3,20 \pm 0,01^{(\mathrm{w})}$ & $3,33 \pm 0,06^{(\mathrm{x})(\mathrm{w})}$ & $3,4 \pm 0,2^{(\mathrm{x})}$ \\
8 & $3,497 \pm 0,006^{(\mathrm{y})}$ & $3,273 \pm 0,006^{(\mathrm{x})}$ & $3,37 \pm 0,06^{(\mathrm{y})}$ & $2,9 \pm 0,0^{(\mathrm{v})}$ \\
10 & $3,503 \pm 0,006^{(\mathrm{y})}$ & $3,357 \pm 0,006^{(\mathrm{y})}$ & $2,90 \pm 0,00^{(\mathrm{w})}$ & $3,1 \pm 0,1^{(\mathrm{w})}$ \\
\hline
\end{tabular}

(a)(b)(c) Grupos homogéneos establecidos por el ANOVA $(\alpha<0,05)$ con el factor ciclo de deshidratación.

$(v)(w)(x)(y)$ Grupos homogéneos establecidos por el ANOVA $(\alpha<0,05)$ con el factor tiempo de almacenamiento.

En relación a los resultados obtenidos para el ácido ascórbico (AA), la tabla III.6 muestra los valores, expresados en las dos bases de cálculo consideradas para el AC, presentes en las muestras analizadas. Los diferentes lotes de pomelos frescos empleados presentaron una concentración en AA similar a la encontrada por otros autores (Gorinstein et al., 2004), apreciándose diferencias significativas $(\alpha<0,05)$ en función del lote como consecuencia de la variabilidad natural de la fruta. 
Tabla III.6. Contenido en ácido ascórbico (AA), expresado como mg AA/ $100 \mathrm{~g}$ muestra y como mg AA/100g PF de partida, analizado en el pomelo fresco (PF) y pomelo deshidratado, con disolución osmótica sin reutilizar (PD1) y reutilizada durante 3 (PD3) y 5 (PD5) ciclos sucesivos de deshidratación, durante su almacenamiento $\left(10^{\circ} \mathrm{C}\right)$.

\begin{tabular}{|c|c|c|c|c|c|}
\hline Muestras & t(días) & mgAA/100gPD & mgAA/100gPF & $\Delta \mathbf{A A}_{\text {tratamiento }}{ }^{(*)}$ & $\Delta \mathrm{AA}_{\text {almacen. }^{(*)}}{ }^{(*)}$ \\
\hline & 0 & - & $30,1 \pm 1,7^{(v)}$ & - & - \\
\hline \multirow[t]{3}{*}{ PF } & 1 & - & $14,9 \pm 0,7^{(x)}$ & - & $-50,67$ \\
\hline & 3 & - & $15 \pm 0^{(w)(x)}$ & - & $-48,00$ \\
\hline & 6 & - & $16,5 \pm 0,7^{(w)}$ & - & $-45,33$ \\
\hline \multirow[t]{3}{*}{ PF1 } & 0 & - & $31 \pm 5$ & - & - \\
\hline & 0 & (b) $27,2 \pm 1,3$ & $23,52 \pm 1,15^{(v)}$ & $-23,59$ & - \\
\hline & 3 & $20,5 \pm 1,7$ & $17,8 \pm 1,5^{(\mathrm{x})}$ & - & $-24,44$ \\
\hline \multirow[t]{4}{*}{ PD1 } & 6 & $21,4 \pm 1,2$ & $18,51 \pm 1,05^{(\mathrm{x})}$ & - & $-21,29$ \\
\hline & 8 & $24,31 \pm 0,98$ & $21 \pm 0,9^{(w)}$ & - & $-10,55$ \\
\hline & 10 & $14,8 \pm 0,8$ & $12,8 \pm 0,7^{(y)}$ & - & $-45,48$ \\
\hline & 12 & $13,0 \pm 0,8$ & $11,2 \pm 0,7^{(y)}$ & - & $-52,29$ \\
\hline \multirow[t]{3}{*}{ PF3 } & 0 & - & $42 \pm 3$ & - & - \\
\hline & 0 & (a) $34,40 \pm 1,08$ & $26,2 \pm 0,8^{(v)}$ & $-36,94$ & - \\
\hline & 3 & $23,41 \pm 0,99$ & $17,9 \pm 0,8^{(x)}$ & - & $-31,94$ \\
\hline \multirow[t]{4}{*}{ PD3 } & 6 & $23,1 \pm 1,2$ & $17,6 \pm 0,9^{(x)}$ & - & $-32,77$ \\
\hline & 8 & $27,12 \pm 0,98$ & $20,7 \pm 0,8^{(w)}$ & - & $-21,17$ \\
\hline & 10 & $20,4 \pm 0,8$ & $15,6 \pm 0,6^{(y)}$ & - & $-40,71$ \\
\hline & 12 & $16,7 \pm 1,4$ & $12,73 \pm 1,06^{(z)}$ & - & $-51,49$ \\
\hline \multirow[t]{3}{*}{ PF5 } & 0 & - & $38 \pm 4$ & - & - \\
\hline & 0 & (b) $25,79 \pm 1,09$ & $21,8 \pm 0,9^{(v)(w)}$ & $-43,20$ & - \\
\hline & 3 & $24,1 \pm 0,0$ & $20,4 \pm 0,0^{(w)(x)}$ & - & $-6,47$ \\
\hline \multirow[t]{4}{*}{ PD5 } & 6 & $266 \pm 0,0$ & $22,5 \pm 0,0^{(v)}$ & - & 3,04 \\
\hline & 8 & $22,4 \pm 1,4$ & $18,9 \pm 1,2^{(x)}$ & - & $-13,23$ \\
\hline & 10 & - & - & - & - \\
\hline & 12 & $17,2 \pm 0,8$ & $14,6 \pm 0,7^{(y)}$ & - & $-33,11$ \\
\hline
\end{tabular}

$\left(^{*}\right)$ Porcentaje de pérdidas de AA por efecto del tratamiento o almacenamiento, expresado en mg AA perdidos/ 100mg AA inicial.

(a)(b) Grupos homogéneos establecidos por el ANOVA $(\alpha<0,05)$ con el factor ciclo de deshidratación.

$(v)(w)(x)(y)(z)$ Grupos homogéneos establecidos por el ANOVA $(\alpha<0,05)$ con el factor tiempo de almacenamiento. 
Durante las primeras 24 horas de almacenamiento en refrigeración, las muestras frescas presentaron una pérdida importante de su contenido en ácido ascórbico (50,67 mg AA perdido/100 mg AA presente en la fruta fresca), manteniéndose constante desde el primer hasta el sexto día de almacenamiento. Otros estudios, como los realizados por Del Caro et al. (2004), muestran una disminución significativa en el contenido en AA analizado en los segmentos cítricos de mandarina y naranja durante su almacenamiento a $4^{\circ} \mathrm{C}$. Sin embargo, en zumos de pomelo de la variedad Red Blush no se encontraron diferencias significativas a lo largo de 15 días de almacenamiento a la misma temperatura $\left(4^{\circ} \mathrm{C}\right)$.

En todos los casos, el tratamiento osmótico produjo pérdidas significativas en el contenido en AA de las muestras y un descenso adicional del mismo durante su almacenamiento, especialmente a partir de los 8 días. Para explicar estas pérdidas se pueden considerar dos mecanismos independientes (Vial et al., 1991): pérdidas por difusión desde el tejido de la fruta a la SO durante la deshidratación y pérdidas debidas a la degradación química del compuesto durante su procesado y almacenamiento.

El mecanismo de reacción de descomposición del ácido ascórbico en alimentos ha sido ampliamente estudiado (Tannenbaum, 1979; Liao y Seib, 1987). Cuando hay oxigeno presente, la degradación de AA ocurre simultáneamente por mecanismos de oxidación y degradación anaeróbica, siendo el primero más rápido que el segundo (Rojas y Gerschenson, 2001). La degradación oxidativa del AA está relacionada con la actividad ascorbinasa y con la degradación indirecta por la polifenoloxidasa, citocromoxidasa y la actividad peroxidasa (Lee y Kader, 2000). Durante las dos primeras semanas de almacenamiento, se puede suponer que el efecto predominante es la oxidación del AA a 
ácido L-dehidroascórbico (DHA), con una velocidad de degradación mayor, y a partir de las dos semanas la degradación anaerobia es predominante y define la velocidad de pérdida (Wong et al., 1992). El tiempo de almacenamiento considerado en este estudio haría pensar principalmente en la primera vía.

$\mathrm{Si}$ se comparan las pérdidas de $\mathrm{AA}$ ocurridas en el pomelo deshidratado por efecto de la deshidratación y del almacenamiento en refrigeración durante 6 días, éstas son del mismo orden que las ocurridas en el producto fresco almacenado el mismo tiempo, como ocurría también con el AC.

Por su parte, el contenido en AA de la SO aumenta ligeramente hasta el tercer ciclo de reutilización manteniéndose constante posteriormente hasta el quinto ciclo (Figura III.13). Por lo tanto, al menos una parte del AA perdido por el pomelo durante el procesado osmótico queda incorporado a la SO.

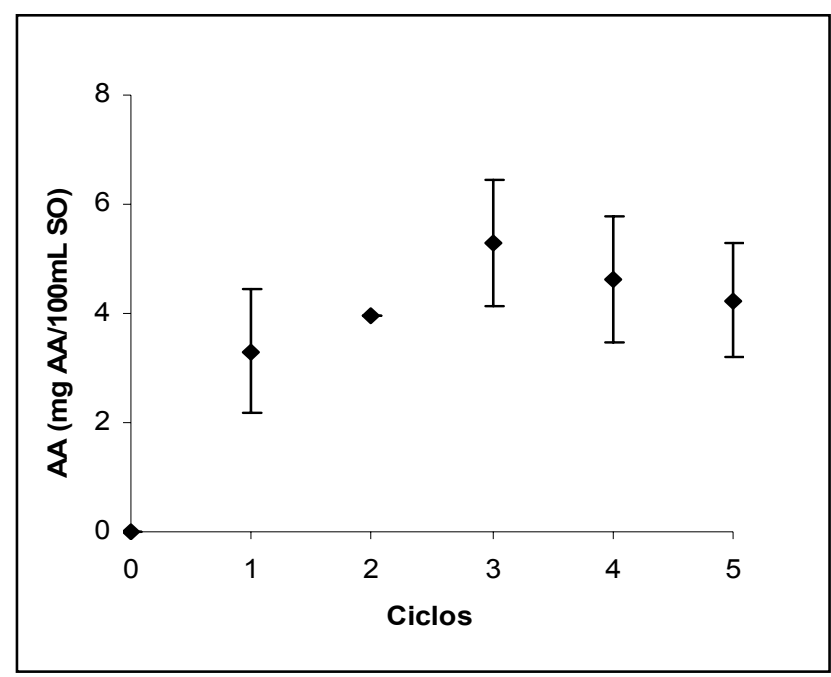

Figura III.13. Contenido en AA de la $\mathrm{SO}$ en función del número de ciclos de deshidratación. 


\section{III.2.2.2.3. Efecto sobre el contenido en cationes}

Tal y como se explica en el apartado III.1.3.7 de materiales y métodos, se analizó el contenido de $\mathrm{Ca}^{2+}$ y del resto de cationes mayoritarios como el $\mathrm{Na}^{+}, \mathrm{Mg}^{2+}$ y $\mathrm{K}^{+}$presentes en el pomelo antes y después del tratamiento de deshidratación, reutilizando la SO durante 1 , 3 y 5 ciclos (Tabla III.7). El análisis de los cromatogramas obtenidos nos permitió conocer el contenido de los distintos cationes en cada una de las muestras estudiadas. Para comparar mejor los resultados obtenidos, los datos aparecen referidos tanto por cada $100 \mathrm{~g}$ de muestra final como por cada $100 \mathrm{~g}$ de muestra fresca de partida.

Tabla III.7. Contenido en cationes de pomelo fresco (PF) y deshidratado después de 1 (PD1), 3 (PD3) y 5 (PD5) ciclos de deshidratación y porcentaje de pérdida de cada mineral.

\begin{tabular}{|c|c|c|c|c|}
\hline Muestras & $\mathrm{Ca}^{2+}$ & $\mathrm{Na}^{+}$ & $\mathrm{Mg}^{2+}$ & $\mathrm{K}^{+}$ \\
\hline $\mathbf{P F}^{\mathrm{a}}$ & $17,6 \pm 0,8^{(\mathrm{x})}$ & $1,5 \pm 0,7^{(\mathrm{x})}$ & $15,5 \pm 0,8^{(x)}$ & $158 \pm 3^{(x)}$ \\
\hline PD1 $^{a}$ & $11,6 \pm 0,4^{(y)}$ & $1,3 \pm 1,9^{(x)}$ & $8,7 \pm 0,2^{(y)}$ & $85,5 \pm 0,3^{(y)}$ \\
\hline $\mathrm{PD}^{\mathrm{b}}$ & $13,1 \pm 0,5$ & $1,9 \pm 1,6$ & $9,8 \pm 0,3$ & $97,0 \pm 0,3$ \\
\hline Pérdidas $^{c}$ & $-34,19$ & $-10,74$ & $-44,10$ & $-46,01$ \\
\hline $\mathrm{PD}^{\mathrm{a}}$ & $11,1 \pm 0,2^{(y)}$ & $1,39 \pm 0,02^{(x)}$ & $10,7 \pm 0,9^{(y)}$ & $85 \pm 6^{(y)}$ \\
\hline PD3 $^{b}$ & $12,4 \pm 0,2$ & $1,55 \pm 0,02$ & $12,0 \pm 1,1$ & $95 \pm 7$ \\
\hline Pérdidas $^{c}$ & $-37,03$ & $-6,62$ & $-31,01$ & $-46,54$ \\
\hline PD5 $^{a}$ & $12,8 \pm 0,9^{(y)}$ & $1,457 \pm 0,014^{(\mathrm{x})}$ & $10,3 \pm 0,9^{(y)}$ & $93 \pm 5^{(y)}$ \\
\hline $\mathrm{PD5}^{\mathrm{b}}$ & $14,2 \pm 1,1$ & $1,62 \pm 0,02$ & $11,36 \pm 1,08$ & $104 \pm 6$ \\
\hline Pérdidas $^{c}$ & $-27,36$ & $-1,77$ & $-33,94$ & $-40,98$ \\
\hline \multicolumn{5}{|c|}{$\begin{array}{l}{ }^{a} \mathrm{mg} \text { mineral/ } 100 \mathrm{~g} \text { muestra fresca } \\
{ }^{\mathrm{b}} \mathrm{mg} \text { mineral/ } 100 \mathrm{~g} \text { muestra deshidratada } \\
{ }^{\mathrm{c}} \mathrm{mg} \text { mineral perdido / } 100 \mathrm{mg} \text { mineral muestra fresca. Calculado como } 100 \cdot\left(\mathrm{PD}^{\mathrm{a}}-\mathrm{PF}^{\mathrm{a}}\right) / \mathrm{PF}^{\mathrm{a}} \\
\text { (x)(y) Grupos homogéneos establecidos por el ANOVA }(\alpha<0,05) .\end{array}$} \\
\hline
\end{tabular}


El valor del contenido en calcio, sodio, magnesio y potasio de las muestras de pomelo fresco y deshidratado fueron similares a los encontrados por otros autores (Mataix, 1998; Peiró et al., 2006). Como podemos observar, el valor del potasio del pomelo fresco es casi diez veces mayor que el valor del calcio, siendo el mineral más abundante, como ocurre en la mayoría de las frutas.

El tratamiento de deshidratación osmótica aplicado ocasionó pérdidas en todos los cationes analizados en la fruta deshidratada, tal y como ha sido descrito previamente por otros autores en diferentes frutas (Peiró et al., 2006; Peiró-Mena et al., 2007a). Sin embargo no resultaron significativas en el caso del $\mathrm{Na}^{+}$.

Aunque en general las pérdidas parecen ser menores al deshidratar la fruta con disolución osmótica reutilizada, no se observaron diferencias significativas en el contenido de cationes de las muestras deshidratadas en función del ciclo.

En cuanto al contenido en cationes de la SO (Tabla III.8) se observó la presencia de todos ellos, aunque ésta sólo fue más importante en el caso del catión mayoritario del pomelo, el potasio. Para él se observó un aumento lineal en su concentración con la reutilización de la $\mathrm{SO}$, siguiendo la ecuación: $y=2,2575 x+1,6808, R^{2}=0,9993$. Para el resto de cationes, salvo en el caso del $\mathrm{Mg}^{2+}$, el aumento no resultó significativo, debido probablemente a la baja concentración presente en la SO. 
Tabla III.8. Contenido en cationes de la disolución osmótica ( $\mathrm{mg} / 100 \mathrm{~g} \mathrm{SO}$ ) después de 1,3 y 5 ciclos de deshidratación.

\begin{tabular}{ccccc}
\hline Ciclos & $\mathbf{C a}^{\mathbf{2 +}^{\mathbf{}}}$ & $\mathbf{N a}^{+}$ & $\mathbf{K}^{+}$ & $\mathbf{M g}^{\mathbf{2 +}}$ \\
\hline $\mathbf{1}$ & $3,9 \pm 1,2^{(\mathrm{a})}$ & $1,1 \pm 0,4^{(\mathrm{a})}$ & $3,87 \pm 1,05^{(\mathrm{a})}$ & $0,13 \pm 0,12^{(\mathrm{a})}$ \\
$\mathbf{3}$ & $3,1 \pm 0,3^{(\mathrm{a})}$ & $0,9 \pm 0,2^{(\mathrm{a})}$ & $8,59 \pm 0,05^{(\mathrm{a})(\mathrm{b})}$ & $1,0 \pm 0,3^{(\mathrm{b})}$ \\
$\mathbf{5}$ & $5 \pm 2^{(\mathrm{a})}$ & $1,08 \pm 0,07^{(\mathrm{a})}$ & $12,9 \pm 0,6^{(\mathrm{b})}$ & $1,2 \pm 0,2^{(\mathrm{b})}$ \\
\hline
\end{tabular}

(a)(b) Grupos homogéneos establecidos por el ANOVA $(\alpha<0,05)$.

\section{III.2.2.2.4. Efecto sobre la tasa respiratoria}

Como indicador de las alteraciones fisiológicas ocasionadas por el efecto del corte y de los tratamientos de deshidratación estudiados, se utilizó la evolución de la tasa respiratoria (TR) de la fruta a lo largo del almacenamiento de la fruta a $10^{\circ} \mathrm{C}$ durante 6 días. Ésta se midió, tal y como se describe en el apartado III.1.3.11 de materiales y métodos, en el espacio de cabeza de los envases contenedores de las muestras, a partir de la obtención de los datos de concentración de oxígeno y anhídrido carbónico. En la figura III.14 se representa la TR de $\mathrm{CO}_{2}$ de las muestras de pomelo fresco y deshidratado después de 1,3 y 5 ciclos sucesivos de DO.

Durante el almacenamiento de frutos climatéricos se produce un incremento muy elevado en la producción de $\mathrm{CO}_{2}$ y etanol. Sin embargo, en frutos no climatéricos, como es el caso del pomelo, este aumento no es tan acusado y sólo se produce un aumento ligero de la respiración por la llegada de la senescencia. No obstante, si se produce una herida severa (como en este caso el corte), se llega a un estrés que induce a la producción de $\mathrm{CO}_{2}$ y en algunos casos también de etanol (Taiz y Zeiger, 1991; Brecht, 1995). 


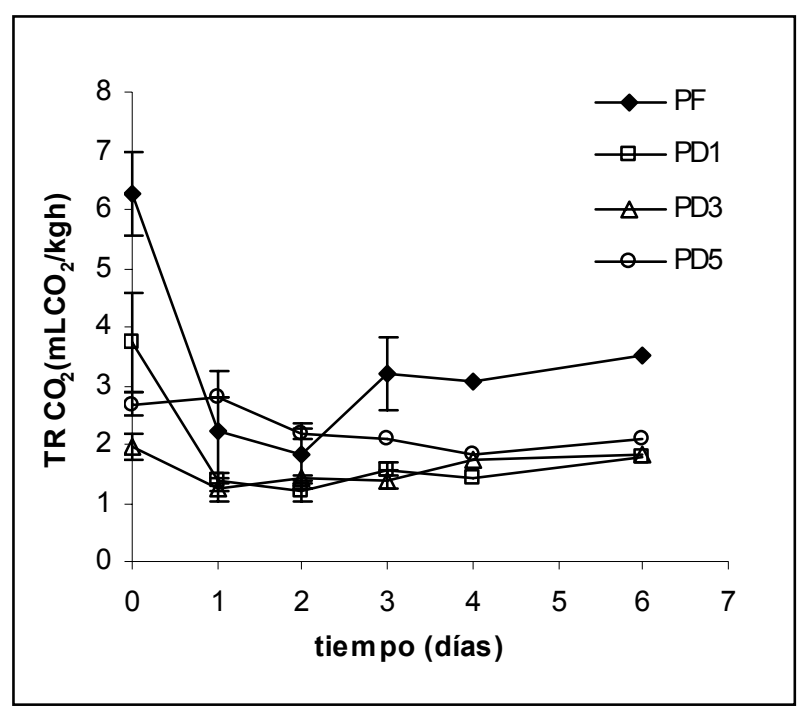

Figura III.14. Tasa respiratoria, expresada como $\mathrm{mL} \quad \mathrm{CO}_{2}$ producido/kg.h, del pomelo fresco (PF) y pomelo deshidratado osmóticamente con SO sin reutilizar (PD1) y reutilizada durante 3 (PD3) y 5 (PD5) ciclos de deshidratación y su evolución durante el almacenamiento de las muestras a $10^{\circ} \mathrm{C}$.

Esto se ve reflejado en la evolución de la $\mathrm{TR}$ de $\mathrm{CO}_{2}$ de las muestras de pomelo fresco (Figura III.14), que presenta un valor inicial elevado, probablemente como respuesta al estrés generado por el corte, y una posterior reducción en los primeros días de almacenamiento, aumentando a partir del tercer día, como consecuencia de la llegada de la senescencia de la fruta. En el caso del pomelo deshidratado con disolución osmótica sin reutilizar (PD1), éste también presentó una producción de $\mathrm{CO}_{2}$ a tiempo cero alta, aunque no tanto como el pomelo fresco. Resultados similares se recogen en otros trabajos realizados con fresa y manzana y se explican en base a un estrés fermentativo en las primeras horas posteriores al tratamiento de corte y deshidratación 
después de un ciclo de deshidratación osmótica (Castelló et al., 2005). Dicho efecto no se observó en la fruta deshidratada con la SO reutilizada durante 3 y 5 ciclos sucesivos de deshidratación. Esta aparente ausencia de procesos fermentativos podría estar relacionado con la mayor vida útil microbiológica de estas muestras.

El efecto de diferentes tratamientos de deshidratación osmótica sobre la pauta respiratoria de frutas ha sido ampliamente estudiado y se explica en base a la alteración de las células como consecuencia del daño estructural que la deshidratación provoca en las células más próximas a la superficie del corte, así como a la presencia de perfiles de concentración que dan lugar a perfiles de alteración fisiológica (Ceballos, 2006; Castelló, 2007; Torres, 2007). En función de la intensidad del tratamiento osmótico y la aplicación o no de presiones subatmosféricas el número de células alteradas o no viables será diferente. Las células alteradas presentarán pautas respiratorias diferentes debido al estrés inducido, mientras que las no viables no presentarán actividad respiratoria (Ceballos, 2006).

En nuestro estudio, el tratamiento de deshidratación aplicado dio lugar a una reducción de la TR de $\mathrm{CO}_{2}$ que se mantuvo durante el almacenamiento en refrigeración. Esta reducción en la actividad respiratoria de las muestras sería consecuencia del efecto de la deshidratación osmótica, que puede producir la plasmólisis en las células próximas a la disolución o incluso la rotura de la membrana plasmática generando la muerte celular. Esta reducción del número de células viables en el conjunto de la muestra produce una reducción del flujo neto de los gases de generación y degeneración celular, lo que podría estar relacionado con el aumento en la vida útil de las muestras deshidratadas. En ese sentido, las muestras PD3, con menor actividad 
respiratoria que las PD5, presentaron a su vez mayor vida útil microbiológica.

\section{III.2.3. Optimización de la formulación de un producto gelificado empleando tratamientos osmóticos. Efecto del almacenamiento en refrigeración}

\section{III.2.3.1. Estudio previo}

En lo que se refiere a la formulación del producto gelificado con pomelo objeto de este estudio, estudios previos ponen de manifiesto la necesidad de equilibrar la fruta deshidratada con el gel desde un punto de vista termodinámico, a fin de evitar la transferencia de agua entre ambos durante el almacenamiento. No obstante, cabría la posibilidad de formular el producto gelificado con fruta fresca y un gel de menor $a_{w}$, de manera que la deshidratación ocurriera en la propia matriz gelificada. La viabilidad de este proceso requeriría que la estabilidad composicional del producto se alcanzara a un tiempo razonable de almacenamiento, previo al consumo del mismo. En este sentido, se programaron diferentes formulaciones, unas con pomelo fresco (PF) y otras con pomelo deshidratado (PDO), utilizando como medio gelificante la disolución osmótica de $55^{\circ}$ Brix (G55), la obtenida después de 5 ciclos de deshidratación ( $\sim 50^{\circ}$ Brix, G50) y una equilibrada a la misma $a_{w}$ que el pomelo deshidratado ( $30^{\circ}$ Brix, G30).

La figura III.15 muestra la evolución de la $a_{w}$ de la fruta y el gel, para los cuatro sistemas, en función del tiempo. La condición de equilibrio en operaciones de deshidratación osmótica se establece en términos de igualdad de la actividad del agua del producto y del agente osmótico (Barat et al.,1998). En este sentido, cuanto mayor sea la diferencia entre 
la actividad del agua del gel y de la fruta mayor será la fuerza impulsora para la transferencia de materia.

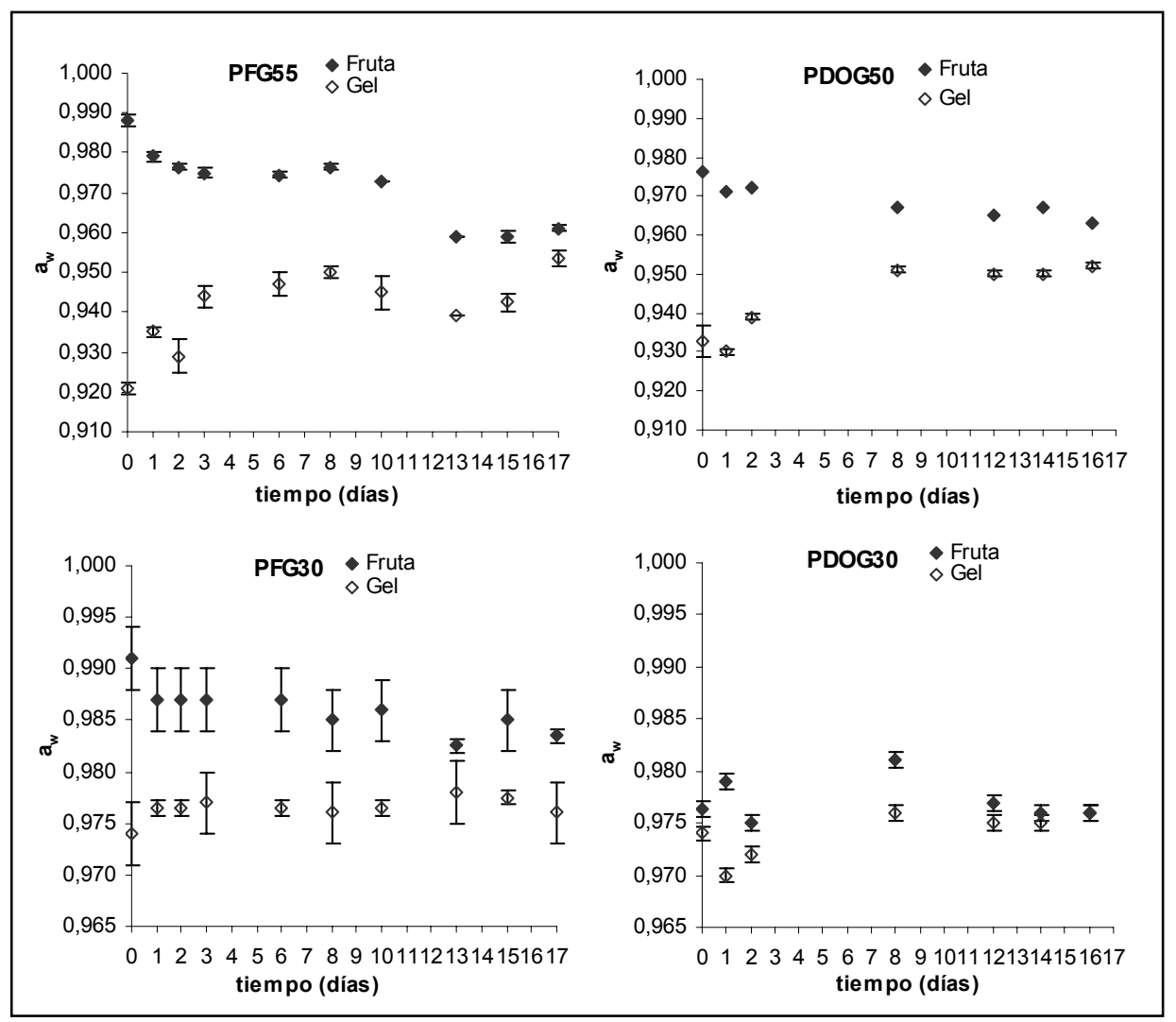

Figura III.15. Evolución de la $a_{w}$ de la fruta y del gel en los cuatro sistemas estudiados: PFG55 y PFG30 (pomelo fresco en gel de 55 y 30 'Brix, respectivamente), PDOG50 y PDOG30 (pomelo deshidratado en gel de 50 y $30^{\circ}$ Brix, respectivamente).

En la figura III.15 se observa la diferencia en cuanto a fuerzas impulsoras donde se puede ver que el sistema más alejado del 
equilibrio es el PFG55, seguido de PDOG50 y PFG30 y por último PDOG30.

Las tablas III.9 y III.10 muestran la fracción másica de agua y solutos tanto de la fruta como del gel en los sistemas gelificados PFG55 y PDOG50, respectivamente, para cada tiempo de almacenamiento en refrigeración a $10^{\circ} \mathrm{C}$.

Tabla III.9. Fracción másica de agua y solutos de la fruta y del gel para el sistema PFG55 a cada tiempo de almacenamiento a $10^{\circ} \mathrm{C}$.

\begin{tabular}{ccccc}
\hline & \multicolumn{2}{c}{ Fruta } & $\mathbf{x}_{\mathbf{s}}$ & Gel \\
$\mathbf{t}($ días) & $\mathbf{x}_{\mathbf{s}}$ & $\mathbf{x}_{\mathbf{w}}$ & $\mathbf{x}_{\mathbf{w}}$ \\
\hline 0 & $0,103 \pm 0,003^{(\mathrm{a})}$ & $0,874 \pm 0,01^{(\mathrm{a})}$ & $0,552 \pm 0,001^{(\mathrm{a})}$ & $0,448 \pm 0,001^{(\mathrm{a})}$ \\
1 & $0,212 \pm 0,001^{(\mathrm{b})}$ & $0,767 \pm 0,002^{(\mathrm{b})}$ & $0,483 \pm 0,002^{(\mathrm{c})}$ & $0,517 \pm 0,002^{(\mathrm{c})}$ \\
2 & $0,238 \pm 0,001^{(\mathrm{c})}$ & $0,746 \pm 0,002^{(\mathrm{c})}$ & $0,506 \pm 0,001^{(\mathrm{b})}$ & $0,494 \pm 0,001^{(\mathrm{b})}$ \\
3 & $0,245 \pm 0,000^{(\mathrm{d})}$ & $0,734 \pm 0,002^{(\mathrm{d})}$ & $0,458 \pm 0,008^{(\mathrm{d})}$ & $0,542 \pm 0,008^{(\mathrm{d})}$ \\
6 & $0,296 \pm 0,001^{(\mathrm{g})}$ & $0,676 \pm 0,001^{(\mathrm{g})}$ & $0,434 \pm 0,002^{(\mathrm{f})(\mathrm{g})}$ & $0,566 \pm 0,002^{(\mathrm{f})(\mathrm{g})}$ \\
8 & $0,267 \pm 0,001^{(\mathrm{e})}$ & $0,702 \pm 0,002^{(\mathrm{e})}$ & $0,445 \pm 0,002^{(\mathrm{e})}$ & $0,555 \pm 0,002^{(\mathrm{e})}$ \\
10 & $0,282 \pm 0,000^{(\mathrm{f})}$ & $0,694 \pm 0,002^{(\mathrm{f})}$ & $0,430 \pm 0,001^{(\mathrm{g})}$ & $0,570 \pm 0,001^{(\mathrm{g})}$ \\
13 & $0,351 \pm 0,001^{(\mathrm{i})}$ & - & $0,457 \pm 0,002^{(\mathrm{d})}$ & $0,543 \pm 0,002^{(\mathrm{d})}$ \\
15 & $0,361 \pm 0,001^{(\mathrm{j})}$ & $0,622 \pm 0,002^{(\mathrm{i})}$ & $0,434 \pm 0,012^{(\mathrm{e})(\mathrm{f})}$ & $0,566 \pm 0,012^{(\mathrm{e})(\mathrm{f})}$ \\
17 & $0,307 \pm 0,001^{(\mathrm{h})}$ & $0,6637 \pm 0,0003^{(\mathrm{h})}$ & $0,436 \pm 0,006^{(\mathrm{e})(\mathrm{f})(\mathrm{g})}$ & $0,564 \pm 0,006^{(\mathrm{e})(\mathrm{f})(\mathrm{g})}$ \\
\hline
\end{tabular}

(a)-(j) Grupos homogéneos establecidos por el ANOVA $(\alpha<0,05)$ con el factor tiempo de almacenamiento.

Los valores de la fruta fresca y deshidratada a tiempo cero permiten observar el efecto de la deshidratación osmótica en la composición de la fruta. Así, la concentración en sólidos solubles de la fruta aumenta de 10,3 a $23{ }^{\circ}$ Brix, disminuyendo la fracción másica de agua de 0,874 a 0,745 y su actividad del agua de 0,988 $\pm 0,001$ hasta $0,976 \pm 0,001$ (Figura III.15). Este cambio en la composición de la fruta se consigue en 
la matriz gelificada de $55^{\circ}$ Brix (producto PFG55) en tan sólo dos días, sin embargo ésta sigue deshidratándose durante el resto del almacenamiento, de la misma manera que la fruta del producto PDOG55, por no encontrarse en equilibrio termodinámico.

Tabla III.10. Fracción másica de agua y solutos de la fruta y del gel para el sistema PDOG50 a cada tiempo de almacenamiento a $10^{\circ} \mathrm{C}$.

\begin{tabular}{ccccc}
\hline & \multicolumn{2}{c}{ Fruta } & \multicolumn{2}{c}{ Gel } \\
$\mathbf{t}$ (días) & $\mathbf{x}_{\mathbf{s}}$ & $\mathbf{x}_{\mathbf{w}}$ & $\mathbf{x}_{\mathbf{s}}$ & $\mathbf{x}_{\mathbf{w}}$ \\
\hline 0 & $0,23 \pm 0,01^{(\mathrm{a})}$ & $0,745 \pm 0,014^{(\mathrm{a})}$ & $0,502 \pm 0,003^{(\mathrm{a})}$ & $0,498 \pm 0,003^{(\mathrm{a})}$ \\
1 & $0,281 \pm 0,001^{(\mathrm{b})}$ & $0,693 \pm 0,003^{(\mathrm{b})}$ & $0,481 \pm 0,001^{(\mathrm{b})}$ & $0,519 \pm 0,001^{(\mathrm{b})}$ \\
2 & $0,300 \pm 0,000^{(\mathrm{c})}$ & $0,687 \pm 0,000^{(\mathrm{b})}$ & $0,469 \pm 0,000^{(\mathrm{c})}$ & $0,531 \pm 0,000^{(\mathrm{c})}$ \\
6 & $0,345 \pm 0,000^{(\mathrm{d})}$ & $0,646 \pm 0,101^{(\mathrm{c})}$ & $0,457 \pm 0,001^{(\mathrm{d})}$ & $0,543 \pm 0,001^{(\mathrm{d})}$ \\
8 & $0,340 \pm 0,001^{(\mathrm{d})}$ & $0,648 \pm 0,000^{(\mathrm{c})}$ & $0,457 \pm 0,000^{(\mathrm{d})}$ & $0,543 \pm 0,000^{(\mathrm{d})}$ \\
12 & $0,372 \pm 0,001^{(\mathrm{e})}$ & - & $0,449 \pm 0,001^{(\mathrm{e})}$ & $0,551 \pm 0,001^{(\mathrm{e})}$ \\
14 & $0,374 \pm 0,001^{(\mathrm{e})}$ & $0,641 \pm 0,001^{(\mathrm{c})}$ & $0,442 \pm 0,001^{(\mathrm{f})}$ & $0,558 \pm 0,001^{(\mathrm{f})}$ \\
16 & $0,375 \pm 0,000^{(\mathrm{e})}$ & $0,643 \pm 0,006^{(\mathrm{c})}$ & $0,438 \pm 0,001^{(\mathrm{g})}$ & $0,562 \pm 0,001^{(\mathrm{g})}$ \\
\hline
\end{tabular}

(a)-(g) Grupos homogéneos establecidos por el ANOVA $(\alpha<0,05)$ con el factor tiempo de almacenamiento.

Por otra parte, la reutilización de la SO en 5 ciclos sucesivos de DO supone una disminución de los ${ }^{\circ}$ Brix de 55 a 50 (valores del gel a tiempo cero en el producto PDOG50) y un aumento de la $\mathrm{a}_{\mathrm{w}}$ en el gel de $0,921 \pm 0,001$ a $0,933 \pm 0,004$ (Figura III.15). En ambos casos, la deshidratación de la fruta en la matriz gelificada conlleva una variación composicional en el gel, como era de esperar, disminuyendo la fracción másica de sólidos solubles y aumentando la fracción másica de agua y, por lo tanto, su actividad del agua.

Las tablas III.11 y III.12 muestran la fracción másica de agua y solutos tanto de la fruta como del gel en los sistemas gelificados PFG30 
y PDOG30, respectivamente, para cada tiempo de almacenamiento en refrigeración a $10^{\circ} \mathrm{C}$.

Tabla III.11. Fracción másica de agua y solutos de la fruta y del gel para el sistema PFG30 a cada tiempo de almacenamiento a $10^{\circ} \mathrm{C}$.

\begin{tabular}{ccccc}
\hline \multicolumn{2}{c}{ Fruta } & \multicolumn{2}{c}{ Gel } \\
$\mathbf{t}($ días) & $\mathbf{x}_{\mathbf{s}}$ & $\mathbf{x}_{\mathbf{w}}$ & $\mathbf{x}_{\mathbf{s}}$ & $\mathbf{x}_{\mathbf{w}}$ \\
\hline 0 & $0,110 \pm 0,006^{(\mathrm{a})}$ & $0,881 \pm 0,006^{(\mathrm{a})}$ & $0,301 \pm 0,001^{(\mathrm{a})}$ & $0,700 \pm 0,001^{(\mathrm{a})}$ \\
1 & $0,1545 \pm 0,001^{(\mathrm{b})}$ & $0,87 \pm 0,04^{(\mathrm{a})}$ & $0,283 \pm 0,002^{(\mathrm{b})}$ & $0,718 \pm 0,002^{(\mathrm{b})}$ \\
2 & $0,160 \pm 0,000^{(\mathrm{c})}$ & $0,8339 \pm 0,0015^{(\mathrm{b})}$ & $0,277 \pm 0,001^{(\mathrm{c})}$ & $0,724 \pm 0,001^{(\mathrm{c})}$ \\
3 & $0,158 \pm 0,000^{(\mathrm{b})(\mathrm{c})}$ & $0,8330 \pm 0,0007^{(\mathrm{b})}$ & $0,277 \pm 0,002^{(\mathrm{c})}$ & $0,724 \pm 0,002^{(\mathrm{c})}$ \\
6 & $0,1745 \pm 0,001^{(\mathrm{d})}$ & $0,8103 \pm 0,0000^{(\mathrm{b})(\mathrm{c})}$ & $0,271 \pm 0,001^{(\mathrm{e})}$ & $0,730 \pm 0,001^{(\mathrm{e})}$ \\
8 & $0,1865 \pm 0,001^{(\mathrm{e})}$ & $0,801 \pm 0,003^{(\mathrm{c})(\mathrm{d})}$ & $0,269 \pm 0,001^{(\mathrm{e})(\mathrm{f})}$ & $0,732 \pm 0,001^{(\mathrm{e})(\mathrm{f})}$ \\
10 & $0,1825 \pm 0,001^{(\mathrm{e})}$ & $0,8015 \pm 0,0011^{(\mathrm{c})(\mathrm{d})}$ & $0,267 \pm 0,001^{(\mathrm{f})}$ & $0,734 \pm 0,001^{(\mathrm{f})}$ \\
13 & $0,2055 \pm 0,001^{(\mathrm{g})}$ & $0,7821 \pm 0,0001^{(\mathrm{d})}$ & $0,270 \pm 0,001^{(\mathrm{e})}$ & $0,731 \pm 0,001^{(\mathrm{e})}$ \\
15 & $0,2025 \pm 0,001^{(\mathrm{f})(\mathrm{g})}$ & $0,7845 \pm 0,0006^{(\mathrm{c})(\mathrm{d})}$ & $0,270 \pm 0,000^{(\mathrm{e})}$ & $0,730 \pm 0,000^{(\mathrm{e})}$ \\
17 & $0,1985 \pm 0,001^{(\mathrm{f})}$ & $0,7869 \pm 0,0003^{(\mathrm{c})(\mathrm{d})}$ & $0,274 \pm 0,000^{(\mathrm{d})}$ & $0,726 \pm 0,000^{(\mathrm{d})}$ \\
\hline
\end{tabular}

(a)-(g) Grupos homogéneos establecidos por el ANOVA $(\alpha<0,05)$ con el factor tiempo de almacenamiento.

El valor de $a_{w}$ de $0,974 \pm 0,001$ obtenido en el gel formulado para la elaboración del producto PDOG30 $\left(a_{w}\right.$ del gel a tiempo cero de almacenamiento) permite comprobar el buen cálculo efectuado a partir de la ecuación de Norrish. La pequeña diferencia respecto al valor de $a_{w}$ del pomelo deshidratado $(0,976 \pm 0,001)$ puede deberse al efecto depresor de la $a_{w}$ que pueda tener el carragenato. Por otra parte, ambas $a_{w}$ se mantienen estables durante el almacenamiento. En este sentido, la fruta y el gel del producto PDOG30 apenas cambia en cuanto a su composición durante el periodo de almacenamiento, ya que el producto está termodinámicamente estable. 
En el caso del producto PFG30, la fuerza impulsora no fue lo suficientemente elevada como para conseguir un nivel de deshidratación apropiado en la fruta (importante desde el punto de vista microbiológico). Por otra parte, tampoco se alcanzó el equilibrio termodinámico a un tiempo razonable de almacenamiento.

Tabla III.12. Fracción másica de agua y solutos de la fruta y del gel para el sistema PDOG30 a cada tiempo de almacenamiento a $10^{\circ} \mathrm{C}$.

\begin{tabular}{|c|c|c|c|c|}
\hline \multirow[b]{2}{*}{ t(días) } & \multicolumn{2}{|c|}{ Fruta } & \multicolumn{2}{|c|}{ Gel } \\
\hline & $\mathbf{X}_{\mathbf{s}}$ & $\mathbf{x}_{\mathrm{w}}$ & $\mathbf{x}_{\mathbf{s}}$ & $\mathbf{x}_{\mathrm{w}}$ \\
\hline 0 & $0,23 \pm 0,01^{(b)}$ & $0,745 \pm 0,014^{(a)}$ & $0,296 \pm 0,003^{(\mathrm{c})}$ & $0,704 \pm 0,003^{(\mathrm{c})}$ \\
\hline 1 & $0,221 \pm 0,001^{(\mathrm{a})}$ & $0,758 \pm 0,001^{(a)}$ & $0,307 \pm 0,001^{(b)}$ & $0,693 \pm 0,001^{(b)}$ \\
\hline 2 & $0,228 \pm 0,000^{(a)(b)}$ & $0,762 \pm 0,000^{(a)}$ & $0,315 \pm 0,000^{(a)}$ & $0,685 \pm 0,000^{(a)}$ \\
\hline 6 & $0,236 \pm 0,001^{(b)(c)}$ & $0,755 \pm 0,072^{(a)}$ & $0,293 \pm 0,001^{(d)}$ & $0,707 \pm 0,001^{(d)}$ \\
\hline 8 & $0,237 \pm 0,000^{(b)(c)}$ & $0,751 \pm 0,001^{(a)}$ & $0,299 \pm 0,000^{(\mathrm{c})}$ & $0,701 \pm 0,000^{(\mathrm{c})}$ \\
\hline 12 & $0,245 \pm 0,000^{(\mathrm{c})}$ & - & $0,298 \pm 0,001^{(\mathrm{c})}$ & $0,702 \pm 0,001^{(\mathrm{c})}$ \\
\hline 14 & $0,264 \pm 0,000^{(d)}$ & $0,7212 \pm 0,0001^{(a)}$ & $0,2953 \pm 0,0006^{(\mathrm{c})(\mathrm{d})}$ & $0,7047 \pm 0,0006^{(\mathrm{c})(\mathrm{d})}$ \\
\hline 16 & $0,257 \pm 0,001^{(d)}$ & $0,730 \pm 0,001^{(a)}$ & $0,2883 \pm 0,0006^{(e)}$ & $0,7117 \pm 0,0006^{(e)}$ \\
\hline
\end{tabular}

(a)-(e) Grupos homogéneos establecidos por el ANOVA $(\alpha<0,05)$ con el factor tiempo de almacenamiento.

En resumen, debido a la necesidad de que el producto presente una estabilidad composicional durante el periodo de almacenamiento previo al consumo del mismo y ya que ésta no se consigue o lo hace a tiempos demasiado prolongados en las formulaciones PFG55, PDOG50 y PFG30, se seleccionó la formulación PDOG30 como la óptima para la elaboración del producto deseado. Con ella se realizó el estudio de almacenamiento que se describe a continuación. 
En base a todo lo anterior, en la figura III.16 se muestra el diseño experimental planteado para la preparación del producto gelificado optimizado.

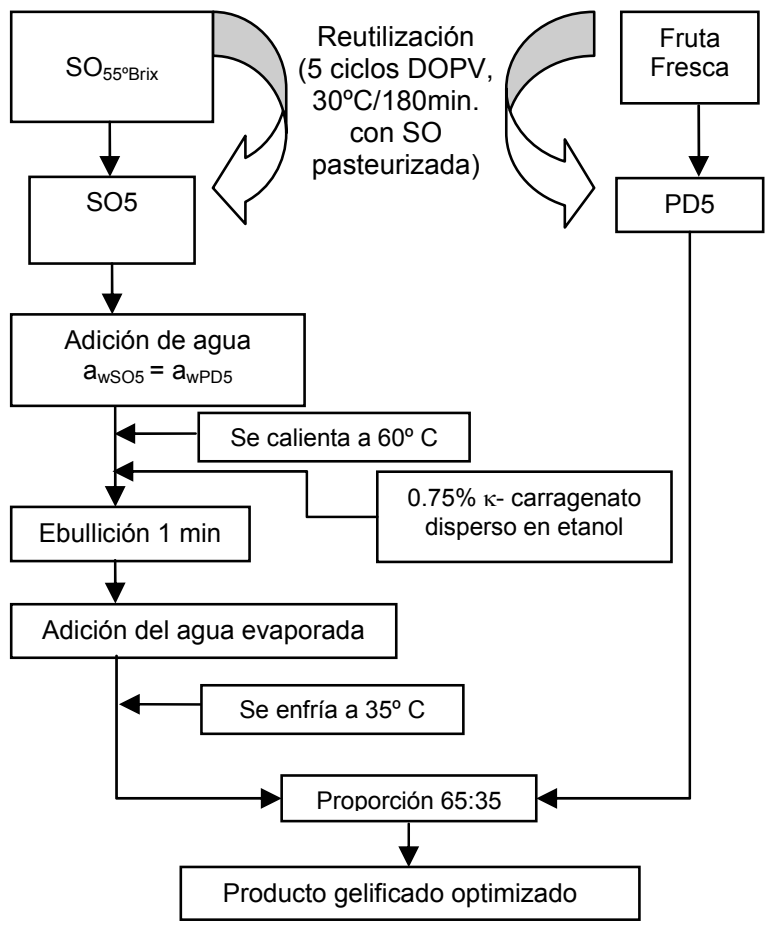

Figura III.16. Diseño experimental para la preparación del producto gelificado optimizado.

\section{III.2.3.2. Estudio de almacenamiento del producto gelificado optimizado}

En este estudio, tal y como se describe en el apartado III.1.2.3.2 de materiales y métodos, se analizaron los cambios en el contenido en ácido ascórbico durante su almacenamiento en refrigeración, tanto en la fruta (PDG) como en el gel (G). La evolución del color y las propiedades 
mecánicas de la fruta deshidratada en el interior de la matriz gelificada se comparó con la de la fruta fresca (PF) y la deshidratada sin incluir en el gel (PD). Por último se realizó el estudio de vida útil microbiológica del producto gelificado (PDOG30), comparándose a su vez con las muestras PF y PD.

\section{III.2.3.2.1. Evolución del contenido en ácido ascórbico (AA)}

Dado que el AA es uno de los compuestos más lábiles de las frutas, se seleccionó como parámetro de control de posibles cambios en el valor nutritivo del producto formulado.

Como se observa en la figura III.17, el contenido en AA del pomelo deshidratado incluido en el gel se mantuvo bastante estable durante el almacenamiento en refrigeración, no presentando diferencias significativas $(\alpha>0,05)$ las muestras a $0,3,15$ y 20 días. Sin embargo, la muestra almacenada un tiempo superior presentó un contenido significativamente inferior $(\alpha<0,05)$ al resto. Además, el ANOVA realizado en este sentido reflejó un aumento significativo de AA en los días intermedios del almacenamiento (6-13 días). Si se tiene en cuenta que las muestras analizadas a cada tiempo provienen de pomelos diferentes, esto puede justificar dichas diferencias. Por lo tanto, parece poder afirmarse que el contenido en AA del pomelo deshidratado incluido en la matriz gelificada se mantiene en estable con el almacenamiento.

Por otro lado, en el caso del pomelo deshidratado no incluido en el gel (Figura III.17) sí que se observa una disminución significativa de su contenido en AA durante el almacenamiento, como ya se había observado en el estudio de reutilización de la SO (Tabla III.6). En base a lo anterior, puede decirse que la presencia del gel previene de la 
degradación de $\mathrm{AA}$, lo que podría estar relacionado con la menor accesibilidad del oxígeno a la fruta. Así, el valor del contenido en AA del pomelo deshidratado incluido en el gel a los 12 días de almacenamiento fue de $\sim 35 \mathrm{mg} \mathrm{AA} / 100 \mathrm{~g}$ frente al del pomelo deshidratado no incluido en el gel que fue de $\sim 17 \mathrm{mg} \mathrm{AA} / 100 \mathrm{~g}$.

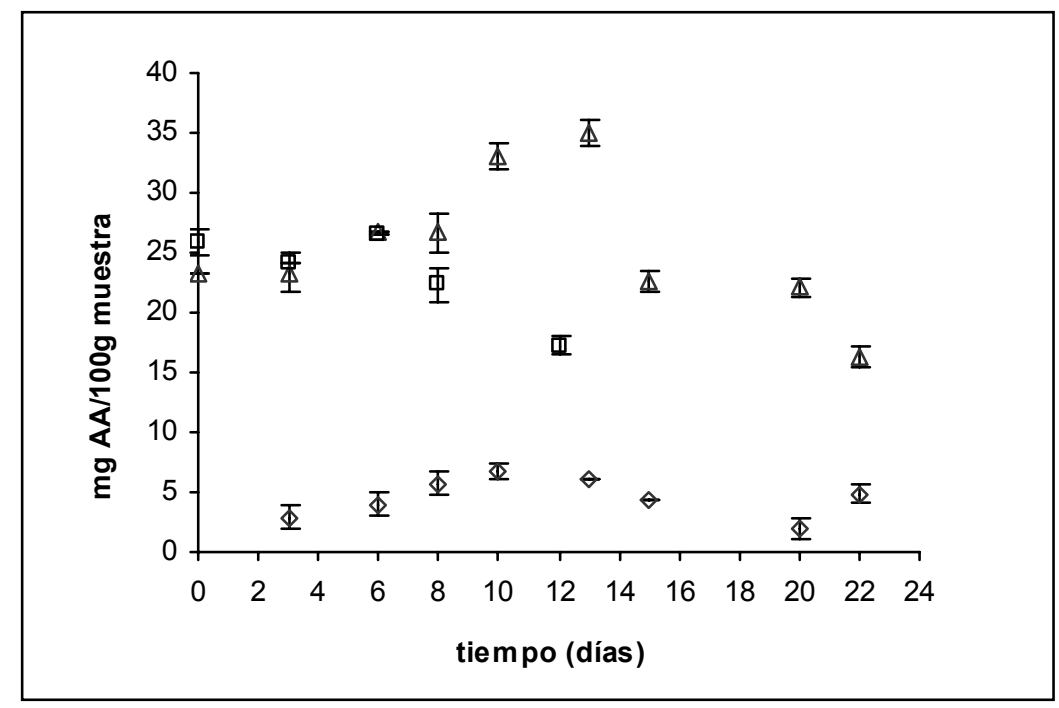

Figura III.17. Evolución del contenido en AA de las muestras de pomelo deshidratado no incluido en gel (口), pomelo deshidratado incluido en gel $(\triangle)$ y del gel $(\diamond)$.

En el gel, el contenido en AA aumentó durante los primeros 10 días de almacenamiento hasta alcanzar un valor de $\sim 7 \mathrm{mg} \mathrm{AA} / 100 \mathrm{~g}$. Posteriormente éste disminuyó siguiendo una pauta similar a la fruta. 


\section{IIl.2.3.2.2. Color y propiedades mecánicas}

A partir de la medida del espectro de reflexión de las muestras, siguiendo el procedimiento descrito en el apartado III.1.3.10 de materiales y métodos, se obtuvieron las coordenadas de color CIE L*a*b*. Empleando las ecuaciones III.8, III.9 y III.10 se calcularon las coordenadas psicométricas, tono $\left(\mathrm{h}^{*}\right)$ y croma $\left(\mathrm{C}^{*}\right)$ y al mismo tiempo se calculó la diferencia de color $\left(\Delta \mathrm{E}^{*}\right)$ provocado por el tratamiento de deshidratación así como por efecto del tiempo de almacenamiento.

La tabla III.13 muestra los valores de la luminosidad $\left(L^{*}\right)$, el tono $\left(h^{*}\right)$ y el croma $\left(C^{*}\right)$ o pureza de color de las muestras estudiadas. En ella se recogen los datos de color, durante su almacenamiento en refrigeración, de los tres tipos de muestras a comparar: pomelo fresco (PF), pomelo deshidratado (PD) y pomelo deshidratado incluido en la matriz gelificada (PDG). Por otro lado, en la figura III.18, o diagrama cromático, se representan las coordenadas cromáticas $a^{*}$ y $b^{*}$ de las muestras. A su vez, la localización de los valores de $a^{*}$ y $b^{*}$ en el plano cromático nos permite comparar el croma y el tono de las muestras, ya que el tono se corresponde con el ángulo respecto del eje de $a^{*}$ positivo y el croma está relacionado con la distancia al centro de coordenadas.

En la figura III.18, se pueden observar tres grupos diferentes, donde podemos destacar que las muestras de pomelo deshidratado presentaron una tonalidad más roja y más pura (con mayor valor de la coordenada $a^{*}$ y menor de $b^{*}$ ), comparándolas con las muestras de pomelo fresco. Sin embargo su luminosidad fue menor (Tabla III.13). La inclusión de las muestras de pomelo deshidratado en la matriz gelificada produjo un descenso significativo $(\alpha<0,05)$ en el croma y en el ángulo de tono, potenciándose aún más el rojo de la fruta. 
Tabla III.13. Valores de tono $\left(\mathrm{h}^{*}\right)$, croma $\left(\mathrm{C}^{*}\right)$ y diferencia de color calculada en función del tiempo de almacenamiento $\left(\Delta \mathrm{E}^{*}\right)$ para las muestras de pomelo fresco (PF), pomelo deshidratado (PD) y pomelo deshidratado incluido en la matriz gelificada (PDG).

\begin{tabular}{cccccc}
\hline Muestras & $\mathbf{t}$ (días) & $\mathbf{L}^{*}$ & $\mathbf{h}^{*}$ & $\mathbf{C}^{*}$ & $\Delta \mathbf{E}^{*}$ \\
\hline & $\mathbf{0}$ & $42,4 \pm 3,4^{(\mathrm{a})}$ & $49,8 \pm 1,6^{(\mathrm{a})}$ & $23,5 \pm 2,4^{(\mathrm{a})}$ & - \\
& $\mathbf{3}$ & $38,5 \pm 1,1^{(\mathrm{b})}$ & $48,0 \pm 1,9^{(\mathrm{a})}$ & $20,1 \pm 1,7^{(\mathrm{b})(\mathrm{c})}$ & 13,7 \\
$\mathbf{P F}$ & $\mathbf{6}$ & $37,8 \pm 0,5^{(\mathrm{b})}$ & $46,3 \pm 3,3^{(\mathrm{a})}$ & $18,2 \pm 1,1^{(\mathrm{c})}$ & 25,3 \\
& $\mathbf{8}$ & $39,3 \pm 1,8^{(\mathrm{a})(\mathrm{b})}$ & $46,5 \pm 1,1^{(\mathrm{a})}$ & $18,7 \pm 0,3^{(\mathrm{c})}$ & 17,1 \\
& $\mathbf{1 0}$ & $40,5 \pm 2,2^{(\mathrm{a})(\mathrm{b})}$ & $46,7 \pm 3,8^{(\mathrm{a})}$ & $23,0 \pm 2,0^{(\mathrm{a})(\mathrm{b})}$ & 2,6 \\
\hline \multirow{4}{*}{ PD } & $\mathbf{0}$ & $32,6 \pm 1,3^{(\mathrm{a})}$ & $32,3 \pm 1,1^{(\mathrm{a})}$ & $20,1 \pm 1,4^{(\mathrm{a})}$ & - \\
& $\mathbf{3}$ & $35,3 \pm 1,7^{(\mathrm{c})}$ & $35,2 \pm 1,1^{(\mathrm{a})}$ & $21,5 \pm 2,5^{(\mathrm{b})}$ & 5,4 \\
& $\mathbf{6}$ & $33,3 \pm 0,5^{(\mathrm{a})(\mathrm{b})}$ & $32,2 \pm 1,0^{(\mathrm{a})}$ & $22,8 \pm 2,3^{(\mathrm{a})}$ & 4,0 \\
& $\mathbf{9}$ & $34,1 \pm 0,4^{(\mathrm{a})(\mathrm{b})(\mathrm{c})}$ & $34,0 \pm 1,6^{(\mathrm{a})(\mathrm{b})}$ & $23,3 \pm 1,5^{(\mathrm{a})(\mathrm{b})}$ & 6,3 \\
& $\mathbf{1 3}$ & $34,5 \pm 0,5^{(\mathrm{b})(\mathrm{c})}$ & $35,9 \pm 0,6^{(\mathrm{b})}$ & $26,9 \pm 2,0^{(\mathrm{b})}$ & 25,6 \\
\hline \multirow{4}{*}{ PDG } & $\mathbf{3}$ & $28,6 \pm 0,6^{(\mathrm{a})}$ & $28,1 \pm 2,2^{(\mathrm{a})}$ & $10,6 \pm 2,0^{(\mathrm{c})}$ & - \\
& $\mathbf{6}$ & $30,0 \pm 1,6^{(\mathrm{a})(\mathrm{b})}$ & $21,1 \pm 9,5^{(\mathrm{a})}$ & $8,6 \pm 4,1^{(\mathrm{b})(\mathrm{c})}$ & 3,3 \\
& $\mathbf{8}$ & $32,0 \pm 1,7^{(\mathrm{c})}$ & $40,9 \pm 8,5^{(\mathrm{a})}$ & $5,0 \pm 2,2^{(\mathrm{a})}$ & 22,6 \\
& $\mathbf{1 0}$ & $32,1 \pm 2,6^{(\mathrm{c})}$ & $22,6 \pm 9,8^{(\mathrm{a})}$ & $3,9 \pm 3,0^{(\mathrm{a})}$ & 28,8 \\
& $\mathbf{1 3}$ & $32,1 \pm 1,3^{(\mathrm{c})}$ & $23,0 \pm 4,2^{(\mathrm{a})}$ & $6,1 \pm 2,4^{(\mathrm{a})(\mathrm{b})}$ & 16,9 \\
& $\mathbf{1 5}$ & $31,2 \pm 1,1^{(\mathrm{b})(\mathrm{c})}$ & $18,9 \pm 3,0^{(\mathrm{a})}$ & $6,2 \pm 1,6^{(\mathrm{a})(\mathrm{b})}$ & 14,5 \\
& $\mathbf{2 0}$ & $29,1 \pm 1,5^{(\mathrm{a})}$ & $22,9 \pm 2,2^{(\mathrm{a})}$ & $9,6 \pm 2,3^{(\mathrm{c})}$ & 1,1 \\
& $\mathbf{2 2}$ & $28,8 \pm 1,7^{(\mathrm{a})}$ & $25,6 \pm 1,9^{(\mathrm{a})}$ & $9,7 \pm 2,0^{(\mathrm{c}),}$ & 0,6 \\
\hline
\end{tabular}

(a)(b)(c) Grupos homogéneos establecidos por el ANOVA $(\alpha<0,05)$ con el factor tiempo de almacenamiento.

El tono de las muestras no varió significativamente durante el período de almacenamiento estudiado $(\alpha>0,05)$. Por otro lado, aunque el ANOVA estableció diferencias significativas a lo largo del almacenamiento para la luminosidad y el croma de las muestras, éstas 
no siguieron ninguna pauta lógica por lo que las diferencias pueden atribuirse a la variabilidad propia de la fruta. No obstante, esta variabilidad hace que lleguen a encontrarse diferencias de color de hasta 25-29 unidades en los 3 tipos de muestra estudiados en algunos de los tiempos considerados.

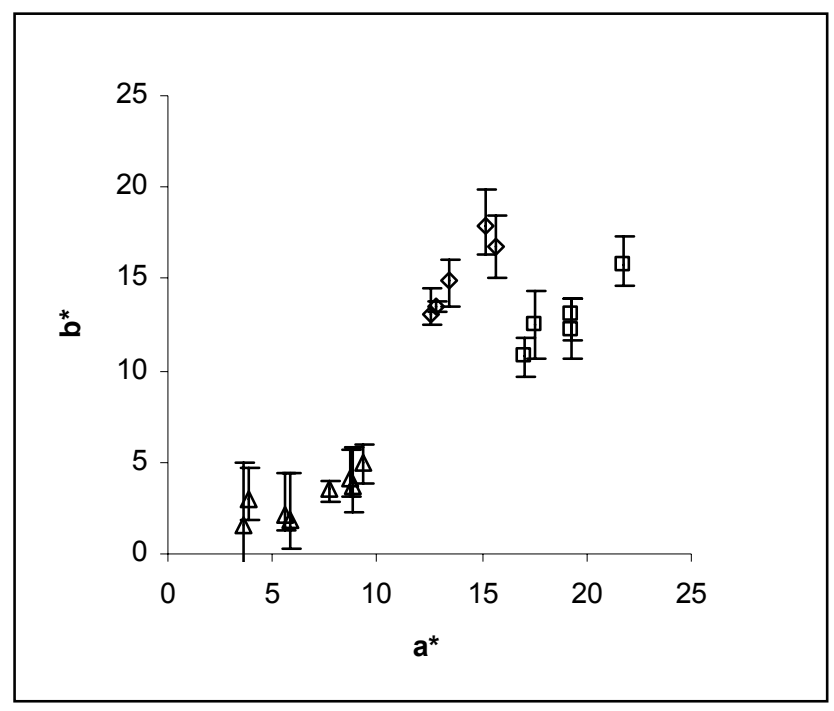

Figura III.18. Diagrama cromático $\left(\mathrm{a}^{*}, \mathrm{~b}^{*}\right)$ obtenido para las muestras de pomelo fresco $(\diamond)$, pomelo deshidratado $(\square)$ e inmerso en la matriz gelificada seleccionada $(\triangle)$.

En cuanto a las propiedades mecánicas, con el objetivo de estudiar cómo afecta el tratamiento de deshidratación aplicado así como la inclusión de la fruta deshidratada en la matriz gelificada seleccionada sobre las mismas, a lo largo de su almacenamiento en refrigeración, se llevó a cabo el ensayo de compresión-extrusión descrito en el apartado III.1.3.9 de materiales y métodos en el pomelo fresco, el pomelo deshidratado y el mismo incluido en el gel. 
La figura III.19 muestra, a modo de ejemplo, una curva fuerza (F) distancia (d) tipo obtenida en cada una de las muestras analizadas. En concreto corresponde con la respuesta mecánica de muestras de pomelo fresco y deshidratado sin almacenar, así como pomelo incluido en el la matriz gelificada durante 10 días de almacenamiento.

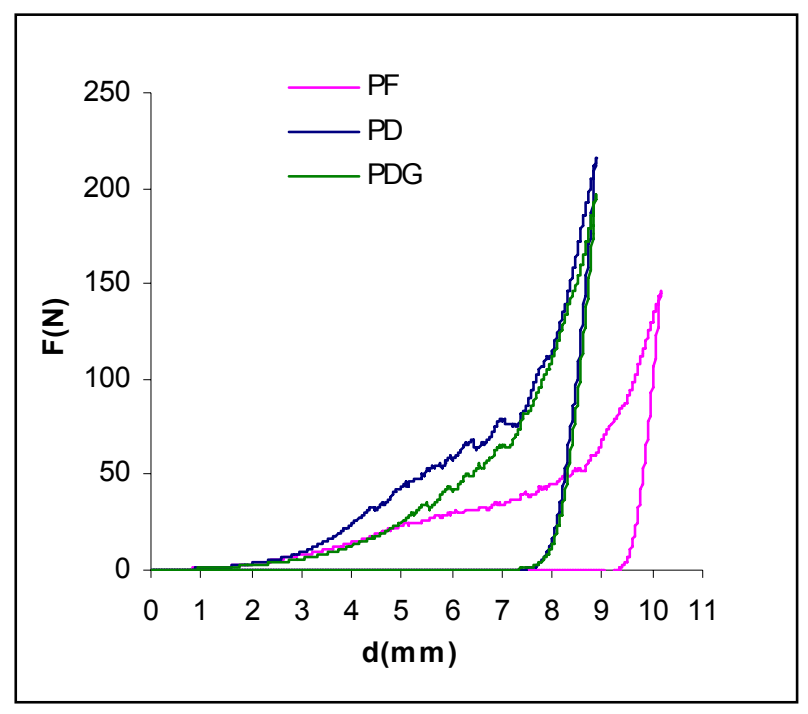

Figura III.19. Curvas fuerza (F)-distancia (d) tipo obtenidas en pomelo fresco (PF) y deshidratado (PD) sin almacenar, así como pomelo incluido en el la matriz gelificada (PDG) durante 10 días de almacenamiento.

En todas las curvas analizadas, el comportamiento fue similar. En primer lugar se observó un aumento paulatino de la fuerza que corresponde a una deformación y compresión del producto y posteriormente un aumento más acusado hasta alcanzar un valor de fuerza máxima $\left(F_{\text {máx }}\right)$ necesaria para hacer extrusionar la muestra a través de los orificios de la célula Ottawa. Como puede observarse, la 
deshidratación osmótica implicó una disminución del espesor de las muestras, permaneciendo prácticamente invariable en el interior del gel.

La figura III.20 muestra los valores de $F_{\text {máx }}$ obtenidos en cada una de las muestras estudiadas en función del tiempo de almacenamiento en refrigeración.

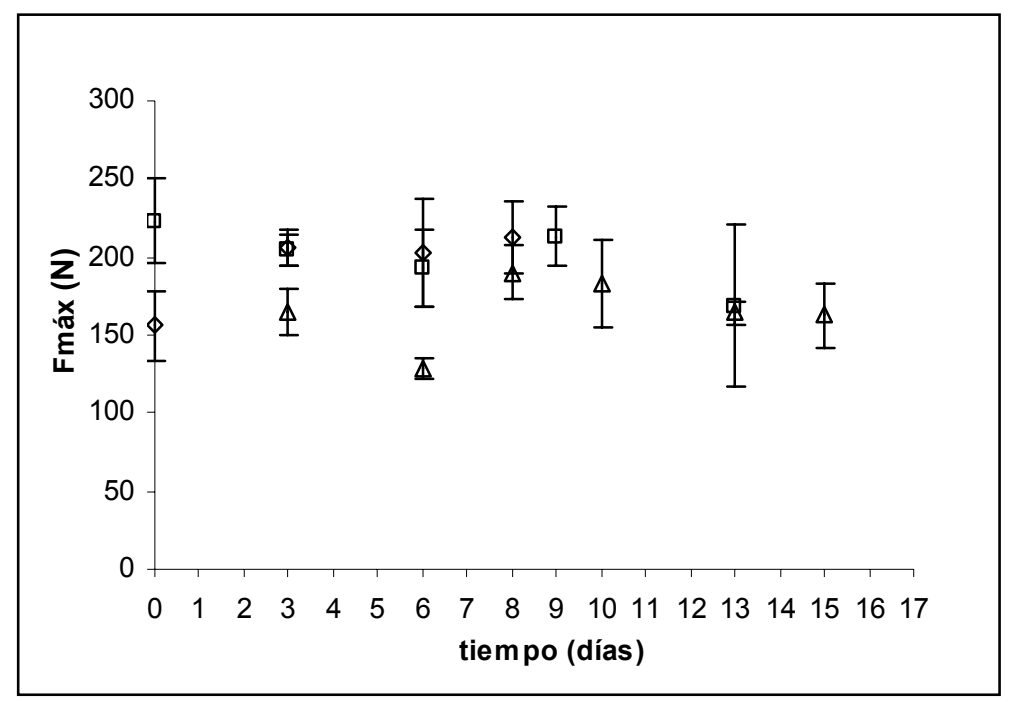

Figura III.20. Valores de la fuerza máxima $\left(F_{\text {máx }}\right)$ obtenidos a partir del ensayo de compresión-extrusión de las muestras de pomelo fresco $(\diamond)$, pomelo deshidratado $(\square)$ e inmerso en la matriz gelificada $(\triangle)$.

El tratamiento osmótico supuso un aumento significativo en la $F_{\text {máx }}$, que disminuyó ligeramente durante su período de almacenamiento. A los 3 días de almacenamiento, el pomelo fresco sufrió un aumento

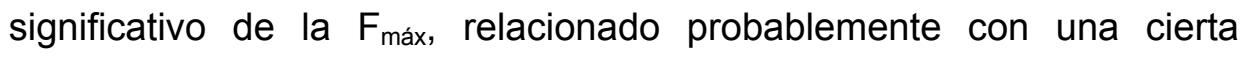
pérdida de líquido, que se mantuvo constante hasta el final del estudio. 
El comportamiento de las muestras de pomelo inmersas en la matriz gelificada no parece indicar un ablandamiento de la fruta, la cual presenta un comportamiento mecánico semejante al del pomelo deshidratado.

\section{III.2.3.3. Estudio microbiológico}

La figura III.21 ( $\mathrm{a}$ y b) muestra el recuento de viables totales y de mohos y levaduras en las muestras de pomelo fresco, pomelo deshidratado y en el producto gelificado optimizado. Cabe recodar que éste se formuló con pomelo deshidratado con disolución osmótica reutilizada durante 5 ciclos sucesivos de deshidratación, por lo que la vida útil microbiológica se comparó con la del pomelo deshidratado en las mismas condiciones sin incluir en el gel (muestra PD5, apartado III.2.2.1), ya que ésta resultó diferente en función del número de ciclos de reutilización de la disolución osmótica.

Al igual que se vio en el apartado anterior (III.2.2.1.), siendo el límite para mohos y levaduras el primero que se alcanzó, éste fue el factor limitante considerado para asignar la vida útil de cada muestra (Figura III.21.b). En este sentido, se alcanzó el límite establecido para mohos y levaduras a los 5,9 y 12 días de almacenamiento para las muestras de pomelo fresco, pomelo deshidratado con disolución reutilizada durante 5 ciclos sucesivos y en el producto gelificado formulado con este último inmerso en una matriz gelificada, respectivamente.

Los resultados mostrados en la figura III.21 parecen indicar que aunque el pomelo deshidratado es inicialmente de mayor calidad microbiológica que el producto gelificado, lo que podría ser consecuencia de los microorganismos que pudiera haber en el gel, a los tiempos más largos de almacenamiento el producto gelificado es 
microbiológicamente más estable. Esto también podría estar relacionado con la menor accesibilidad del oxígeno a la fruta en este último caso, el cual es necesario para el desarrollo de las levaduras aeróbicas que se desarrollan en este tipo de producto.

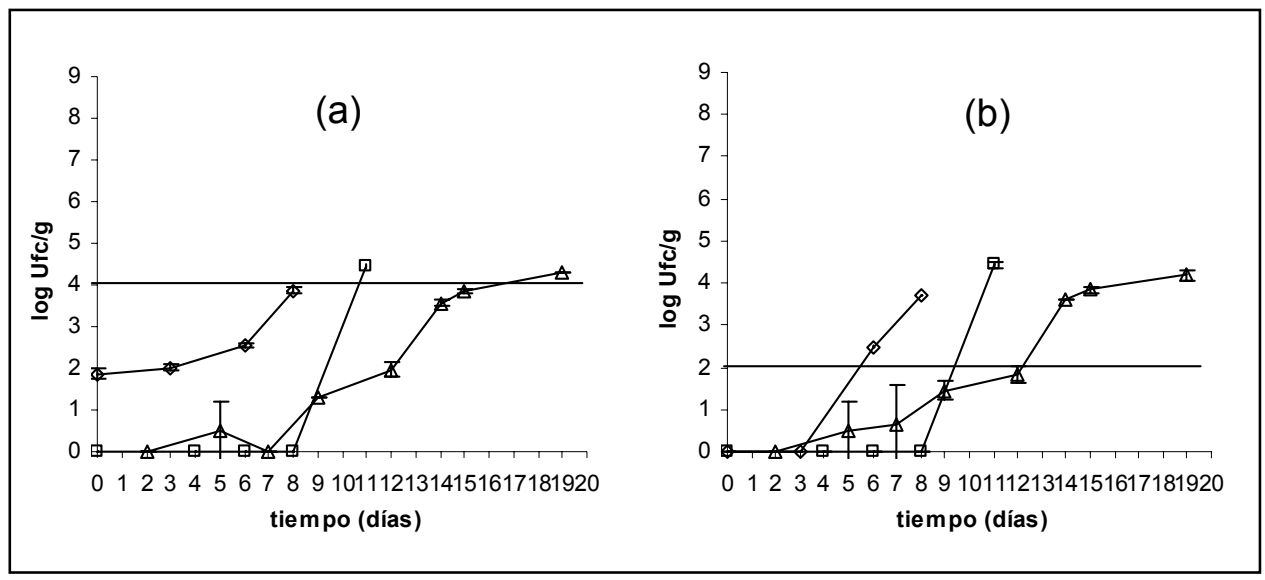

Figura III.21. Recuento de (a) viables totales y (b) mohos y levaduras, en pomelo fresco $(\diamond)$, pomelo deshidratado $(\square)$ y en el producto gelificado seleccionado $(\triangle)$. 
IV. ESTUDIO DEL EFECTO

DE LA ADICIÓN DE LACTATO CÁLCICO A LA DISOLUCIÓN OSMÓTICA PARA LA OBTENCIÓN DE PRODUCTOS GELIFICADOS CON POMELO 

IV. ESTUDIO DEL EFECTO DE

LA ADICIÓN DE LACTATO CÁLCICO A LA DISOLUCIÓN OSMÓTICA PARA LA OBTENCIÓN DE PRODUCTOS GELIFICADOS CON POMELO

\section{IV.1. MATERIALES Y MÉTODOS}

IV.1.1. Materia prima

\section{IV.1.1.1. Fruta}

Para la elección de las muestras se siguió el mismo procedimiento inidicado en el apartado III.1.1.1 de materiales y métodos. 


\section{IV.1.1.2. Disoluciones}

Las disoluciones utilizadas se prepararon en un vaso de precipitados de plástico de $5 \mathrm{~L}$ de capacidad con diferente proporción de agua destilada y sacarosa en función del tratamiento a aplicar, agitando y calentando dicha mezcla a una temperatura no superior a $30^{\circ} \mathrm{C}$.

Para los tratamientos de deshidratación osmótica con pulso de vacío (PVOD) se empleó una disolución hipertónica de $55^{\circ}$ Brix y para los tratamientos de impregnación a vacío (IV) una disolución isotónica de $18^{\circ}$ Brix. Posteriormente se añadió lactato cálcico 5 hidrato aditio (E-327) (PANREAC, Barcelona, España) al 0, 1 y $2 \%$ en peso. De esta forma se prepararon un total de seis disoluciones, las cuales fueron previamente pasteurizadas a $72^{\circ} \mathrm{C}$ durante 15 segundos antes de su utilización.

El cálculo de la concentración de la disolución isotónica se efectuó mediante la ecuación de predicción de Norrish (ecuación III.4) considerando la existencia de un único soluto, la sacarosa. Posteriormente se analizó la actividad del agua para comprobar la isotonicidad de las mismas.

\section{IV.1.1.3. Agente gelificante}

El tipo y proporción del agente gelificante para la obtención de los postres gelificados con pomelo fue el mismo indicado en el apartado III.1.1.3 de materiales y métodos. 


\section{IV.1.2. Procedimiento experimental}

\section{IV.1.2.1. Preparación de las muestras de pomelo fresco}

Para la preparación de las muestras frescas de pomelo se siguió el mismo procedimiento que se indica en el apartado III.1.2.1 de materiales y métodos.

\section{IV.1.2.2. Estudio cinético}

El procedimiento que se siguió para realizar el estudio del efecto del calcio en la cinética de deshidratación osmótica con pulso de vacío de pomelo y los tiempos elegidos para dicho estudio fueron los mismos que se describen en el apartado III.1.2.2.1 de materiales y métodos. En este caso como agente osmótico se empleó una disolución de sacarosa de $55^{\circ}$ Brix a la que se añadió un $2 \%$ de lactato cálcico, preparada tal y como se indica en el apartado IV.1.1.2.

\section{IV.1.2.3. Tratamientos de impregnación a vacío y de deshidratación} osmótica con pulso de vacío

Una vez preparadas las muestras, tal y como se indica en el apartado III.1.2.1 de materiales y métodos, se sometieron a 6 tratamientos diferentes, 3 de impregnación a vacío con disolución isotónica de $\sim 18^{\circ}$ Brix al 0,1 y $2 \%$ en lactato cálcico (muestras $\mathrm{IV}_{0 \%}, \mathrm{IV}_{1 \%}$ e $\mathrm{IV}_{2 \%}$, respectivamente) y 3 de deshidratación osmótica con pulso de vacío (DOPV) con disolución hipertónica de $55^{\circ}$ Brix al 0,1 y $2 \%$ en lactato cálcico (muestras $\mathrm{PD}_{0 \%}, \mathrm{PD}_{1 \%}$ y $\mathrm{PD}_{2 \%}$, respectivamente). 
En los tratamientos IV, una vez la fruta se puso en contacto con la disolución isotónica se procedió a realizar un pulso de vacío (50 mbar) durante los primeros 10 minutos del proceso. A continuación se restauró la presión atmosférica y se dejaron otros 10 minutos más antes de sacarlas de la disolución, promoviéndose la impregnación a vacío de las muestras. En el caso de los tratamientos de DOPV, la aplicación del pulso de vacío (50 mbar, $10 \mathrm{~min}$ ), se realizó en la disolución osmótica de $55^{\circ}$ Brix, permaneciendo las muestras posteriormente en dicha $\mathrm{SO}$, a presión atmosférica, durante 180 min más. La metodología seguida para la aplicación del tratamiento se describe en el apartado III.1.2.2 de materiales y métodos.

El conjunto de muestras obtenidas en los diferentes tratamientos de IV y DOPV fueron almacenadas en refrigeración junto a muestras frescas, tal y como se describe en el apartado IV.1.2.5 de materiales y métodos.

A cada una de ellas, al inicio y a los 7 días de almacenamiento en refrigeración, se les analizó la variación en el peso, el contenido en humedad y sólidos solubles, el $\mathrm{pH}$, la acidez valorable, la concentración de cationes $\left(\mathrm{Ca}^{2+}, \mathrm{Na}^{+}, \mathrm{Mg}^{2+}, \mathrm{K}^{+}\right)$y la respuesta mecánica de las muestras. Además, se les realizó un estudio sobre la tasa respiratoria a lo largo de 6 días de almacenamiento en refrigeración.

Con otro lote diferente, se analizó la vida útil microbiológica de las muestras deshidratadas osmóticamente sin y con $2 \%$ lactato cálcico añadido a la disolución osmótica $\left(\mathrm{PD}_{0 \%}, \mathrm{PD}_{2 \%}\right)$. Éstas fueron a su vez evaluadas desde un punto de vista sensorial, recién procesadas $\left(\mathrm{PD}_{0} \%\right.$, $\mathrm{PD}_{2 \%}$ ) y después de 5 días de almacenamiento en refrigeración $\left(P_{0 \%}(5 d), P D_{2 \%}(5 d)\right)$.

La metodología seguida para la realización de estos análisis se describe en el apartado IV.1.3 de materiales y métodos. 


\section{IV.1.2.4. Preparación de los geles con pomelo}

La metodología seguida coincide con la descrita en el apartado III.1.2.3, empleada en la elaboración del producto gelificado optimizado (Figura III.16).

En este caso, para analizar la influencia del catión calcio se partió de disolución osmótica de $55^{\circ}$ Brix con 0 y $2 \%$ de lactato cálcico añadido, preparadas tal y como se describe en el apartado IV.1.1.2 de materiales y métodos. Para la elaboración de los geles se empleó la fruta deshidratada y la SO, con 0 y $2 \%$ de lactato cálcico añadido, obtenidas después del $5^{\circ}$ ciclo de deshidratación.

Los productos obtenidos $\left(\mathrm{PDG}_{0 \%}\right.$ y $\mathrm{PDG}_{2 \%}$ ) fueron envasados y almacenados en refrigeración, tal y como se describe en el apartado IV.1.2.5 de materiales y métodos. Ambos se analizaron desde un punto de vista microbiológico durante 17 días de almacenamiento y se evaluó su aceptación sensorial, tanto recién formulado como a los 7 días de almacenamiento en refrigeración ( $P \mathrm{PG}_{0 \%}(7 \mathrm{~d})$ y $\mathrm{PDG}_{2 \%}(7 \mathrm{~d})$ ).

Además, al producto gelificado con calcio añadido a la $\mathrm{SO}$, se analizó el contenido en cationes (de forma separada en el gel y en la fruta) durante 16 días de almacenamiento en refrigeración.

\section{IV.1.2.5. Almacenamiento en refrigeración}

El conjunto de muestras de pomelo obtenidas en los tratamientos IV y DOPV con los distintos niveles de lactato cálcico aplicado, así como los productos gelificados elaborados con pomelo, se almacenaron en las mismas condiciones que se detallan en el apartado III.1.2.4 de materiales y métodos (envases PET de $200 \mathrm{~mL}$, previamente sometidos a UV durante 30 minutos en campana de flujo laminar). Para el estudio 
de la tasa respiratoria, las muestras también fueron almacenadas en las mismas condiciones pero en botes de cristal.

\section{IV.1.3. Análisis realizados}

La determinación de la actividad del agua, los sólidos solubles, la humedad, el $\mathrm{pH}$, la acidez valorable, la concentración de cationes, la variación de masa, la tasa de respiración y el análisis microbiológico de las muestras se realizó tal y como se detalla en el Capítulo III, apartados III.1.3.1, III.1.3.2, III.1.3.3, III.1.3.4 III.1.3.5, III.1.3.7, III.1.3.8, III.1.3.11 y III.1.3.12 de materiales y métodos, respectivamente.

\section{IV.1.3.1. Determinación de las propiedades mecánicas}

El equipo utilizado fue el mismo que se describe en el apartado III.1.3.9. de materiales y métodos. Se realizó un ensayo de puncióncompresión, con un punzón de $15 \mathrm{~mm}$ de diámetro. Se aplicó una deformación relativa del $95 \%$ a las muestras y se realizó a una velocidad de $0,2 \mathrm{~mm} \mathrm{~s}^{-1}$. Las medidas se realizaron a temperatura ambiente y sobre las muestras previamente atemperadas.

La zona de ensayo fue la superficie entre las membranas que separan los gajos (Figura IV.1). Se realizaron 6 repeticiones para cada tipo de muestra, obteniéndose las correspondientes curvas fuerza $(N)$ distancia $(\mathrm{mm})$ que, a su vez, fueron transformadas en curvas fuerza $(F)$-deformación relativa $(\varepsilon)$ empleando la ecuación IV.1.

$$
\varepsilon(t)=\frac{d(t)}{e_{0}}
$$


donde:

$\varepsilon$ : Deformación relativa.

d: Distancia de avance del punzón durante el ensayo $(\mathrm{mm})$.

$\mathrm{e}_{0}$ : Espesor inicial de la muestra $(10 \mathrm{~mm})$.

A partir de las curvas fuerza $(F)$-deformación relativa $(\varepsilon)$ obtenidas se analizaron los siguientes parámetros:

- La pendiente del tramo lineal inicial de la curva $F-\varepsilon(E)$, expresada en Newtons.

- La fuerza de fractura $\left(F_{F}\right)$, expresada en Newtons.

- La deformación relativa en el punto de fractura $\left(\varepsilon_{F}\right)$, (adimensional).

- $\quad$ El área total $\left(A_{T}\right)$ debajo de la curva, expresada en Newtons.

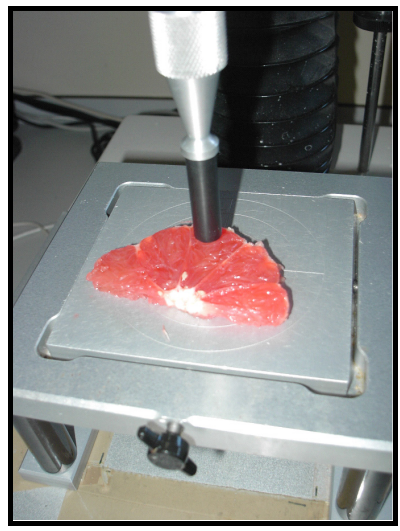

Figura IV.1. Punzón empleado en el ensayo de puncióncompresión y zona de la muestra analizada. 


\section{IV.1.3.2. Análisis sensorial}

Para el estudio del efecto del calcio y del almacenamiento en refrigeración sobre la aceptación sensorial del pomelo deshidratado se evaluaron las siguientes muestras:

A: Pomelo deshidratado sin calcio, sin almacenar $\left(\mathrm{PD}_{0 \%}\right)$.

B: Pomelo deshidratado sin calcio, almacenado durante 5 días $\left(P D_{0 \%}(5 d)\right)$.

C: Pomelo deshidratado con calcio, sin almacenar $\left(\mathrm{PD}_{2 \%}\right)$.

D: Pomelo deshidratado con calcio, almacenado durante 5 días $\left(P D_{2 \%}(5 d)\right)$.

Para el estudio del efecto del calcio y del almacenamiento en refrigeración sobre la aceptación sensorial del pomelo deshidratado incluido en matriz gelificada (Figura IV.2.) se evaluaron las siguientes muestras:

$A^{\prime}$ : Geles de pomelo sin calcio, sin almacenar $\left(\mathrm{PDG}_{0 \%}\right)$.

B': Geles de pomelo sin calcio, almacenados durante 7 días $\left(\operatorname{PDG}_{0 \%}(7 \mathrm{~d})\right)$.

$C^{\prime}$ : Geles de pomelo con calcio, sin almacenar $\left(\mathrm{PDG}_{2} \%\right)$.

D': Geles de pomelo con calcio, almacenados durante 7 días $\left(\mathrm{PDG}_{2 \%}(7 \mathrm{~d})\right)$.

El análisis sensorial fue realizado empleando una prueba discriminativa, la prueba de comparación por parejas según la norma ISO 87-005-92 equivalente a la norma ISO 5495: 1983, descrita en el apartado 1.5 .3 de la introducción. En este tipo de pruebas se pretende establecer si existen o no diferencias entre dos o más muestras y la magnitud o la importancia de esas diferencias (Larmond, 1977), sin llegar a cuantificarlas. Para la prueba de comparación pareada, a cada 
panelista se le presentó dos muestras y se le pidió que las compararan y que indicaran cual de las dos tenía mayor intensidad en cuanto a los atributos sensoriales elegidos (Larmond, 1973). Además los catadores eligieron para cada pareja de muestras la preferida.

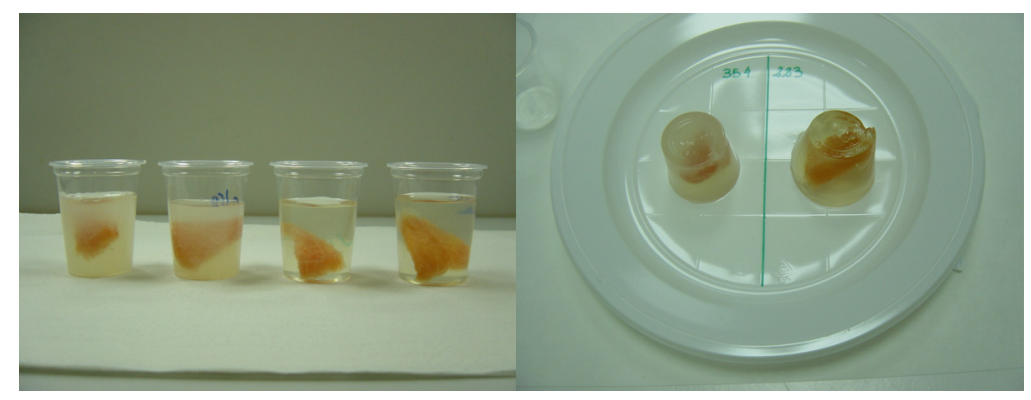

Figura IV.2. Preparación de las muestras para los análisis sensoriales.

Para la realización de la prueba sensorial se constituyó un panel de 30 jueces no entrenados, algunos no consumidores habituales de pomelo. Los atributos elegidos para el análisis fueron: apariencia, aroma, color, textura, sabor y muestra preferida.

A cada juez se le ofreció 6 parejas de muestras en cada sesión que fueron el resultado de todas las combinaciones posibles de las distintas muestras preparadas; a cada una de ellas se le asignó un código para que el catador no supiera de qué muestra se trataba.

Las parejas de muestras en ambos análisis sensoriales fueron las siguientes: $A B, A C, A D, B C, B D, C D$ y $A^{\prime} B^{\prime}, A^{\prime} C^{\prime}, A^{\prime} D^{\prime}, B^{\prime} C^{\prime}, B^{\prime} D^{\prime}$, C'D'.

A cada juez se le explicó en que consistía la prueba y posteriormente se les repartió un cuestionario donde tenían que evaluar las distintas parejas de muestras, eligiendo entre los distintos atributos 
para cada pareja. No se le repartía la siguiente pareja hasta que no hubieran acabado de evaluar la anterior.

Para el análisis de resultados se hizo una comparación pareada múltiple, mediante la técnica de Análisis de Friedman (Pairwase Ranking Test) (Meilgaard et al., 1999). Esta técnica nos permite ordenar las muestras para el atributo escogido en una escala de intensidad, indicando mediante una escala numérica las diferencias entre las muestras y la significación de esas diferencias.

Para determinar de manera conjunta el efecto del calcio y del almacenamiento tanto del pomelo deshidratado como de los geles con pomelo deshidratado, así como la preferencia por parte de los jueces, se realizó un análisis de correspondencias (Benzecri, 1982). Para ello, se elaboró una tabla resumen, con las cuatro muestras en las filas y los 6 atributos en las columnas, valorando así el número de respuestas positivas y negativas de cada atributo (las negativas se obtuvieron restando al total de respuestas las positivas de cada atributo). Se considera respuesta positiva cuando la muestra es preferida. De esta forma todos los atributos tienen la misma importancia en el análisis y las respuestas tanto positivas como negativas son representadas en el espacio factorial (Judez-Asensio, 1989). El análisis de correspondencia se realizó con el Matlab 5.3. 
IV. ESTUDIO DEL EFECTO DE

LA ADICIÓN DE LACTATO CÁLCICO A LA DISOLUCIÓN OSMÓTICA PARA LA OBTENCIÓN DE PRODUCTOS GELIFICADOS CON POMELO

\section{IV.2. RESULTADOS Y DISCUSIÓN}

IV.2.1. Estudio cinético de la deshidratación osmótica del pomelo. Influencia del catión calcio

Con el fin de estudiar la influencia del calcio en la cinética de deshidratación osmótica con pulso de vacío del pomelo, se siguió el procedimiento experimental que aparece en el apartado IV.1.2.2 de materiales y métodos. Éste fue idéntico al realizado para el estudio de la cinética de deshidratación osmótica de pomelo del Capítulo anterior (Apartado III.2.1), salvo que se añadió un $2 \%$ de lactato cálcico a la 
disolución osmótica, por lo que la comparación con los resultados ya mostrados permitirá analizar el efecto del catión calcio.

\section{IV.2.1.1. Caracterización de las propiedades fisicoquímicas del pomelo durante la deshidratación osmótica}

Los pomelos frescos de partida se seleccionaron en base a los ${ }^{\circ} \mathrm{Brix}$, presentando un valor promedio de 9,1 \pm 0,2, sin diferencias significativas respecto al lote empleado en el estudio cinético sin calcio.

De la misma forma que en el estudio anterior, para cada tiempo de deshidratación se midió la fracción másica de agua y sólidos solubles, así como la $\mathrm{a}_{\mathrm{w}}$ de las muestras, cuyos valores promedio aparecen en la tabla IV.1. Como las desviaciones experimentales de la medida de la actividad del agua fueron inferiores a la sensibilidad del equipo $(0,003)$, se ha considerado dicha sensibilidad como desviación (Tabla IV.I).

Cabe recordar que el tiempo cero corresponde al pomelo después de la aplicación del pulso de vacío y una vez restaurada la presión atmosférica.

Como ya se comentó en el estudio cinético sin calcio (Apartado III.2.1), se observa un cambio composicional inicial importante como consecuencia de la entrada de la disolución osmótica en los poros del tejido durante el pulso a vacío y posteriormente una disminución más gradual en la fracción másica de agua y $\mathrm{a}_{\mathrm{w}}$ de las muestras, así como un aumento en la fracción de sólidos solubles, como era de esperar debido a los gradientes de concentración que se producen durante el proceso osmótico.

La influencia del catión calcio sobre la cinética de deshidratación osmótica del pomelo se analizará a continuación en base la difusividad efectiva del agua en ambas experiencias, con y sin calcio. A su vez se 
estudiará el efecto del catión en términos de la cinética de pérdida de agua y ganancia de solutos (Apartado IV.2.1.3).

Tabla IV.1. Fracción másica de agua y sólidos solubles y actividad del agua del pomelo deshidratado osmóticamente, con $2 \%$ de lactato cálcico añadido, en función del tiempo de deshidratación.

\begin{tabular}{|c|c|c|c|c|c|c|c|c|}
\hline$t(\min )$ & & $x_{w}$ & & & $x_{s}$ & & $a_{w}$ & \\
\hline 0 & 0,8331 & & $0,0006^{(a)}$ & 0,1575 & $\pm 0,0001^{(\mathrm{a})}$ & 0,985 & + & $0,003^{(a)}$ \\
\hline 15 & 0,806 & & $0,000^{(\mathrm{c})}$ & 0,182 & $\pm 0,002^{(\mathrm{c})}$ & 0,984 & \pm & $0,003^{(a)(b)}$ \\
\hline 30 & 0,8149 & \pm & $0,0001^{(b)}$ & 0,179 & $\pm 0,000^{(b)}$ & 0,982 & + & $0,003^{(b)(c)}$ \\
\hline 45 & 0,8098 & - & $0,0005^{(\mathrm{c})}$ & 0,1790 & $\pm 0,0001^{(b)}$ & 0,978 & + & $0,001^{(f)(g)}$ \\
\hline 60 & 0,806 & & $0,000^{(\mathrm{c})}$ & 0,1830 & $\pm 0,0000^{(\mathrm{c})}$ & 0,981 & & $0,001^{(\mathrm{c})(\mathrm{d})(\mathrm{e})}$ \\
\hline 90 & 0,8004 & & $0,0052^{(\mathrm{d})}$ & 0,1914 & $\pm 0,0012^{(\mathrm{d})}$ & 0,981 & & $0,003^{(c)(d)}$ \\
\hline 180 & 0,7953 & & $0,0005^{(\mathrm{e})}$ & 0,200 & $\pm 0,000^{(e)}$ & 0,980 & \pm & $0,003^{(d)(e)(f)}$ \\
\hline 300 & 0,785 & & $0,001^{(f)}$ & 0,202 & $\pm 0,000^{(f)}$ & 0,978 & \pm & $0,001^{(\mathrm{g})}$ \\
\hline 480 & 0,7682 & \pm & $0,0002^{(\mathrm{g})}$ & 0,2160 & $\pm 0,0009^{(\mathrm{g})}$ & 0,979 & \pm & $0,003^{(e)(f)(g)}$ \\
\hline
\end{tabular}

$(a)(b)(c)(d)(e)(f)(g)$ Grupos homogéneos establecidos por el ANOVA $(\alpha<0,05)$ con el factor tiempo de deshidratación.

\section{IV.2.1.2. Estimación de la difusividad efectiva del agua}

A partir de los datos de composición se calculó la fuerza impulsora para la transferencia de agua $\left(Y_{w}^{t}\right)$ a cada tiempo deshidratación (Ecuación III.2). La pendiente del ajuste lineal de los valores de 1- $Y_{w}^{t}$ frente a la raíz cuadrada del tiempo (Figura IV.3), permitió obtener el valor de la difusividad efectiva $\left(D_{e}\right)$ del agua en este proceso de deshidratación osmótica con calcio (Ecuación III.1), que resultó ser de $1,80 \cdot 10^{-11} \mathrm{~m}^{2} / \mathrm{s}\left(\mathrm{R}^{2}=0,939\right)$. 


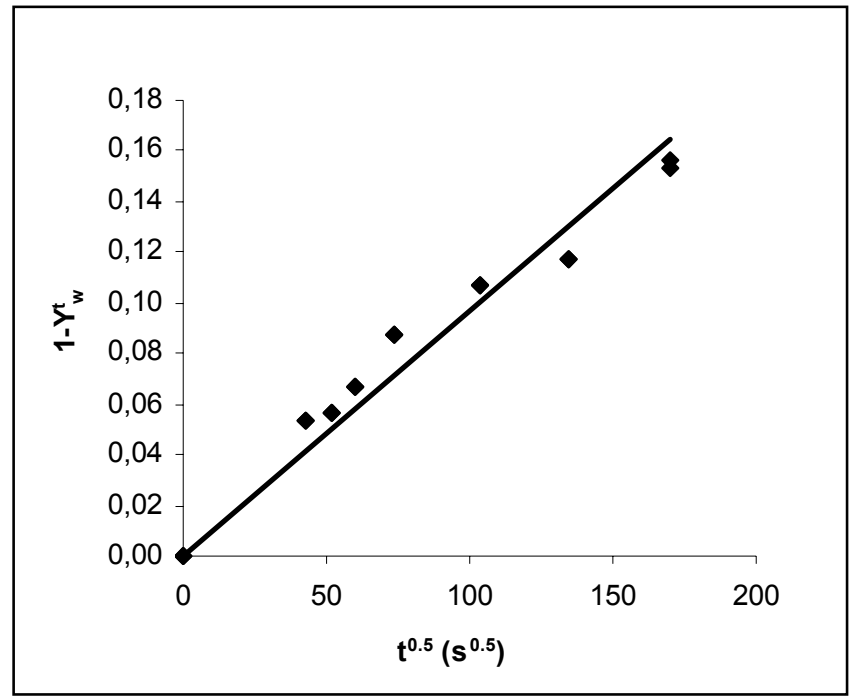

Figura IV.3. Representación de $1-Y_{w}^{t}$ frente a la raíz cuadrada del tiempo (ver ecuación III.1).

Este valor de $D_{e}$ fue aproximadamente la mitad del valor obtenido para la $D_{e}$ en la cinética de deshidratación osmótica de pomelo sin calcio (Apartado III.2.1.2) que fue de $3,64 \cdot 10^{-11} \mathrm{~m}^{2} / \mathrm{s}$. Por lo tanto, podemos afirmar que la adición de lactato cálcico a la disolución osmótica redujo el transporte global de agua en el tejido, tal y como ha sido descrito por otros autores. Barrera et al. (2004) encontraron una $D_{e}$ en manzana de $23,0 \cdot 10^{-11} \mathrm{~m}^{2} / \mathrm{s}$ en condiciones similares al estudio realizado sin calcio, mientras que al agregar un $1 \%$ de lactato cálcico, la $\mathrm{D}_{\mathrm{e}}$ disminuyó a $17,6 \cdot 10^{-11} \mathrm{~m}^{2} / \mathrm{s}$. En mitades de fresa, la adición de un $1 \%$ de lactato cálcico supuso una reducción de la $D_{e}$ de $6,97 \cdot 10^{-11} \mathrm{~m}^{2} / \mathrm{s}$ a $5,78 \cdot 10^{-11} \mathrm{~m}^{2} / \mathrm{s}$ (Castelló, 2007). La mayor reducción del valor de $D_{e}$ en nuestro estudio podría estar relacionado con la mayor concentración de lactato cálcico añadido (2\%). 
Estos autores atribuyen el descenso en la velocidad de transferencia de materia al efecto del calcio, que actuaría como refuerzo de la estructura celular (Azcón-Bieto y Talón, 2000), haciendo menos permeables a las membranas y paredes celulares.

Por otro lado, se ha descrito un efecto protector del calcio frente al estrés osmótico, ya que actúa frenando el transporte de agua a través de la membrana. Esta reducción en el transporte de agua al aumentar la disponibilidad de $\mathrm{Ca}^{2+}$, podría ser explicada por la interacción de este catión con la proteína PM28A, canal proteico de transporte activo de agua (aquaporin) que ocurre con consumo de ATP (Lynch et al. 1989; Tyerman et al., 1999; Knight y Knight, 1999). Al aumentar la concentración de $\mathrm{Ca}^{2+}$ en el interior del protoplasto, la célula incrementa sus mecanismos de defensa frente al estrés osmótico, reduciéndose la pérdida de agua a través de la membrana plasmática a la ocurrida sólo por transporte pasivo, más lento que el activo, mostrándose un transporte global de agua más lento en todo el tejido.

\section{IV.2.1.3. Cinética de pérdida de agua y ganancia de solutos}

Para el cálculo de las variaciones de masa total $\left(\Delta \mathrm{M}_{\mathrm{T}}\right)$, de agua $\left(\Delta \mathrm{M}_{\mathrm{w}}\right)$ y solutos $\left(\Delta \mathrm{M}_{\mathrm{s}}\right)$ se utilizaron las mismas ecuaciones descritas en el Capítulo III, apartado III.2.1.3 de resultados. En la tabla IV.2 se muestran los valores obtenidos, referidos por unidad de masa inicial de producto en función del tiempo de deshidratación osmótica. La representación de las pérdidas relativas de agua más las ganancias de solutos frente a las pérdidas de masa total permitió verificar el balance de materia en esta experiencia de deshidratación osmótica (Figura IV.4). 
Tabla IV.2. Valores de la variación de masa total $\left(\Delta \mathrm{M}_{\mathrm{T}}\right)$, ganancia de solutos $\left(\Delta \mathrm{M}_{\mathrm{S}}\right)$ y pérdida de agua $\left(\Delta \mathrm{M}_{\mathrm{W}}\right)$, referidos por unidad de masa inicial de producto en función del tiempo de deshidratación osmótica.

\begin{tabular}{ccccccccccc}
\hline $\mathbf{t}(\mathbf{m i n})$ & \multicolumn{3}{c}{$\Delta \mathbf{M}_{\mathbf{T}}$} & \multicolumn{3}{c}{$\Delta \mathbf{M}_{\mathbf{w}}$} & \multicolumn{3}{c}{$\Delta \mathbf{M}_{\mathbf{s}}$} \\
\hline 0 & $-0,07$ & \pm & 0,02 & & - & & & - & \\
15 & $-0,011$ & \pm & 0,001 & $-0,036$ & \pm & 0,008 & 0,022 & \pm & 0,003 \\
30 & $-0,09$ & \pm & 0,01 & $-0,096$ & \pm & 0,009 & 0,004 & \pm & 0,002 \\
45 & $-0,092$ & \pm & 0,005 & $-0,098$ & \pm & 0,004 & 0,0050 & \pm & 0,001 \\
60 & $-0,070$ & \pm & 0,008 & $-0,083$ & \pm & 0,006 & 0,012 & \pm & 0,001 \\
90 & $-0,111$ & \pm & 0,012 & $-0,121$ & \pm & 0,005 & 0,013 & \pm & 0,001 \\
180 & $-0,093$ & \pm & 0,012 & $-0,111$ & \pm & 0,009 & 0,024 & \pm & 0,002 \\
300 & $-0,07$ & \pm & 0,02 & $-0,100$ & \pm & 0,014 & 0,031 & \pm & 0,004 \\
480 & $-0,11$ & \pm & 0,03 & $-0,15$ & \pm & 0,02 & 0,035 & \pm & 0,007 \\
\hline
\end{tabular}

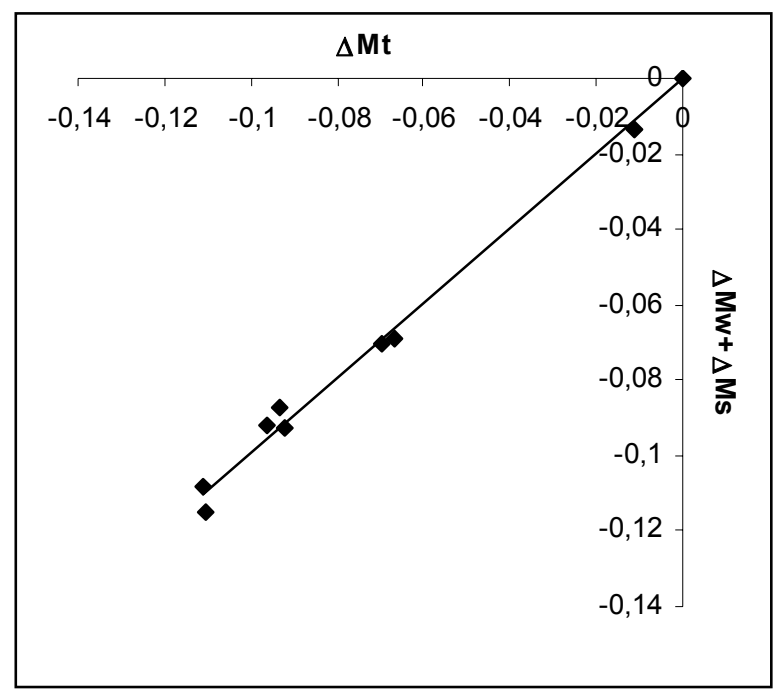

Figura IV.4. Relación entre la pérdida de peso de las muestras a cada tiempo de deshidratación y la pérdida de agua más la ganancia de solutos. 
Si se comparan los valores con los de la tabla III.2, para el tiempo de estudio seleccionado (180 min), la pérdida de agua es más acusada en el tratamiento sin calcio. Esto concuerda con los resultados comentados en el apartado anterior en relación con el papel del calcio en la defensa celular frente al estrés osmótico.

De igual manera, al agregar calcio el transporte de solutos también se ve reducido, lo que se observa al comparar ambas tablas (Tablas III.2 y IV.2).

La representación gráfica de las variaciones de masa total, masa de agua y masa de solutos frente al tiempo de tratamiento (Figura IV.5) permite observar un comportamiento oscilante en cada una de ellas, como ya fue descrito para el tratamiento sin calcio (Figura III.9).

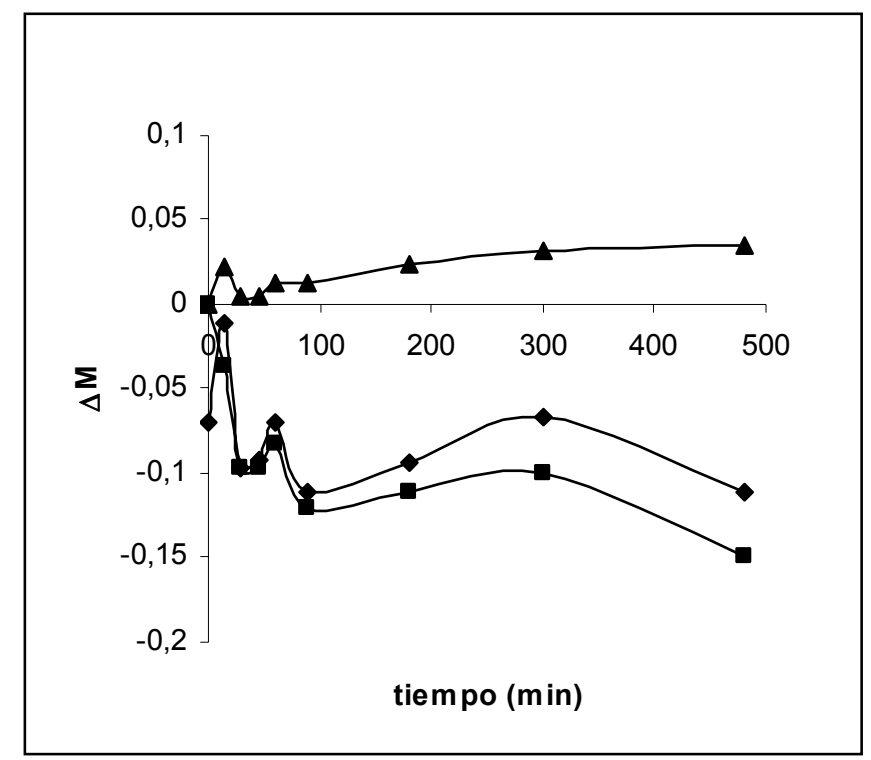

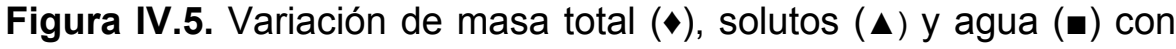
el tiempo de procesado osmótico. 
Como ya se comentó en el capítulo anterior, este comportamiento refleja la existencia de dos mecanismos acoplados contrapuestos, el difusional (por diferencias de potencial químico) y el mecánico (por diferencias de presión). La adición de calcio parece aportar mayor carácter elástico al tejido, lo que se desprende de la mayor frecuencia con la que aparecen los ciclos de relajación-compresión en el tejido. Esto podría estar relacionado con la función del calcio en la lámina media, que forma puentes de pectato cálcico, aportando carácter elástico al tejido (Azcón-Bieto y Talón, 2000).

\section{IV.2.2. Obtención de pomelo deshidratado para la formulación del} producto gelificado. Influencia del catión calcio, del pulso de vacío y del almacenamiento en refrigeración

Con el objetivo de estudiar el efecto del calcio y el impacto causado por los tratamientos de impregnación a vacío (IV) y de deshidratación osmótica con pulso de vacío (DOPV) sobre diferentes propiedades del pomelo, se prepararon las muestras tal y como se describe en el apartado IV.1.2.3 de materiales y métodos.

Para los tratamientos de impregnación a vacío se empleó una disolución isotónica de $18^{\circ} \mathrm{Brix}$ al 0,1 y $2 \%$ en lactato cálcico, obteniéndose las muestras $\mathrm{IV}_{0 \%}, \mathrm{IV}_{1 \%}$ y $\mathrm{IV}_{2 \%}$, respectivamente. En el caso de los tratamientos de deshidratación osmótica con pulso de vacío se empleó una disolución hipertónica de $55^{\circ}$ Brix al 0,1 y $2 \%$ en lactato cálcico obteniéndose las muestras $P_{0}, \quad \mathrm{PD}_{1 \%}$ y $\mathrm{PD}_{2 \%}$, respectivamente.

Las disoluciones empleadas en los tratamientos IV presentaron un valor de actividad del agua de $0,987 \pm 0,003,0,988 \pm 0,003$ y $0,987 \pm$ 0,003 para $I V_{0 \%}, \quad I V_{1 \%}$ y $\quad \mathrm{IV}_{2 \%}$, respectivamente, sin diferencias 
significativas $(\alpha>0,05)$ con respecto a la actividad del agua del pomelo fresco $(0,987 \pm 0,003)$, confirmándose la isotonicidad de las mismas.

La selección de 180 min como tiempo óptimo de aplicación de los tratamientos de deshidratación osmótica con pulso de vacío se realizó a partir de los resultados obtenidos en el estudio cinético (Capítulo III, apartado III.2.1 de resultados). A partir de este tiempo la deshidratación se hace mucho más lenta, por lo que no se justifica el prolongar el tiempo de permanencia de las muestras en la disolución osmótica.

IV.2.2.1. Efecto de los tratamientos de impregnación a vacío y de deshidratación osmótica con pulso de vacío en la fruta deshidratada. Influencia del catión calcio y del almacenamiento en refrigeración

\section{IV.2.2.1.1. Efecto sobre la humedad y los sólidos solubles}

A continuación se muestra la fracción másica de agua y solutos de las muestras estudiadas, tanto frescas como tratadas, antes (Tabla IV.3) y después de su almacenamiento durante 7 días en refrigeración (tabla IV.4). En estas tablas aparecen las variaciones de masa, agua y solutos asociadas a los tratamientos y al almacenamiento en refrigeración, respectivamente. 


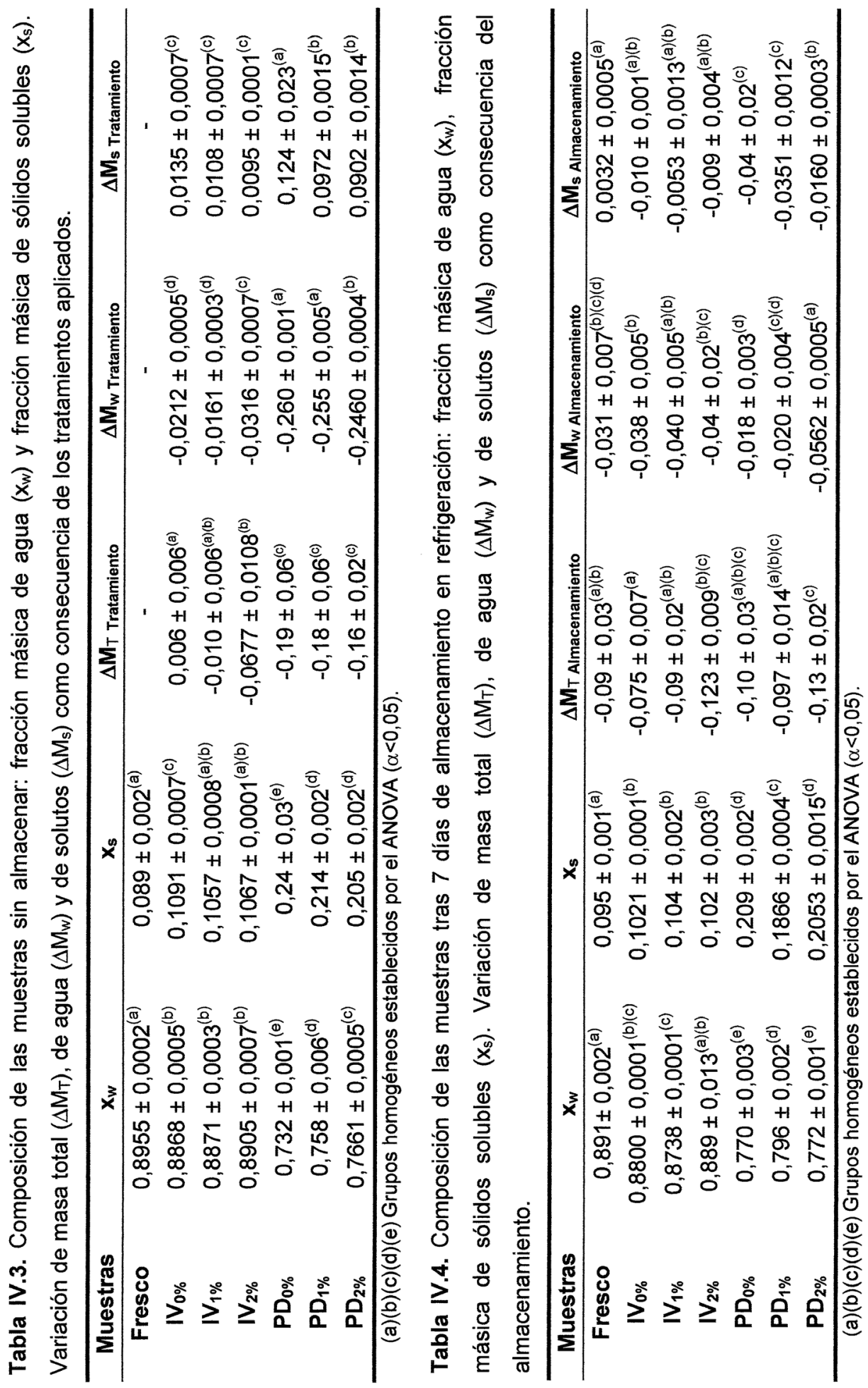


Para su cálculo se emplearon las ecuaciones III.2, III.13 y III.14 descritas en el Capítulo III, apartado III.2.1.3 de resultados, teniendo en cuenta que, para el cálculo de las variaciones provocadas por el tratamiento (Tabla IV.3), el estado inicial corresponde a la muestra fresca y el final a la muestra después de cada tratamiento, mientras que, para el cálculo de las variaciones provocadas por el almacenamiento en refrigeración (Tabla IV.4), el estado inicial corresponde a la muestra tratada sin almacenar y el final a la muestra tratada y almacenada durante 7 días.

Los lotes de pomelo fresco empleados no presentaron diferencias significativas $(\alpha>0,05)$ en cuanto a la fracción másica de agua y solutos, por lo que en las tablas aparece el valor promedio de los valores obtenidos.

Los tratamientos de impregnación aplicados provocaron pequeñas variaciones de masa en las muestras. Por un lado, como consecuencia del llenado de los poros del tejido por disolución isotónica, sería esperable un aumento en la variación de masa. Sin embargo, debido a las características del tejido, la gran pérdida de fase líquida de las células próximas al corte como consecuencia del pulso de vacío aplicado, contrarrestaría este aumento, llegando a ser negativo en algunos casos.

Aunque la disolución empleada para los tratamientos osmóticos fue isotónica se observaron ligeras variaciones composicionales, sin observarse un efecto claro en función del nivel de calcio añadido. Las muestras impregnadas ganaron en promedio un $1,1 \%$ de sólidos solubles y perdieron un $2,3 \%$ de agua. Puesto que el proceso de impregnación con disolución isotónica no supone una deshidratación celular por mecanismos difusionales, la ligera variación composicional será debida a la sustitución del gas ocluido en los poros por la 
disolución empleada en cada caso, la cual, por ser isotónica presentó un valor de $a_{w}$ igual a la fruta aunque la fracción másica de agua y solutos no lo fueran.

Durante el proceso de deshidratación con pulso de vacío, la variación de masa de las muestras fue del 17-18\%, sin diferencias significativas en función del nivel de calcio empleado. La humedad del pomelo disminuyó de manera considerable, como consecuencia del gradiente de potencial químico del agua generado entre la disolución hipertónica y la muestra, presentando después del tratamiento un contenido en humedad que varió entre el 73 y el $76 \%$, en función del nivel de calcio añadido a la disolución. De nuevo se observa el efecto protector del calcio frente a la deshidratación celular, ya comentado anteriormente.

Cuanto mayor fue el nivel de calcio empleado, menor fue la deshidratación del tejido y, por tanto, mayor la fracción másica del agua después del tratamiento, aunque únicamente resultó significativa $(\alpha<0,05)$ la variación de agua provocada en el producto al deshidratarlo con disolución osmótica al $2 \%$ de lactato cálcico. La adición de calcio, independientemente del nivel empleado, provocó una reducción significativa $(\alpha<0,05)$ en el transporte de solutos, lo que ya fue observado con anterioridad en el estudio cinético realizado (Apartado IV.2.1.3 de resultados).

Durante el almacenamiento en refrigeración, todas las muestras perdieron peso, siendo esta pérdida algo superior en los tratamientos con calcio (Tabla IV.4). En las muestras impregnadas se observa fundamentalmente pérdida de agua como consecuencia del equilibrado de las muestras con el ambiente en el interior del envase, ya que prácticamente no hay pérdida de solutos por lixiviación, mientras que en las muestras deshidratadas también ocurre una pérdida importante de 
solutos, probablemente debido a la sacarosa que queda en la superficie tras el tratamiento osmótico.

\section{IV.2.2.1.2. Efecto sobre el $\mathrm{pH}$ y la acidez valorable}

La figura IV.6 muestra los valores de pH y acidez valorable (g ácido cítrico/100g de muestra) obtenidos en las muestras estudiadas, antes y después de 7 días de almacenamiento en refrigeración. Los lotes de pomelo fresco empleados para los diferentes tratamientos aplicados no fueron homogéneos, ya que presentaron diferencias significativas $(\alpha<0,05)$ en estos parámetros, por lo que ambos se representan en la figura IV.6.

La fruta fresca empleada para los tratamientos de impregnación a vacío resultó tener mayor acidez y menor $\mathrm{pH}$ que la empleada para los tratamientos de deshidratación osmótica, presentando ambos lotes un índice de madurez (IM), calculado a través de la ecuación IV.1, de 5,45 $\pm 0,07$ y $7,34 \pm 0,13$ respectivamente.

$$
\mathrm{IM}=\frac{{ }^{\circ} \text { Brix }}{\text { Acidez }}
$$

Como se puede observar en la figura IV.6, las muestras frescas presentaron mayor acidez que las muestras tratadas. Como ya fue descrito en el Capítulo III, apartado III.2.2.2.2 de resultados, el tratamiento de deshidratación implicó un descenso significativo $(\alpha<0,05)$ en el contenido en ácido cítrico de las muestras, el cual pasa junto con el agua de la fruta a la disolución osmótica durante el proceso de deshidratación. Esta disminución fue significativamente mayor $(\alpha<0,05)$ en las muestras deshidratadas con calcio. 


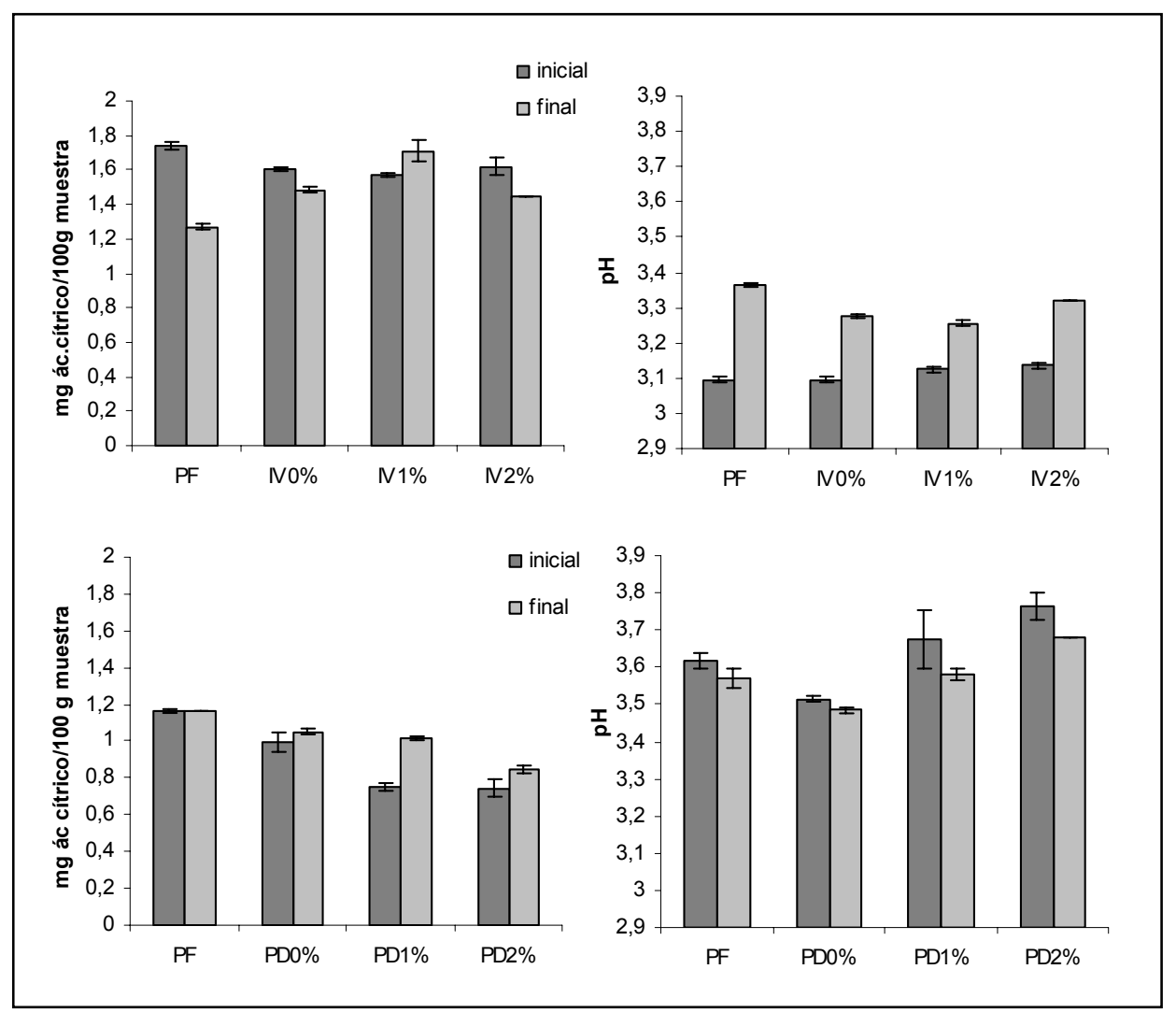

Figura IV.6. Acidez valorable ( $\mathrm{mg}$ ácido cítrico/100 g muestra) y $\mathrm{pH}$ de las muestras PF: pomelo fresco, IV: pomelo impregnado a vacío con disolución isotónica y PD: pomelo deshidratado, antes (inicial) y después (final) de 7 días de almacenamiento en refrigeración. El subíndice 0,1 y $2 \%$ hace referencia al porcentaje de lactato cálcico presente en la disolución.

Durante el proceso de impregnación, como consecuencia del pulso de vacío, habrá una salida de líquido nativo (agua más solutos solubles presentes en ella como el ácido cítrico) procedente de las células más próximas al corte, que pasará a la disolución, lo que explicaría la 
significativa $(\alpha<0,05)$ menor acidez de las muestras IV, que fue independiente del nivel de calcio presente en la disolución.

Respecto al $\mathrm{pH}$, se puede observar que corresponde con los valores de acidez, de manera que cuando ésta tiene valores elevados, el pH, es bajo, y viceversa. Sin embargo, la diferente acidez de las muestras antes y después de cada tratamiento dio lugar a pequeños cambios en el $\mathrm{pH}$ de las mismas. El efecto de la adición de lactato calcio a la disolución sobre el $\mathrm{pH}$, resultó significativo $(\alpha<0,05)$ tanto en las muestras impregnadas como en las deshidratadas, de manera que su adición, implicó un aumento en el pH de las muestras, probablemente debido al efecto de la unión del lactato con hidrogeniones al disociarse.

Tras 7 días de almacenamiento en refrigeración se observaron cambios significativos en los parámetros de acidez y pH. Así, el pomelo fresco empleado para los tratamientos IV, presentó una pérdida de acidez y un aumento de $\mathrm{pH}$ durante el almacenamiento, pauta que fue seguida por las muestras IV, salvo en el caso de la muestras $\mathrm{IV}_{1 \%}$ que presenta un valor anómalo en la acidez, lo que podría ser debido a errores experimentales. Sin embargo, las muestras PD sigueron la pauta inversa ya que tras el almacenamiento aumentó ligeramente la acidez de las mismas y disminuyó ligeramente el $\mathrm{pH}$, sin llegar a ser este cambio, por lo general, estadísticamente significativo.

\section{IV.2.2.1.3. Efecto sobre el contenido en cationes}

Siguiendo la metodología descrita en el apartado IV.1.3 de materiales y métodos, se analizó por cromatografía iónica el contenido en $\mathrm{Ca}^{2+}$ y otros minerales mayoritarios en el pomelo como el $\mathrm{Na}^{+}, \mathrm{Mg}^{2+} \mathrm{y}$ $\mathrm{K}^{+}$. El análisis de los cromatogramas obtenidos nos permitió calcular el contenido en estos cationes en cada una de las muestras estudiadas. 
En la tabla IV.5 aparecen los resultados obtenidos para el calcio, expresados tanto por cada $100 \mathrm{~g}$ de muestra final como por cada $100 \mathrm{~g}$ de muestra fresca de partida. Además, en ella se muestran las ganancias y pérdidas de este catión $\left(\mathrm{mg} \mathrm{Ca}^{2+}\right.$ perdido o ganado/ $\mathrm{mg}$ $\mathrm{Ca}^{2+}$ en la muestra fresca) durante los diferentes tratamientos estudiados así como después de 7 días de almacenamiento en refrigeración.

Tabla IV.5. Contenido en calcio de las muestras estudiadas. Ganancias o pérdidas de $\mathrm{Ca}^{2+}$ como consecuencia del tratamiento y del almacenamiento.

\begin{tabular}{|c|c|c|c|c|}
\hline Muestras & (a) $\mathrm{Ca}^{2+}$ & (b) $\mathrm{Ca}^{2+}$ & $\begin{array}{l}\text { (c) } \Delta \mathrm{Ca}^{2+} \\
\text { Tratamiento }\end{array}$ & $\begin{array}{l}{ }^{\text {(c) }} \Delta \mathrm{Ca}^{2+} \\
\text { Almacenamiento }\end{array}$ \\
\hline PF & $17,0 \pm 0,9$ & - & - & $-0,06$ \\
\hline $\mathrm{IV}_{0 \%}$ & $11,7 \pm 0,5$ & $11,6 \pm 0,5$ & $-0,31$ & $-0,06$ \\
\hline $\mathbf{I V}_{1 \%}$ & $34,3 \pm 0,9$ & $34,7 \pm 0,9$ & 1,03 & $-0,13$ \\
\hline $\mathbf{I V} \mathbf{V}_{2 \%}$ & $52,3 \pm 0,6$ & $56,2 \pm 0,6$ & 2,09 & $-0,17$ \\
\hline $\mathrm{PD}_{0 \%}$ & $12,33 \pm 0,09$ & $15,13 \pm 0,11$ & $-0,34$ & $-0,04$ \\
\hline $\mathbf{P D}_{1 \%}$ & $43,3 \pm 0,4$ & $52,6 \pm 0,4$ & 1,48 & $-0,13$ \\
\hline $\mathrm{PD}_{2 \%}$ & $74,4 \pm 0,5$ & $88,9 \pm 0,6$ & 3,31 & $-0,22$ \\
\hline
\end{tabular}

${ }^{a} \mathrm{mg}$ mineral/ $100 \mathrm{~g}$ muestra fresca

${ }^{b} \mathrm{mg}$ mineral/ $100 \mathrm{~g}$ muestra deshidratada

${ }^{\mathrm{c}} \mathrm{mg}$ mineral perdido o ganado / mg mineral muestra fresca.

Los lotes de fruta fresca empleados no presentaron diferencias significativas $(\alpha>0,05)$ en cuanto al contenido en calcio, que fue similar al encontrado por otros autores (Peiró et al., 2006; Mataix, 1998). Por ello se calculó el valor promedio de los lotes estudiados, que es el que aparece en la tabla IV.5.

Como era de esperar, todos los tratamientos aplicados ocasionaron pérdidas en este catión, salvo aquellos en que se incorporó calcio a la disolución, que dieron lugar a muestras con un contenido en calcio tanto 
mayor cuanto mayor fue la cantidad del catión incorporado. La pérdida de calcio de las muestras $\mathrm{PD}_{0 \%}$ fue del orden de las obtenidas en el estudio anterior, Capítulo III, apartado III.2.2.2.3 de resultados. En el caso de las muestras $\mathrm{IV}_{0 \%}$, la pérdida de calcio puede deberse a la pérdida de fase líquida durante la etapa a vacío y a la incorporación de disolución sin calcio en los espacios intercelulares del producto.

Como se observa en la tabla IV.6, ambos tratamientos sin calcio ocasionaron pérdidas similares en el contenido de este mineral aunque ligeramente mayores en el tratamiento osmótico. Esto demuestra la importancia de los mecanismos hidrodinámicos asociados al pulso de vacío en el transporte de este mineral, influyendo en menor medida el transporte difusional. La técnica IV se confirma pues como un buen modo de incorporar solutos a alimentos como el pomelo. La ligera mayor pérdida de calcio en las muestras $\mathrm{PD}_{0 \%}$ corresponde con el paso del calcio a la disolución osmótica, conjuntamente con el agua, durante el proceso de deshidratación.

Para el mismo nivel de lactato cálcico incorporado en la disolución, las muestras PD presentan mayores aumentos en el contenido de calcio que las muestras IV. Esto puede deberse a que en los tratamientos de deshidratación osmótica las muestras permanecen sumergidas en la disolución osmótica durante un tiempo más prolongado, alrededor de 3 horas, a diferencia de los tratamientos IV donde la muestra está en contacto con la disolución $20 \mathrm{~min}$. Durante este tiempo, el calcio puede penetrar en el interior de la fruta y atravesar las membranas celulares empleando diferentes mecanismos, tanto activos como pasivos.

El almacenamiento en refrigeración provocó pérdidas en el contenido de este catión de todas las muestras, las cuales fueron mayores cuanto mayor fue el contenido en calcio de partida. 
En cuanto al resto de cationes estudiados, $\mathrm{Na}^{+}, \mathrm{Mg}^{2+}$ y $\mathrm{K}^{+}$, en la figura IV.7 se representan los valores obtenidos expresados por cada $100 \mathrm{~g}$ de muestra fresca de partida, en función del contenido en lactato cálcico añadido, antes y después de su almacenamiento en refrigeración.

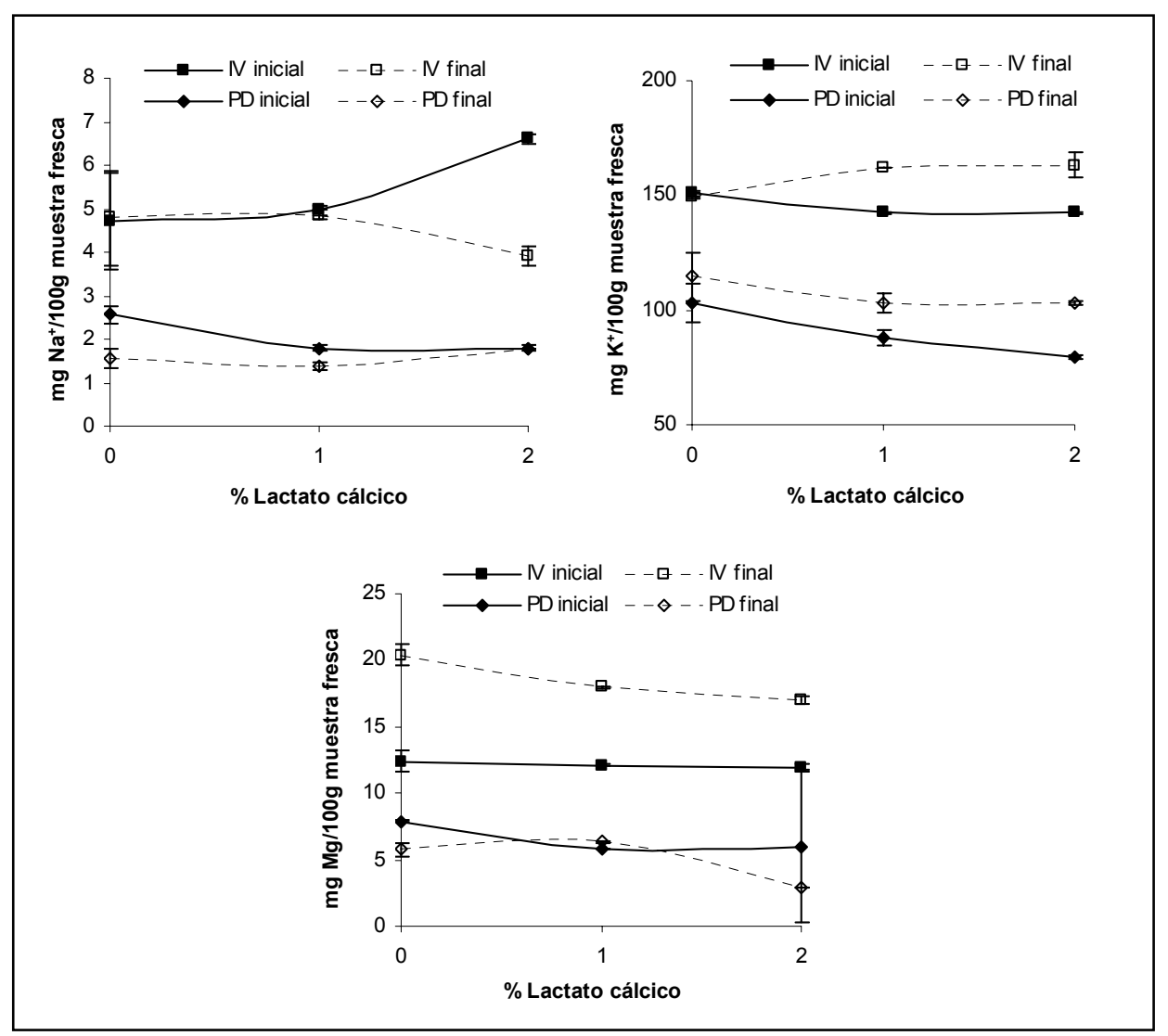

Figura IV.7. Contenido en $\mathrm{Na}^{+}, \mathrm{K}^{+}$y $\mathrm{Mg}^{2+}$ de las muestras estudiadas antes y después de 7 días de almacenamiento en refrigeración, en función del calcio añadido. 
Los dos lotes de fruta fresca empleados presentaron diferencias significativas $(\alpha<0,05)$ en el contenido de estos cationes, presentando una cantidad de $76 \mathrm{mg} \mathrm{Na}^{+}, 21 \mathrm{mg} \mathrm{Mg}^{2+}$ y $196 \mathrm{mg} \mathrm{K}^{+}$por cada $100 \mathrm{~g}$ de muestra fresca, el lote usado en los tratamientos de impregnación a vacío con disolución isotónica y $2 \mathrm{mg} \mathrm{Na}^{+}, 2 \mathrm{mg} \mathrm{Mg}^{2+}$ y $157 \mathrm{mg} \mathrm{K}^{+}$por cada $100 \mathrm{~g}$ de muestra fresca, el lote usado en los tratamientos de deshidratación osmótica.

Si comparamos los resultados obtenidos en estos lotes con respecto a los utilizados en el estudio sin calcio, Capítulo III, apartado III.2.2.2.3 de resultados, o los encontrados por otros autores (de 2 a $4 \mathrm{mg} \mathrm{Na}^{+}, 10$ a $12 \mathrm{mg} \mathrm{Mg}^{2+}$ y 190 a $206 \mathrm{mg} \mathrm{K}^{+}$por cada $100 \mathrm{~g}$ muestra fresca, según Peiró et al., 2006) el valor del contenido en $\mathrm{Na}^{+}$y $\mathrm{Mg}^{2+}$ del primer lote es demasiado elevado, lo que probablemente se deba a un error experimental. A pesar de que los valores de ambos cationes del mencionado lote no puedan ser considerados como reales, si que es posible que sean superiores a los del otro lote, ya que según Kamis et al. (2004) el contenido en cationes disminuye al madurar la fruta.

En todos los casos las muestras PD, que proceden de un lote con menor concentración en estos cationes, presentaron un contenido en $\mathrm{Na}^{+}, \mathrm{Mg}^{2+}$ y $\mathrm{K}^{+}$inferior a las muestras IV, lo que a su vez puede estar relacionado con los mayores tiempos de tratamiento que provocarían mayores pérdidas por difusión.

No existe un efecto claro del calcio en el contenido del resto de cationes analizados aunque, por lo general, se observa una tendencia a disminuir la concentración de los mismos al incorporar lactato cálcico en la disolución, a excepción de las muestras IV, cuyo contenido en $\mathrm{Na}^{+}$ aumenta al incorporar un $2 \%$ de lactato cálcico.

Por lo general el almacenamiento en refrigeración provocó un aumento en el contenido de $\mathrm{K}^{+}$y $\mathrm{Mg}^{2+}$ que podría ser debido a la 
concentración de dichos cationes por la pérdida de agua durante el almacenamiento aunque en el caso del catión $\mathrm{Na}^{+}$, no se advierte el mismo comportamiento.

\section{IV.2.2.1.4. Efecto sobre la tasa respiratoria}

Con el objetivo de analizar las alteraciones fisiológicas ocasionadas en el tejido como consecuencia de los tratamientos estudiados, se midió la tasa respiratoria (TR) de las muestras. Para ello se siguió la metodología descrita en el apartado IV.1.3, obteniéndose la concentración de oxígeno y anhídrido carbónico en el espacio de cabeza de los envases contenedores de las mismas, a lo largo de su almacenamiento a $10^{\circ} \mathrm{C}$ durante 6 días.

La figura IV.8 muestra el efecto de los diferentes tratamientos sobre la TR expresada como consumo de $\mathrm{O}_{2}$ y producción de $\mathrm{CO}_{2}$, de las muestras IV y PD, durante su almacenamiento en refrigeración. En esta figura, a su vez, se representa el cociente respiratorio (CR) de las muestras, calculado a partir del cociente entre la $\mathrm{TR}$ de $\mathrm{CO}_{2}$ y la de $\mathrm{O}_{2}$.

Las diferencias en la pauta respiratoria de las muestras serán consecuencia del diferente grado de alteración celular ocasionado en cada uno de los tratamientos aplicados, como ya fue comentado en el apartado III.2.2.2.4 de resultados. Las muestras deshidratadas mostraron un descenso significativo $(\alpha<0,05)$ tanto en el consumo de $\mathrm{O}_{2}$ como en la producción de $\mathrm{CO}_{2}$, al ser comparadas con las muestras de pomelo fresco e IV, debido probablemente al menor número de células viables presentes en las mismas. El efecto de la deshidratación osmótica sobre la pauta respiratoria del pomelo ha sido estudiado en el Capítulo III, apartado III.2.2.2.4 de resultados. Como ya se comentó, en función de la intensidad del tratamiento osmótico el número de células 
alteradas o no viables será diferente. Las células alteradas presentarán pautas respiratorias diferentes debido al estrés inducido, mientras que las no viables no presentarán actividad respiratoria (Ceballos, 2006).

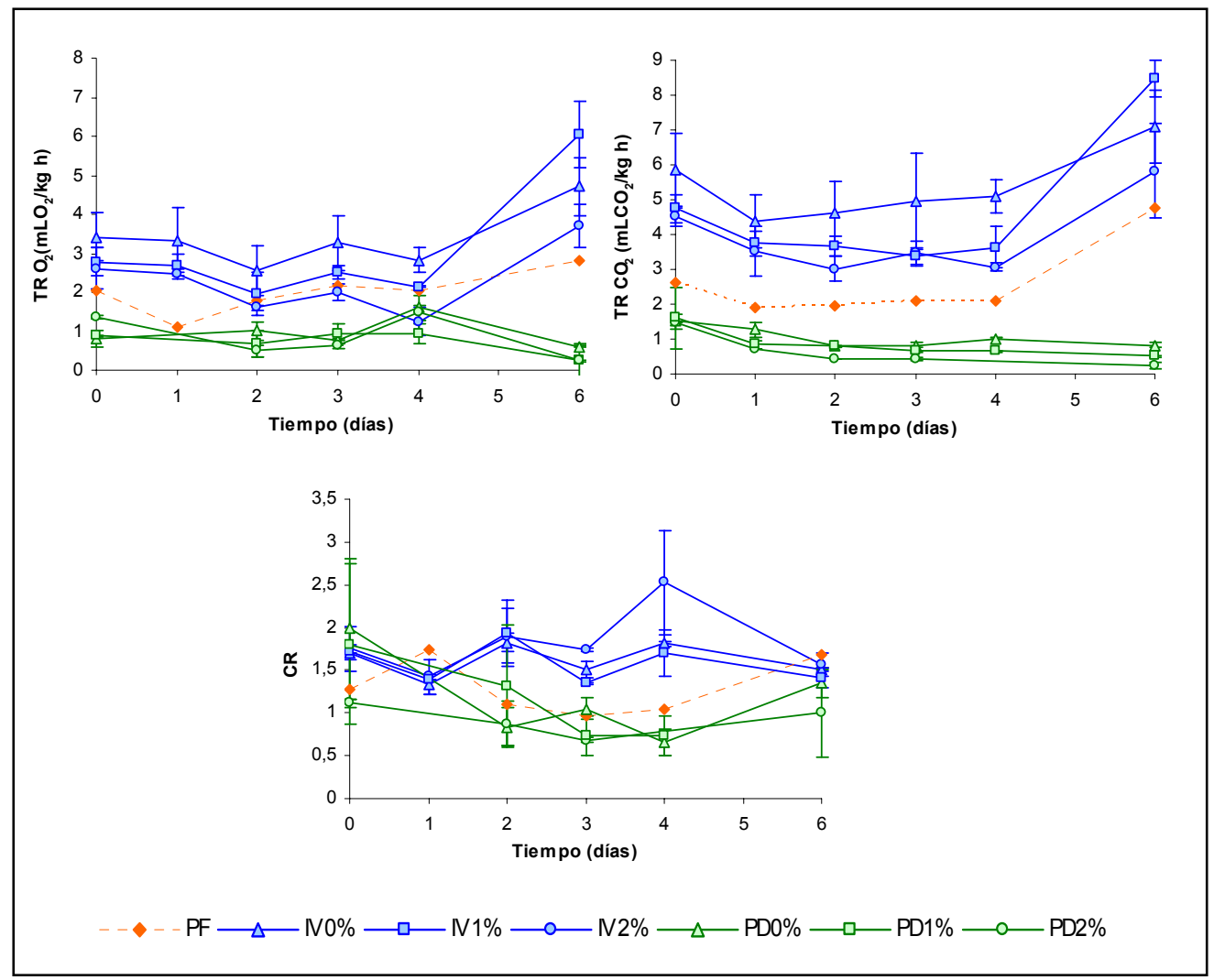

Figura IV.8. Tasas respiratorias expresadas como consumo de $\mathrm{O}_{2}$ y generación $\mathrm{CO}_{2}$, y cociente respiratorio (CR) de las muestras estudiadas.

Esta reducción en la TR de las muestras PD se mantuvo a lo largo de su almacenamiento en refrigeración, siendo las muestras deshidratadas con calcio las que presentaron niveles más bajos. Al comparar los dos niveles de calcio estudiados se puede ver cómo las 
muestras $\mathrm{PD}_{2} \%$ presentaron una mayor reducción en su actividad respiratoria que las $\mathrm{PD}_{1 \%}$.

En otras frutas se observó que la aplicación de calcio en forma de $\mathrm{CaCl}_{2}$, redujo la producción $\mathrm{CO}_{2}$, pero no el consumo de oxígeno (Tsantili et al., 2002; Luna-Guzmán et al., 1999). En nuestro caso, parece que el calcio afecta también al consumo de oxígeno pero en menor medida a cómo afecta al $\mathrm{CO}_{2}$.

En cuanto a las muestras IV, éstas mostraron un aumento significativo $(\alpha<0,05)$ en su actividad respiratoria al ser comparadas con las muestras de pomelo fresco, lo que puede estar relacionado con el estrés provocado por el pulso de vacío. Cuando se añadió lactato cálcico a la disolución isotónica la TR de producción de $\mathrm{CO}_{2}$ y consumo de $\mathrm{O}_{2}$ se redujo, siendo mayor dicha reducción en las muestras $I V_{2} \%$. Además esta pauta se mantuvo durante el periodo de almacenamiento en refrigeración.

A partir del $4^{\circ}$ día de almacenamiento, las muestras de pomelo fresco y las IV, independientemente del nivel de calcio incorporado, presentaron un aumento significativo $(\alpha<0,05)$ en su actividad respiratoria, probablemente debido a la llegada de la senescencia de la fruta, mientras que las muestras PD siguieron con valores bajos de TR, tanto de producción de $\mathrm{CO}_{2}$ como de consumo de $\mathrm{O}_{2}$.

El efecto del calcio en la pauta respiratoria de las muestras IV y PD podría deberse a los factores ya comentados en el capítulo anterior, relacionados con el aumento de la rigidez de la membrana que podría bloquear intercambio gaseoso (Saftner et al., 1999; Serrano et al., 2004), retraso en la llegada a la senescencia en relación con cambios en la microporosidad de la membrana (Lester, 1996) y el efecto del calcio en el bloqueo de la proteína PM28A, canal proteico de transporte activo de agua. Al aumentar la concentración de $\mathrm{Ca}^{2+}$ en el interior del 
protoplasto, el ATP intracelular aumenta (Kinoshita et al., 1995) y queda disponible para participar en otras rutas metabólicas, por lo que la generación de energía a través de la respiración quedaría reducida.

Por otro lado, la reducción en la cantidad de oxígeno disponible en el tejido, provocada por el llenado de los poros con disolución externa en el proceso de impregnación a vacío, parece contribuir al desarrollo de fermentación etanólica en las muestras IV y PD, lo que se deduce de los valores del cociente respiratorio, en general, por encima de 1. Sin embargo, las muestras deshidratadas con un $2 \%$ de lactacto cálcico presentaron un valor de CR próximo a 1, por lo que podemos afirmar que no desarrollaron rutas fermentativas. Esto puede ser explicado teniendo en cuenta la mayor disponibilidad de ATP en estas muestras, que frenaría el desarrollo de estas rutas metabólicas fermentativas.

Durante el periodo de almacenamiento estudiado, las muestras PD presentaron valores de CR próximos a 1 mientras que las muestras IV presentaron valores superiores, mostrando el efecto beneficioso de los tratamientos de deshidratación en la reducción del metabolismo celular.

\section{IV.2.2.1.5. Efecto sobre las propiedades mecánicas}

Para analizar la influencia de los tratamientos aplicados, el efecto del calcio y del almacenamiento en refrigeración sobre las propiedades mecánicas del pomelo, se realizó el ensayo de punción descrito en el apartado IV.1.3.1 de materiales y métodos en cada una de las muestras, antes y después de 7 días de almacenamiento en refrigeración.

La figura IV.9 muestra una curva típica fuerza (F)-deformación relativa $(\varepsilon)$ obtenida a partir del ensayo de punción realizado en el 
pomelo fresco, donde se representan los parámetros mecánicos analizados en las diferentes muestras estudiadas.

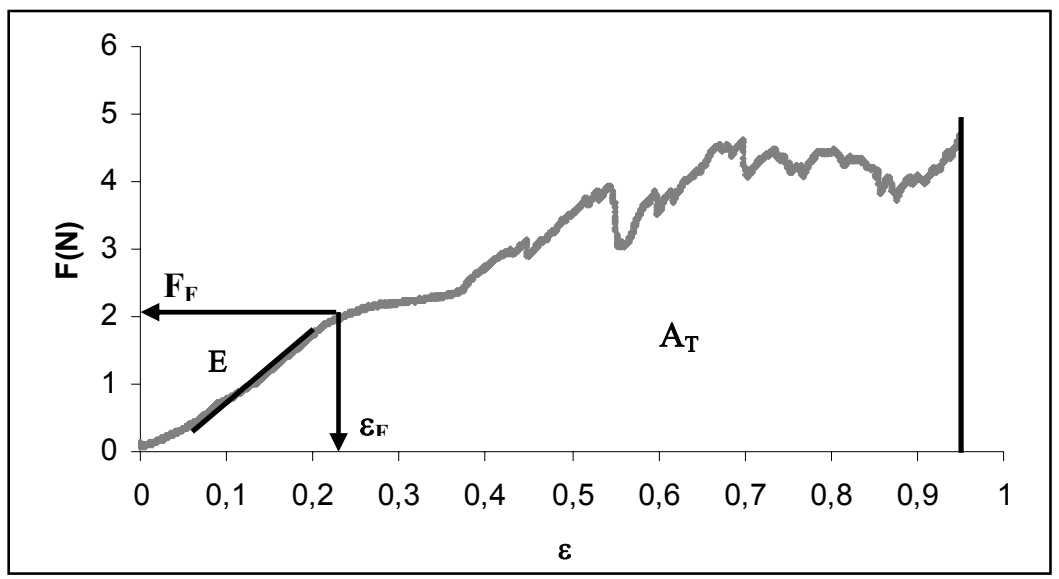

Figura IV.9. Curva típica fuerza $(F)$-deformación relativa $(\varepsilon)$ obtenida en el pomelo fresco y parámetros mecánicos evaluados $\left(F_{F}\right.$ y $\varepsilon_{F}$ : fuerza y deformación en el punto de fractura; $A_{T}$ : área total debajo de la curva; E: pendiente del primer tramo lineal).

En todas las curvas obtenidas se observó un primer tramo lineal, donde la fuerza aumentó progresivamente con la deformación, hasta que se produjo la ruptura del tejido. A partir de este momento la fuerza continuó aumentando apareciendo múltiples picos de fractura hasta alcanzar la deformación máxima programada en el ensayo. La zona lineal anterior al primer pico de fractura está relacionada con la resistencia a la deformación del producto y permite cuantificar a través de los parámetros $\varepsilon_{F}, F_{F}$ y $E$ la firmeza de las muestras. Por otro lado el área evaluada $\left(A_{T}\right)$ se corresponde con la energía necesaria para deformar la muestra un $95 \%$.

En la figura IV.10 se representan los valores medios y las desviaciones de los parámetros mecánicos analizados en las muestras 
de pomelo fresco (PF), IV y PD, en función del nivel del calcio aplicado, antes y después de su almacenamiento en refrigeración.

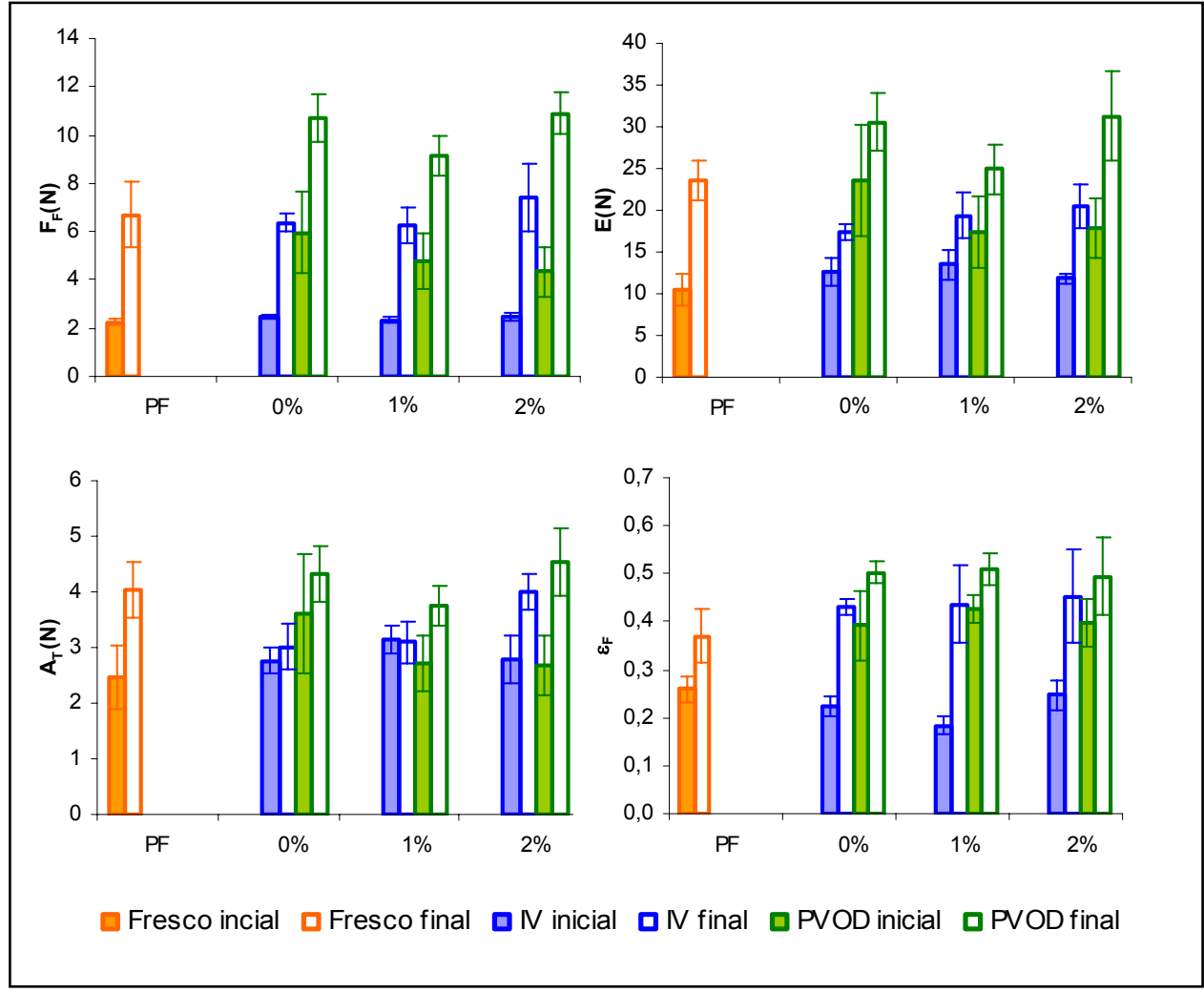

Figura IV.10. Parámetros mecánicos obtenidos a partir de las curvas de punción de pomelo fresco (PF), pomelo impregnado a vacío con disolución isotónica (IV) y pomelo deshidratado (PD), antes (inicial) y después (final) de 7 días de almacenamiento en refrigeración. El subíndice 0,1 y $2 \%$ hace referencia al porcentaje de lactato cálcico presente en la disolución.

Los tratamientos de impregnación a vacío aplicados no dieron lugar a cambios significativos $(\alpha>0,05)$ en la respuesta mecánica de las 
muestras al compararlos con el pomelo fresco. Esto indica que los fenómenos de deformación-relajación de la matriz que ocurren durante el pulso de vacío (Fito y Chiralt, 1997) y el cambio en la fracción volumétrica de aire y fase líquida, no dieron lugar a cambios significativos en la resistencia mecánica asociada a la estructura del producto, lo que podría ser debido al carácter elástico de este tejido. Por otra parte, a diferencia de los resultados obtenidos por otros autores en manzana (Anino et al., 2006), no se encontraron diferencias significativas en función del nivel de calcio aplicado.

En cuanto a los tratamientos de deshidratación, las muestras PD presentaron valores significativamente superiores, con respecto a las muestras frescas e IV, en todos los parámetros analizados, salvo el $A_{T}$. En otras frutas, como mango (Torres et al., 2006), fresa o kiwi (Chiralt y Talens, 2005), se ha descrito una disminución en la relación fuerzadeformación durante los tratamientos osmóticos que ha sido atribuida a la pérdida de turgor celular, alteración de la lámina media, alteración en la resistencia de la pared celular, efecto del perfil de concentración de agua y solutos en el tejido, cambios en la fracción volumétrica de aire y fase líquida y cambios en el tamaño y forma de la muestra. En el caso del pomelo pelado, cortado en rodajas, la estructura del tejido es completamente diferente a las frutas mencionadas. Como ha sido descrito en el apartado I.1.3 de la introducción, la pulpa del pomelo está constituida por segmentos o gajos envueltos por una membrana carpelar, que contienen las vesículas. Éstas son estructuras en forma de saco donde se encuentran las células vacuoladas y en definitiva el zumo (Agustí, 2003). Debido al corte, parte de la fase líquida o zumo se va a liberar de las vesículas, incluso en el pomelo fresco, de ahí la diferente respuesta mecánica de este tipo de tejido en comparación con el tejido parenquimático de otras frutas como la manzana. 
A diferencia de lo que ha sido descrito en otras frutas como el mango (Torres et al., 2006), la incorporación de calcio no implicó una mejora en la firmeza de las muestras deshidratadas osmóticamente. En este sentido no se observaron diferencias significativas en los parámetros analizados al aumentar la concentración de calcio en el tejido, por lo que el efecto del tratamiento osmótico es mucho más notable que el posible efecto beneficioso del calcio.

De manera general, el almacenamiento en refrigeración supuso un aumento en el valor de los parámetros analizados sin diferencias significativas en función de la cantidad de calcio aplicado. Este efecto del almacenamiento podría estar relacionado con la pérdida de masa (Tabla IV.1) o lixiviación de fase líquida que ocurre a lo largo del mismo, lo que podría provocar un endurecimiento de las muestras y un desplazamiento del punto de ruptura, haciendo que las muestras se rompieran más tarde debido al carácter viscoelástico típico de tejidos sin turgor (Pitt, 1992).

Con los resultados obtenidos podemos concluir que no se observa un efecto claro del calcio en la mejora de las propiedades mecánicas de las muestras impregnadas isotónicamente y/o deshidratadas osmóticamente, ni antes ni después de su almacenamiento en refrigeración, independientemente del nivel de calcio aplicado. Sin embargo la reducción en la tasa respiratoria fue más marcada en las muestras $\mathrm{PD}_{2 \%}$, por lo que se seleccionó esta muestra para la posterior formulación del producto gelificado. A continuación se presentan los resultados del análisis microbiológico y sensorial del pomelo deshidratado con $2 \%$ de lactato cálcico, en comparación con el pomelo deshidratado sin calcio y el pomelo fresco. 


\section{IV.2.2.1.6. Análisis microbiológico de las muestras de pomelo}

\section{deshidratado. Efecto del catión calcio}

Para estudiar el efecto del calcio en la vida útil microbiológica del pomelo deshidratado se realizaron recuentos sobre viables totales y mohos y levaduras, siguiendo la Norma Microbiológica, anteriormente explicada en el Capítulo III, apartado III.2.2.1 de resultados.

En la figura IV.11 se puede apreciar el recuento de viables totales y el de mohos y levaduras, a lo largo del período de almacenamiento en refrigeración a $10^{\circ} \mathrm{C}$, tanto para las muestras de pomelo fresco (PF) como para las muestras de pomelo deshidratado con $\left(\mathrm{PD}_{2} \%\right.$ y sin calcio añadido $\left(\mathrm{PD}_{0 \%}\right)$ a la SO.

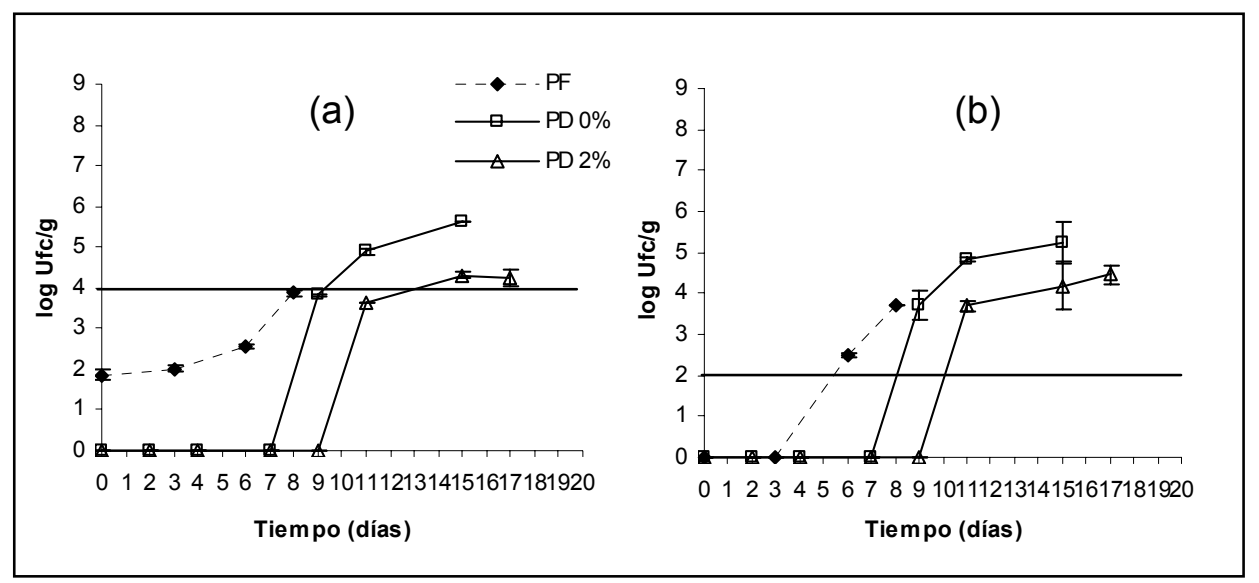

Figura IV.11. Recuento durante el período de almacenamiento en refrigeración a $10^{\circ} \mathrm{C}$ de: (a) viables totales y (b) mohos y levaduras, en pomelo fresco $(\mathrm{PF})$ y deshidratado con $\left(\mathrm{PD}_{2} \%\right.$ y $\sin 2 \%$ lactato cálcico $\left(\mathrm{PD}_{0 \%}\right)$. 
Podemos observar que las muestras $\mathrm{PD}_{0 \%}$ superan el límite de viables totales establecido en este trabajo a los 9 días de almacenamiento. Sin embargo para mohos y levaduras el límite se supera a los 8 días. Por tanto podemos decir que dichas muestras presenta una vida útil de 8 días. Las muestras $\mathrm{PD}_{2 \%}$ superan ambos límites a los 11 días, suponiendo esto un aumento de la vida útil de un $25 \%$, respecto a las muestras sin calcio. En cambio, si comparamos con la muestra fresca cuya vida útil es de aproximademte 5 días, el aumento es del $100 \%$.

Este efecto también se ha demostrado en otros estudios realizados. En melón cortado (Luna-Guzmán y Barrett, 2000) se ha observado que la aplicación de lactato cálcico muestra una reducción del número de colonias de viables totales y de mohos y levaduras. En dicho estudio se defendió que la presencia de calcio podría aumentar la resistencia de los tejidos al ataque de hongos o bacterias por estabilización o refuerzo de la pared celular (Bolin y Huxsoll, 1989). No obstante, en este trabajo no se ha observado este aumento en la resistencia mecánica del tejido por efecto del calcio. Otros autores sin embargo, han defendido las propiedades antimicrobiológicas del calcio en base a acoplamientos al sistema de transporte de electrones (Davidson y Juneja, 1990).

En este estudio, y según los resultados obtenidos en los apartados anteriores, se entiende que el aumento de calcio a nivel celular previene la salida de agua de la célula y aumenta la concentración de ATP, de forma que la célula disminuiría su metabolismo, con lo que las reacciones bioquímicas y microbiológicas también se verían reducidas. 
IV.2.2.1.7. Análisis sensorial de las muestras de pomelo deshidratado. Efecto del catión calcio y del almacenamiento en refrigeración

El mismo lote de pomelo utilizado para analizar la vida útil microbiológica de las muestras deshidratadas $\sin y$ con $2 \%$ lactato cálcico añadido a la disolución osmótica $\left(\mathrm{PD}_{0 \%}, \mathrm{PD}_{2 \%}\right)$ fue empleado para evaluar, desde un punto de vista sensorial, el pomelo deshidratado recién procesado $\left(\mathrm{PD}_{0 \%}, \mathrm{PD}_{2}\right.$ ) y después de 5 días de almacenamiento en refrigeración $\left(\mathrm{PD}_{0 \%}(5 \mathrm{~d}), \mathrm{PD}_{2 \%}(5 \mathrm{~d})\right)$.

\section{Análisis de las respuestas proporcionadas en el análisis sensorial}

Las respuestas de los catadores se obtuvieron a partir del cuestionario que se les repartió a cada catador durante el análisis sensorial, tal y como se explica en el apartado IV.1.3.1 de materiales y métodos. Para analizar las respuestas obtenidas por los catadores en relación a la comparación pareada múltiple llevada a cabo, se elaboró la tabla IV.6 donde en las columnas se encuentra el número de veces (frecuencia) que una determinada muestra fue preferida, cuando se comparaba con todas y cada una del resto de muestras para un mismo atributo (filas). 
Tabla IV.6. Frecuencia de las respuestas de los catadores en la comparación pareada múltiple de las muestras tratadas con calcio $\left(\mathrm{PD}_{2 \%}\right)$ y sin calcio $\left(\mathrm{PD}_{0 \%}\right)$, así como con y $\sin 5$ días de almacenamiento $(5 \mathrm{~d})$ en refrigeración.

\begin{tabular}{ccccc}
\hline Atributos & $\mathbf{P D}_{\mathbf{0}}$ & $\mathbf{P D}_{\mathbf{2} \%}$ & $\mathbf{P D}_{\mathbf{0} \%} \mathbf{( 5 d )}$ & $\mathbf{P D}_{\mathbf{2} \%}(\mathbf{5 d})$ \\
\hline Apariencia & 45 & 62 & 23 & 50 \\
Aroma & 67 & 53 & 20 & 40 \\
Color & 45 & 69 & 28 & 38 \\
Textura & 60 & 41 & 29 & 50 \\
Sabor & 66 & 37 & 23 & 54 \\
Preferencia & 65 & 45 & 18 & 52 \\
\hline
\end{tabular}

Con el fin de comparar todas las muestras en conjunto, se realizaron los análisis estadísticos que se comentan a continuación.

\section{Test de Friedman y Suma de Rangos}

A partir de los datos de la tabla elaborada en el apartado anterior, se obtuvo la suma de rangos de cada muestra (Tabla IV.7). Este valor se obtiene adicionando a la frecuencia con que cada muestra es preferida (Tabla IV.6), dos veces la frecuencia con que no es preferida.

En la figura IV.12 se han representado los valores del análisis de Friedman considerando la suma de rangos, donde se puede observar la afinidad entre sí de las muestras sometidas al análisis sensorial para los atributos evaluados. Hay que tener en cuenta que un menor valor de la suma de rangos equivale a una mayor intensidad del atributo evaluado. 
Tabla IV.7. Suma de rangos en la comparación pareada múltiple de las muestras tratadas con calcio $\left(\mathrm{PD}_{2 \%}\right)$ y sin calcio $\left(\mathrm{PD}_{0 \%}\right)$, así como con y $\sin 5$ días de almacenamiento $(5 \mathrm{~d})$ en refrigeración.

\begin{tabular}{ccccccc}
\hline MUESTRA & Apariencia & Aroma & Color & Textura & Sabor & Preferida \\
\hline $\mathbf{P D}_{\mathbf{0} \%}$ & 135 & 113 & 135 & 120 & 114 & 115 \\
$\mathbf{P D}_{\mathbf{2}}$ & 118 & 127 & 111 & 139 & 143 & 135 \\
$\mathbf{P D}_{\mathbf{0} \%} \mathbf{( 5 d )}$ & 157 & 160 & 152 & 151 & 157 & 162 \\
$\mathbf{P D}_{\mathbf{2} \%} \mathbf{( 5 d )}$ & 130 & 140 & 142 & 130 & 126 & 128 \\
\hline
\end{tabular}

$\left(^{*}\right) 135=45$ (Tabla IV.6) $+2 *(90-45)$, siendo 90 el total de muestras catadas para cada atributo.

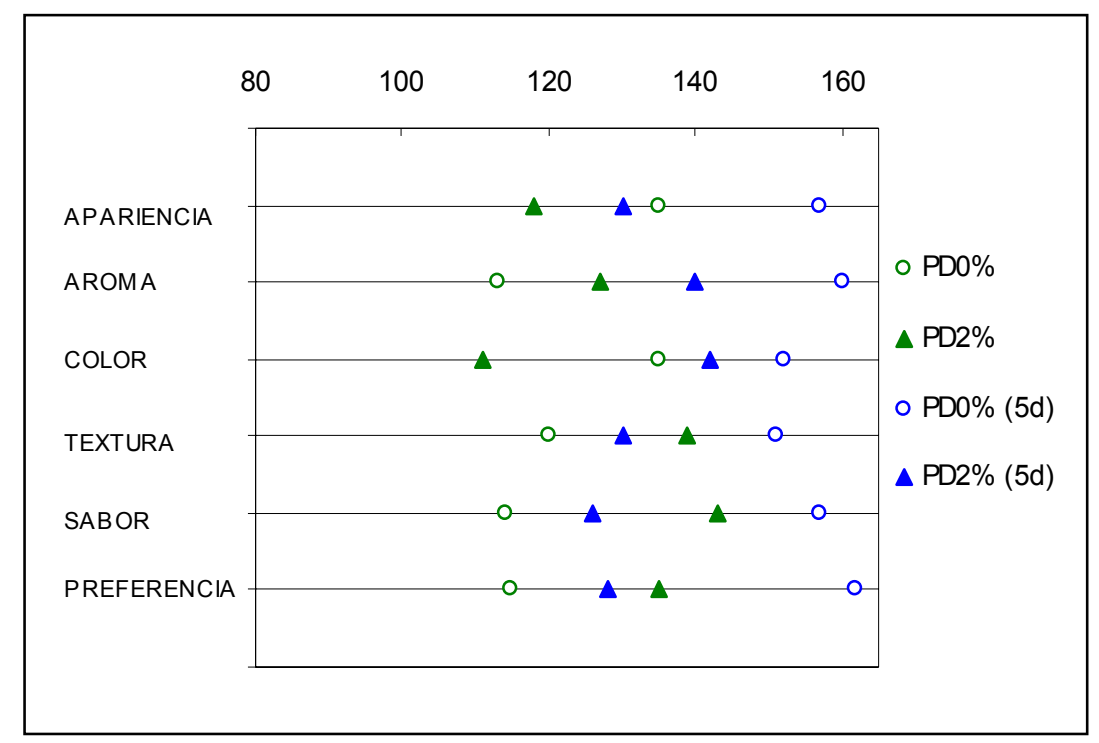

Figura IV.12. Test de Friedman (suma de rangos, obtenido de la comparación pareada múltiple) de las muestras tratadas con calcio $\left(\mathrm{PD}_{2 \%}\right)$ y $\sin$ calcio $\left(\mathrm{PD}_{0 \%}\right)$, así como sin y con 5 días de almacenamiento $(5 d)$ en refrigeración. Los valores en el eje $X$ representan la suma de las puntuaciones. En el eje $Y$ aparecen los atributos evaluados. 
Se puede observar que las muestras que prefirieron los catadores fueron las $\mathrm{PD}_{0 \%}$, comparándolas con el resto de muestras. Los atributos que más contribuyeron en esta preferencia fueron aroma, textura y sabor (menores valores de estos atributos). Para el resto de los atributos (apariencia y color) los catadores prefirieron la muestra $\mathrm{PD}_{2 \%}$. Por otra parte, las muestras menos preferidas (mayores valores en todos los atributos) fueron las muestras tratadas sin calcio $y$ almacenadas.

Comparando las muestras por tratamientos, se vio que hubo mucha diferencia entre las muestras deshidratadas sin calcio almacenadas y sin almacenar. Estas diferencias no fueron tan acusadas para el almacenamiento de las muestras con calcio añadido a la SO.

Para comprobar si las diferencias encontradas en la ordenación de las puntuaciones de los atributos y la preferencia fueron significativas, se calculó la función estadística T de Friedman, según la ecuación IV.2.

$$
T=\left(\frac{4}{p t}\right) \sum_{i=1}^{t} R^{2}-\left(9 p[t-1]^{2}\right)
$$

donde:

$p=$ Número de veces que el diseño básico se repite $(p=30)$.

$\mathrm{t}=$ Número de muestras $(\mathrm{t}=4)$.

$\mathrm{R}=$ Suma de rango para cada tratamiento.

Los valores obtenidos con esta fórmula (Tabla IV.8) se compararon con el valor estadístico tabulado de $\chi^{2}$ con 3 grados de libertad $(7,81$ con un nivel de confianza de $\alpha=0,05)$. En la tabla se aprecia que hubo diferencias significativas para cada uno de los atributos analizados, 
debido a que el valor de T calculado para cada atributo fue mayor que el valor de $\chi^{2}$ tabulado.

Tabla IV.8. Valores $T$ de Friedman para los distintos atributos analizados.

\begin{tabular}{cc}
\hline Atributos & T de Friedman \\
\hline Apariencia & $26,6^{*}$ \\
Aroma & $39,9^{*}$ \\
Color & $30,5^{*}$ \\
Textura & $17,4^{*}$ \\
Sabor & $35,7^{*}$ \\
Preferencia & $39,3^{*}$ \\
\hline
\end{tabular}

$\left(^{*}\right)$ Diferencias significativas, para un $\alpha=0,05$.

Con el fin de ver entre que muestras existen diferencias significativas, se realizó una comparación múltiple entre las muestras, empleando el método HSD (Honestly Significance Difference) de Tukey (Meilgaard et al., 1999). Para calcular el valor HSD de Tukey se utilizó la ecuación IV.3.

$$
H S D=q_{\alpha, t, \infty} \sqrt[p t]{\frac{p t}{4}}
$$

donde:

$\mathrm{q}_{\alpha, \mathrm{t}, \infty}=$ Valor tabulado.

$p=$ Número de veces que el diseño ha sido repetido.

$\mathrm{t}=$ Número de muestras $(\mathrm{t}=4)$. 
En este caso el valor de q tabulado para 4 grados de libertad y un nivel de confianza de $\alpha=0,05$, es de 3,63 . El valor HSD que se obtuvo fue de 19,88. Para comparar entre las distintas parejas que se ofrecieron a los jueces, se hizo la diferencia de suma de rangos (Tabla IV.9), restando lo que dio la suma de rangos de una muestra a la suma de rangos de la muestra con la que se compara siempre en valor absoluto. Las diferencias se compararon con el valor de HSD y fueron significativas cuando superaron este valor.

Tabla IV.9. Diferencia entre suma de rangos en el análisis sensorial de pomelo deshidratado con calcio $\left(\mathrm{PD}_{2 \%}\right)$ y sin calcio $\left(\mathrm{PD}_{0 \%}\right)$, así como con y $\sin 5$ días de almacenamiento (5d) en refrigeración.

\begin{tabular}{|c|c|c|c|c|c|c|}
\hline Atributos ${ }^{(1)}$ & APA & ARO & COL & TEX & $S A B$ & Preferencia \\
\hline $\mathrm{PD}_{0 \%}-\mathrm{PD}_{2 \%}$ & 17 & 14 & $24^{*}$ & 19 & $29^{*}$ & $20^{*}$ \\
\hline $\mathrm{PD}_{0 \%}-\mathrm{PD}_{0 \%}(5 \mathrm{~d})$ & $22^{*}$ & $47^{*}$ & 17 & $31^{*}$ & $43^{*}$ & $47^{*}$ \\
\hline $\mathrm{PD}_{0 \%}-\mathrm{PD}_{2 \%}(\mathbf{5 d})$ & 5 & $27^{*}$ & 7 & 10 & 12 & 13 \\
\hline $\mathrm{PD}_{2 \%}-\mathrm{PD}_{0 \%}(\mathbf{5 d})$ & $39^{*}$ & $33^{*}$ & $41^{*}$ & 12 & 14 & $27^{*}$ \\
\hline $\mathrm{PD}_{2 \%}-\mathrm{PD}_{2 \%}(\mathbf{5 d})$ & 12 & 13 & $31^{*}$ & 9 & 17 & 7 \\
\hline$P D_{0 \%}(5 d)-P_{2 \%}(5 d)$ & $27^{*}$ & $20^{*}$ & 10 & $21^{*}$ & $31^{*}$ & $34^{*}$ \\
\hline
\end{tabular}

Se puede observar en la tabla que si comparamos las muestras recién procesadas con calcio y sin calcio añadido a la SO no hay diferencias significativas entre ellas exceptuando para los atributos de color y sabor. Al comparar las muestras deshidratadas sin calcio almacenadas y sin almacenar, se observan diferencias significativas para todos los atributos excepto para el color, por lo que podemos observar una influencia del almacenamiento a la hora de elegir la 
muestra. Comparando las muestras deshidratadas con calcio recién procesadas y almacenadas, sólo hay diferencias significativas para el color.

Al comparar las muestras deshidratadas almacenadas con y sin calcio, se observaron diferencias significativas en todos los atributos excepto para el color.

\section{Análisis de correspondencia}

Para visualizar mejor la preferencia y las relaciones que existen entre las muestras y los atributos, se realizó un análisis de correspondencias.

Para el análisis de correspondencias se utilizaron las respuestas proporcionadas por los catadores y se elaboró una tabla donde en las filas se colocaron las muestras analizadas y en las columnas cada uno de los atributos por duplicado (positivo $(+)$ y negativo (-).

En las columnas del atributo $(+)$ se colocó el número de veces que el catador prefirió esa muestra y en las columnas del atributo (-) la resta del número máximo de veces que el catador puede elegir esa muestra, menos el número de veces que el catador eligió esa muestra.

En el análisis de correspondencias se obtuvieron tres factores (número de muestras menos uno), que explican dicha variabilidad en forma de porcentaje (Tabla IV.10). El factor 1 explica un $75,05 \%$ de la variabilidad de los datos y la calidad interna del producto. El factor 2 también es importante ya que explica un $21,67 \%$ de la variabilidad de los datos. En este caso hablar de un tercer factor no tendría importancia ya que el porcentaje explicado por este factor es inferior al $5 \%$. 
Tabla IV.10. Porcentaje de variabilidad explicado por los factores del análisis de correspondencias.

\begin{tabular}{ccc}
\hline Factor & \% Explicado & \% Acumulado \\
\hline $\mathbf{1}$ & 75,05 & 75,05 \\
$\mathbf{2}$ & 21,67 & 96,72 \\
\hline
\end{tabular}

En las tablas IV.11 y IV.12 se muestran, respectivamente, las contribuciones de los factores a la inercia de las muestras y de los atributos.

Tabla IV.11. Contribuciones de los factores a la inercia de las muestras.

\begin{tabular}{cccc}
\hline Muestras & Factor $\mathbf{1}$ & Factor 2 & $\begin{array}{c}\text { Suma de } \\
\text { Factores }\end{array}$ \\
\hline $\mathbf{P D}_{\mathbf{0}}$ & 81,85 & 14,98 & 96,83 \\
$\mathbf{P D}_{\mathbf{2}}$ & 12,29 & 87,67 & 99,96 \\
$\mathbf{P D}_{\mathbf{0}} \mathbf{( 5 \mathbf { d } )}$ & 98,66 & 0,91 & 99,57 \\
$\mathbf{P D}_{\mathbf{2} \%} \mathbf{( 5 d )}$ & 16,29 & 34,69 & 50,98 \\
\hline
\end{tabular}

Los datos que se obtuvieron indican que las muestras y los atributos están bien representados a lo largo de los dos primeros factores, ya que los valores de la suma de las contribuciones relativas de los factores a los atributos y las muestras son cercanos al $100 \%$. De esta manera, los resultados más importantes pueden ser deducidos del estudio de la proyección en el plano factorial. 
Tabla IV.12. Contribuciones de los factores a la inercia de los atributos.

\begin{tabular}{cccc}
\hline Atributos & Factor $\mathbf{1}$ & Factor $\mathbf{2}$ & $\begin{array}{c}\text { Suma de } \\
\text { Factores }\end{array}$ \\
\hline Apariencia + & 56,92 & 33,21 & 90,13 \\
Apariencia - & 56,92 & 33,21 & 90,13 \\
Aroma + & 92,22 & 0,41 & 92,63 \\
Aroma - & 92,22 & 0,41 & 92,63 \\
Color + & 32,56 & 66,72 & 99,28 \\
Color - & 32,56 & 66,72 & 99,28 \\
Textura + & 84,70 & 15,21 & 99,91 \\
Textura - & 84,70 & 15,21 & 99,91 \\
Sabor + & 78,06 & 21,32 & 99,38 \\
Sabor - & 78,06 & 21,32 & 99,38 \\
Preferencia + & 95,81 & 3,72 & 99,53 \\
Preferencia - & 95,81 & 3,72 & 99,53 \\
\hline
\end{tabular}

La figura IV.13 muestra la proyección de los atributos y de las muestras evaluadas, en un plano factorial. Según la distribución de las muestras se puede observar como los catadores prefirieron las muestras $\mathrm{PD}_{0 \%}$. Los atributos evaluados positivamente y que guardan una estrecha relación con la preferencia fueron el aroma (ARO+), la textura $(T E X+)$ y el sabor $(S A B+)$. El resto de atributos evaluados positivamente no se sitúan muy lejos en la figura por lo que también tienen una cierta importancia a la hora de elegir la preferencia.

Por el contrario, las muestras que menos prefirieron los catadores fueron las $\mathrm{PD}_{0 \%}(5 \mathrm{~d})$, lo que podría ser debido al efecto del almacenamiento. El atributo evaluado negativamente y que guarda más relación con dichas muestras fue el aroma (ARO-), seguido de sabor 
(SAB-). Esto pone de manifiesto que los atributos mencionados tienen un gran peso en la aceptación del producto por parte de los catadores.

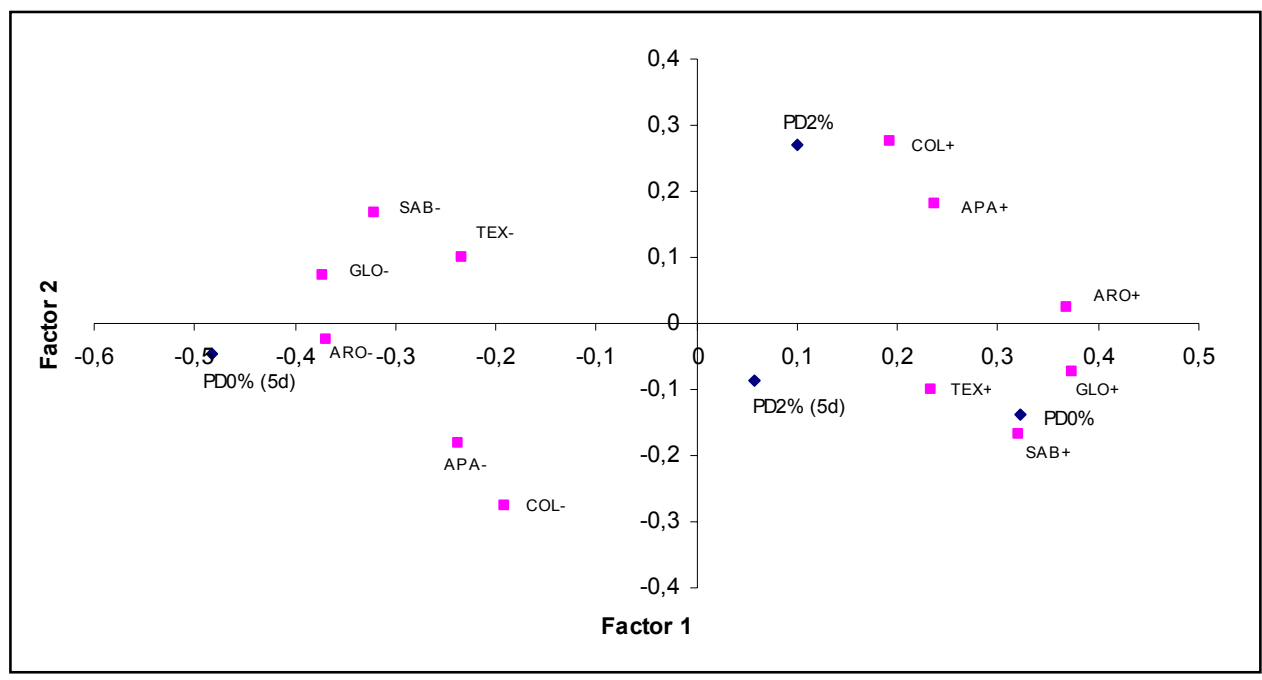

Figura IV.13. Representación de las coordenadas de ambos factores en el plano factorial. APA: apariencia; ARO: aroma; COL: color; TEX: textura; SAB: sabor; GLO: global o preferencia.

Se observa la situación intermedia de las muestras con calcio de manera que recién procesadas no son tan preferidas como las sin calcio, pero cambian mucho menos con el almacenamiento de manera que al final de éste los catadores prefieren las con calcio que las de sin calcio.

En resumen parece que hay un efecto del calcio en la aceptación sensorial del producto, de manera que éste parece afectar negativamente a la textura, aroma y sabor, aunque mejora el color $y$, por tanto, la apariencia del producto. El almacenamiento del pomelo contribuye de forma negativa a su aceptación, de forma más acusada en el producto sin calcio. El aroma es el atributo que más se ve afectado 
por el almacenamiento. Para el producto almacenado parece recomendable el tratamiento con calcio. Los atributos que más contribuyen a la aceptación de este producto son el aroma y el sabor.

IV.2.2.2. Estudio del efecto del almacenamiento en refrigeración del producto gelificado formulado con lactato cálcico

\section{IV.2.2.2.1. Evolución de los cationes en los geles y en la fruta}

\section{deshidratada}

Siguiendo la metodología descrita en el Capítulo III, apartado III.1.3.7, se analizó por cromatografía iónica el contenido en $\mathrm{Ca}^{2+}$ y otros minerales como el $\mathrm{Na}^{+}, \mathrm{Mg}^{2+}$ y $\mathrm{K}^{+}$, presentes tanto en la fruta deshidratada utilizada para la elaboración de los geles de fruta, como en los geles, durante su almacenamiento en refrigeración. Los resultados en este caso se expresaron en $\mathrm{mg}$ de catión $/ 100 \mathrm{~g}$ de muestra inicial. Los postres de fruta se prepararon como se describe en el apartado IV.1.2.4 de materiales y métodos.

En la figura IV.14 se puede observar la evolución del catión $\mathrm{Ca}^{2+}$ en la fruta deshidratada y el gel del producto $\mathrm{PDG}_{2 \%}$ durante los 16 días de su almacenamiento en refrigeración. En el pomelo deshidratado incluido en el gel, a los 2 días de almacenamiento se observó un ligero aumento en el contenido en $\mathrm{Ca}^{2+}$ de $60,95 \pm 1,02$ a 72,5 $\pm 17,0 \mathrm{mg} \mathrm{Ca}^{2+} / 100 \mathrm{~g}$ muestra. Una vez alcanzados los 2 días de almacenamiento se observó que el contenido en $\mathrm{Ca}^{2+}$ se mantuvo más o menos constante hasta llegar a los 14 días, aumentando significativamente $(\alpha<0,05)$ a los 16 días de almacenamiento. En los geles, se observó una ligera disminución del contenido en $\mathrm{Ca}^{2+}$ durante el almacenamiento. 


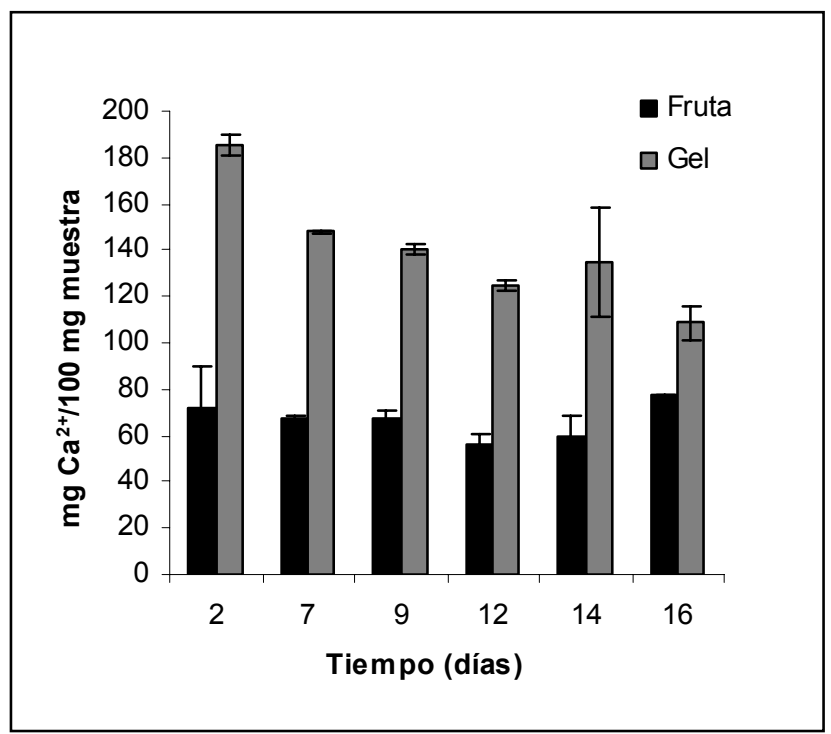

Figura IV.14. Evolución del $\mathrm{Ca}^{2+}$ en la fruta deshidratada y el gel del producto $\mathrm{PDG}_{2 \%}$ durante su almacenamiento en refrigeración.

En cuanto al contenido en $\mathrm{Na}^{+}$y $\mathrm{Mg}^{2+}$ de la fruta deshidratada incluida en el gel y el gel, no se pudo estudiar su evolución con el almacenamiento pues los valores cuantificados fueron del mismo orden que la desviación.

Con respecto al contenido en $\mathrm{K}^{+}$de las muestras de pomelo incluidas en los geles, se observó un aumento del catión de $89 \pm 4 \mathrm{mg}$ de $\mathrm{K}^{+} / 100 \mathrm{mg}$ de muestra a $105 \pm 13 \mathrm{mg}$ de $\mathrm{K}^{+} / 100 \mathrm{mg}$ de muestra a los 2 días de almacenamiento. Una vez alcanzado los 2 días de almacenamiento se observó una ligera disminución del catión durante su almacenamiento. En cuanto al gel, la cantidad de $\mathrm{K}^{+}$se mantiene constante a lo largo del almacenamiento (Figura IV.15.). 


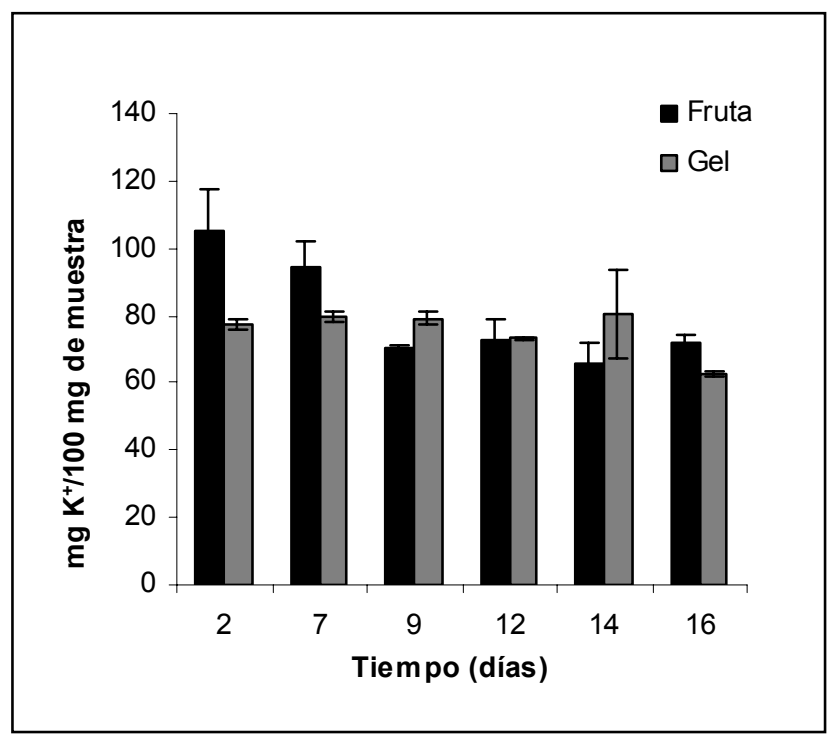

Figura IV.15. Evolución del $\mathrm{K}^{+}$en la fruta deshidratada utilizada para la elaboración de los geles de fruta y el gel del producto $\mathrm{PDG}_{2 \%}$ durante su almacenamiento en refrigeración.

En general, lo que parece observarse es un intercambio de minerales desde donde se encuentran en mayor cantidad hacia donde son menos abundantes. Los cambios se detectan mejor cuanto mayor es la cantidad del mineral analizado.

\section{IV.2.2.2.2. Estudio microbiológico de las muestras}

En la figura IV.16 se puede apreciar el recuento de viables totales y el de mohos y levaduras, a lo largo del período de almacenamiento en refrigeración a $10^{\circ} \mathrm{C}$, tanto para las muestras de pomelo fresco (PF) como para las muestras de geles de pomelo deshidratado con calcio $\left(P D G_{2}\right)$ y sin calcio añadido $\left(\mathrm{PDG}_{0 \%}\right)$. 


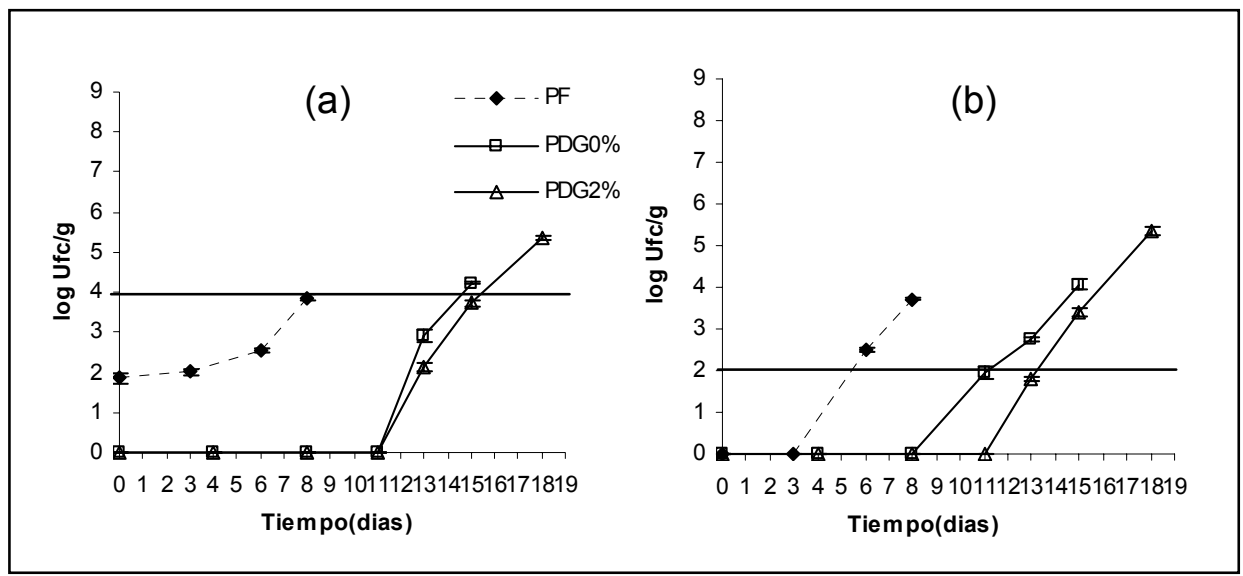

Figura IV.16. Recuento durante el período de almacenamiento en refrigeración a $10^{\circ} \mathrm{C}$ de: (a) viables totales y (b) mohos y levaduras, para las muestras de pomelo fresco (PF) y las muestras de geles de pomelo deshidratado con calcio $\left(\mathrm{PDG}_{2}\right.$ ) y sin calcio añadido $\left(\mathrm{PDG}_{0 \%}\right)$.

Las muestras de pomelo fresco sobrepasaron el límite microbiológico establecido a los 8 días de almacenamiento, para los viables totales, y 5 días para los mohos y levaduras. Por tanto podemos decir que dichas muestras presentan una vida útil de 5 días. En cuanto a las muestras de geles, los geles con pomelo deshidratado sin calcio, superan el límite microbiológico establecido a los 15 días, para los viables totales y 11 días para los mohos y levaduras.

Para las muestras de geles con pomelo deshidratado con calcio, el límite de viables totales se supera cerca de los 16 días de almacenamiento, y cerca de los 14 días para mohos y levaduras, suponiendo esto un aumento de su vida útil de un $23 \%$ respecto a las muestras sin calcio. Si las comparamos con las muestras de pomelo fresco, esto supone un aumento de un $63 \%$. 
IV.2.2.2.3. Análisis sensorial de geles con fruta deshidratada con y sin calcio. Estudio del almacenamiento

\section{Análisis de las respuestas proporcionadas en el análisis sensorial}

Se procedió de la misma manera que para el análisis sensorial de pomelo deshidratado explicado anteriormente en el apartado IV.2.2.1.7.

Con las respuestas obtenidas por los catadores en relación a la comparación pareada múltiple llevada a cabo, se elaboró la tabla IV.13 donde en las filas se encuentra el número de veces (frecuencia) que una determinada muestra fue preferida, cuando se comparaba con todas y cada una del resto de muestras para un mismo atributo (columnas).

Tabla IV.13. Respuestas de los catadores en el análisis sensorial de geles con pomelo deshidratado con calcio $\left(\mathrm{PDG}_{2 \%}\right)$ y sin calcio $\left(\mathrm{PDG}_{0 \%}\right)$, así como con y $\sin 7$ días de almacenamiento (7d) en refrigeración.

\begin{tabular}{ccccc}
\hline Atributos & $\mathbf{P D G}_{0 \%}$ & $\mathbf{P D G}_{2 \%}$ & PDG $_{0 \%}(\mathbf{7 d})$ & $\mathbf{P D G}_{\mathbf{2}}(\mathbf{7 d} \mathbf{d}$ \\
\hline Apariencia & 75 & 12 & 68 & 25 \\
Aroma & 59 & 24 & 65 & 32 \\
Color & 80 & 9 & 70 & 21 \\
Textura & 43 & 43 & 58 & 36 \\
Sabor & 67 & 40 & 46 & 27 \\
Preferida & 69 & 28 & 55 & 28 \\
\hline
\end{tabular}

Con el fin de comparar todas las muestras en conjunto, se realizaron los análisis estadísticos que se comentan a continuación. 


\section{Test de Friedman y Suma de Rangos}

Al igual que en el análisis sensorial de pomelo deshidratado, se obtuvo la suma de rangos (Tabla IV.14) a partir de las respuestas proporcionadas por los catadores.

Tabla IV.14. Suma de rangos en el análisis sensorial de geles con pomelo deshidratado con calcio $\left(\mathrm{PDG}_{2 \%}\right)$ y sin calcio $\left(\mathrm{PDG}_{0 \%}\right)$, así como con y $\sin 7$ días de almacenamiento (7d) en refrigeración.

\begin{tabular}{ccccccc}
\hline Muestra & Apariencia & Aroma & Color & Textura & Sabor & Preferida \\
\hline PDG $_{\mathbf{0}}$ & 105 & 121 & 100 & 137 & 113 & 111 \\
PDG $_{\mathbf{2} \%}$ & 168 & 156 & 171 & 137 & 140 & 152 \\
$\mathbf{P D G}_{\mathbf{0}}$ (7d) & 112 & 115 & 110 & 122 & 134 & 125 \\
$\mathbf{P D G}_{\mathbf{2} \%}$ (7d) & 155 & 148 & 159 & 144 & 153 & 152 \\
\hline
\end{tabular}

Esta suma de rangos se representa en la figura IV.17. Como se puede ver en la figura, fueron las muestras $\mathrm{PDG}_{0 \%}$ las elegidas un mayor número de veces por los catadores (menores valores en la escala del test de Friedman). Los atributos que más contribuyeron en esta preferencia fueron, apariencia, color y sabor.

Para el resto de los atributos (aroma y textura) los catadores prefirieron las muestras $\mathrm{PDG}_{0 \%}(7 \mathrm{~d})$. Por otra parte, las muestras menos preferidas (mayores valores en todos los atributos) fueron las muestras $\mathrm{PDG}_{2 \%}$ y $\mathrm{PDG}_{2 \%}(7 \mathrm{~d})$.

Para comprobar si las diferencias de las puntuaciones de los atributos y la preferencia de las muestras estudiadas en este análisis sensorial fueron significativas, se calculó la función estadística T de Friedman (Ecuación IV.2), de la misma manera que se explica 
anteriormente en el apartado IV.2.2.1.7. Como se puede observar en la tabla IV.15, se encontraron diferencias significativas en todos los atributos, pero destacó más en el color, lo que podría ser debido a que los geles realizados con la SO a la que se le añadió calcio fueron más opacos, influyendo a su vez también en la apariencia (segundo atributo donde hubo más diferencias significativas).

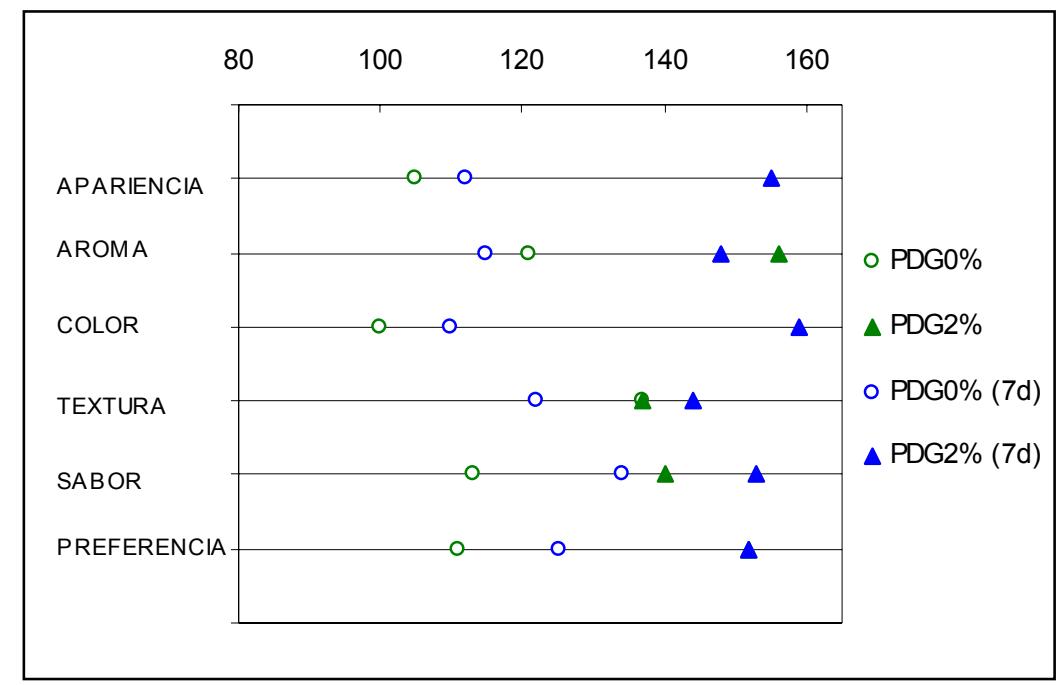

Figura IV.17. Test de Friedman (suma de rangos, obtenido de la comparación pareada múltiple) de los geles con calcio $\left(\mathrm{PDG}_{2 \%}\right)$ y $\sin$ calcio $\left(\mathrm{PDG}_{0 \%}\right)$, así como con y $\sin 7$ días de almacenamiento (7d) en refrigeración. Los valores en el eje $X$ representan la suma de las puntuaciones; y en el eje $\mathrm{Y}$, los atributos evaluados.

Como hubo diferencias significativas para todos los atributos, se realizó la comparación múltiple entre las muestras. Para ello se procedió de la misma manera que se explica anteriormente en el apartado IV.2.2.1.7, utilizando el método HSD de Tukey. El valor de HSD calculado fue el mismo en ambos análisis sensoriales $(19,88)$. 
En la tabla IV.16 se observa que, para los atributos de apariencia, aroma, color, sabor y preferencia, hay diferencias significativas en todas las muestras excepto entre las muestras $\mathrm{PDG}_{0 \%}$ y $\mathrm{PDG}_{0 \%}(7 \mathrm{~d})$ y entre las muestras $\mathrm{PDG}_{2 \%}$ y $\mathrm{PDG}_{2 \%}(7 \mathrm{~d})$. En cuanto al atributo textura sólo hay diferencias significativas entre las muestras $P D G_{0 \%}(7 d)$ y $P G_{2 \%}(7 d)$.

Tabla IV.15. Test de Friedman en el análisis sensorial de geles con pomelo deshidratado.

\begin{tabular}{cc}
\hline Atributo & Test de Friedman \\
\hline Apariencia & $97,3^{*}$ \\
Aroma & $40,2^{*}$ \\
Color & $124,1^{*}$ \\
Textura & $8,6^{*}$ \\
Sabor & $27,8^{*}$ \\
Preferida & $41,8^{*}$ \\
\hline${ }^{*}$ Diferencias significativas, para un $\alpha=0,05$.
\end{tabular}

Tabla IV.16. Diferencia entre suma de rangos en el análisis sensorial de geles con pomelo deshidratado con calcio $\mathrm{PDG}_{2 \%}$ y $\sin$ calcio $\mathrm{PDG}_{0 \%}$, así como con y $\sin 7$ días de almacenamiento (7d) en refrigeración.

\begin{tabular}{ccccccc}
\hline Atributos & APA & ARO & COL & TEX & SAB & Preferida \\
\hline PDG $_{0 \%}-$ PDG $_{2 \%}$ & $63^{*}$ & $35^{*}$ & $71^{*}$ & 0 & $27^{*}$ & $41^{*}$ \\
PDG $_{0 \%}-$ PDG $_{0 \%}$ (7d) & 7 & 6 & 10 & 15 & $21^{*}$ & 14 \\
PDG $_{0 \%}-$ PDG $_{2 \%}$ (7d) & $50^{*}$ & $27^{*}$ & $59^{*}$ & 7 & $40^{*}$ & $41^{*}$ \\
PDG $_{2 \%}-$ PDG $_{0 \%}$ (7d) & $56^{*}$ & $41^{*}$ & $61^{*}$ & 15 & 6 & $27^{*}$ \\
PDG $_{2 \%}-$ PDG $_{2 \%}$ (7d) & 13 & 8 & 12 & 7 & 13 & 0 \\
PDG $_{0 \%}$ (7d)-PDG & & \\
\hline
\end{tabular}

(1) APA: apariencia; ARO: aroma; COL: color; TEX: textura; SAB: sabor.

$\left({ }^{*}\right)$ Diferencias significativas entre muestras según el método HSD. 


\section{Análisis de correspondencia}

De la misma manera que se procedió en el apartado IV.2.2.1.7 se realizó un análisis de correspondencias para determinar la preferencia y las relaciones que existen entre las muestras de geles de pomelo deshidratado y los atributos estudiados.

Para analizar la variabilidad de los datos en el análisis de correspondencias se obtuvieron tres factores (Tabla IV.17). Se observa que el primer factor nos explica un $94,16 \%$ de la variabilidad de los datos y el segundo un $4,35 \%$.

Tabla IV.17. Factores del análisis sensorial de geles con pomelo deshidratado.

\begin{tabular}{ccc}
\hline Factor & \% Explicado & \% Acumulado \\
\hline 1 & 94,16 & 94,16 \\
2 & 4,35 & 98,51 \\
\hline
\end{tabular}

Las contribuciones relativas en este análisis sensorial, están representadas en las tablas IV.18 y IV.19.

Los datos que se obtuvieron indican que las muestras y los atributos están bien representados a lo largo de los dos primeros factores, ya que los valores de la suma de las contribuciones relativas de los atributos son altos con respecto a cada muestra. De esta manera, los resultados más importantes pueden ser deducidos del estudio de la proyección en el plano factorial. 
Tabla IV.18. Contribuciones de los factores a la inercia de las muestras.

\begin{tabular}{cccc}
\hline Muestras & Factor $\mathbf{1}$ & Factor 2 & $\begin{array}{c}\text { Suma de } \\
\text { Factores }\end{array}$ \\
\hline PDG $_{0 \%}$ & 95,02 & 4,75 & 99,77 \\
PDG $_{2 \%}$ & 96,84 & 1,63 & 98,47 \\
PDG $_{0 \%}$ (7d) & 88,01 & 10,86 & 98,87 \\
PDG $_{2 \%}$ (7d) & 94,11 & 1,81 & 95,92 \\
\hline
\end{tabular}

Tabla IV.19. Contribuciones de los factores a la inercia de los atributos.

\begin{tabular}{cccc}
\hline Atributos & Factor $\mathbf{1}$ & Factor $\mathbf{2}$ & $\begin{array}{c}\text { Suma de } \\
\text { Factores }\end{array}$ \\
\hline Apariencia + & 99,39 & 0,32 & 99,71 \\
Apariencia - & 99,39 & 0,32 & 99,71 \\
Aroma + & 93,80 & 6,02 & 99,82 \\
Aroma - & 93,80 & 6,02 & 99,82 \\
Color + & 99,83 & 0,05 & 99,88 \\
Color - & 99,83 & 0,05 & 99,88 \\
Textura + & 32,15 & 25,48 & 57,63 \\
Textura - & 32,15 & 25,48 & 57,63 \\
Sabor + & 66,81 & 29,27 & 96,78 \\
Sabor - & 66,81 & 29,27 & 96,78 \\
Preferencia + & 96,45 & 3,52 & 99,97 \\
Preferencia - & 96,5 & 3,52 & 99,97 \\
\hline
\end{tabular}

La figura IV.18 representa como se distribuyen cada uno de los atributos y cada una de las muestras, en el plano factorial. Observando la figura, al igual que en análisis anterior, los atributos que marcan la calidad interna del producto son el color $(\mathrm{COL}+)$ y la apariencia $(\mathrm{APA}+)$, 
que como se comentó anteriormente están relacionados con la misma. En cuanto a las muestras, vemos que las preferidas por los catadores son las muestras $\mathrm{PDG}_{0 \%}$, aunque no difieren mucho de las muestras $\mathrm{PDG}_{0 \%}(7 \mathrm{~d})$. Por otro lado, si que se observaron diferencias considerables con los geles elaborados con calcio. Recién formulados son poco aceptados por su aroma y preferencia global, mientras que después de almacenados empeora el sabor y la textura. En concreto, se observó un endurecimiento excesivo del gel por efecto del calcio.

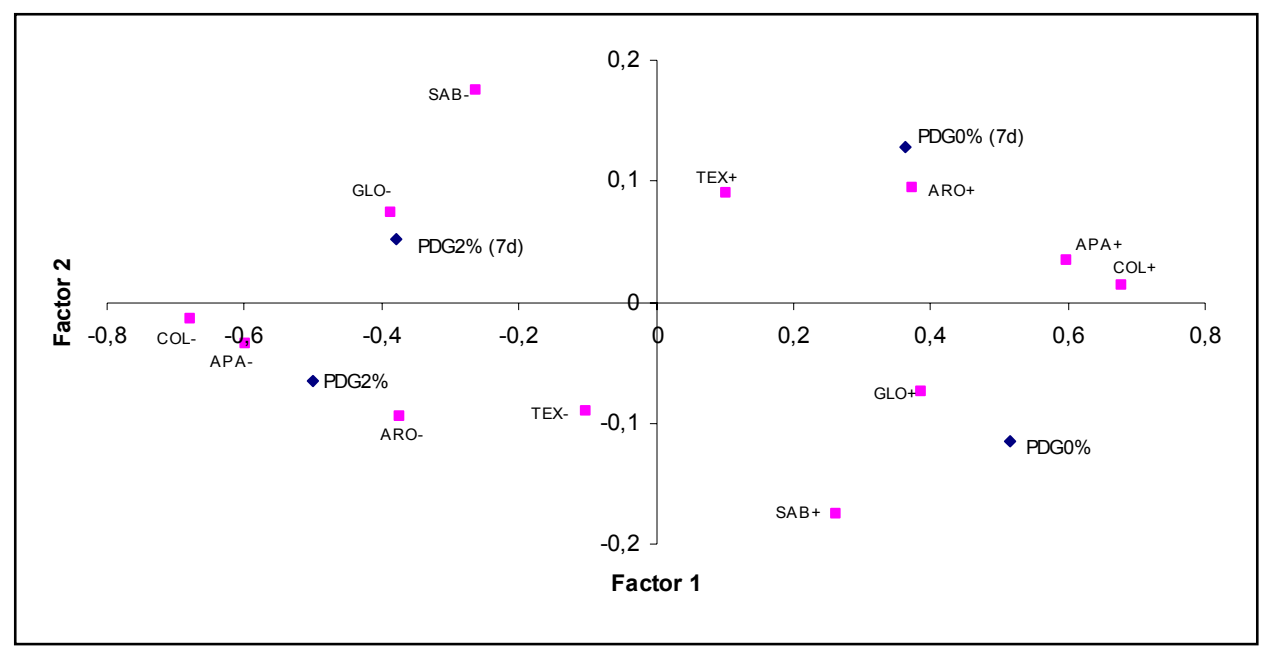

Figura IV.18. Representación de las coordenadas de ambos factores en el plano factorial. APA: apariencia; ARO: aroma; COL: color; TEX: textura; SAB: sabor; GLO: global o preferencia.

Este estudio, por tanto, pone de manifiesto que la adición de calcio no es recomendable para la elaboración del producto gelificado debido, básicamente, a su contribución a la opacidad y textura del gel. 
V. CONCLUSIONES 

- El estudio cinético realizado de la deshidratación osmótica de pomelo con pulso de vacío en las condiciones de este estudio permite seleccionar el tiempo de $180 \mathrm{~min}$ como el óptimo para la obtención de pomelo mínimamente procesado, ya que a ese tiempo se obtiene la máxima pérdida relativa de agua.

- Con ese tiempo de proceso, la reutilización de la disolución osmótica durante 5 ciclos consecutivos de deshidratación osmótica, sin tratamientos previos de reconcentración, no comporta diferencias en cuanto al nivel de deshidratación alcanzado por el pomelo. Por lo tanto, desde el punto de vista de la gestión de residuos, sería recomendable dicha reutilización. Sin embargo, desde el punto de vista de la calidad microbiológica del pomelo deshidratado obtenido, resulta conveniente aplicar un tratamiento suave de pasteurización $\left(75^{\circ} \mathrm{C} / 15 \mathrm{~s}\right)$ antes de cada ciclo de deshidratación osmótica. 
- El tratamiento osmótico conlleva pérdidas en el contenido en ácido cítrico, ácido ascórbico y minerales del pomelo. Sin embargo, en el caso del ácido cítrico y ácido ascórbico, las pérdidas ocasionadas por el tratamiento y por el almacenamiento del pomelo deshidratado en refrigeración son del mismo orden que las que se observan en el producto fresco sólo por efecto del almacenamiento. La reutilización de la disolución osmótica supone una disminución de las pérdidas de ácido cítrico del pomelo causadas por el procesado osmótico.

- La deshidratación osmótica es también responsable de una disminución de la tasa respiratoria del pomelo, como consecuencia del menor número de células viables presentes, y por lo tanto, de un aumento de la vida útil microbiológica. La reutilización de la disolución osmótica parece evitar el desarrollo de procesos fermentativos, lo que se relaciona con la menor actividad microbiológica de estas muestras.

- En relación con las propiedades físicas estudiadas, el tratamiento osmótico potencia la tonalidad roja del pomelo y aumenta su resistencia mecánica. El color se mantiene estable durante el almacenamiento del producto aunque la firmeza aumenta en coherencia con la pérdida de fase líquida observada.

- La disolución osmótica incorpora parte de los micronutrientes que pierde el pomelo durante su deshidratación osmótica. Se confirma, por tanto, el interés de su uso final en la formulación de alimentos.

- En base a las conclusiones 2, 3, 4 y 6, se sugiere como proceso optimizado para la formulación del producto gelificado objeto de este 
estudio la realización de 5 ciclos consecutivos de deshidratación osmótica, con los correspondientes tratamientos térmicos de la disolución osmótica antes de cada uno de ellos. La disolución osmótica resultante, debidamente diluida a fin de equilibrar su $\mathrm{a}_{\mathrm{w}}$ con la del pomelo deshidratado, puede utilizarse como medio solvente para la agregación del carragenato. Esta mezcla junto con el pomelo deshidratado permiten, según el proceso expuesto en la figura III.16, formular un producto optimizado a base de pomelo mínimamente procesado sensorialmente aceptable y estable durante al menos 12 días de almacenamiento en refrigeración.

- La presencia de la matriz gelificada formulada a partir de la disolución osmótica reutilizada aporta una serie de ventajas al producto. Por una parte, el pomelo presente en ella preserva en mayor medida su contenido en ácido ascórbico, muestra un tono más rojo, no ve afectadas sus propiedades mecánicas y es microbiológicamente más estable. Por otra parte, el gel contribuye al aporte de parte de los micronutrientes que la fruta ha perdido durante su procesado osmótico (ácido cítrico, ácido ascórbico y minerales).

- La impregnación a vacío se confirma como una herramienta útil para favorecer la incorporación de solutos como el calcio al pomelo, sin afectar a las características mecánicas de la fruta. Sin embargo, es responsable de la pérdida de micronutrientes como el ácido cítrico y minerales y da lugar a un aumento del metabolismo celular, reflejado en un aumento en la tasa respiratoria, que lleva al desarrollo de procesos fermentativos. 
- La incorporación de lactato de calcio a la disolución osmótica supone una reducción a la mitad de la difusividad efectiva del agua en el pomelo, haciendo más lento el intercambio de agua y sacarosa entre la fruta y la disolución osmótica. No obstante, la pérdida de ácido cítrico durante el procesado osmótico es mayor cuando se agrega calcio a la disolución osmótica. No se observa una mejora de las propiedades mecánicas de las muestras por efecto del calcio.

- El calcio contribuye a la disminución del metabolismo respiratorio y aumento de la vida útil microbiológica, lo que puede explicarse en base a un bloqueo de los canales de transporte activo del agua, con el consiguiente aumento de la concentración de ATP intracelular.

- El lactato cálcico afecta negativamente a la textura, aroma y sabor del pomelo deshidratado, aunque mejora el color y, por tanto, la apariencia del producto. No obstante, su presencia mantiene más estable al producto durante el almacenamiento, en lo que se refiere a los parámetros evaluados sensorialmente.

- La adición de lactato de calcio a la disolución osmótica y su utilización para la formulación del producto gelificado supone un aumento de la vida útil del producto. Sin embargo, el aumento que ocasiona en la opacidad y dureza del gel no lo hacen recomendable. 
VI. BIBLIOGRAFÍA 

AENOR. (1997). Análisis sensorial. Alimentación. Recopilación de Normas UNE. Vol. 1.

Agar, I.T., Hess-Pierce, B., Kader, A.A. (1999). Postharvest $\mathrm{CO}_{2}$ and ethylene production and quality maintenance of fresh-cut kiwifruit slices. Journal of Food Science, 64(3): 433-440.

Agustí, M. (2003). Citricultura. $2^{\mathrm{a}}$ edición. Ed. Mundi-Prensa, Madrid, España.

Albors, A. (2002). Estudio de perfiles composicionales y estructurales en tejido de manzana (var. Granny Smith) deshidratada. Tesis Doctoral, Universidad Politécnica de Valencia, Valencia, España.

Alzamora, S.M., Gerschenson, L.N., Vidales, S.L., Nieto, A. (1997). Structural changes in the minimal processing of fruits: Some effects of blanching and sugar impregnation. En: Fito, P., Ortega-Rodríguez, E., Barbosa-Cánovas, G.V. (eds.). Food Engineering 2000. Ed. International Thomson, New York, pp. 117-139.

Amerine, M.A., Pangborn, R.M., Roessler, E.B. (1965). Principles of Sensory Evaluation of Foods. Ed. Academic Press, New York, USA.

Anino, S.V., Salvatori, D.M., Alzamora, S.M. (2006). Changes in calcium level and mechanical properties of apple tissue due to impregnation with calcium salts. Food Research International, 39(2): 154-164.

Anzaldúa-Morales, A. (1982). The texture of fibrous fruits and vegetables. PhD Thesis, Reading University, National College of Food Technology. Weybridge, Surrey, England.

Anzaldúa-Morales, A. (1994). La Evaluación Sensorial de los Alimentos en la Teoría y en la Práctica. Ed. Acribia, Zaragoza, España.

Anzaldúa-Morales, A., Vernon, E.J., Léver, C. (1983). Nuevos métodos de evaluación sensorial y su aplicación en reología y textura. Revista de Tecnología de Alimentos (México),18(5): 4. 
AOAC. (1980). Official methods of analysis (13 ${ }^{\text {th }}$ edition) Washington DC: Association of official analytical chemists.

AOAC. (2000). Official methods of analysis of AOAC International (17 edition). Gaithersburg, MD, USA.

Azcón-Bieto, J., Talón, M. (2000). Fundamentos de Fisiología Vegetal. Ed. McGraw-Hill, Madrid; Edicions Universitat de Barcelona, Barcelona, España.

Baker, R.A. (1993). Firmness of cannes grapefruit sections improved with calcium lactate. Journal of Food Science, 58: 1107-1110.

Baker, R.A. (1994). Potential dietary benefits of citrus pectin and fiber. Food Technology, 48(11): 133-136, 138-139.

Barat, J.M., Chiralt, A., Fito, P. (1997). A mass transfer modelling in osmotic dehydration. En: Jowitt, R. (ed.). Proceedings of the $7^{\text {th }}$ International Congress on Engineering and Food (ICEF7). Ed. Sheffield Academic Press Ltd, Brighton, Inglaterra, pp. 81-84.

Barat, J.M., Albors, A., Chiralt, A., Fito, P. (1998). Equilibration of apple tissue in osmotic dehydration. Microstructural changes. En: Akritidis, C.B., Marinos-Kuris, D., Saravacos, G.D. (eds.). Proceedings of the $11^{\text {th }}$ International Drying Symposium (Drying'98), Ziti Editions, Halkidiki, Grecia, Vol. A, pp. 827-835.

Barat, J.M., Albors, A., Chiralt, A., Fito, P. (1999). Equilibration of apple tissue in osmotic dehydration: Microstructural changes. Drying Technology, 17(7 y 8): 1375-1386.

Barat, J.M., Fito, P., Chiralt, A. (2001a). Modelling of simultaneous mass transfer and structural changes in fruit tissues. Journal of Food Enginering, 49(2-3): 77-85.

Barat, J.M., Chiralt, A., Fito, P. (2001b). Effect of osmotic solution concentration, temperature and vacuum impregnation pretreatment on 
osmotic dehydration kinetics of apple slices. Food Science and Technology International, 7(5): 451-456.

Barrera, C., Betoret, N., Fito, P. (2004). $\mathrm{Ca}^{2+}$ and Fe ${ }^{2+}$ influence on the osmotic dehydration kinetics of apple slices (var. Granny Smith). Journal of Food Engineering, 65(1): 9-14.

Beaudry, R.M., Cameron, A.C., Shirazi, A., Dostal-Lange, D.L. (1992). Modified atmosphere packaging of blueberry fruit: Effect of temperature on package $\mathrm{O}_{2}$ and $\mathrm{CO}_{2}$. Journal of the American Society for Horticultural Science, 117(3): 436-441.

BeMiller, J.N., Whistler, R.L. (1996). Carbohydrates. En: Fennema, O.R. (Ed.). Food Chemistry, $3^{\text {rd }}$ Ed., Marcel Dekker, New York.

Benzecri, J.P. (1982). L’Analyse des Données. Tomo 2. En: L'Analyse Des Correspondences. Ed. Dunod, Paris, Francia, pp. 334-343.

Bereiter, M. (2001). Effect of osmodehydrofreezing on quality attributes of kiwi fruit. Trabajo Final de Carrera. Universidad Politécnica de Valencia, Valencia, España.

Berkaloff, A., Favard, J., Bourquet, J., Lacroix, J.C. (1986). Biología y Fisiología Celular. Ed. Omega, Barcelona, España.

Biale, J.B. (1964). Growth maturation and senescence in fruits. Recent knowledge on growth regulation and on biological oxidations has been applied to studies with fruits. Science, 146 (364): 880-888.

Bolin, H.R., Huxsoll, C.C. (1989). Storage stability of minimally processed fruit. Journal of Food Process and Preservation, 13(4): 281292.

Brecht, J.K. (1995). Physiology of lightly processed fruits and vegetables. HortScience, 30(1): 18-22.

Buescher, R.W., Hobson, G.E. (1982). Role of calcium and chelatingagents in regulating the degradation of tomato fruit tissue by polygalacturonase. Journal of Food Biochemistry, 6(3): 147-160. 
Bush, D.S. (1995). Calcium regulation in plant cells and its role in signaling. Annual Review of Plant Physiology and Plant Molecular Biology, 46: 95-122.

Cardona, A., Castelo, M., Sanjuán, E., Millán, R., Gómez, R. (1992). Zumos de fruta. Principios generales de elaboración y estabilidad. Alimentaria, abril: 53-56.

Castelló, M.L. (2007). Efecto de las condiciones de operación en los cambios fisicoquímicos y fisiológicos de frutas mínimamente procesadas por deshidratación osmótica. Tesis Doctoral, Universidad Politécnica de Valencia, Valencia, España.

Castelló, M.L., Esmatjes, V., Fito, P.J., Chiralt, A. (2004). Efecto de la impregnación y la deshidratación con y sin calcio en la respiración de fresas durante el almacenamiento. III Congreso Español de Ingeniería de Alimentos. Pamplona, España, pp. 723-732

Castelló, M.L., Fito, P.J., Chiralt, A. (2005). Effect of osmotic dehydration and vacuum impregnation on respiration rate of cut strawberries. LWT-Food Science and Technology, 39(10): 1171-1179.

Ceballos, G. (2006). Estudios en papaya mínimamente procesada por deshidratación osmótica. Tesis Doctoral, Universidad Politécnica de Valencia, Valencia, España.

Cervera, P., Clapes, J., Rigolfas, R. (2005). Alimentación y Dietoterapia: Nutrición Aplicada en la Salud y en la Enfermedad. Ed. McGraw-Hill Interamericana de España, Aravaca, España.

Chiralt, A., Fito, P. (2003). Transport mechanisms in osmotic dehydration: The role of the structure. Food Science and Technology International, 9(3): 179-186.

Chiralt, A., Talens, P. (2005). Physical and chemical changes induced by osmotic dehydration in plant tissues. Journal of Food Engineering, 67(1-2): 167-177. 
Chiralt, A., Martínez-Navarrete, N., Martínez-Monzó, J., Talens, P., Moraga, G., Ayala, A., Fito, P. (2001). Changes in mechanical properties throughout osmotic processes. Cryoprotectant effect. Journal of Food Engineering, 49(2-3): 129-135.

Chrispeels M.J., Crawford, N.M., Schroeder, J.I. (1999). Proteins for transport of water and mineral nutrients across the membranes of plant cells. Plant Cell, 11(4): 661-675.

Côme, D., Corbineau, F. (2001). Clasificación y principales características fisiológicas de las hortalizas. En: Tirilly, Y., Bourgeois, C.M. (eds.) Tecnología de las Hortalizas. Ed. Acribia, Zaragoza, España, pp. 3-14.

Conway J., Castaigne, F., Picard, G., Vovan, X. (1983). Mass transfer consideration in the osmotic dehydration of apples. Canadian Institute Food Science Technology Journal, 16: 25-29.

Córdoba, A., García-Martínez, E., Martínez-Navarrete, N., Camacho, M.M., Martínez-Monzó, J. (2002). Enriquecimiento de la disolución osmótica en ácido ascórbico durante ciclos sucesivos de deshidratación de kiwi. En: Fito. P., Chiralt, A., Martínez-Navarrete, N. (eds). Series de Ciencia e Ingeniería de Alimentos. Investigación del Postgrado del IADDTA. Año 2001. Editorial UPV, Valencia, España, pp. 103-121.

Costell, E., Durán, L. (1981). El análisis sensorial en el control de calidad de los alimentos (II). Planteamiento y planificación: Selección de pruebas. Revista de Agroquímica y Tecnología de Alimentos, 21(2): 149-166.

Crank, J. (1975). The mathematics of diffusion. Oxford University Press, London, UK.

Dalla Rosa, M., Giroux, F. (2001). Osmotic treatments (OT) and problems related to the solution management. Journal of Food Engineering, 49(2-3): 223-236. 
Davidson, P.M., Juneja, V.K. (1990). Antimicrobial agents. In: Branen, A.L., Davidson, P.M., Salminen, S. (Eds.). Food Additives. Ed. Marcel Dekker Inc., New York, USA, pp. 83-137.

De Nisi, P., Dell'Orto, M., Pirovano, L., Zocchi, G. (1999). Calciumdependent phosphorylation regulates the plasma-membrane $\mathrm{H}+-\mathrm{ATP}_{\text {ase }}$ activity of maize (Zea mays L.) root. Planta, 209(2): 187-194.

Del Caro, A., Piga, A., Vacca, V., Agabbio, M. (2004). Changes of flavonoids, vitamin $\mathrm{C}$ and antioxidant capacity in minimally processed citrus segments and juices during storage. Food Chemistry, 84(1): 99105.

Dickinson, E., Pawlowsky, K. (1997). Effect of $\lambda$-carrageenan on flocculation, creaming and rheology of a protein-stabilized emulsion. Journal of Agricultural and Food Chemistry, 45(10): 3799-3806.

Dziezak, J.D. (1991). A focus on gums. Food Technology, 45(3):115.

Eliasson, A.C. (1996). Carbohydrates in Foods. Ed. Marcel Dekker, Inc, New York, USA.

Elston, T., Wang, H.Y., Oster, G. (1998). Energy transduction in ATP synthetase. Nature, 391: 510-513.

Escriche, I., Acosta E., Serra, J. A., Chiralt, A., Fito, P. (1999). Vida útil de papaya mínimamente procesada obtenida por deshidratación osmótica a vacío. Alimentaria, 105-109.

Escriche, I., Chiralt, A., Moreno, J., Serra, J. A. (2000a). Influence of blanching-osmotic dehydration treatments on volatile fraction of strawberries. Journal of Food Science, 65(7): 1107-1111.

Escriche, I., García-Pinchi, R., Andrés, A., Fito, P. (2000b). Osmotic dehydration of kiwifruit (Actinidia Chinensis): Fluxes and mass transfer kinetics. Journal of Food Process Engineering. 23(3): 191-205. 
Evans, D.E., Briars, S.A., Williams, L. (1991). Active calcium transport by plant cell membranes. Journal of Experimental Botany, 42(3): 285303.

FAO. (2002). FAO Statistical Database.

FAO. (2003). Proyecciones de la producción y consumo mundiales de cítricos en el año 2010. $13^{a}$ reunión grupo intergubernamental sobre frutos cítricos. La Habana, Cuba.

Fellows, P. (1988). Food Processing Technology. Principles and Practice. Ed. Ellis Horwood, Chichester, UK.

Fernie, A.R., Carrari, F., Sweetlove, L.J. (2004). Respiratory metabolism: glycolysis, the TCA cycle and mitochondrial electron transport. Current Opinion in Plant Biology, 7(3):254-261.

Fito, P., Chiralt, A. (1997). An approach to the modelling of solid foodliquid operations: application to osmotic dehydration. En: Fito, P., Ortega, E., Barbosa, G.V. (eds.). Food Engineering 2000. Ed. International Thomson, New York, pp. 231-252.

Fito, P., Chiralt, A. (2000). Vacuum impregnation of plant tissues. En: Alzamora, S., Tapia, M.S., López-Malo, A., (eds.). Design of Minimal Processing Technologies for Fruit and Vegetables. Aspen Publishers, Inc. Gaithersburg, Maryland, USA, pp. 189-205.

Fito, P., Pastor, R. (1994). Non-diffusional mechanism occuring during vacuum osmotic dehydration. Journal of Food Engineering, 21(4): 513519.

Fito, P., Andrés, A., Pastor, R., Chiralt, A. (1994). Vacuum osmotic dehydration of fruits. En: Singh, R.P., Oliveira, F.A.R. (eds.). Minimal Processing of Foods and Process Optimization, Boca Ratón, CRC Press, Florida, pp. 107-122.

Fito, P., Andrés, A., Chiralt, A., Pardo, P. (1996). Coupling of hydrodynamic mechanism and deformation-relaxation phenomena 
during vacuum treatments in solid porous food-liquid systems. Journal of Food Engineering, 27(3): 229-240.

Fito, P., Chiralt, A., Barat, J.M., Martínez-Monzó, J. (2000). Vacuum impregnation in fruit processing. En: Lozano, J.E., Añón, C., ParadaArias, E., Barbosa-Cánovas, G.V. (eds.). Trends in Food Engineering. Technomic Publishing Company, Inc., Lancaster, Pennsylvania, USA, pp. 149-163.

Fito, P., Chiralt, A., Barat, J.M., Spiess, W.E.L., Behsnilian, D. (2001). Osmotic dehydration and vacuum impregnation. Application in Food Industries. Technomic Publishing Company, Inc., Lancaster, Pennsylvania.

Floros, J.D., Ekanayake, A., Abide, G.P., Nelson, P.E. (1992). Optimization of a diced tomato calcification process. Journal of Food Science, 57(6): 1144-1148.

Fonseca, S.C., Oliveira, F.A.R., Brecht, J.K. (2002). Modelling respiration rate of fresh fruits and vegetables for modified atmosphere packages: A review. Journal of Food Engineering, 52(2): 99-119.

García, J.M., Herrera, S., Morilla, A. (1996). Effects of postharvest dips in alcium chloride on strawberry. Journal of Agricultural and Food Chemistry, 44(1): 30-33.

García-Martínez, E. (2005). Cambios fisicoquímicos en la disolución osmótica durante la deshidratación de kiwi. Reutilización y aplicación en la elaboración de mermeladas y productos gelificados. Tesis Doctoral. Universidad Politécnica de Valencia, Valencia, España.

García-Martínez, E., Martínez-Monzó, J., Camacho, M.M., MartínezNavarrete, N. (2002a). Characterization of reused osmotic solution as ingredient in new product formulation. Food Research International, 35(2-3): 307-313. 
García-Martínez, E., Ruíz-Díaz, G, Martínez-Monzó, J., Camacho, M.M., Martínez-Navarrete, N., Chiralt, A. (2002b). Jam manufacture with osmodehydrated fruit. Food Research International, 35(2-3): 301306.

Garrote, R.L., Bertone, R.A. (1989). Osmotic concentration at low temperature of frozen strawberry halves. Effect of glycerol, glucose and sucrose solutions on exudates loss during thawing. LebensmittelWissens Chaft \& Technologie, 22(5): 264-267.

Gey, K.F., Stahelin, H.B., Eichholzer, M. (1993). Poor plasma status of carotene and vitamin $C$ is associated with higher mortality from ischemic heart disease and stroke: Basel prospective study. Clinical Investigator, 71(1): 3-6.

Giangiacomo, R., Torreggiani, D., Abbo, E. (1987). Osmotic dehydration on fruits. Part I. Sugars exchange between fruit and extracting syrups. Journal of Food Processing and Preservation, 11(3): 183-195.

Gil-izquierdo, A., Gil, M.I., Ferreres, F., Tomas-Barberan, F.A. (2001). In vitro availability of flavanoids and other phenolics in orange juice. Journal of Agricultural Food Chemistry, 49(2): 1035-1041.

Giraldo, G., Talens, P., Fito, P., Chiralt, A. (2003). Influence of sucrose solution concentration on kinetics and yield during osmotic dehydration of mango. Journal of Food Engineering, 58(1): 33-43.

Glicksman, M. (1969). Gum Technology in the Food Industry. Ed. Academic Press, New York, USA.

Glicksman, M. (1976). Hydrocolloid utilization in fabricated food. Cereal Foods World, 21(1):17-26.

Goldschmidt, E.E., Huberman, M., Goren, R. (1993). Probing the role of endogenous ethylene in the degreening of citrus fruit with ethylene antagonists. Plant Growth Regulation, 12(3): 325-329. 
Gonzáles-Mariño, G., Barat, J.M., Chiralt, A., Fito, P. (2001). Yield increase in osmotic processes by applying vacuum impregnation: Aplications in fruits candying. En: Fito, P., Chiralt, A., Barat, J.M., Spiess, W.E.L., Behsnilian, D. (eds.). Osmotic Dehydration and Vacuum Impregnation: Application in Food Industries. Publishing Company, Inc., Lancaster, Pennsylvania, pp. 79-81.

Gorinstein, S., Cvikrová, M., Machackova, I., Haruenkit, R., Park, Y.S., Jung, S.T., Yamamoto, K., Martínez Ayala, A.L., Katrich, E., Trakhtenberg, S. (2004). Characterization of antioxidant compounds in Jaffa sweeties and white grapefruits. Food Chemistry, 84(4): 503-510.

Gorny, J.R., Gil, M.I., Kader, A.A. (1998). Postharvest physiology and quality maintenance of fresh-cut pears. Acta HortScience, 464: 231-236.

Guennengues, P. (1986). Etude thermodynamiqué des transferts de masse en déshydratation osmotique. D.E.A., E.N.S.I.A., Massy, France.

Guo, J.H., Skinner, G.W., Harcum, W.W., Barnum, P.E. (1998). Pharmaceutical applications of naturally occurring water-soluble polymers. Pharmaceutical Science \& Technology Today, 1(6): 254-261.

Hagen, R.E., Dunlap, W.J., Wender, S.H. (1966). Seasonal variation of naringin and certain other flavanone glycosides in juice sacs of Texas Ruby Red grapefruit. Journal of Food Science, 31(4): 542-543.

Heng, K., Guilbert, S., Cuq, J.L. (1990). Osmotic dehydration of papaya: Influence of process variables on the product quality. Science des Aliments, 10(4): 831-848.

Hussein, A.A. (1944). Respiration in the orange: A study of systems responsible for oxygen uptake. Journal of Biological Chemistry, 155(1): 201-211.

Huxsoll, C.C., Bolin, H.R., (1989). Processing and distribution alternatives for minimally processed fruits and vegetables. Food Technology, 43 (2):124-128. 
Igual, M., Castelló, M.L., Moraga, M.J., Fito, P.J., Chiralt, A. (2004). Influencia de la deshidratación osmótica con pulso de vacío y calcio en la vida útil, respiración y textura de rodajas de manzana var. Granny Smith. Jornadas de Investigación en Ciencia e Ingeniería de alimentos, Valencia, España.

Imeson, A. (1997). Thickening and Gelling Agents for Food. $2^{\mathrm{a}}$ edition. Ed. Blackie Academic and Professional, London, UK.

Infoagro (2007). El cultivo del pomelo, [en línea]. Dirección URL:<http://www.infoagro.com/cítricos/pomelo.htm>. [Consulta: 2 Enero de 2007].

IVIA (2007). Variedades de cítricos, [en línea]. Dirección URL:< http://www.ivia.es/deps/otri/Index_Var.htm>. [Consulta: 2 Enero de 2007].

Ivorra, L., Moraga, M.J., Moraga, G., Martínez-Navarrete, N., Chiralt, A. (2003). Pomelo mínimamente procesado por deshidratación osmótica. Cambios en las propiedades fisicoquímicas y microbiológicas durante el almacenamiento. En: Fito, P., Chiralt, A., Andrés, A., Martínez-Navarrete, N. (eds.). Series de Ciencia e Ingeniería de los Alimentos. Investigación del Postgrado del IAD-DTA. Año 2002. Ed. UPV, Valencia, España, pp. 99-111.

Izumi, H., Watada, A.E. (1994). Calcium treatments affect storage quality of shredded carrots. Journal of Food Science, 59(1): 106-109.

Jimeno, A., Ballesteros, M., Ugedo, L. (1997). Biología. 2 Ciencias de la Naturaleza y de la Salud. Ed. Santillana, Madrid, España.

Judez-Asensio, L. (1989). Técnicas de Análisis de Datos Multidimensionales. Bases Teóricas y Aplicaciones en Agricultura. Ministerio de Agricultura, Pesca y Alimentación. Madrid, España.

Kader, A.A. (1985). Ethylene-induced senescence and physiological disorders in harvested horticultural crops. HortScience, 20 (1): 54-57. 
Kader, A.A. (1987). Respiration and gas exchange of vegetables. En: Weichman, J. (ed.). Postharvest Physiology of Vegetables. Marcel Dekker Inc., New York, USA, pp. 25-43.

Kader, A.A., Saltveit, M. (2002). Respiration and gas exchange. En: Weichman, J. (ed.). Postharvest Physiology of Vegetables. Marcel Dekker Inc., New York, USA, pp. 7-16.

Kader, A.A., Zagory, D., Kerbel, E.L. (1989). Modified atmosphere packaging of fruits and vegetables. Critical Reviews in Food Science and Nutrition, 28(1): 1-30.

Kamis, A.B., Modu, A.S., Mwajim, B. (2004). Effect of ripening on the proximate and some biochemical composition of a local tomato cultivar (Nadaffreta) grown at Lake Alau Region of Borno State. Journal of Applied Sciences, 4(3): 424-426.

Karel, M. (1973). Recent research and development in the field of low moisture and intermediate-moisture foods. CRC Critical Review Food Technology, 3: 329-373.

Katime, I.A., Pérez, J.A., Gutiérrez, A., Goñi, F.M. (1994). Termodinámica de los procesos irreversibles: Reacciones oscilantes. Ed. Universidad del País Vasco, Bilbao, España.

Ke, D., Kader, A.A. (1992). External and internal factors influence fruit tolerance to low-oxygen atmospheres. Journal of the American Society for Horticultural Science, 117(6): 913-918.

King, A.D., Bolin, H.R. (1989). Physiological and microbiological storage stability of minimally processed fruits and vegetables. Food Technology, 43(2): 132-135.

Kinoshita, T., Nishimura, M., Shimazaki, K. (1995). Cytosolic concentration of $\mathrm{Ca}^{2+}$ regulates the plasma membrane $\mathrm{H}^{+}$-ATPase in guard cells of fava bean. Plant Cell, 7(8): 1333-1342. 
Knight, H., Knight, M.R. (1999). Calcium signalling in plants responding to stress. En: Smallwood, M.F., Calvert, C.M., Bowles, D.J. (eds.). Plant Responses to Environmental Stress. Ed. BIOS Scientific Publishers Ltd., Oxford, UK, pp. 1-8.

Kramer, A., Twigg, B.E. (1972). Quality Control for the Food Industry. $3^{\text {a }}$ edition. Ed. AVI Publishing Co., Westport, Connecticut, USA.

Larmond, E. (1973).Physical requirements for sensory testing. Food Technology, 27(11): 28, 30, 32.

Larmond, E. (1977). Method for sensory evaluation of food. Canada Department of Agriculture. Publ. No 1286, p.36-37.

Lee, S.K., Kader, A.A. (2000). Preharvest and postharvest factors influencing vitamin $\mathrm{C}$ content of horticultural crops. Postharvest Biology and Technology, 20(3): 207-220.

Lenart, A., Lewicki, P.P. (1990). Osmotic dehydration of apples at high temperature. En: Mujumdar, A.S. (ed.). Drying'89. Ed. Hemisphere Publishing Corporation, pp. 7-14.

León-Crespo, F., Galán-Soldevilla, H. (1991). Modernas Técnicas en el Procesado de Alimentos.

Lester, G. (1996). Calcium alters senescence rate of postharvest muskmelon fruit disks. Postharvest Biology and Technology, 7(1-2): 9196.

Levi, A., Gagel, S., Juven, B. (1983). Intermediate moisture tropical fruit products for developing countries I. Technological data on papaya. Journal of Food Technology, 18(6): 667-685.

Li, S., Andrews, P. K., Patterson, M. E. (1994). Effects of etephon on the respiration and ethylene evolution of sweet cherry (Prunus avium L.) fruit at different development stages. Postharvest Biology and Technology, 4: 235-243. 
Liao, M.L., Seib, P.A. (1987).Selected reactions of L-ascorbic acid related to foods. Food Technology, 41(11): 104-111.

López-Gálvez, G., El-Bassuoni, R., Nie, X., Cantwell, M. (1997). Quality of red and green fresh-cut peppers stored in controlled atmospheres. Proceedings of the $7^{\text {th }}$ Internacional Controlled Atmosphere Research Conference, Vol. 5, pp. 152-157.

Luna-Guzmán, I., Barrett, D.M. (2000). Comparison of calcium chloride and calcium lactate effectiveness in maintaining shelf stability and quality of fresh-cut cantaloupes. Postharvest Biology and Technology, 19(1): 61-72.

Luna-Guzmán, I., Cantwell, M.I., Barrett, D.M. (1999). Fresh-cut cantaloupe: effects of $\mathrm{CaCl}_{2}$ dips and heat treatments on firmness and metabolic activity. Postharvest Biology and Technology, 17(3): 201-213.

Lynch, J., Polito, V.S., Launchli, A. (1989). Salinity stress increases cytoplasmic calcium activity in maize root protoplasts. Plant Physiology, 90(4): 1271-1274.

Main, G.L., Morris, J.R., Wehunt, E.J. (1986). Effect of preprocessing treatments on the firmness and quality characteristics of whole and sliced strawberries after freezing and thermal processing. Journal of Food Science, 51(2): 391-394.

Mangione, M.R., Giacomazza, D., Bulone, D., Martorana, V., San Biagio, P.L. (2003). Thermoreversible gelation of kappa-Carrageenan: relation between conformational transition and aggregation. Biophysical Chemistry, 104(1): 95-195.

Martínez-Monzó, J., Martínez-Navarrete, N., Chiralt, A., Fito, P. (1998a). Osmotic dehydration of apple as affected by vacuum impregnation with HM pectin. En: Akritidis, C.B., Marinos-Kounis, D., Saravacos, G.D. (eds.). Proceedings of the $11^{\text {th }}$ International Drying Symposium (Drying'98), Ziti Editions, Thessaloniki, Vol. A, pp. 836-843. 
Martínez-Monzó, J., Martínez-Navarrete, N., Chiralt, A., Fito, P. (1998b). Mechanical and structural changes in apple (var. Granny Smith) due to vacuum impregnation with cryoprotectants. Journal of Food Science, 63(3): 499-503.

Mataix, J. (1998). Tabla de Composición de Alimentos Españoles. $3^{a}$ edición. Ed. Universidad de Granada, Granada, España.

McMurchi, E.J., McGlasso, W.B., Eaks, I.L. (1972). Treatment of fruit with propylene gives information about the biogenesis of ethylene. Nature, 237(5352): 235-236.

Meilgaard, M., Civille, G.V., Carr, B.T. (1999). Attribute differences test. III. Pairwise Ranking Test: Friedman Analysis. En: Meilgaard, M., Civille, G.V., Carr, B.T. (eds.). Sensory Evaluation Techniques. $3^{\text {rd }}$ Edition. Ed. CRC Press Inc., Florida, USA, pp. 103-106.

Middleton, E., Kandaswami, C. (1994). Potential health-promoting properties of citrus flavonoids. Food Technology, 48(11): 115-119.

Mignani, I., Greve, L.C., Benarie, R., Stotz, H.U., Li, C.Y., Shackel, K.A., Labavitch, J.M. (1995). The effects of GA(3) and divalent cations on aspects of pectin metabolism and tissue softening in ripening tomato pericarp. Physiologia Plantarum, 93(1): 108-115.

Mikhailova, L. (2005). Pectin - the healthy additive. Khranitelnovkusova-Promishlenost, (3): 23-26.

Monsalve-González, A., Barbosa-Cánovas, G.V., Cavalieri, R.P. (1993). Mass transfer and textural changes during processing of apples by combined methods. Journal of Food Science, 58(5): 1118-1124.

Moraga, G. (2002). Aspectos físicoquímicos relacionados con la crioprotección de fresa y kiwi. Tesis Doctoral, Universidad Politécnica de Valencia, Valencia, España.

Moraga, G., Martínez-Navarrete, N., Martínez-Monzó, J., Chiralt, A. (2000). Influence of convective and osmotic drying on some color and 
firmness properties of strawberry. En: Kerkhof, P.J.A.M., Coumans, W.J., Mooiweer, G.D. (eds.). Proceedings of $12^{\text {th }}$ International Drying Symposium (IDS2000). Elsevier Science B.V., Noordwijkerhout, Netherlands.

Moraga, G., Martínez-Navarrete, N., Chiralt, A. (2006). Compositional changes of strawberry due to dehydration, cold storage and freezingthawing processes. Journal of Food Processing and Preservation, 30 458-474.

Moraga, M.J., Moraga, G., Fito, P.J., Martínez-Navarrete, N. (2008). Effect of vacuum impregnation with calcium lactate on the osmotic dehydration kinetics and quality of osmodehydrated grapefruit. Journal of Food Engineering. (Aceptado para su publicación).

Moreno, J. (1999). Optimización de un procesamiento para la obtención de fresas deshidratadas osmóticamente y estudios de parámetros de calidad en algunos productos obtenidos de ellas. Tesis Doctoral, Universidad Politécnica de Valencia, España.

Moreno, J., Chiralt, A., Escriche, I., Serra, J.A. (2000). Effect of blanching/osmotic dehydration combined methods on quality and stability of minimally processed strawberries. Food Research International, 33(7): 609-616.

Morris J.R., Sistrunk, W.A., Sims, C.A., Main, G.L., Wehunt, E.J. (1985). Effects of cultivar, postharvest storage, preprocessing dip treatments and style of pack on the processing quality of strawberries. Journal of the American Society for Horticultural Science, 110(2): 172177.

Navarro, M. (1975). Control de calidad. Curso de postgrado. Universidad Iberoamericana. Departamento de Ciencias de la Nutrición y de los Alimentos. México D.F. 
Nieto, A.B., Salvatori, D.M., Castro, M.A., Alzamora, S.M. (2004). Structural changes in apple during glucose and sucrose osmotic dehydration: Shrinkage, porosity, density and microscopic features. Journal of Food Engineering, 61(2): 269-278.

Norrish, R.S. (1966). An equation for the activity coeficients and equilibrium relative humidities of water in confectionery syrups. Journal of Food Technology, 1:25.

Oakenfull, D. (1998). Polysaccharide molecular structures. En: Walter, R.H. (ed.). Polysaccharide Association Structures in Food. Ed. Marcel Dekker Inc., New York, USA, pp. 15-36.

Olsen, R.W., Barrow, R.W., Huggart, R.L., Wenzel, F.W. (1966). Proceedings of the Florida State Horticultural Society,79: 326.

Olson, R.E. (1988). D-Limonene, an anticarcinogenic terpene. Nutrition Reviews, 46:363-5.

Panagiotou, N.M., Karathanos, V.T., Maroullis, Z.B. (1998). Mass transfer modelling of the osmotic dehydration of some fruits. International Journal of Food Science and Technology, 33(3): 267-284.

Parker, M., Wardoswki, W., Dewey, D. (1984). A damage test for oranges in a commercial packing house line. Proceedings of the Florida State Horticultural Society, 94:136-137.

Pascual, M.R., Calderón, V. (2000). Microbiología Alimentaria. Metodología Analítica para Alimentos y Bebidas. $2^{\text {a }}$ Edicion. Ed. Diaz de Santos, Madrid, España, pp. 315-319, 337-345.

Pasquel, A. (2001). Gomas: Una aproximación a la industria de alimentos. Alimentaria, 1(1):1-8.

Peiró, R., Dias, V.M.C., Camacho, M.M., Martínez-Navarrete, N. (2006). Micronutrient flow to the osmotic solution during grapefruit osmotic dehydration. Journal of Food Engineering, 74(3): 299-307. 
Peiró, R. (2007). Cambios en los nutrientes y compuestos fitoquímicos asociados al procesado osmótico de frutas y su estabilidad en un producto gelificado. Tesis Doctoral, Universidad Politécnica de Valencia, Valencia, España.

Peiró-Mena, R., Camacho, M.M., Martínez-Navarrete, N. (2007a). Compositional and physicochemical changes associated to successive osmodehydration cycles of pineapple (Ananas comosus). Journal of Food Engineering, 79(3): 842-849.

Peiró-Mena, R., Camacho, M.M., Martínez-Navarrete, N. (2007b). Optimización de la formulación de un producto gelificado con pomelo. Alimentación, mayo: 54-57.

Pino, J.A., Castro, D., Fito, P., Barat, J.M., López, F. (1999). Multivariate statistical analysis of volatile compounds as criterion for selecting technological parameters in the osmotic dehydration of pineapple. Journal of Food Quality, 22(6): 653-662.

Piñeros, M., Tester, M. (1997). Calcium channels in higher plant cells: Selectivity, regulation and pharmacology. Journal of Experimental Botany, 48: 551-577.

Pitt, R.E. (1992). Viscoelastic properties of fruits and vegetables. En: Rao, M.A., Steffe, J. F., (eds.). Viscoelastic Properties of Foods. Ed. Elsevier Applied Science, London, UK, pp. 49-76.

Ponting, J.D., Watters, G.G., Forrey, R.R., Jackson, R., Stanley, W.L. (1966). Osmotic dehydration of fruits. Food Technology, 20(10): 125128.

Ponting, J.D., Jackson, R., Watters, G. (1971). Refrigerated apple slices. Effects of $\mathrm{pH}$, sulfites and calcium on texture. Journal of Food Science, 36(2): 349-350. 
Ponting, J.D., Watters, G., Jackson, R. (1972). Refrigerated apple slices. Preservative effects of ascorbic acid, calcium and sulfites. Journal of Food Science, 37(3): 434-436.

Poovaiah, B.W. (1986). Role of calcium in prolonging storage life of fruits and vegetables. Food Technology, 40(5): 86-89.

Purvis, A.C., Barmore, C.R. (1981). Involvement of ethylene in chlorophyll degradation in peel of citrus fruits. Plant Physiology, 68(4): 854-856.

Rao, M.A. (1999). Rheological behavior of processed fluid and semisolid foods. En: Rao, M.A. (ed.). Rheology of Fluid and Semisolid Foods, Aspen Publishers, Gaithersburg, Maryland, pp. 153-218.

Renault, P., Houal, L., Jacquemin, G., Chambroy, Y. (1994). Gas exchange in modified atmosphere packaging. 2. Experimental results with strawberries. International Journal of Food Science and Technology, 29(4): 379-394.

Roberts, M.A., Quemener, B. (1999). Measurement of carrageenans in food: Challenges, progress, and trends in analysis. Trends in Food Science and Technology, 10(4-5): 169-181.

Rojas, A.M., Gerschenson, L.N. (2001). Ascorbic acid destruction in aqueous model systems: An additional discussion. Journal of the Science of Food and Agriculture, 81(15): 1433-1439.

Rolle, R.S., Chism, G.W. (1987). Physiological consequences of minimally processed fruits and vegetables. Journal of Food Quality, 10(3): 157-177.

Rosen, J.C., Kader, A.A. (1989). Postharvest physiology and quality maintenance of sliced pear and strawberry fruits. Journal of Food Science, 54(3): 656-659.

Saftner, R.A., Conway, W.S., Sams, C.E. (1999). Postharvest calcium infiltration alone and combined with surface coating treatments influence 
volatile levels, respiration, ethylene production, and internal atmospheres of Golden Delicious apples. Journal of the American Society for Horticultural Science, 124(5): 553-558.

Sams, C.E., Conway, W.S., Abbot, J.A., Lewis, R.J., Ben-Shalom, N. (1993). Firmness and decay of apples following postharvest pressure infiltration of calcium and heat treatment. Journal of the American Society for Horticultural Science, 118(5): 623-627.

Seguí, L., Fito, P.J., Albors, A., Fito, P. (2006). Mass transfer phenomena during the osmotic dehydration of apple isolated protoplasts (Malus domestica var. Fuji). Journal of Food Engineering, 77(1): 179187.

Serrano, M., Martínez-Romero, D., Castillo, S., Guillén, F., Valero, D. (2004). Role of calcium and heat treatments in alleviating physiological changes induced by mechanical damage in plum. Postharvest Biology and Technology, 34(2): 155-167.

Seymour, G.B., Taylor, J.E., Tucker, G.A. (1993). Biochemistry of Fruit Ripening. Ed. Chapman \& Hall, London, UK.

Shi, X.Q., Chiralt, A., Fito, P., Serra, J.A., Escoin, C., Gasque, L. (1996). Application of osmotic dehydration technology on jam processing. Drying Technology, 14(3-4): 841-857.

Soto, J. (2005). Detección de Fitoquímicos, contenido de Vitamina C y Ácido fólico en Chironja (Citrus sinensis x Citrus paradisi) injertada en diferentes patrones de cítrica. Tesis Doctoral. Universidad de Puerto Rico. Recinto Universitario de Mayagüez.

Stanley, N.F. (1990). Carrageenans. En: Harris, P. (ed.). Food Gels. Elsevier Applied Science, London, UK, pp. 79-119.

Stewart, I., Wheaton, T.A. (1972). Carotenoids in citrus: Their accumulation induced by ethylene. Journal of Agricultural and Food Chemistry, 20(2): 448-449. 
Sworn, G., Sanderson, G.R., Gibson, W. (1995). Gellan gum fluid gels. Food Hydrocolloids, 9(4): 265-271.

Tadege, M., Dupuis, I., Kuhlemeier, C. (1999). Ethanolic fermentation: New functions for an old pathway. Trends in Plant Science, 4(8): 320325.

Taiz, L., Zeiger, E. (1991). Plant Physiology. Ed. Benjamin Cummings, Cop., Redwood City, California, USA.

Talens, P. (2002). Tratamientos osmóticos en la crioprotección de fresa y kiwi. Tesis Doctoral, Universidad Politécnica de Valencia, Valencia, España.

Talens, P., Escriche, I., Martínez-Navarrete, N., Chiralt, A. (2002). Study of the influence of osmotic dehydration and freezing on the volatile profile of strawberries. Journal of Food Science, 67(5): 1648-1653.

Tannenbaum, S.R. (1979). Nutritional and Safety Aspects of Food Processing. Ed. Marcel Dekker, New York, USA.

Thomas, W.R. (1992). Carrageenan. En: Imeson, A. (ed.) Thickening and Gelling Agents for Food. Ed. Blackie Academic and Professional, London, UK, pp. 25-39.

Torreggiani, D. (1993). Osmotic dehydration in fruit and vegetable processing. Food Research International, 26(1): 59-68.

Torreggiani, D., Bertolo, G. (2001). Osmotic pre-treatments in fruit processing: chemical, physical and structural effects. Journal of Food Engineering, 49(2-3): 247-253.

Torres, J.D. (2007) Optimización de las condiciones de operación de tratamientos osmóticos destinados al procesado mínimo de mango (mangifera indica I.). Tesis Doctoral, Universidad Politécnica de Valencia, Valencia, España.

Torres, J.D., Castelló, M.L., Escriche, I., Chiralt, A. (2004). Efecto de la deshidratación osmótica y el calcio en la tasa respiratoria de mango 
durante el almacenamiento. III Congreso Español de Ingeniería de Alimentos. Pamplona, España, pp. 523-532.

Torres, J.D., Talens, P., Escriche, I., Chiralt, A. (2006).Influence of process conditions on mechanical properties of osmotically dehydrated mango. Journal of Food Engineering, 74(2): 240-246.

Tovar, B., García, H.S., Mata, M. (2001a). Physiology of pre-cut mango II. Evolution of organic acids. Food Research International 34(8): 705714.

Tovar, B., García, H.S., Mata, M. (2001b). Physiology of pre-cut mango I. ACC and ACC oxidase activity of slices subjected to osmotic dehydration. Food Research International 34(2-3): 207-215.

Tsantili, E., Konstantinidis, K., Athanasopoulos, P.E., Pontikis, C. (2002). Effects of postharvest calcium treatments on respiration and quality attributes in lemon fruit during storage. Journal of Horticultural Science and Biotechnology, 77(4): 479-484.

Tyerman, S.D., Bohnert, H.J., Maurel, C., Steudle, E., Smith, J.A.C. (1999). Plant aquaporins: Their molecular biology, biophysics and significance for plant water relations. Journal of Experimental Botany, 50: 1055-1071.

Vakis, N., Grierson W., Soule, J. (1970). Chilling Injury in Tropical and Subtropical fruits III. The Role of $\mathrm{CO} 2$ in Suppressing Chilling Injury of Grapefruit and Avocados. Proceedings of the Tropical Region of the American Society for Horticultural Science, 14: 89-100.

Valdez-Fragoso, A., Welti-Chanes, J., Giroux, F. (1998). Properties of a sucrose solution reused in osmotic dehydration of apples. Drying Technology, 16(7):1429-1445.

Vial, C., Guilbert, S., Cuq, J.L. (1991). Osmotic dehydration of kiwi fruits: Influence of process variables on the color and ascorbic acid content. Sciences des Aliments, 11(1): 63-84. 
Whistler, R.L., BeMiller, J.N. (1997). Carbohydrate Chemistry for Food Scientist. Ed. Eagan Press, Minnesota, USA.

Wiley, R. C. (1997). Frutas y Hortalizas Mínimamente Procesadas y Refrigeradas. Ed. Acribia, Zaragoza, España.

Wills, E.D. (1985). Metal catalysts in the diet. En: Sies, H. (ed.). Oxidative Stress. Ed. Academic Press, New York, USA, pp. 206-208.

Wills, R.H.H., Lee, T., McGlasson, W., Hall, E., Graham, D. (1984). Fisiología y Manipulación de Frutas y Hortalizas. Postrecolección. Ed. Acribia, Zaragoza, España.

Wong, M., Stanton, D.W., Burns, D.J.W. (1992). Effect of initial oxidation on ascorbic acid browning in stored kiwifruit juice and model concentrates. LWT-Food Science and Technology, 25(6): 574-578.

Zabetakis, I., Holden, M.A. (1997). Strawberry flavour: Analysis and biosynthesis. Journal of the Science of Food and Agriculture, 74(4): 421434. 
